
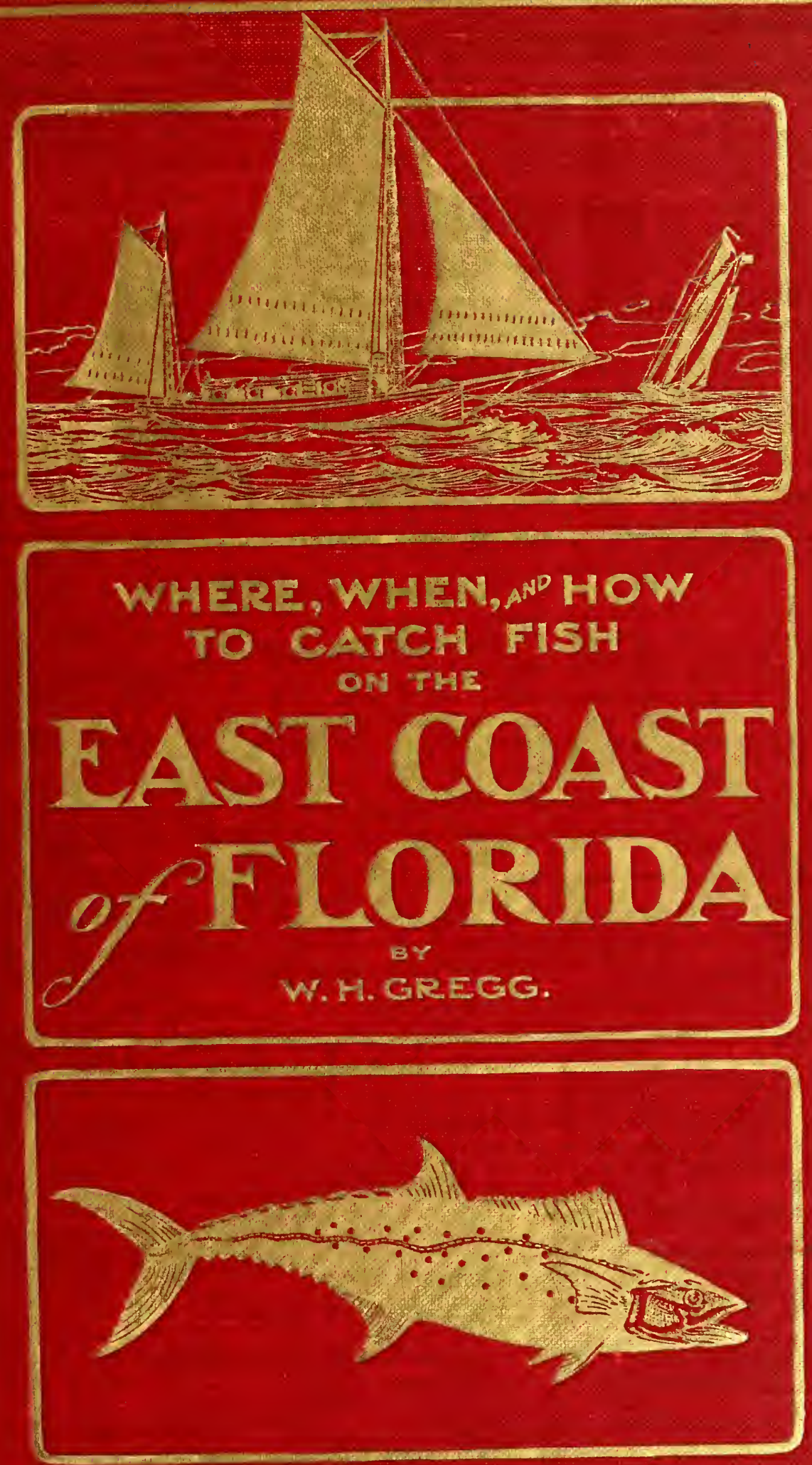


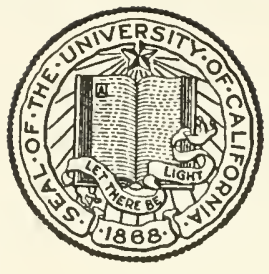

THE LIBRARY

OF

SANTA BARBARA

COLLEGE OF THE UNIVERSITY OF CALIFORNIA

PRESENTED BY

WR.AID IIRS R.W.VAUGHAR 






\title{
Where, When, and How
}

\section{to Catch Fish}

\section{ON THE \\ East Coast of Florida.}

\author{
BY \\ WILLIAM H. GREGG, \\ of St. Louis, Mo., \\ ASSISTED BY \\ CAPT. JOHN GARDNER, \\ of Ponce Park, Mosquito Inlet, Fla.
}

WITH

ONE HUNDRED ENGRAVINGS, AND TWELVE COLORED ILLUSTRATIONS OF FISHES. 
Coptright, 1902, BY

WILLIAMH. GREGG,

ST. Lovis, Mo.

All rights reserved. 


\section{TABLE OF CONTENTS.}

CIAPTER I.- Introductory.

CHAPTER II. - List of fishes on the East Coast, with mention of 187, description of 125, engravings of 100 , and plates in natural colors of 12 species. Also weights of fishes, appropriate baits and tackles, method of catching, and edible qualities, of each species.

CHAPTER III. - List of baits, natural and artificial.

CHAPTER IV. - List of fishing tackle, with illustrations of same, and of artificial baits.

CHAPTER V.- Fishing localities; general remarks regarding them.

CHAPTER VI. - Mayport (mouth of St. Johns River), Atlantic Beach (Hotel Continental), and San Pablo (Pablo Beach).

CHAPTER VII. - Saint Augustine, Sebastian River, Matanzas River, Matanzas Inlet, and the beach.

CHAPTER VIII.- Halifax River, Ormond, Daytona, Port Orange, Ponce Park, Mosquito Inlet, and the beach.

CHAPTER IX.- Hillsboro River, New Smyrna, and Hawks Park, to Mosquito Lagoon, the Haulover Canal, and beach.

CHAPTER X.- Indian River, from the Haulover Canal to Indian River Inlet, and the beach.

CHAPTER XI. - Indian River Inlet, Saint Lucie and Fort Pierce, to Jupiter, Lake Worth, and the beach.

CIIAPTER XII. - Lake Worth, the pier, beach and reefs.

CIIAPTER XIII. - Canal from Lake Worth to Biscayne Bay, beach and reefs.

CHAPTER XIV.-Biscayne Bay, Lemon City, Miami and Cocoanut Grove.

CIIAPTER XV. - Cape Florida to Cesar's Creek and reefs.

CHAPTER XVI. - Cæsar's Creek to Indian Key and reefs.

CHAPTER XVII. - Indian Key to Key West.

CHAPTER IVIII. - Key West.

CHAPTER XIX. - Inside Route Key West to Bahia Honda.

CHAPTER XX.- Hotel and Boarding House List. East Coast.

CHAPTER XXI.-Conclusion.

INDEX.

MAI OF EAST COAST OF FLORIDA. 



\section{CHAPTER I.}

\section{INTRODUCTORY.}

I have been a frequent visitor to Florida, my first visit occurring in February, 1885, and I have spent the most of my time at the various angling resorts on the Eastern and Western Coasts of the State.

Before going there I had been a reader of the angling literature of the times, wholly, or in part, devoted to that part of the United States.

Among the works I consulted were Frank Forester (Henry William Herbert), "Fish and Fishing," 1859 ; Thaddeus Norris, "American Anglers' Book," 1864; Genio C. Scott, "Fishing in American Waters," 1869 ; "Camp Life in Florida," edited by Charles Hallock, principal contributors: S. C. Clarke, "Al Fresco" (Doctor Kenworthy), and "Fred Beverly," 1876 ; "Sportsmen's Gazetteer," Charles Hallock, 1877 ; "Camping and Cruising in Florida," James A. Henshall, 1884.

The above books, with the contemporaneous articles and contributions to "Forest and Stream" and other periodicals devoted to hunting and fishing, furnished to the visiting anglers a wealth of information as to where to fish in Florida.

At the time Dr. Henshall published his "Camping and Cruising" there were only the following named railroads in the State: The Narrow Gauge, between Jacksonville and St. Augustine; the Peninsular, between Fernandina and Cedar Keys ; and the one from Jacksonville to Palatka, on St. Johns River.

Parties visiting the West Coast were obliged to go by steamer up the St. Johns River, and stage or wagon across to the coast; or by rail to Cedar Keys, and then north or south to their destination by small steamers, or small sailing craft. Parties for the East Coast could go from Jacksonville to New Smyrna by steamer or sailboat, then up or down the inside, or outside, waters to destination on sailboats; or could take steamer up the St. Johns to Sanford, or Enterprise, and stage or wagon to New Smyrna or Titusville, then small sailboat up or down the coast.

While the above conditions of transportation prevailed, it can be readily seen that the fishing tourists were not very numerous. Since 
then the State has been covered with a network of railroads, reaching all important points on both coasts, except Key West.

While this transformation has been in progress, I know of no book having been published wholly devoted to the angler's pursuit in the State, the field having been only partially covered by articles in, and contributions to, "Forest and Stream," the "American Angler," various isolated articles in other sporting papers and magazines, and in a few books. Among the latter I will mention "American Game Fishes," published by Rand \& McNally, 1892, which contains contributions by W. N. Haldeman on the Tarpon; the Bluefish, by G. Browne Goode ; and Sea Bass and other Fishes, by S. C. Clarke. All of these are fragmentary and desultory, so can be of but little practical use to the angling visitor who desires to know where he ought to go to get fair success at the present time. It has seemed strange to me that no one of the very many anglers of well-known literary ability has undertaken to write a systematic book of information and instruction on the game fishes of the State, for which there is certainly an apparent need.

As no one has appeared to take the task, it has occurred to me that possibly I could assume it, although not as fully qualified in every respect as many other anglers of more literary experience would be. I have, to quote Thaddeus Norris in his introduction to "American Anglers Book," "'overcome my scruples as to my shortcomings as a writer, for I profess to be only an angler,' and have decided to write and publish the book, with the hope that it will be of substantial benefit to my brothers of the craft. In the preparation of the book I am to have the assistance of Capt. John Gardner of Ponce Park (Mosquito Inlet), Florida, who has had thirty years' experience as fisherman, boatman and guide on the East Coast. In order to show the reader the captain's qualifications and my own, to impart the information contained in the book, I think it well to give a short account of our experience on the waters included in the territory I treat of.

Capt. Gardner was born in the interior of Florida, and at an early age removed to St. Augustine, where he "fished on de sea wall " with the Minorcan boys, and since 1871 has resided on the Halifax River, Hillsboro River, and Mosquito Lagoon, all of which waters are connected and continuous, extending from the Tomoka River, four miles north of Ormond, south to the north end of Indian River. At 
the age of fourteen years he commenced to row and sail boats for parties fishing for sport, his headquarters then being at that wellknown sportsmen's and family winter resort, the Oak Hill House, situated on the west side of Mosquito Lagoon, managed by Mr. Frank W. Sams, then and now the proprietor of the Ocean House at New Smyrna on the Hillsboro River, five miles south of Mosquito Inlet. From the above until the present time Capt. Gardner has been almost constantly engaged during the fall, winter and spring seasons, and often during the summer, in guiding fishing parties; and in charge of sailboats and yachts on the inside and outside waters of the East Coast. During a few of the summer seasons he has worked as a carpenter and boat builder, having built five sailboats and many rowboats adapted to the East Coast waters and the occupation in which he has been engaged. His home has been : seven years at Oak Hill, seven at New Smyrna, and sixteen at Ponce Park, which village is situated at Mosquito Inlet, eighteen miles south of Ormond, twelve south of Daytona, and five north of New Smyrna.

All three of above-mentioned places of his residence are wellknown sport fishing resorts, and for many years were the leading resorts on the East Coast. Among the many sportsmen he has guided, I will mention a few, namely: Mr. S. C. Clarke of Boston, widely known as an angler, and writer on angling and other subjects, who spent much time at Ponce Park; Mr. Benson, who fished at Enterprise, on St. Johns River, and at New Smyrna and Ponce Park for many years; Mr. Samuel H. Jones of Philadelphia, whom he guided five consecutive winter seasons, being with him when he caught the first Tarpon ever taken with rod and reel, which occurred at Indian River Inlet during the winter of 1884 ; Mr. C. E. Hillman and Mr. Saury of Nashville, Tenn.; Mr. McFarren and Doctor Diehl of Louisville, Ky.; Commodore Asten of New York; Mr. George F. Peabody of Appleton, Wis.; Mr. W. E. Comnor of New York; Mr. Edward P. Borden of Philadelphia; Professor IV. A. Walker of Charleston, S. C.; Messrs. John G. Prather, John A. Scudder, H. G. Brookings, James Lupe, the two brothers Mandeville, W. H. Gregg, IV. H. Gregg, Jr., and Frederic Hawley of St. Louis; and Mr. Charles M. Hays of Montreal, Canada.

While with several of the above gentlemen he sailed their boats, or yachts, on cruises extending in some cases from Ormond to Key West, and extending in time from a few days to eight months. 
He accompanied Mr. Frank W. Sams, U. S. Inspector of Life Saving Stations and Houses of Refuge, on the East Coast, on twelve inspection trips during 1884-5-6-7-8, from New Smyrna to Biscayne Bay, there being at that time no regular steamer or rail communication, and no canals except the old "Haulover" between Mosquito Lagoon and Indian River. These trips were made in small sailboats to Jupiter, and from there south to Biscayne Bay in canoes. During eleven of these trips they came north by the inside route from Biscayne Bay to the south end of Lake Worth, through the saw-grass of the eastern edge of the Everglades, utilizing the sounds and other waters of New and Hillsboro rivers, and Lake Worth Creek, as much as possible. (There are two Hillsboro rivers on the East Coast and one on the West Coast, which latter enters Hillsboro Bay at Tampa.) During April, 1895, he made a land hunting trip from New Smyrna to Biscayne Bay in a small sailboat, going ontside from Jupiter to the Bay, where he remained two weeks. During all these trips he paid particular attention to the fishing, while en route, and when at the stations.

$\mathrm{He}$ has also sailed freight and passenger schooners and sloops between New Smyrna and Jacksonville, calling many times at St. Augustine, and has made one visit to Fernandina.

During the thirty years covered by the above recital, he has fished for sport, and sometimes for market, at many points above Jacksonville, on the St. Johns River; at St. Augustine, in the Matanzas and St. Sebastian rivers; at Matanzas Inlet, eighteen miles south of the city; and outside from there, both from boats and in the surf from the beach; and inside, through the rivers, lagoons, canals, Lake Worth, Biscayne Bay, and the line of Keys, all the way to Key West, covering every inlet and pass of importance the entire distance.

I first came to Florida early in February, 1885, stopping at St. Angustine. I fished in the Matanzas and Sebastian rivers many times, and before leaving spent three days at Matanzas Inlet, at the south end of Matanzas River.

About the first of March I went by stage from St. Augustine to Daytona, a distance of sixty-five miłes, where, with two other gentlemen, I chartered a small sloop in charge of her owner, Capt. Ward.

We proceeded to Ponce Park, twelve miles to the south, fishing 
there four or five days, and then on to New Smyrna, where we stopped at the Ocean House about a week, putting in our time on the water. Then on south to the Oak Hill House on Mosquito Lagoon, where we stayed one day, then to the "Haulover" one day, from where we went on down Indian River to Paine's boarding house, opposite Indian River Inlet, having stopped one day each at Titusville and Rock Ledge. We remained at Paine's several days, when my companions left me and returned to St. Augustine. I continued on to Jupiter, where I remained several days, then returning to Indian River Inlet, where I took a small steamer, belonging to Jacob Lorillard, to Rock Ledge. That steamer was the first one to carry passengers on Indian River. We were four days making the trip to Rock Ledge, owing to oyster bars in the river which the steamer often ran onto. At Rock Ledge I took a wagon over to Lake Poinset, where I boarded a steamer for Sanford, and from the latter place, steamer to Jacksonville.

My next trip to the State was during the winter of 1890 , when I repeated the above trip on Indian River down to Jupiter on the sloop "Hillsboro," in charge of her owner, B. J. Pacetti, with John Gardner as assistant.

During the winter of 1891, I again repeated the two former cruises, on the sloop " Lillie Shippey,' with the owner, Dick McCarty, in charge, and John Gardner assistant. On this cruise I made more stops than I had before. From 18!) 2 to 1897, inclusive, I cruised over the same waters as above with B. J. Pacetti on the "Hillsboro," also visiting Lake Worth many times, where I first stopped at Dimmick's Hotel, and later at the Royal Poinciana. In 1896 I spent the month of April at the Hotel Riviera on the west side of the lake, nearly opposite the inlet. During the season I spent a week at Mayport, mouth of St. Johns River. In March, 1892, Mr. Edward P. Borden and myself chartered the schooner "Manatee," her owner, Capt. John Zellers, in charge, for a cruise down a part of the East Coast and around the capes to the West Coast. We sailed out at Gilbert's Bar, Indian River, at 8.30 A. M. and made Bears Cut, Biscayne Bay, at 7.30 P. M., a run of one hundred and ten miles.

On the run we trolled for Bluefish, Spanish Mackerel, and Kingfish, catching a large number, returning all to the water except a few for the table.

We remained on the Bay about a week, visiting the rapids, five 
miles up the Miami River, Cocoanut Grove, and other places of interest, passing on south, inside, stopping at Cape Florida, Soldier Key, Ragged Keys, Sands Cut (called by Capt. Zellers, the Aquarium), Cæsar's Creek (a pass into the ocean), then outside to Indian Key, where we fished around Alligator Lighthouse, four and one-half miles off the Key, for Barracouda, catching seven, trolling with squids from rowboats.

Mr. Borden took one of forty-six pounds, my largest weighing twenty-four pounds.

Our next stop was inside Long's Key, from whence we sailed, across the Bay of Florida to Cape Sable, forty-five miles, from which point we proceeded up the West Coast, stopping at Shark Creek, Whitewater Bay, Horse Creek, Chuckaluska, Marco, and some other unimportant creeks and bays, finally running into Punta Rassa, on Charlotte Harbor, through San Carlos Pass.

We devoted about two weeks to Charlotte Harbor and Ostero Bay, five miles to the south, catching many kinds of fishes, including Tarpon, in the harbor and bay. Mr. Borden also caught Tarpon at Marco.

In addition to the above cruise, I have made four fishing trips to the West Coast, having spent some days, or weeks, at each of the following places: Homosassa, on the Homosassa River; Tarpon Springs, on the Anclote River; Duneden, Clear Water, Johns Pass, Pass a Grille, and Disston City, on Clearwater Harbor; St. Petersburgh, Port Tampa, and Tampa, on Tampa Bay; Sarasota, on Sarasota Bay; Punta Gorda, Pease Creek, St. James City (on Pine Island), Punta Rassa, on Charlotte Harbor ; and Fort Meyers, on the Caloosa River.

I have also visited the following points on the Gulf of Mexico : Pass Christian three times, one visit of two months; Bay St. Louis, Wolf River, English Lookout at mouth of Pearl River, Biloxi, Ocean Springs and Pensacola.

In the above account I have purposely refrained from giving details of the fishing at the different places visited, because the account was written partly to show the basis for Capt. Gardner's and my own knowledge of the subject in hand; and, in addition, because I intend to give all the detail when I describe the fishes and the localities where they are caught. And, as a still more potent reason for avoiding detail, I did not desire to tell "any big fish stories," thus raising the expectations of my readers by recounting the condition of 
affairs before the advent of the steamboat, the railway, and last, but not least, the ice factory, which were quickly followed by the "man with the net."

The above mentioned factors have measurably decreased the number of fishes, but there are still enough left to satisfy the average sport fisher, who is willing and persevering. My book is written with the intention of giving, to the best of my ability, the conditions existing at the present time on the entire coast, and I will refer those of my readers who wish to read of the fishing "as it used to be" to the writers I have already mentioned.

In the next chapter I will give a list of the fishes I have caught, observed, or know to have been caught on the coast ; and in succeeding chapters will give list of baits, natural and artificial, which, according to my experience, should be used for each kind of fish; and a description of the tackle I consider necessary. After the above, I will treat of the fishing places I consider of importance, stating the variety of fishes at each place, and how, and where, to fish for them.

At the risk of wearying the reader with a too long introductory chapter, I close this one by quoting the opinions of some very high authorities regarding the coasts of Florida as to their angling resorts. Barton W. Evermann, Ichthyologist of United States Fish Commission, in a paper read at Fishery Congress, held at Tampa, Fla., January 19, 1898, says: "There is perhaps no State in the Union whose fishes have attracted more general attention than those of Florida. The interest in the fishes of this State is shared by the commercial fisherman, the angler and the ichthyologist.

"The number of species that are sought because of their commercial value is far greater than in any other section of America. Those that are of interest to the angler are more numerous than any other State can boast, while the richness and peculiarities of the fish fauna of Florida have made this State a fascinating field to the ichthyologist and student of geographic distribution." "The total number of fishes known from Floridian waters is about 600 , or about one-fifth of the entire fauna of America, north of Panama.'” "The warm waters of the Keys serve as a more or less effective barrier to the passage of fishes living in colder water. As a result, 
many species are found on the East Coast of Florida which do not occur on the Gulf Coast, and vice versa. There are so many species found on the West Coast that are not known on the East Coast that the two coasts may be regarded as having separate fauna." "There is no other place in the United States where one can study live fishes so satisfactorily as at Key West." "'Trolling for kingfish, jack, crevalle, bluefish, Spanish mackerel, and spotted sea trout at Indian River, Lake Worth, Key IVest, or Biscayne Bay, furnishes sport of the most exciting kind; while still fishing for sheepshead and mangrove snappers at Indian River Inlet; for chubs, porgies, porkfish, yellowtails, snappers, and grunts at Key West ; or for red snappers, red groupers, and others of their kin on the Snapper Banks furnishes sufficient variety to please any angler, in whatever mood he may chance to be. I have fished in every State and Territory in the Union but three, and from Siberia and Behring Sea to the Gulfs of California and Mexico, and, all things considered, regard Florida as unequaled in the richness and variety of its attractions for all sorts of sport with rod and reel."

Lieut. William Henn of the British Navy, a well-known yachtsman and sportsman, in an article contributed to the Century Magazine, June, 1893, entitled "Caught on a Lee Shore," says: “The coasts of Florida, from the head of Indian River on the east to Tampa Bay or Cedar Keys on the west, are about the best cruisinggrounds for a small or medium-sized yacht that I am acquainted with. As for the fishing, for variety, gameness, size and quantity of the fish, I believe it to be the best in the world. And game, both fin and feather, is more or less abundant, according as the country is more or less settled." 


\section{CHAPTER II.}

\section{LIST OF FISHES CAUGHT ON THE EAST COAST.}

In the classification, nomenclature, and illustrations in the following list I have followed " Bulletin No. 47 " of the United States National Museum, prepared by David Starr Jordan, Ph. D., President of the Leland Stanford University, and Barton Warren Evermann, Ph. D., Ichthyologist of the United States Fish Commission, which work was completed in four volumes in March, 1900, and is entitled "The Fishes of North and Middle America, a Descriptive Catalogue of the Species of Fish-like Vertebrates found in the waters of North America, North of the Isthmus of Panama.' It contains descriptions of 3,263 species, and 958 illustrations of fishes. As is well known, the United States National Museum is under the supervision of the Smithsonian Institution.

The above work is a continuation, revision, and correction of Bulletin 16 of the United States National Museum, published in 1883 by Jordan \& Gilbert, entitled "Synopsis of the Fishes of North America," with addition of species discovered between the dates of the two bulletins, so is the standard authority at this time as to the classification and scientific and common names of the fishes of North America.

It, naturally, must be the authority, or "court of last resort," to decide all disputes as to the correct names of all the fishes mentioned in it, and there are many disputes as to the common names. In the United States Fish Commission Report of 1895 there is a "Check List" of the scientific names in the above work, in which is included the common names of many of the fishes, and there is also a separate " List of Common names of fishes occurring in the Check List." Only Vol. 1, of Bulletin 47, had been printed when the Report of 1895 was issued, other volumes being in manuscript. In the report of 1899 there is a "Check List of the fishes of Florida," giving their scientific and many of their common names.

While I follow Jordan \& Evermann as to classification and nomenclature, I give priority to the common name by which each fish is known to the market fishermen, sportsmen, and residents of the East Coast of Florida. 
After quoting the scientific names given by Jordan \& Evermann, I give the additional names used on the coast, then the common names used by J. \& E., and in my index place all of them, scientific and common, so that any reader can probably find any fish he may be in search of. I treat the game qualities of the fishes as I have found them during my long experience on the coast, and as to their edible qualities have done the same. I have lived on the waters from two to over seven months during each of the last twelve years, and one year before; have eaten fish from one to three times per day during all the time; have had them cooked in all sorts of ways on boats, and at hotel by special orders, and on the regular menus, so, possibly, ought to be considered a judge, but "tastes differ," and probably many persons will not accept my classification as to the edible qualities of the fishes. I grade them as $\mathrm{A} 1, \mathrm{~A}, \mathrm{~B}$, and $\mathrm{C}$.

I have enumerated only a small proportion of the species on the coast treated in Jordan \& Evermann, the larger number of which are designated only by scientific names, and are interesting to the ichthyologist and other naturalists, but possess no especial attractions for the average angler.

In the common and local names there are many misnomers, which is unavoidable. When the scientific men have visited the different localities, they have been obliged to report the names as they have found them, as otherwise they could not designate a fish so that it would be known to the people where it was caught.

As many different fishes are known by the same common name in different localities, an apparent confusion exists, for which there appears to be no remedy. I mention all the names as I find them, making such explanation as I think necessary in each case. In explanation of what some readers may consider a great variety in some of the species, I will refer to the "Check List" of Jordan \& Evermann, in which they give, under heading of "Pampanos" (in which they include the Cavalles, Jacks, Permits, Moon-fishes, Look-Downs, and Pampanos), sixty-five rarieties; under Catfishes, 102 ; Sharks, sixty-five; Rays, thirty-one; Suckers, sixty-eight ; and Carps, 254. The Groupers, Snappers, Grunts, and Porgies are numerous. In making my list, I have, in addition to Jordan \& Evermann, consulted the United States Fish Commission reports of 1895, 1896, 1897,1898 , and 1899, and its Bulletins of 1896, 1897, 1898; as also Jordan \& Gilbert's synopsis, $188^{\circ}$ and 1883 ; Fishes of Porto Rico, 
Barton W. Evermann, 1900 ; American Fishes (Goode), the Catalogue of the New York Aquarium, Webster's Dictionary, and the various angling works, I have already mentioned, but, of course, accept Jordan \& Evermann as the only, and final, authority.

I am especially careful to give all the Spanish and French names in Jordan \& Evermann, because those names are the ones by which the fishes were first known by civilized people in this country, and many of them are singularly appropriate, as they indicate characteristics and especial features in the fishes, which is not the case, to the same extent, in the English names.

Instead of making my list run in alphabetical order, I feel obliged to conform to the method adopted by Jordan \& Evermann and other ichthyologists in the United States. Contrary to the methods generally adopted in Europe of giving precedence to the higher forms of fish life, the Americans have given it to the lowest or simplest orders, commencing with the Lancelets, Lampreys, then Sharks, Skates, Rays, etc., and then coming on up to the more highly organized orders and species. My index, however, will enable the reader to find the fish he is looking for. This procedure compels me to commence my list with nineteen worthless fishes, which do not make a very pleasant introduction to my readers, who, however, if they fish long on the coast, especially among the Keys, will catch them all, thus being compelled to take the bitter with the sweet. As the technical descriptions are necessarily long, I give only such as I consider of importance, but give one or more in every family, and give illustration of one or more in nearly every family mentioned which is illustrated in Jordan \& Evermann's Bulletin 47.

There seems to have been no generally accepted rule, or custom, among the angling writers as to whether the common names of fishes should begin with a capital letter or not. The earlier writers in this country seem to have capitalized quite generally in their texts, while some of those of later dates have abandoned the practice, and others have continued it. Among those who have continued, I will mention: Frank Forrester, 1859; Thaddeus Norris, 1864; J. C. Wilcocks in the "Sea Fisherman" (English), 1884; Rand, McNally \& Co., 1892 ; and G. Brown Goode, who was "Secretary of the Smithsonian Institution in charge of the United States National Nuseum, and Commissioner to the International Fisheries exhibitions in Berlin and London." Mr. Goode seems to have made it an especial point to 
capitalize the name of every, or nearly every, fish he mentions in his "American Fishes," 1887. He is one of the leading ichthyologists of the country. Albert C. L. G. Giunther, M. A., M. D., Ph. D., F. R. S., Keeper of the Zoological Department in the British Museum, in his "Introduction to the Study of Fishes," Edinburgh, 1880 , capitalizes every fish he mentions.

I can find no exception in the book, which has 720 pages. I want no better authority than Doctor Giinther and Doctor Goode.

On the contrary, Genio C. Scott, 1869 ; Hallock, 1873-5; Henshall, 1884; and Eugene McCarthy, 1900, have not capitalized.

The scientific people do not practice it except in their captions and headings of lists, indexes, etc., which latter practice is, of course, customary with all.

The same general lack of iniformity exists regarding the use of the hyphen, as very ferv writers use it alike. I have, as a general rule followed the scientific people in its use.

As I can see no sufficient reason why the capitalizing has been abandoned by some of the modern angling writers, and because I think its continuance tends to identify, and make prominent, the different species, I make free use of capitals. I have some regard and respect for the fishes, too, and think they are entitled to have their names handed down in capitals, especially by the angling fraternity.

I quote from Jordan \& Evermann their formula, or method, of describing the fishes in their list:

"In our description of species, we have attempted to bring the principal comparative measurements first. The expressions 'head 4,' or ' depth 4,' mean that the length of the head in the one case, or the greatest depth of the body in the other, is contained 4 times in the length of the fish, measured from the tip of the snont to the end of the last cauclal vertebra, the caudal fin being not included. The size of the eye and the length of the snout and other head parts are compared with the length of the side of the head, unless otherwise stated; thus ' eye 5 ' means that the horizontal diameter of the eye is $\frac{1}{5}$ the length of the head.

" 'Scales 5-61-7' means that there are 5 rows of scales between the base of the clorsal fin and the lateral line (the scale in the lateral line exchuded), 64 oblique transierse series crossing the lateral line, and 7 horizontal series between the lateral line and the base of the anal or the vent. When the number of pores in the lateral line is 
fewer than the number of scales in it, we have usually indicated the fact.

"The fin formulæ are usually shortened as much as possible ; thus 'D. 10,' 'D. IV , 9,' or 'D. VIII-13,' means that in the first case the fish has a single dorsal fin of 10 soft or articulated rays; in the second case, a single dorsal fin of 4 spines and 9 soft rays; and the last indicates a fish with 2 dorsal fins, the first composed of 8 spines and the second of 13 rays.

"Spines are always indicated in Roman letters.

"The abbreviations for the other fin formulæ are similarly explained.

"The measurements given in the text are intended to apply to the average of mature fishes. Young fishes usually have the depth less, the head and eye larger, and the mouth smaller than adult examples of the same species.

"Descriptions not taken from specimens, or at least not verified by us, are credited to the author from whom they have been copied.

“' 'Eu.' after the account of any species indicates that it is found in Europe.

"The names of the localities from which the types of the species were obtained are printed in antique old style type in connection with the synonymy of each species.

"When the type specimens are in the United States National Museum, we have given the numbers which they bear on the register of that institution.

"An atlas, containing anatomical figures and illustrations of many of the more important species, is now in preparation and will appear upon the completion of the second volume of the present work."

I am afraid the above will seem complex and tedious to some of my readers, but the scientific men must have formulas to go by, and they have, of course, devised as simple ones as will meet the case. It is a very difficult matter to find language which will convey to the layman's, or non-expert's, mind a clear idea of the construction of any animal. Nothing but an illustration (or the animal itself) will convey the information desired, and in the case of fishes one in colors of each fish is necessary. It is to be hoped that some Audubon will arise to illustrate fishes in colors as well as the great man of that name illustrated the "Birds of America."

I will give, 1st - The common names of the fishes. 
$2 \mathrm{~d}$ - The scientific names.

$3 \mathrm{~d}-$ The numbers of the illustrations in Jordan \& Evermann.

4 th - The page on which the fishes are described by Jordan \& Evermann.

5 th - Description of the fishes.

Then weight of the fishes, Bait, Tackle, method of fishing, and edible qualities.

The numbers of the fishes in my list are my own.

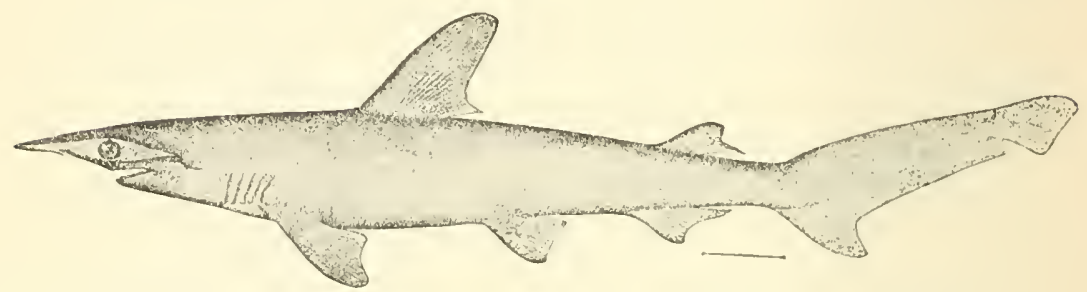

I. "SPHYRNA TIBURO."

lllustration. Page.

19

44

SilARKS ;

"Body rather slender, not much compressed; head SHOVEL-HEAd; depressed, simicircular in front; reniform, the posBONNET-HEAD. terior free margins short, the lateral margins continuous with the anterior; pectorals large; first dorsal high, midway between pectorals and ventrals; second dorsal much smaller, produced behind, higher and shorter than anal; ventral fins moderate; caudal moderate; mouth small, crescentic ; teeth small, very oblique, with a deep notch on the outer margin. Head $4 \frac{1}{3}$ in length, 6 to tip of caudal; width of head slightly less than length of head. Color, uniform ashy, paler beneath. Length, 3 to 5 feet." Weight to 200 pounds. Non-edible.

2. "SPHYRNA ZYGANA." Not illustrated. 45

SHARK ;

"Head truly hammer-shaped; width of head about twice HAMMER - its length; length of hinder margin of hammer nearly HEADED. equal to its width near the eye; nostril close to eye, prolonged into a groove which runs along nearly the whole front margin of head; first dorsal large; second quite small, smaller than anal; pectoral rather large. Color, gray. A large voracious shark, reaching a length of 15 feet or more." Weight to 200 pounds. Non-edible. 


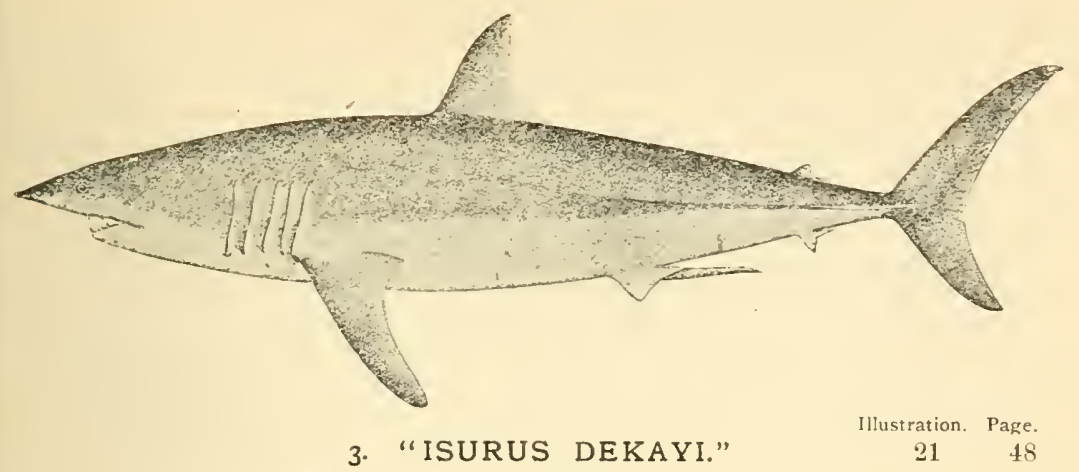

MACKEREI.

W' eight to 400 pounds.

SHARK.

Parties wishing to catch the above fishes, can use a clothes line or $\frac{1}{16}$ to $1 / 8$-inch cotton line, and Shark hook. Bait with live or dead fish, one-half to two or three pounds, or chunk of meat. Stand on the shore at or near any pass or inlet and cast out the bait. They will swallow the bait and hook, so all you have to do is to haul them in ; or you can fish from rowboat, or sailboat, or launch in same manner.

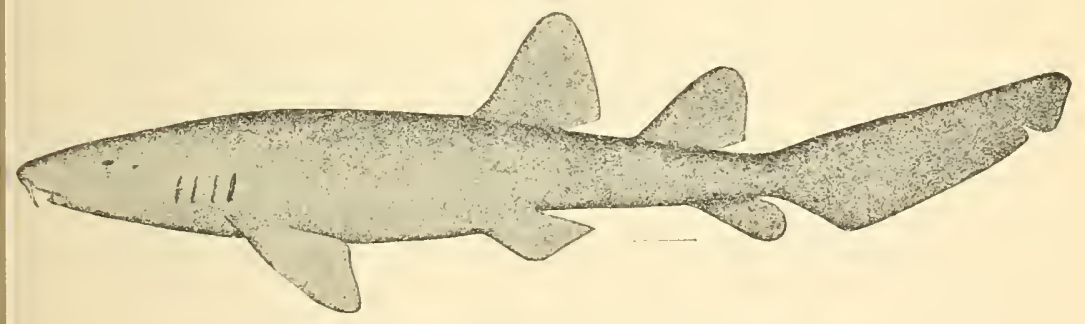

4. "GingLYMOSTOMA CiRRATUM."

$13 \quad 26$

Nurse Shark This Shark will average about 2.5 pounds.

Gata.

"CARCHARIAS LITTORALIS." Not illustrated. 46 Sand Shark. Average about 25 pounds. Non-edible.

The two last described Sharks are scarcely ever fished for by sportsmen, but take his bait while he is fishing for better 
fish. All of the Sharks are exceedingly troublesome from Mayport to Key West, as they will not only take your bait, but will frequently take the fish you have hooked while you are reeling him in or playing him. They are simply an unmitigated nuisance to any angler after he has caught the first one or two in his angling experience. Get rid of the Sharks as soon as possible by getting them as ncar as you can to the boat, or shore, and cutting the line, losing as little as you can. They are especially troublesome while fishing outside on the " "patches," or trolling, as they very frequently cut off your fish, wholly, or in part. The Shark has fine game qualities, and affords sport to those who desire to fish for them, but usually sportsmen are satisfied with a few. Non-edible.

I have often heard it said in Florida that "a cat has nine lives, and that a shark and an alligator has each ten," and it almost seems true in some cases.

There are many stories told of Sharks coming to life or reviving, after apparently being killed, some of which are true, and many slightly exaggerated.

One of the best of the latter kind was told by Mr. Saury of Nashville. A lot of us anglers were at the Detroit Hotel, St. Petersburgh, seven or eight years ago, and several big fish stories were told, some of them about Sharks. Finally, Saury's turn came.

He said he was out on the main shore off Clear Water Harbor with some other gentlemen, sharking. Finally, they hauled in a very large one, nine or ten feet long. Some one suggested that they experiment with him and see if the huge stories told about their coming to life were true. So they opened up the Shark and scattered his " innards" around on the beach within a space of ten feet or so, and then went off some distance to eat their lunch. In a short time they heard a commotion on the beach, and all stepped down to see what was going on. The Shark had revived and was in the act of swallowing some of his "innards," and they stayed there until he had swallowed all there was of them and swam off all O. K.

As the reader probably knows, some four or five years ago there was quite a controversy in the press, and among anglers, as to whether or not a Shark would attack a live man in the water. A New York gentleman, according to my recollection, offered a reward of a thousand dollars for a well authenticated instance of a Shark attacking a 
man, and the reward was never claimed. I forget whether he confined his offer to the vicinity of New York and the Jersey coast, or included the coast farther south, but think he covered the entire eastern coast in his offer. Now, I know of two instances where Sharks have evidently eaten the arms and legs off a man, but it cannot be proven in either case that the men were alive. The first instance was a canoeist who attempted to cross Mosquito Inlet one evening just before dark with the ebb tide running full force. He was carried out and capsized, two or three people at Ponce Park witnessing the performance. His body was found two or three days afterwards with nearly all the limbs eaten off, surely by Sharks, for there are no other fishes there to do it. The mail carrier between Lake Worth and Biscayne Bay, up to seven or eight years ago, carried the mail by walking on the beach, crossing Hillsboro and New River inlets in boats, which he kept for that purpose. One trip he " turned up missing," and was searched for. His body was found with the limbs wholly or partly eaten off.

No one will ever know whether, in either or both cases, the Sharks attacked them in the water, or eat them after death.

While at Indian Key some three years ago we were told that a man, a few days before our arrival, while groping around a small wreck in the channel in about four feet water, after Crawfish, was attacked by a Shark about five feet long and bitten badly in the leg. He had to go to Key West for surgical and medical treatment. This seems to be an authentic case. I believed the story because it was of very recent date, told in apparently the utmost candor simply as a piece of news, and without any motive to tell an untruth.

During the summer of 1901, Michael O'Brien, a resident of Woodley, near Indian River Narrows, while bathing in the surf, a few miles north of Indian River Inlet, was attacked by a large Shark which came between him and the shore and bit him badly on his side near his stomach or bowels, the wound being a very dangerous one.

He was taken to Fort Pierce and carried on a stretcher to Doctor C. P. Platt, under whose care he recovered. The above was told to me by Mr. R. C. Somerlin of Saint Lucie, whom I know to be perfectly reliable, and the incident is well known to the residents of Fort Pierce and Saint Lucie.

Here is a well authenticated case of a Shark attacking a live man, one where the attacked party, and many witnesses, are alive and can be called upon to substantiate the facts in the case. 
I trust my readers will not think I have devoted too much time and space to the Shark subject, if they do, my excuse is, that the matter has been much debated among anglers, and I have endeavored to throw as much light on it as possible.

I conclude that I, for one, am perfectly satisfied that many Sharks have attacked many live men.

Since writing the above $m y$ attention has been called to an article in the Charleston News and Couricr of August 29, 1901, on the maneating Shark subject, which I herewith quote.

I am of the opinion, however, that a mistake is made in the account of the Florida mail carrier's death. I was at Lake Worth at the time the news came there, which was, that the carrier not arriving on time, some people went out to look for him, and found his remains at the inlet with the head and limbs bitten off.

"It is a much mooted question as to whether or not there are man-eating sharks in the South Atlantic Ocean. It is generally conceded that the shark will devour the dead body of a human being, but it has never been thoroughly and satisfactorily established that a live person is liable to attack. The Rev. W. B. Yates, who, for more than forty years, was a sailor's chaplain in this city, and who in his youth had spent some years at sea, maintained that there were no authentic instances of a man being eaten by a shark. The waters of the Charleston harbor and the coast of South Carolina were as an open book to him, and he went to his grave believing that sharks, in this section, at least, were perfectly harmless.

"Captain William C. Ferguson, of No. 10 Pinckney Street, yesterday, in speaking to a reporter for The News and Courier, gave out some facts and figures to prove that there are man-eating sharks and that many unfortunate persons have been killed and devoured by these sea monsters. Captain Ferguson has collected some data relating to the question and arranged his facts in a chronological order. He says :

“ "In Charleston harbor, about 1840, as near as I can recall, one of the crew of a pilot boat was accidently thrown overboard. The boat was lowering her sails and coming up to her wharf at the time. The two men pulling a skiff to his rescue were passed by a large shark, which took the man under, and he was not seen again. The morning paper noted that the man was treading water lightly with his chest ont. The shark was said to lue twenty-five feet long. 
" A large shark caught with hook and line on Southern wharf had in it a part of a white man's body with a portion of his sailor's clothes about it. This, too, was said to be a twenty-five foot shark. The date of this, as near as I can remember, was 1837 .

" "In the year 1852 Charles Chambers and friend were capsized near Mount Pleasant. Each took an oar and was wading ashore, when the friend looked back and saw Charlie fighting off a shark. Charlie was pulled under and lost to sight forever.

" 'In 1853 or' 54 a young man was capsized off the Battery; he disappeared. His gold watch was afterwards found in a shark. About 1883 a Charleston man's body was recovered in Bull's Bay, from which an arm had been bitten off by a shark.

" 'In 1883, or near it, an old negro fishing near Castle Pinckney was annoyed by a shark, which pulled the fish off his hook. The shark finally made a deep dive, but before the man could thank his lucky star the shark reappeared in a grand leap over the boat, fortunately without touching the fisherman. The old fellow having no taste for a mix-up of circus and tragedy went home to his dinner.

" 'In 1847 I was in the act of taking a front seat on what is now the Clyde Line wharf, when a streak flashed along the water near the wharf and out in the stream. The wharf is higher out of water now than it was then. Suddenly the streak flashed in sight as from a long turn, far out in the stream. It came swift and straight to the wharf, and two large sharks appeared side by side, as though on a trial of speed. They curved in front of me, within three feet of the wharf and two feet of the surface, and out in the stream again. They turned this time nearer and shorter, and were back to the wharf frightfully quick. Speeding side by side they dashed close up to the wharf, and on the surface of the water. It was all interesting. The last dash was a grand display. I saw it by leaning forward and looking over the edge of the wharf. The egg-shaped ring performance stopped abruptly, when quick to the front they gave a fine show of graceful movements on the water, followed by a sea-raising demonstration. Then, seeming to have lost all interest in me, they retired behind the sea scene they had raised.

" That summer, or one within a year or two of it, a person's hand at the side of a boat was bitten off by a shark. A young sailor swam across to Castle Pinckney and back again to the wharf. He said he had no fear of sharks; that no shark could ever get sight or scent of 
him. He had all to learn about sharks. While swimming along he suddenly disappeared.

" 'In or about 1883 a steamboat on the coast of South Carolina sighted a balloon descending. It failed to land and came across the beach, dragging the balloonist over the water. A school of sharks, with a great splashing, leaped out of the water and caught the aeronaut.

“ 'In 1895 a Florida mail carrier was crossing an inlet in a boat. He was seen fighting sharks with his oar. The sharks pulled his boat to pieces and the man disappeared.

" "It was about 1853 that Capt. George Jacob Hanscheldt, who was born and raised in Charleston, chanced to be knocked overboard near Fernandina bar. A large shark, seen at the side, had now disappeared and all to be seen of the captain was a bloody streak in the water. The skipper had dressed to go ashore to call on his sister, who was on a visit to Fernandina from Charleston. Captain Hanscheld had just said, looking at the shark, "I hope it is not me you are waiting for, old boy.'

" 'A boy was badly lacerated by a shark in a creek near Jacksonville in 1898 or 1899 . Many newspaper articles discussed the question as to whether it was a shark or an alligator. 'Old Sea Captain,' in a Florida paper, had the last say. His experience of many-years taught him to know that a shark would not eat a man. Such ignorance may lead many venturesome swimmers to a horrible death.

“ 'In 1899 two Jacksonville pilots had a frightful experience with sharks. The pilots were pulling ashore on the St. Johns. The sharks plunged about and under the boat, biting and pulling at the oars, and there was great danger of the boat being swamped or turned over.

" 'In 1896, three men swimming ashore from a filibuster were met by a shark, which passed the first man and took the second one. A ship's crew in the water near their vessel in the Mediterranean had a shark come among them and take the carpenter, who was the center man of the group.

" "The above are only a few examples. I hardly think there is room for doubt on the subject.' ", 


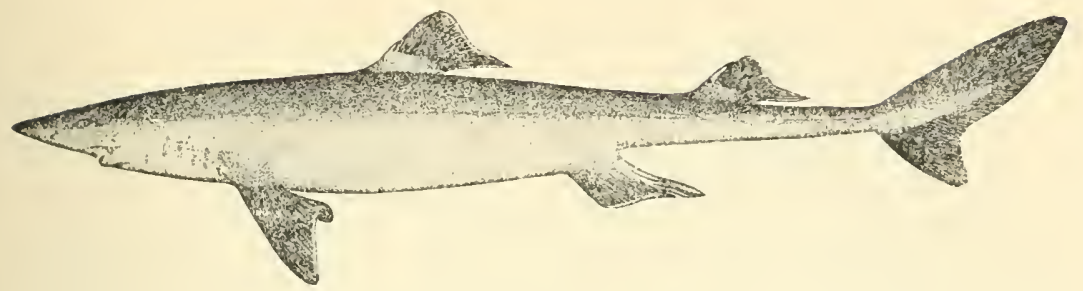

\section{5. "SQUALUS ACANTHIAS." $\quad 24 \quad 24 a \quad 54$}

DOGFISH ;

Picked Dogfish ; BONEDOG ;

SkitTle-Dog.
Weight to 30 pounds.

This fish, like the Sharks, may take your bait while fishing for better fish, and is to be treated the same as the Sharks. There are several species, none of which are worthy of the angler's attention. Non-edible.

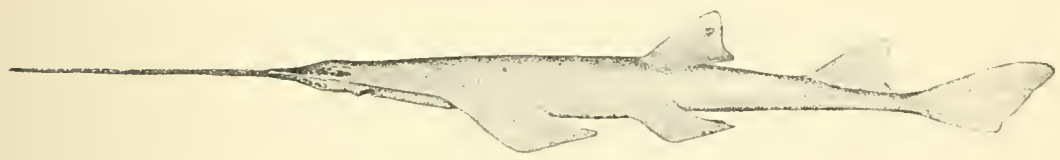

6. "PRISTIS PECTINATUS."

$27 \quad 60$

SAwfish, Common; "First dorsal over ventrals; second dorsal Pez Sierra; $\quad$ scarcely smaller than first; no lower caudal lobe. Pez de Espada. Saw with 24 to 32 pairs of teeth, the posterior farther apart than the anterior." Length, 1 to 20 feet. Weight to 800 pounds and over.

A large worthless fish. Caught with a large hook and fish bait; clothes line. "One in a life time," as a curiosity, will usually satisfy the angler. Non-edible. 


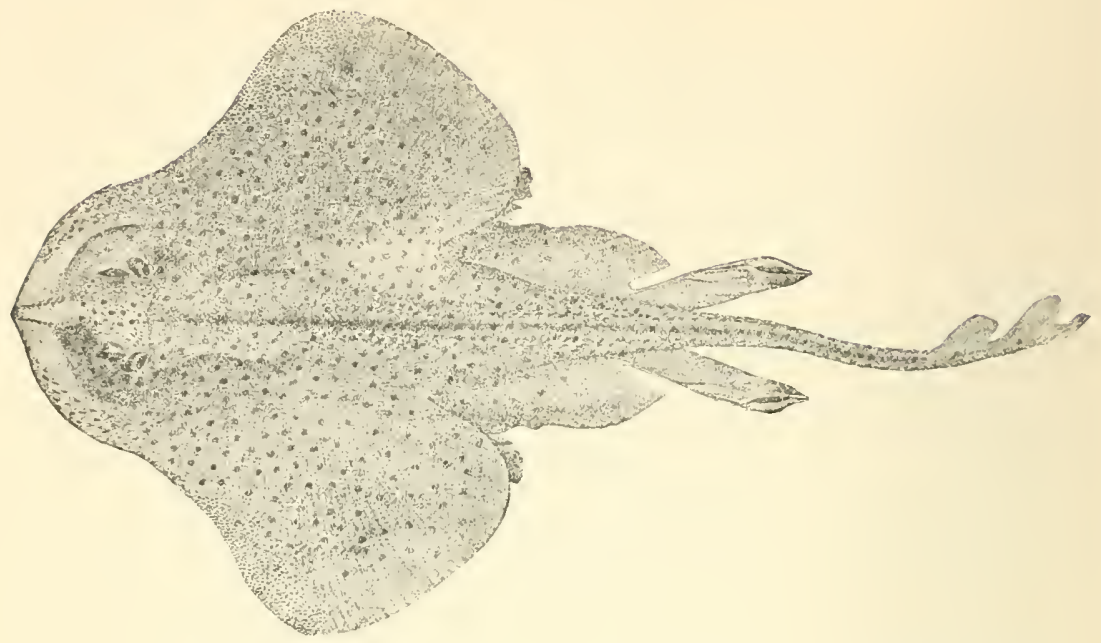

Illustration. Page.

7. "RAJA ERINACEA."

$29 \quad 68$

SkATE ;

"Form rhomboid, with all the angles rounded;

Common Skate; spines largest on the anterior extensions of the pecLittle SkAte; torals, where they are close set, strong, laterally Tовассо Box. compressed, and hooked backward; smaller ones are scattered over the head above the spiracles, above and in front of the eyes, and on the back, the median line of which is comparatively smooth, without larger median series, except in the young; a triangular patch on the shoulder girdle; inner posterior angles of the pectorals nearly smooth; in the males near the exterior angles of the pectorals are two rows of large erectile hooks, pointing backward. Females with groups of small scales on each side of the vent; teeth small, the middle ones sharp in the males; all blunt in the females; jaws much curved; each side of tail with dermal fold; caudal fins rough, not separate to the base. Color light brown, with small round spots of dark brown; no pectoral ocelli; females larger than the males. Length, 1 to 2 feet." Weight to 25 pounds.

Usually caught while fishing for better fish. Non-edible. 


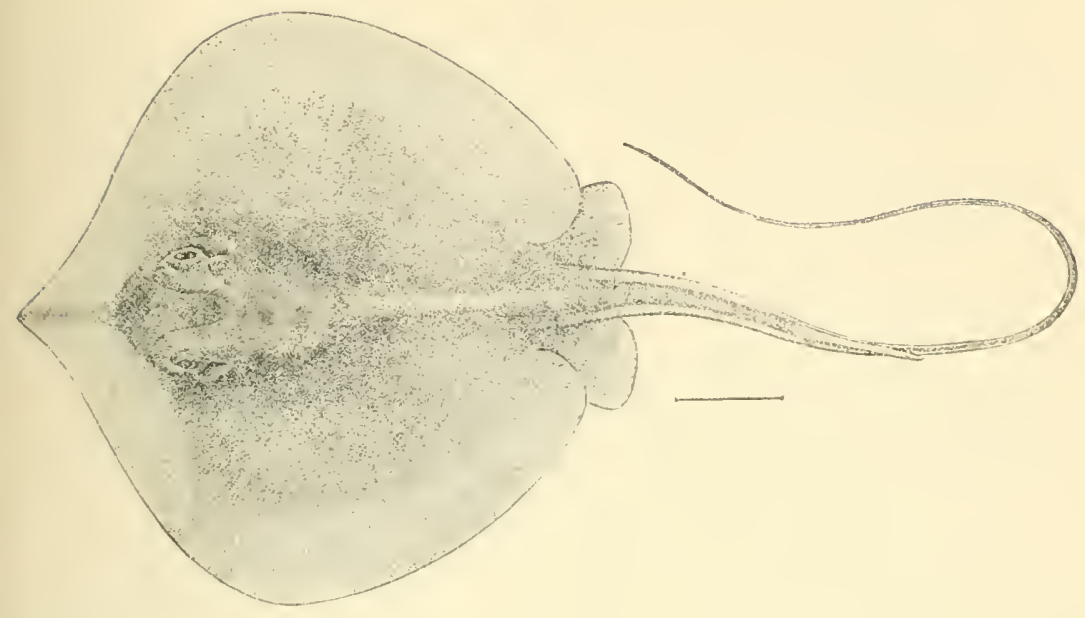

\section{8. "DASYATIS SAY."}

RAY ;

STING RAY;

Southern Sting Ray ; STINGAREE.

"Disk quadrangular, one-sixth wider than long; anterior margins nearly straight; posterior and inner borders convex; outer and posterior angles rounded; snout not protruding beyond the lines of the margins; ventrals rounded; tail strong, rather more than $1 \mathrm{I} / 2$ times the length of the disk, with a strong serrated spine, bearing a short, low, cutaneous expansion behind the spine on the upper side, and a longer, little wider one below, ending nearly opposite; upper jaw undulated; lower prominent in the middle; teeth small, smooth in young and females, sharp in adult males; 3 papillæ at the bottom of the mouth, and 1 at each side; body and tail smooth. Color olive brown in adult, reddish or yellowish in young; lower surface whitish. Closely resembles the European species, D. pastinaca. In D. say, the anterior margins form a more blunt angle at the end of the snout, which is less prominent at the apex, the outer and posterior extremities of the pectorals are rounder, the posterior margins are more convex, the disk is broader toward the ventrals, and the tail is longer; in $D$. pastinaca, the lateral and hinder angles of the pectorals and the lateral angle of the ventrals are marked by blunted corners; a single 
small rounded tubercle on the middle of the back." Weight to 400 pounds.

Caught same as the Skates. Get rid of him as soon as possible by cutting the line. Be careful, as the stinger on his tail makes a bad sore if he hits you with it. Non-edible.

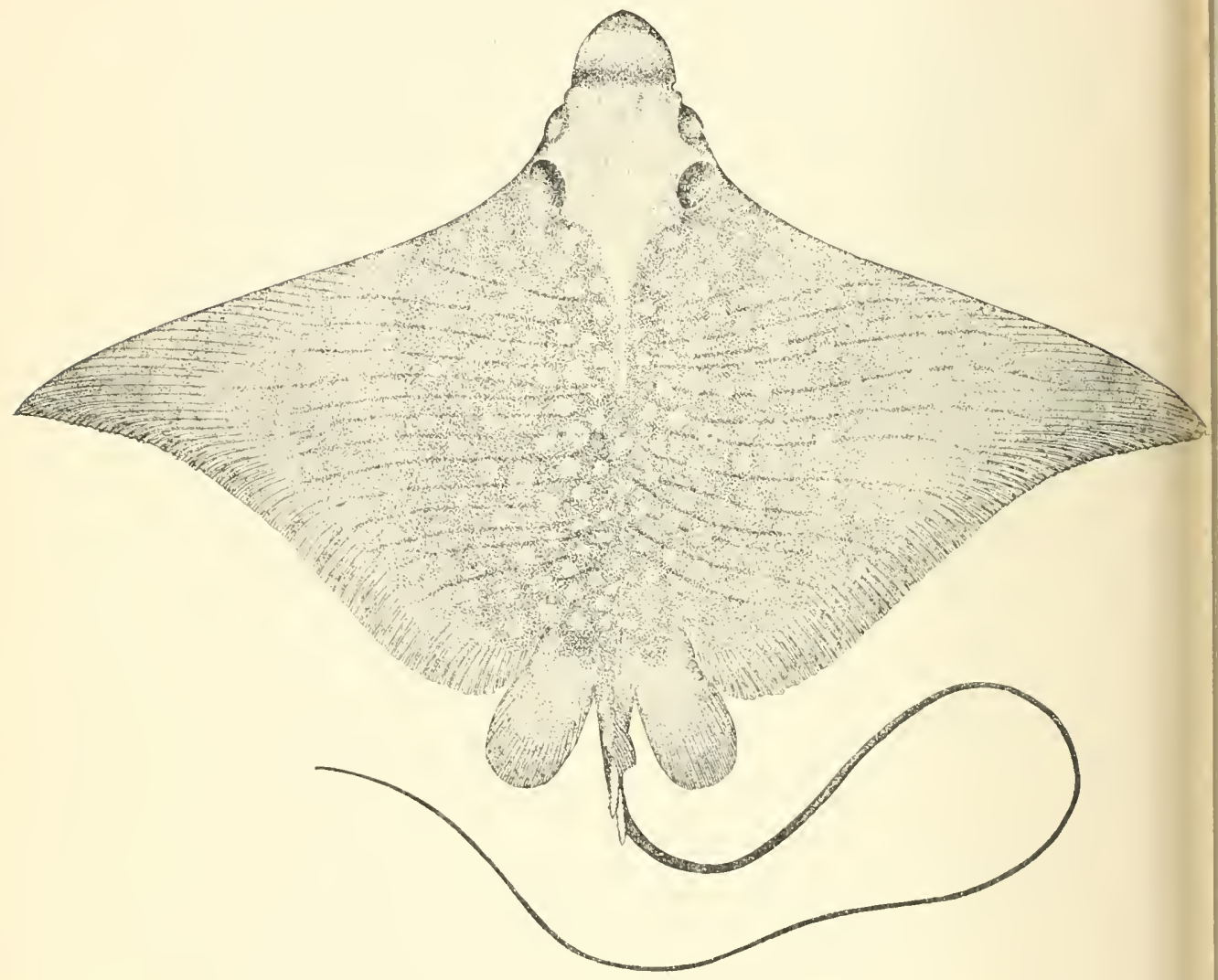

Illustration, Page.

9. "AETOBATUS NARINARI." $\quad 37 \quad 37 \mathrm{a} \quad 88$

WHIP-TAILED RAY;

"Disk twice as broad as long, its anterior Clam Cracker ; borders a little convex, posterior concave, Spotted Sting Ray. outer angles pointed. Cephalic fin about $1 / 3$ broader than long. Teeth of the lower jaw straight or more or less 
angularly bent. Tail 3 to 4 times length of disk. Brown with small round pale spots. (Dumeril.)" Weight to 600 pounds.

Very seldom caught with rod and reel. The Rays are often grained (speared) by the guides on Biscayne Bay. Non-edible.

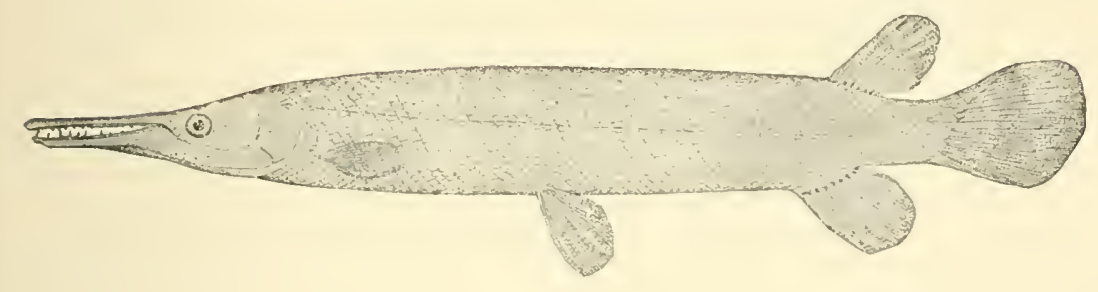

I0. “LEPISOSTEUS TRISTECHUS." $50 \quad \begin{array}{cc}\text { Illustration. } & \text { Page. } \\ 50 & 111\end{array}$

GAR (FRESH WATER); "Snout usually not quite so long as the rest GREAT GAR ; MANJUARI ; of the head, its least width contained $3 \mathrm{r} / 2$ times Alligator Gar; 8 ; V. 6. Lat line 60 . Scales in an oblique in its length. Head $31 / 2$ in length. D. 8 ; A. series from the ventrals to middle of back 18 to 20. Color greenish, paler below, the adult usually not spotted. Length, 8 to 10 feet." Weight to 50 pounds; average, 5 to 10 pounds.

Caught still fishing, with or without sinker, rod and reel, $4 \%$ to 6\% hook, 18 or 21 line, live or dead Minnow, or small Bream; or trolling with hand line; or with rod and reel, with Minnow, cut bait, spoon or phantom. Non-edible.

II. "LEPISOSTEUS PLATOSTOMUS." 49

GAR,

Weight to 25 pounds.

SHORT-NOSED.

Caught by same method and tackle as Alligator Gar. Non-edible. 


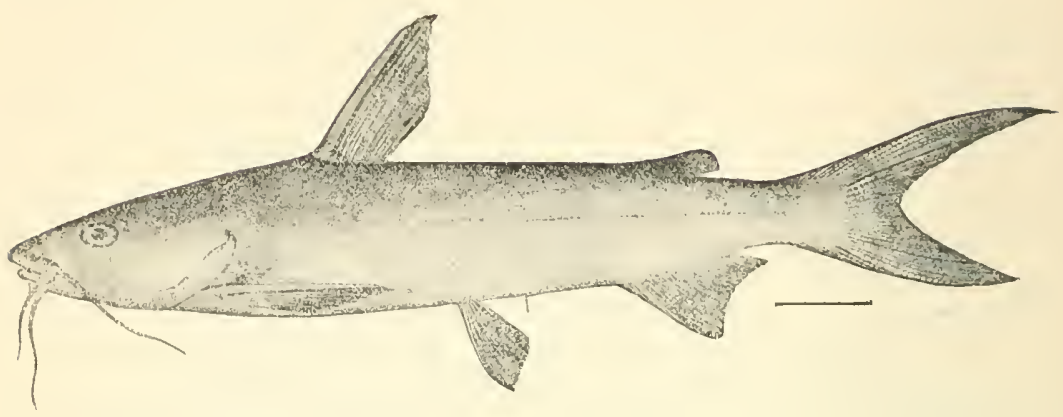

12. "GALEICHTHYS OR HEXANEMATICHTHYS FELIS."

Illustration. Page. $53 \quad 128$

Sea Catfish; "Head $33 / 4$; depth 5 . D. I, 7 ; P. I, 6 ; A. Common Sea Cat; 16. Body rather elongate, not compressed, tapFLORIDA CAT. ering into the slender tail; head subconic, depressed, flattish above; maxillary barbel nearly as long as the head; gill membranes broadly united, forming a narrow, free fold across the isthmus; occipital process with a median keel, long, about $1 / 3$ head, its tip convex; fontanelle, forming a narrow groove; top of head comparatively smooth; humeral process nearly $\mathrm{I} / 2$ the length of the pectoral spine; caudal deeply forked, the upper lobe the longer. Steel blue, sides and belly silvery, lower fins pale. Length, 24 inches." Weight to 3 pounds ; average about $11 / 2$ pounds.

This fish will, unfortunately for himself and for you, take any kind of bait you are using for better fish, while still fishing in his habitat, but will not usually take a troll. Non-edible; generally so considered. 


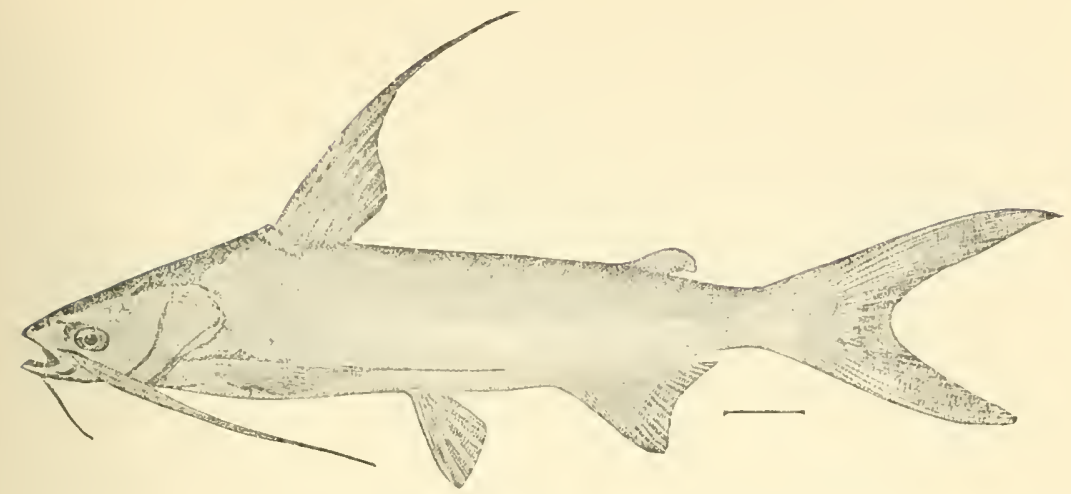

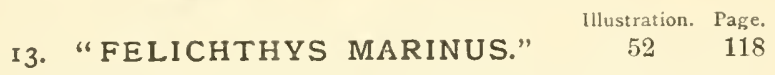

GaFF TOPSAlL

" Head rather short and broad, rounded anteriorly ; CAT. occipital buckler small, oblong, not much broader before than behind; band of palatine teeth nearly continuous, extremely variable; maxillary barbels extending about to the end of the pectoral spine; pectoral spine longer than the dorsal spine, $2 / 3$ the length of the head, its filament reaching the vent; dorsal filament reaching adipose fin; upper lobe of caudal much the longer; anal fin falcate. Dusky bluish, silvery below. Head $41 / 4$. D. I, 7 ; A. 23 . P. I, 12 ; B. 6 . Vert. $20+30$." Weight to 10 pounds; average, 3 to 4 pounds. Caught same as Common Sea Cat. Non-edible.

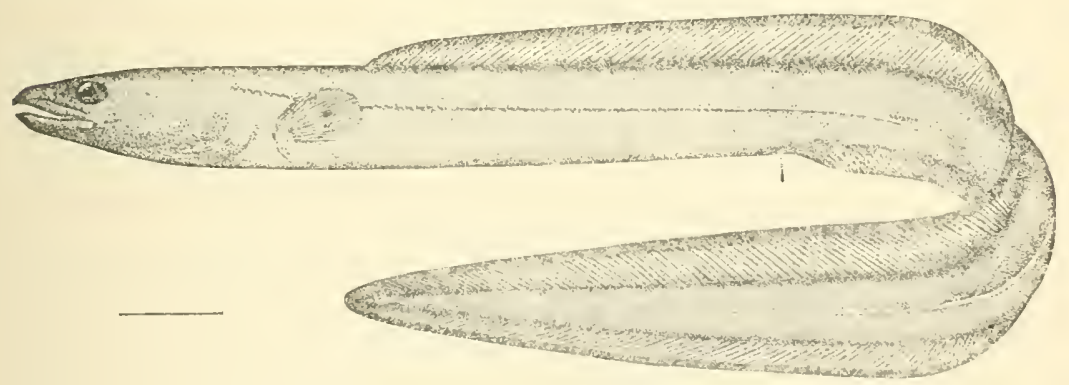

I4. "LEPTOCEPHALUS CONGER." 148 354

CONGER Eel. Weight 3 to 8 pounds.

The Conger Eels, Snake Eels, and Morays are all very undesirable customers. They will occasionally take any bait 
you may be fishing with for better fish south of Indian River Inlet, but mostly among the Keys. When unfortunate enough to hook one, cut the line a foot or so ahove him and let him go. Non-edible.

SNAKE EEL.

WORM EEL.
I6. "AHLIA EGMONTIS."

I5. "VERMA KENDALLI." $\quad 159 \quad 159 \mathrm{a} \quad 375$

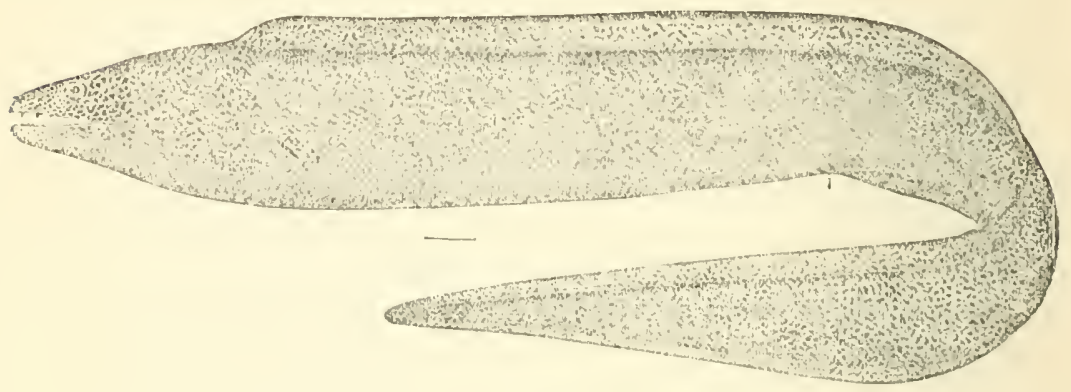

Moray, Spotted; I7. "LYCODONTIS MORINGA."

395 HAMLET.

I8. "LYCODONTIS FUNEBRIS." No illustration. 396

Moray, Black ; "Tail a little longer than head and trunk. Teeth Morena Verde. uniserial in the jaws in the adults; teeth on vomer uniserial (var. ? erebus), or biserial (funebris); long, depressible canines on front of vomer; eye 2 to $2 \mathrm{t} / 2$ in snout, above middle of gape; cleft of mouth $2 \frac{1}{2}$ in head; head $2 \frac{1}{2}$ in trunk. Color, dark olive brown, nearly plain, paler on throat, sometimes with very faint darker marblings; dorsal and anal fins with dark lines running longitudinally; belly without black transverse lines. Jaws not completely closing. The largest of our eels, reaching 5 or 6 feet or more ; extremely ferocious."

'These last four species to be treated the same as the Conger Eel. 

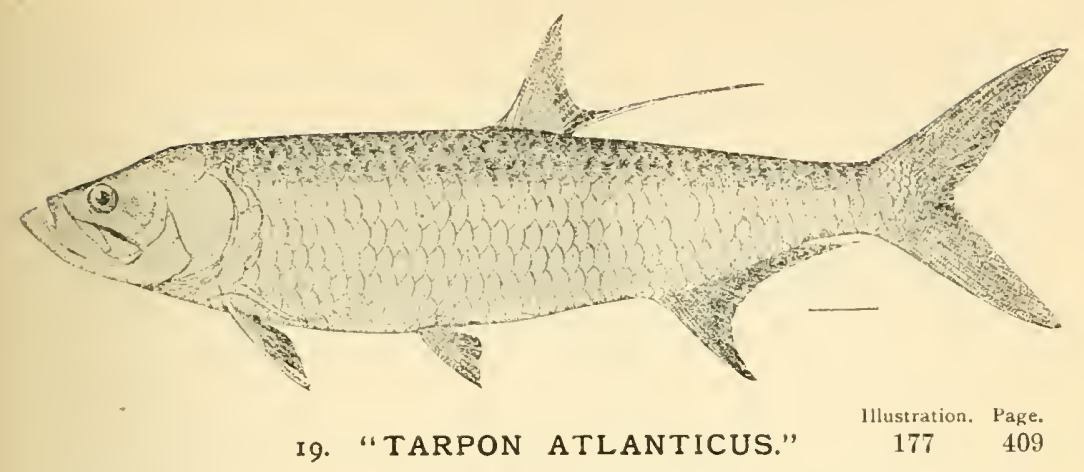

TARPON, OK

TARPUM ;

Silver King;

Grande Ecallle;

SILVER Fish ;

SABALO ;

SAVANILla ;

SAVAllE.
"Head, 4; depth, $3 \frac{4}{5}$; D. 12 ; A. 20 ; lateral line, 42; branchiostegals, 23 . Body elongate, compressed, little elevated; dorsal filament longer than head; mouth large, the maxillary extending beyond eye. Uniform bright silvery, the back darker. Length 6 feet. Noted for the great size of its scales, which are used in ornamental work.

It is not much valued for food, although much appreciated by anglers.

'An immense and active fish, preying eagerly on schools of small fry, in pursuit of which it ascends fresh-water rivers quite a long distance.' (Stearns.) It is often dangerous to seine fishermen, leaping over or through the nets with great force." IVeight to 213 pounds.

The first Tarpon caught in Florida with Rod and Reel was taken by Mr. Samuel H. Jones of Philadelphia, at Indian River Inlet, Captain Gardner being his boatman. It was taken on a large Buel Spoon, and weighed $1721 / 2$ pounds, and was 7 feet 4 inches long. Very many more were caught there afterwards, by Senator Quay, Mr. George of Danbury, Conn., and other sportsmen, and nearly all were caught with a 600 -feet Cod Line, used as a hand line and at night. Afterward Charlotte Harbor on the West Coast became the principal resort for Tarpon sportsmen, and somewhat later Fort Meyers, eighteen miles up the Caloosa River, became the leading resort. During the past two or three years Boca Grand and Captiva passes (Charlotte Harbor) are much frequented. Mr. W. H. Wood of New York was the leading sportsman to introduce the sport on the IVest Coast. On the Vest Coast the fish was first caught with Rod and Reel, 18 to 21 Hall Line, Tarpon Hook, with curtain cord, hard-twisted 
linen, or rawhide snoods. Bait, Nullet of $1 / 4$ to $1 / 2$ pound, with head and tail cut off. Still fishing on bottom. Boat anchored, bait cast out 50 to 100 feet, then wait, leaving the reel loose. When the fish takes the bait allow him to run a few feet, then strike. If he is hooked he will almost instantly jump ont of water, sometimes where you would least expect him. Recover the line, and the fun commences. He will jump many times, then run long or short distances, with occasional less vigorous leaps, until he surrenders. The time varies from fifteen minutes to an hour or more, according to the size and condition of the fish, and the skill of the sportsman, or his desire to kill the fish quickly or take his time. The method at present with many sportsmen is to fish in the passes, on the tides, with live floating Mullet, which is by far the most scientific method, and gives the fish a better chance for his life. Weight to 213 pounds. Mr. George holds the record for weight, as he caught one of the above weight the present season (1901). Non-edible, or barely edible for $5^{\circ}$ to 10 pound fish. 


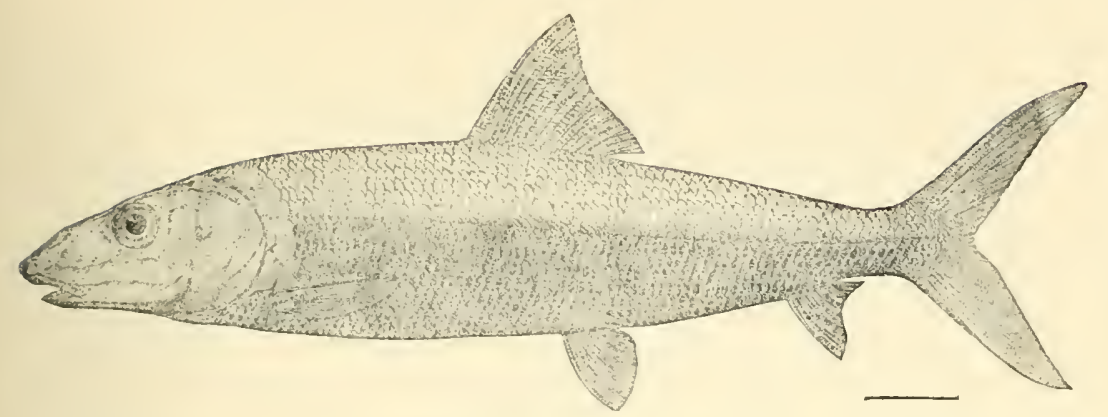

21. "ELOPS SAURUS."

lllustration. Page. $179 \quad 411$

BONEFISH ;

BONY-FISH ;

Ten Pounder; JOHN-MARIGGLE; Big Eyed Herring; Matajuelo Real; Lisa Francesa.
"Head, $33 / 4$; depth, 4. D. 15 ; A. 8 ; scales, 9-71-7. Upper lobe of caudal the longer. A broad band of peculiar, elongate, membranaceous scales along middle line of back; accessory ventral scale large. Brilliantly silvery; olivaceous above; back and sides with faint streaks along the rows of scales; fins plain; axils dusky. Length 18 inches to 3 feet." Weight to 10 pounds; average about $4 \mathrm{I} / 2$ pounds.

Caught, preferably, on banks or bars where there are short weeds, or in some cases near passes and sand bars, near shores, and in shallow bays. This fish runs onto the shallow water to feed, with the tide, and off with the tide. Caught still fishing on bottom. Rod and Reel, No. 6 or 9 Line, $3 \%$ or $4 \%$ hook, strong gut leader 12 to 18 inches, No. 6, 7 or 8 Egg Sinker. He is a Mollusca and Crustacæ eater, and was first caught for sport with sand fleas and Fiddler Crabs ; but at present the Soldier or Hermit Crab is mostly used, although the Sand Crab, or "Sprite," is a good bait. Commence to fish with the rise of the tide, fasten the boat with an oar pushed into the sand, cast as far as possible, sit still, and wait for a bite. The fish can usually be seen, when present, as their tails and dorsal fins stick out of water until the tide is too high to show. They wander over the banks like a drove of cattle feeding, and may or may not come along where your bait is. If they see it, some one of them will make a rush for it, and the fun begins. They have a long majestic run ; as they cannot go down they make it up in horizontal distance, often 200 to 300 feet from the boat. Play the fish until he surrenders, 
which will be from ten to twenty minutes. He will come alongside entirely played out, if time enough is allowed. They can also be caught, with same tackle and bait, in the deeper water around the banks while running on or off, and especially where the banks are near a pass, as at Norris Cut, Bears Cut, Soldier Key, and many places among the Keys. They have no superior as game fish. Edible, B.

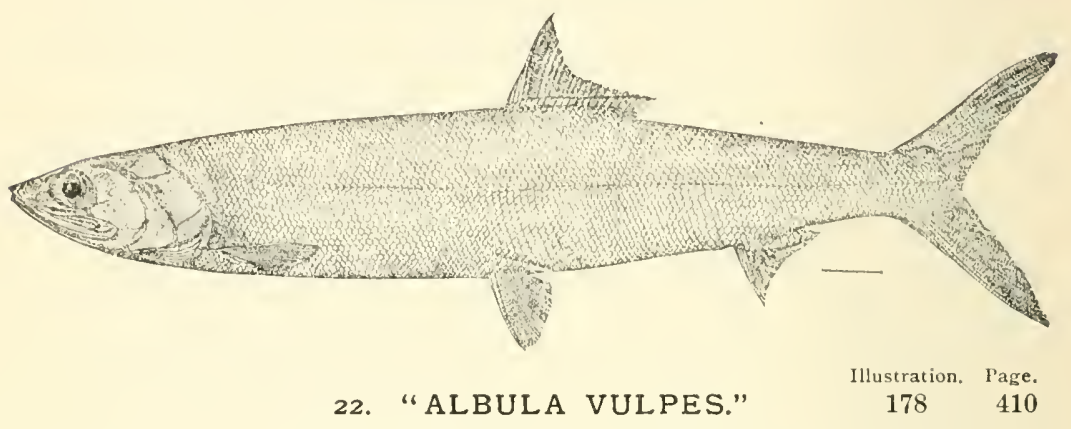

LADY-FISH ;

"Head, $4 \mathrm{I} / 4$; depth, 5 to 6 ; eye large; 4 to 5 . Bonefish; $\quad$ D. 20 ; A. 13 ; V. 15 ; B. 30 ; scales, 12-120-13. Bony-Fish; Gular plate 3 to 4 times as long as broad. I Length Banana-fisil; 3 feet." Weight to 10 pounds; average, 3 to 4 SKIP JACK; pounds.

Caught with Rod and Reel, still bottom or floating; 18 Line $4 \%$ or $5 \%$ hook. Trolling, Spoon, Phantom, cut bait. Inside and outside one of the gamest fish that swims when taken with rod and reel. When hooked they will make many rapid jumps, and seemingly are on both sides of the boat at the same time. I have had several land in my boat while jumping. In spring of 1900, two such instances at Jupiter Inlet. Barely edible, C. Many fine bones.

23. "POMOLOBUS PSEUDOHARENGUS." 189426

Alewife;

BRANCH HERRING ;

Gaspereau ;

WALL-EYED HERRING ; Big-Eyed Herring; ELLWIFE.
"Head, 42/3; depth, $3 \mathrm{x} / 3$; eye, $3 \mathrm{r} / 2 ;$ D. 16 ; A. 19 ; lateral line, 50 ; scutes, $21+14$. Body rather deep and compressed, heavy forward; head short, nearly as deep as long, the profile somewhat steep and slightly depressed above the nostrils; maxillary extending to posterior margin of pupil; lower jaw somewhat projecting; 
upper jaw emarginate; eye large, slightly longer than snout; gillrakers long, 30 to 40 below the angle of the arch, shorter and stouter than in $A$. sapidissina; lower lobe of caudal the longer; dorsal fin high, a little higher than long, its height $61 / 2$ in length of body. Bluish above; sides silvery; indistinct dark stripes along the rows of scales; a blackish spot behind opercle ; peritoneum pale."

A small fish or Minnow caught in cast nets, and used as bait. Indian River.

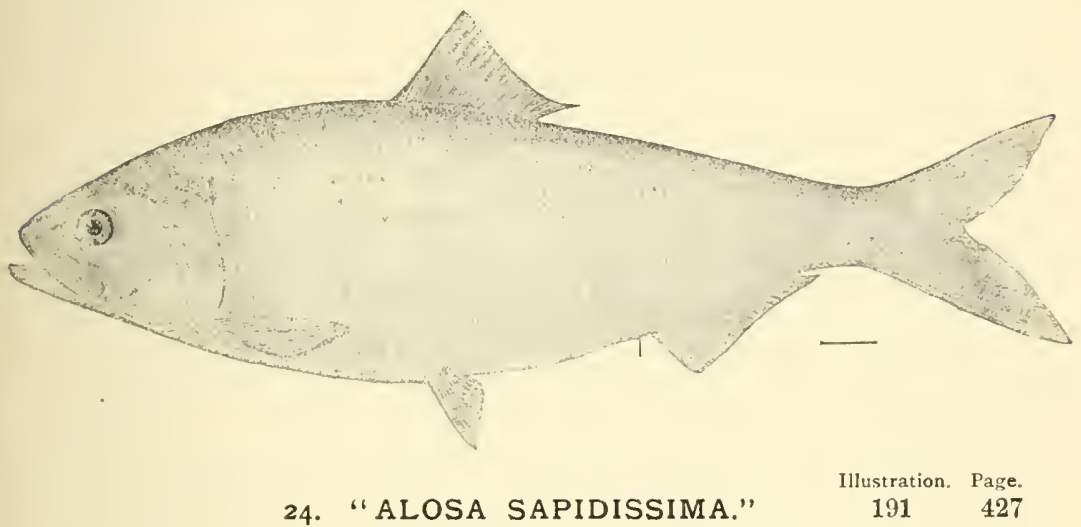

SHAD ;

COMMON SHAD;

AMERICaN SHad ;

North River ShaD;

Potomac Shad.
"Head, 41/4; depth, 3. D. 15; A. 21; lateral line, 60 ; ventral scutes, $21+16$. Body comparatively deep; mouth rather large, the jaws about equal, the lower fitting into a notch in the tip of the upper; no teeth; preorbital moderate; cheeks much deeper than long, the preopercle extending little forward, joining the mandible at a point rather behind the eye ; gill rakers extremely long and slender, much longer than eye, about 60 below the angle of the arch, the number smaller in specimens from the Gulf of Mexico, which perhaps represent a tangible variety; fins small, dorsal much nearer snout than base of caudal; peritoneum white. Bluish above; sides white and silvery; a dark spot behind opercle, and sometimes several along the line dividing the color of the back from that of the sides; axil dusky. Length $2 \mathrm{I} / 2$ feet."

This well-known fish is caught in Florida in St. Johns River only, and in nets. Edible, A. 


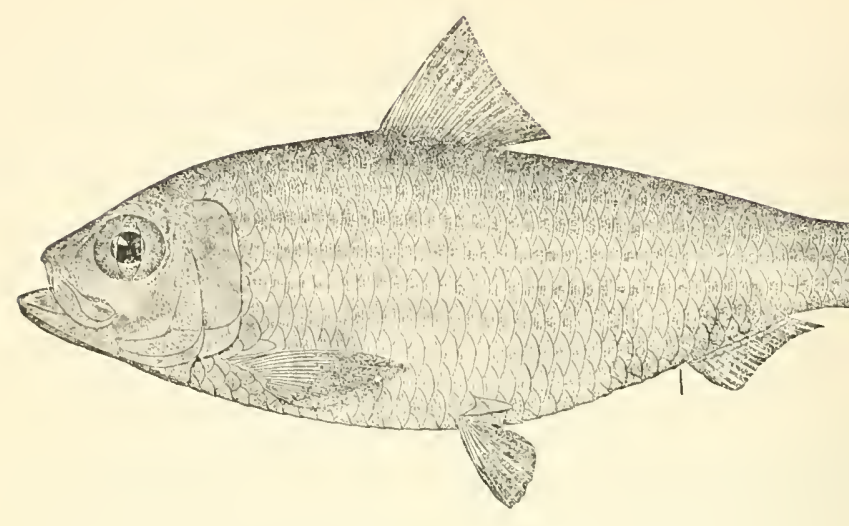

25. "SARDINELLA SARDINA."
Illustration. Page. 193 430

Sardina de Ley.

"Head, $3 \frac{4}{5}$; depth, $23 / 4$ to 3 ; the Florida specimens (Var. Pensacolæ) averaging 23/4; Cuban examples about 3 ; eye, 22/3. D. 16 ; A. 17 ; scales, 40 ; scutes, $16+12$. Body deep, with the ventral outline forming an even curve from chin to vent; eye moderate, $1 / 3$ longer than snout; insertion of ventrals nearer tip of snout than base of caudal; teeth in jaws small; a large patch on tongue; scales very adherent, each with 1 to 4 vertical curved striæ, those before dorsal more or less laciniate. Silvery, dark humeral spot usually present, but often obscure or wanting; surrounded by golden in life; usually a row of dark points extending backward from it along upper parts of body; no distinct longitudinal streaks. Length, 8 inches."

Caught in cast nets and used only as bait. Especially at Key West. Several species, but I give only one. 


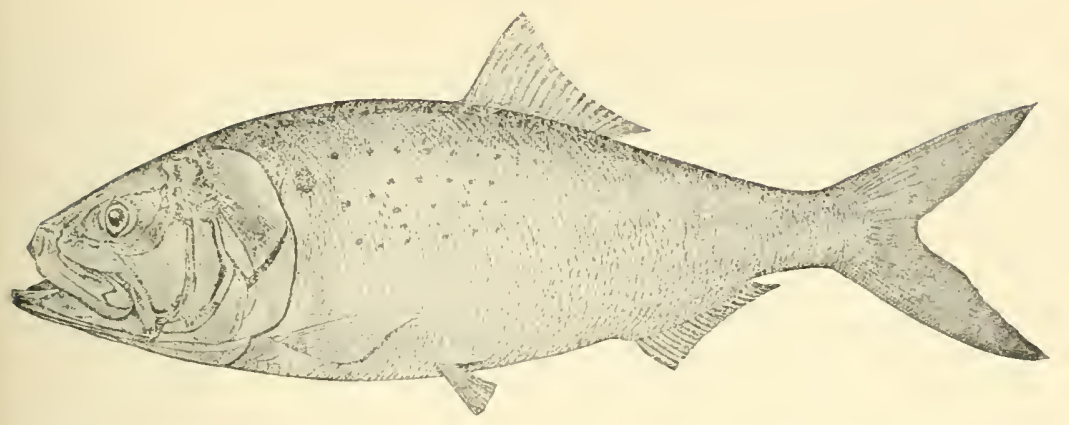
26. "BREVOORTIA TYRANNUS. $195 \quad 433$

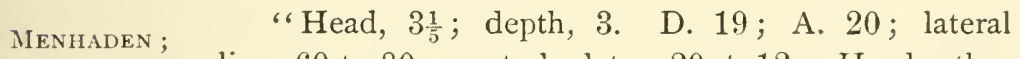
Mossbunker; line, 60 to 80 ; ventral plates, $20+12$. Head rather BoNy-FISH; short and heavy; fins comparatively short, the height Whitefish; of the dorsal less than the length of the maxillary; BUGFISH ; FATBACK ; POGY. height of anal less than half the length of the maxillary; pectorals not reaching to ventrals; dorsal inserted slightly behind ventrals, about midway between snout and base of caudal ; scales moderate, strongly serrated, arranged very irregularly, those before dorsal strongly pectinate ; operculum strongly striated or almost smooth (Var. Aurea); gill rakers much longer than eye. Bluish above; sides silvery, with a strong brassy luster; fins usually yellowish; a conspicuous dark scapular blotch, behind which are often smaller spots. Length, 18 inches."

Caught in cast nets at Mosquito Inlet, and used as bait. Very plentiful in October and November. Several species, I give only two.

27. “BREVOORTIA IYRANNUS PATRONUS." Not illustrated. 434 MeNHADEN ; Gulf Menhaden.

Caught in cast net and used as bait all along the coast. 


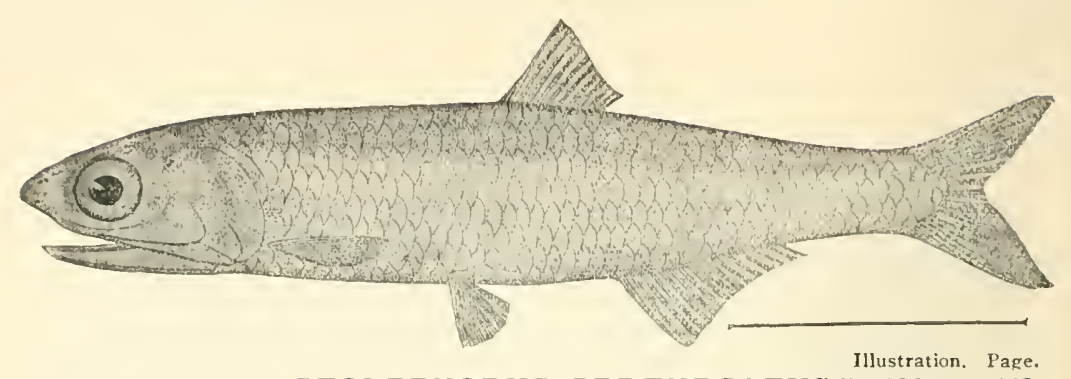

28. "STOLEPHORUS PERTHECATUS." $196 \quad 442$

Anchovy. "Head, $32 \frac{2}{3}$; depth, 5 ; eye, $31 \frac{1}{3}$. D. 11 ; A. 16 ; scales, 38. Body somewhat compressed, the belly not carinated nor serrated; eye longer than snout; snout conical; teeth minute, in both jaws; maxillary with acute tip almost reaching gill opening; gill rakers numerous, $2 / 3$ eye; dorsal inserted midway between center of eye and base of caudal ; pectorals not quite reaching ventrals; axillary sheaths very large, almost as long as pectoral or ventral. Olivaceous, with a narrow silvery stripe, $1 / 4$ depth of body, not half as wide as eye. Length, $32 / 3$ inches."

Caught in cast net and used as bait.

29. "STOLEPHORUS BROWNII." Not illustrated. 443

ANCHOVy ; Caught in cast net and used as bait.

STRIPED ANCHOVY ;

Manjua.

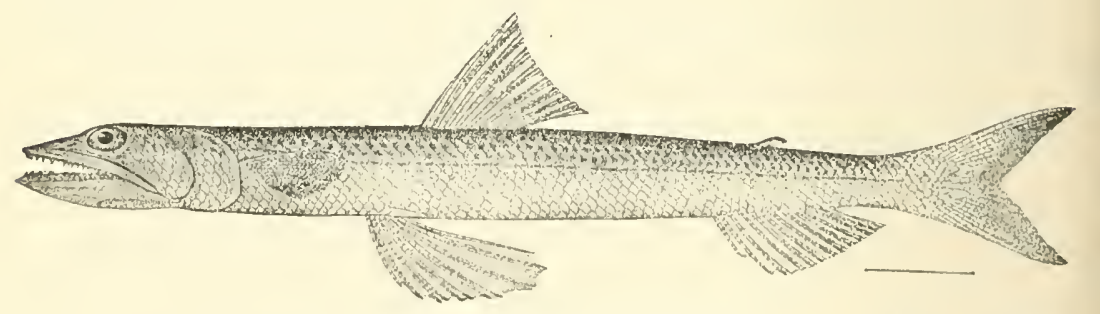

30. "SYNODUS FETENS." 230

538

LizARD FISH ;

GalliwasP ;

LAGARTO;

SOAPFISII ;

Ground Spearing.

ularly arranged, and the rows less oblique than in

Synodus lucioceps; those on the opercle in about 5 rows, on the 
cheeks in $7 ; 25$ to 30 scales along back before dorsal ; 4 in a vertical row between adipose fin and lateral line, 5 in an oblique row; pectoral fin short, 2 in head, not reaching ventrals, its length $3 / 4$ that of the premaxillary ; ventral large, $1 \mathrm{I} / 4$ in head, its length from outer edge of base greater than from tip of snout to upper edge of gill opening; interorbital space considerably concave, with radiating ridges. Olivaceous or sandy gray; yellowish below; back mottled; upper surface of head brownish, distinctly vermiculated with yellowish; ventral fins, lower side of head, and inside of mouth tinged with yellow; no scapular spot; snout not black at tip; dorsal scarcely barred. Length 12 inches." Weight to 1 or 2 pounds; average $1 / 4$ to $1 / 2$ pound.

Caught: I have caught them only in Biscayne Bay while fishing for Squirrel Fish, Sand Perch, or Goat Fish, with No. 1 or No. 2 hooks. Bait: Small cut fish, light rod and reel. They will take a troll. Non-edible.

NeEDlefish ;

31. "TYLOSURUS ACUS." $\quad \begin{array}{cc}\text { Illustration. Page. } \\ \text { 309 }\end{array}$

HOUNDFISH ;

Agujon ;

BillfFish.

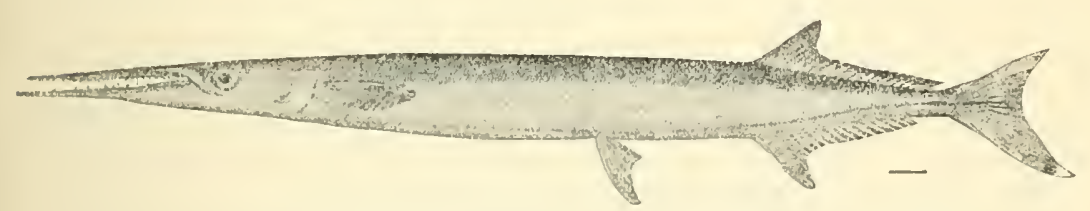

32. "TYLOSURUS RAPHIDOMA."

308

715

Needlefish ;

HoUNDFISII ;

Aguja de, CASTa Guardfish ;

LONG-JAWS.
"D. 21 to 24 ; A. 22 to 24 ; scales, 350 . Caudal keel rather strong, black, one or more folds of skin across edge of preopercle; body robust, little compressed, its greatest breadth a little more than $2 / 3$ greatest depth; caudal peduncle slightly depressed, a little broader than deep, with a slight black dermal keel; head broad, interorbital space nearly $2 / 3$ length of postorbital part of head, with a broad, shallow, nearly naked median groove, which is wider behind and forks at the nape; supraorbital bones with radiating strix; jaws unusually short, stiff, strong, rapidly tapering forward; large teeth of jaws very strong, 
knife-shaped; upper jaw from eye about $13 / 4$ times as long as the rest of the head; eye large, 7 in snout, $2 \frac{2}{3}$ in postorbital part of head, and $1 \frac{4}{5}$ in interorbital width; maxillary entirely covered by the preorbital; cheeks densely scaled; opercles mostly naked except along the anterior margin; scales of body minute, especially above; dorsal fin low posteriorly, the height of its anterior lobe equaling that of anal or length of postorbital part of head, its longest ray $\frac{2}{5}$ the base of the fin, last rays of dorsal and anal much elevated in young; caudal lunate, its lower lobe nearly half longer than the upper; middle rays about as long as eye; ventrals inserted midway between base of caudal and middle of eye, their length a little less than that of pectoral, and equal to postorbital part of head, insertion of anal opposite that of dorsal. Color green, silvery below; no lateral stripe; pectorals and dorsal blackish; scales and bones green. Length, 3 to 5 feet."

All Needlefishes are worthless, and only mentioned as a curiosity. Very troublesome while fishing with any Crustacean or Mollusk bait for Bonefish, as they eat your bait out of its shell, first boring into the shell. Weight, $1 / 4$ pound to 10 pounds, my experience. Nonedible.

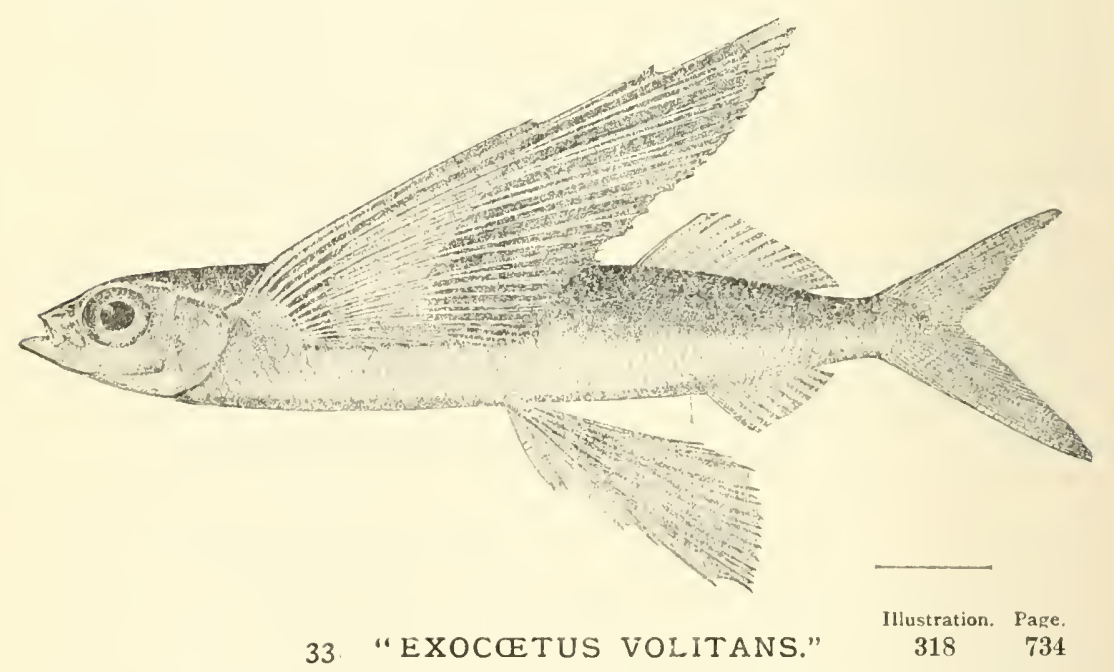

FLYING FISII.

Head $41 / 4$; depth $6 \frac{1}{1}$. D. 12 ; A. 11 ; scales, 55,25 before ventrals, 30 before dorsal ; 6 rows between dorsal and lateral line. Snout rather obtuse, 4 in head; eye 
large, $23 / 4$ in head; interorbital space slightly concave, $22 / 3$ in head; width of body at base of pectorals $13 / 4$ in head; anal fin long, opposite dorsal ; second ray of pectorals divided, the first simple, the third and fourth longest; insertion of ventrals midway between posterior edge of preopercle and base of caudal; pectoral fins not uniform, in color dark brown, with an oblique, whitish band, which begins in the axil and runs obliquely backward to middle of fin; edges of pectorals whitish; pectoral fins $1 \frac{2}{5}$ in length of body, their tips reaching beyond dorsal; ventrals $31 / 2$ in body, reaching about to ninth ray of anal ; longest dorsal ray $2 \mathrm{I} / 2$ in head, anal ray 3 ; lower lobe of caudal $3 \frac{1}{5}$ in body. Ventral fins white, with a slight dusky shade in the axil, no dark markings on dorsal or anal. Length, 12 inches."

\section{"FODIATOR ACUTUS" 1llustration. Page.}

Flying-fishes are occasionally, and accidentally, FlYiNG-Fish, caught outside. Are of no value, except as curiosities. Sharp-nosed. Weight, $1 / 4$ pound. Non-edible.

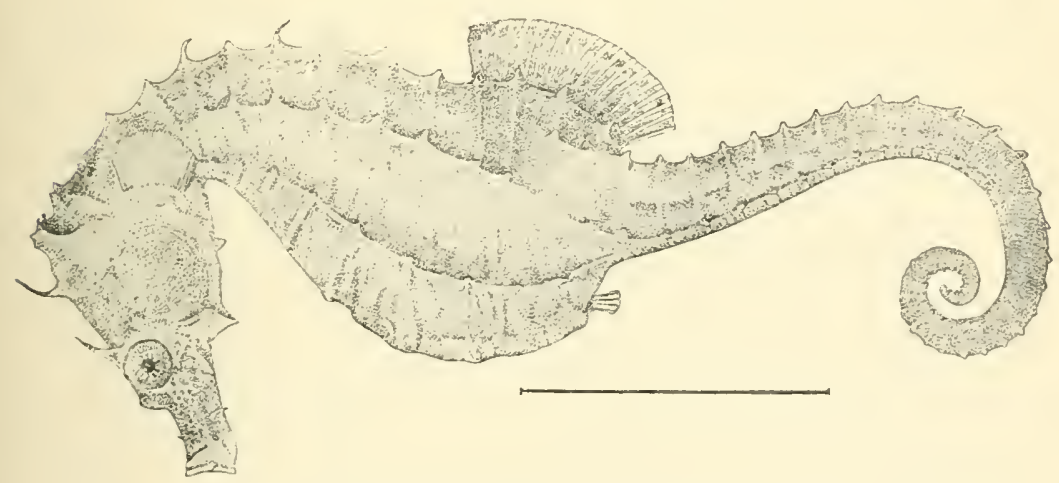

35. "HIPPOCAMPUS HUDSONIUS." $327 \quad 777$

SEA-HORSE,

"D. 19 ; rings $12+32$ to 35 ;

Common American Sea-horse. depth equal to length of head. Snout $1 \frac{1}{3}$ in rest of head; spines of head weak, provided with cirri ; spines of body all short and bluntish; dorsal on $31 / 2$ of the 11 rings. Dusky, without spots, but with pale grayish blotches, which are sharply edged with paler and blackish; 
some of these between eyes and on neck, the most distinct blotch forming an hour-glass-shaped figure, extending down each side of the back; similar blotches on belly and tail; dorsal with a submarginal dark band." Non-edible.

\section{6. “HIPPOCAMPUS ZOSTERE." $\begin{array}{ccc}\text { Illustration. } & \text { Page. } \\ & 328 & 778\end{array}$}

SEA-HORSE. This is a small fish, resembling a horse, caught in net. One was caught on my boat, with landing net, at Jewfish Creek, winter of 1900 . Weight, $1 / 4$ pound. Of no value except as a curiosity. Non-edible.

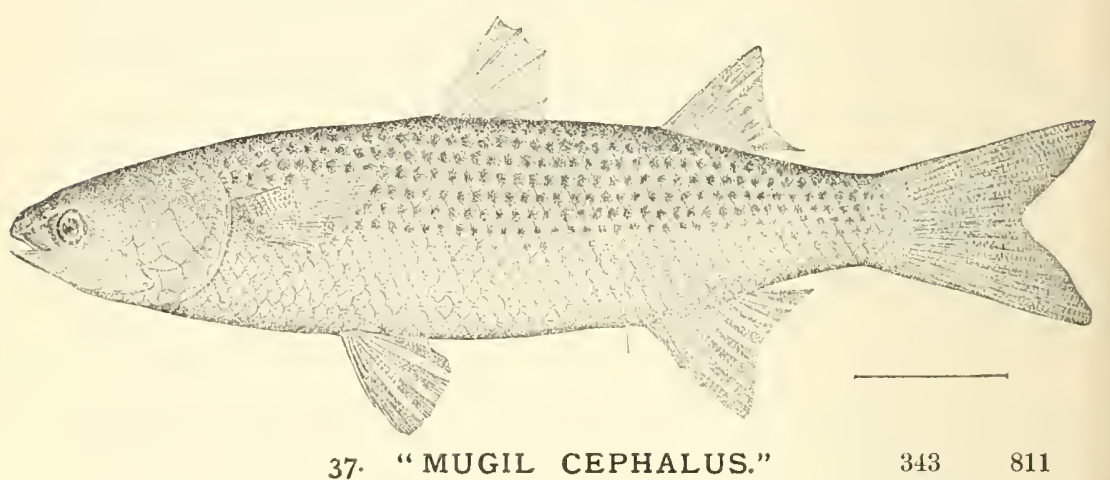

Mullet ;

COMMON MUllet ;

Strifed Mullet;

Cefalo;

MACHO;

MACHuto ;

Lisa Cabezuda.

"Head $4 \frac{1}{6}\left(5 \frac{1}{3}\right.$ in total with caudal); depth $3 \frac{5}{6}$ ( 5 in total). D. IV-I, 8 ; A. III, 8 (very rarely III, 7) ; scales 41-13. Body rather robust, somewhat compressed, its depth moderate; snout rather narrow and acutish, its upper profile little less oblique than lower; interorbital space slightly convex, $2 \frac{2}{5}$ in head; upper lip rather thin; space at the chin between the mandibulary bones oblanceolate, acutish posteriorly; preorbital narrow, not nearly covering the maxillary; eyes hidden anteriorly and posteriorly by a broad adipose membrane; teeth close-set, rather small, but evident; scales rather small; about 23 large scales between origin of dorsal and tip of snout; scales on top of head slightly enlarged; soft dorsal and anal with very few scales ; first dorsal spine usually a little more than half head, its length subject to some variation; margin of soft dorsal concave, the seventh ray shortest, $2 \mathrm{I} / 2$ times in length of second or longest ray; anal 
similar to soft dorsal, but less concave; pectoral reaching nearly to front of spinous dorsal, its insertion above axis of body; caudal deeply forked. Color dark bluish above; sides silvery, with conspicuous dark stripes along each row of scales; pale yellowish below ; ventrals yellowish, the other fins more or less dusky. Length, 1 to 2 feet."

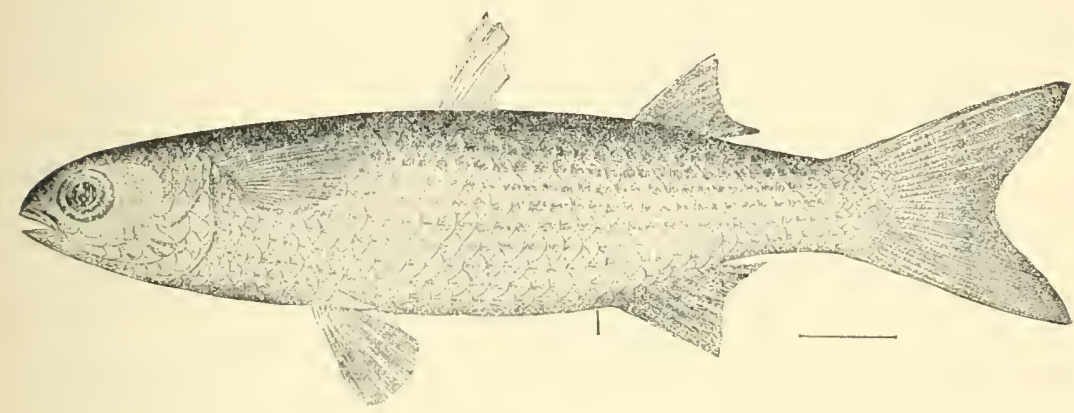

38. "MUGIL CUREMA."

Illustration. Page. $344 \quad 813$

MULLET;

White Mullet;

Mullets are used by sportsmen as bait, and Blue-back Mullet; used alive and cut, according to needs. Nearly LIZA ;

Lisa Blanca; Silver Mullet. all fish will, at times, take them. Edible, C; but the large Roe Mullet will rank B.

Before leaving the Mullet question I wish to tell some stories about them, which are true, even if they are fish stories.

I have often heard the statement that the Mullet crop in Florida is as important to the inhabitants of the State as the corn crop is to the inhabitants of Illinois, Iowa, and some other Western States.

The statement may not be strictly true, but the crop certainly furnishes employment and food to a great many men and their families.

Taken in connection with "Grits," called in the North (usually) hominy or fine hominy, they are in some cases quite a portion, and sometimes all, of the food, in some seasons of the year, of many of the colored population. Grits is one of the cheapest foods in the world, very seldom reaching in Florida more than two and a half cents per pound at retail. 
Capt. John calls it "Florida Food."

About the close of the season of 1896, during which I had kept house in Augustine three months, I was down at Corbett's Dock, where nearly all the sailboats lie. A party of five or six white and black boatmen were talking over and lamenting the bad season, which had been a cold one. Some of them were wondering how they would get through the summer.

One colored man said: "Well, Ise got money enuff to buy two barls grits, and I can ketch de Mullet wid my cast net, so I kin get along."

He illustrated the situation with a good many colored brothers, and probably many white men.

G. Brown Goode, in "American Fishes," 1887, says : "Although Mullets are abundant almost everywhere, it is probable that no stretches of sea coast in the world are so bountifully supplied with them as those of our own Southern Atlantic and Gulf States, with their broad margin of partially or entirely land-locked brackish water and the numerous estuaries and broad river mouths. The Mullet is probably the most generally popular and the most abundant fish of our whole southern sea board.

"Like the Menhaden, it utilizes food inaccessible to other fishes, groping in the bottom mud, which it swallows in large quantities. Like the Menhaden, it is not only caught extensively by man, but is the main article of food for all the larger fishes, and is the best bait fish of the regions in which it occurs." And, "In October, Charlotte Harbor, Sarasota Bay, and Palmasola Bay, seem to be the headquarters of all the Mullets of the Gulf. Tampa Bay, Anclote River, Homosassa River and vicinity, are also favorite spawning places. During the fall they move in such immense schools, that the noise of their splashing in the water resembles distant thunder; and to persons living near the river or bay, their noise, kept up day and night, becoming very annoying."

I have heard and seen all the above movements of schools of Mullet in Indian River; many times their rushes, when pursued by Porpoise, Sharks, and Cavalle, somnding like distant thunder or artillery.

About November 1, 1900, while I was aboard my boat, at anchor, opposite Mosquito Lighthonse, about the middle of the stream, just after lark I heard a great commotion in the water; looking out I 
found the river full of Mullet bound in from Mosquito Inlet, half a mile distant. The water seemed alive with them, from shore to shore.

Capt. Gardner was ashore with his family. He got some lanterns and placed them in his skiff, which he held to and at right angle with the shore, thus stopping the Mullet which were running along the shore. About seventy-five jumped in his boat. The lighthouse keepers, by the same tactics, with two or three boats, caught over 200 .

That is a big fish story, but it is a true one.

A few days after, we started on a cruise to the south during the forenoon, and within a mile below New Smyrna met a school which extended from shore to shore, but not so solid. Some eight or ten boats of fishermen were in the school, and had loaded their boats to the gunnels by using their cast nets, and were en route for New Smyrna to market their fish.

I have heard a story of the late Mr. John Ligget of St. Louis, which I cannot vouch for, but presume it to be true. He was on a cruise from Rock Ledge, I believe on the schooner "Tarpon," down Indian River. He had heard wonderful stories of Mullet jumping into boats, but could not believe them. One night, under proper conditions, his boatman took him out into four or five feet of water and, with torches or lanterns, showed him the stories were sometimes true, and he hollered "Enough!"

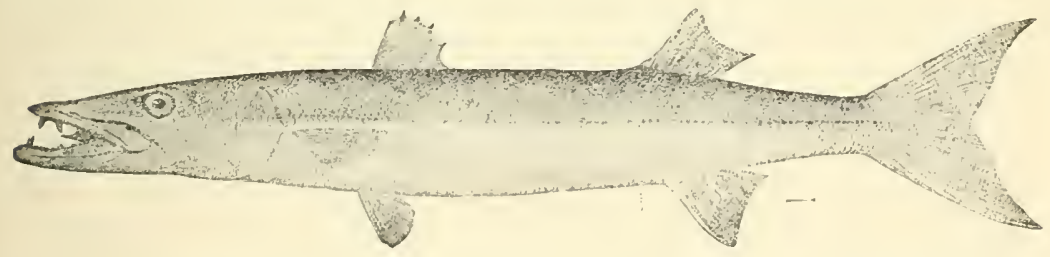
39. " SPHYRANEANA BARRACUDA, OR PICUDA." $349 \quad 823$

BARRACUDA ;

Great BarRaCUda ;

PICUDA;

BECUNA ;

Salt Water Pike $(G)$;

Salt iVater Mascalonge (G). Body oblong, slightly compressed, covered with large scales; head rather small, about 6 in head, equal to width of interorbital area. D. V-I, 9; A. I, 9 ; scales $10-75$ to $85-10$, the cross series counted from lateral line to front of dorsal and anal fins respectively.

"Head 3 ; depth 2 in head; eye 
large; maxillary large, nearly $1 / 2$ length of head, its posterior margin reaching past front of orbit; lower jaw with fleshy tip, bluntly conical; interorbital area concave, with a shallow medium groove (as wide as pupil at posterior edge of orbit), divided by a ridge in front and behind ; supraocular ridge bony and striate ; preocular ridge present; teeth large; premaxillary teeth small, little compressed, irregularly set nearly uniform in size, somewhat thicker and shorter posteriorly; premaxillary with two pairs of very large compressed teeth, their length more than half width of pupil; anterior ones directed downward, posterior ones downward and backward; teeth in lateral series of lower jaw small anteriorly, increasing gradually backward, when they nearly equal those on palatines; palatine teeth similar to those on lower jaw, arranged in reversed order. Distance from tip of snout to front of dorsal $2 \frac{2}{7}$ in body ; second dorsal spine longest, $1 \frac{1}{3}$ in snout; second dorsal and anal equal; anal inserted under first third of soft dorsal ; caudal forked, upper lobe the longer ; pectorals reaching beyond front of dorsal, $21 / 2$ in head; origin of first dorsal slightly behind the ventrals; cheeks and opercles scaly, about 12 rows of scales on cheeks; upper part of head with small embedded scales. Color silvery, darker above; sides in young with about 10 dark blotches which break up and disappear with age; some inky spots, usually on posterior part of body, are very conspicuous in both old and young specimens; soft dorsal, anal and ventral fins black, except on margins; pectorals plain, except upper part of its margin, which is black; fins of very young specimens nearly plain. The largest and most voracious of the Barracudas, reaching a length of 6 feet." Weight to 75 pounds ; average, 20 pounds.

Caught from rowboat, anchored, still fishing, Tarpon rod and reel, $10 \%$ or Tarpon hook, 21 line, wire snood $1 \frac{1}{2}$ feet long. Bait: Live Mullet, Spot, Grunt or other small fish; no sinker. Keep the bait floating just under or on surface. When the fish bites, let him run a few feet and strike, and play him until he surrenders. Or, trolling from rowboat, sailboat, or launch, with same rig as above. With rod and reel you must slow up to play and land the fish. Or, trolling with $\frac{3}{16}$-cotton handline, squid, or large hook and live or dead small fish. And last, and the best method of all, fish from rowboat on bars near passes, sand banks, along shores, and in shallow small bays, cspecially on west side of Biscayne Bay, in, say, three to five feet of water; 'Tarpon rig, with small brass or iron chain as leader. Bait, 
half-pound Mullet or other small fish, head and tail cut off. Your guide to pole the boat until he sees a fish lying on the bottom, or moving slowly, he then stops and holds the boat with the pole; you keep your seat and cast as near the fish as possible; he will run a short distance, but will soon return and, usually, after eyeing the bait, will make a rush and gobble it. The instant he takes it, strike him. If successful in hooking him, he will make long runs, as, like the Bonefish under same circumstances, he has no deep water to run to. Play him until he surrenders. He has no superior as a game fish when thus caught ; in fact, I consider him fully equal to the Tarpon or any game fish when caught in this way. I call this fish a salt-water Pike, or salt-water Mascalonge. Picuda, Spánish, means Pike. Edible up to 15 pounds. A 1 , or $\mathrm{A}$.

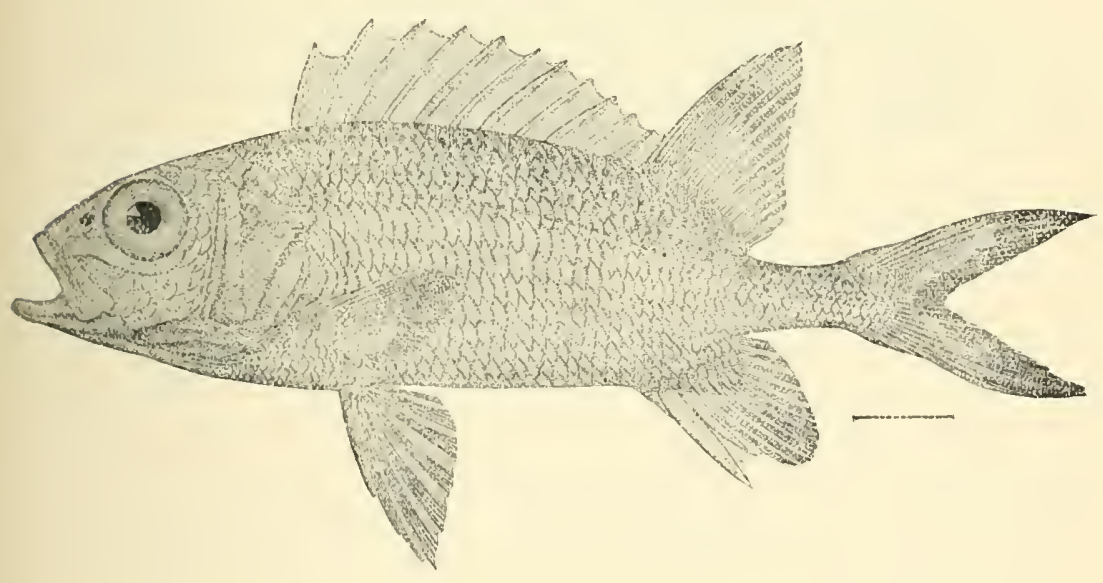

\section{0. "HOLOCENTRUS ASCENSIONIS." $\begin{array}{cc} & \text { Illustration. } \\ 358 & 848\end{array}$}

SQUiRRel-Fish; "Head $32 / 3$; depth $3 \frac{2}{5}$; eye $2 \frac{4}{5}$; snout $4 \mathrm{I} / 4$. Matejuelo; SolDADO;

Welshman. D. XI, 15 ; A. III, 10 ; scales $5-50$ to $54-7$; coeca 2.5 ; vertebræ $11+16$. Mouth small, little oblique, maxiliary scarcely reaching middle of eye; longest dorsal spines more than half length of head; soft dorsal pointed, as high as the body ; third anal spine very strong, as long as 
longest anal rays, $12 / 3$ in depth of body; upper lobe of caudal much the longer. In life, chiefly bright red, with shining longitudinal streaks along the rows of scales; some specimens somewhat darker, and tinged with olive above ; fins light red, the spinous dorsal largely golden olive, its edge scarlet; head quite red above; an oblique white bar descends backward from the eye ; these colors fading in spirits. This species varies much in the depth of body and the height of the fins. Length about 2 feet." Weight to 10 pounds.

Caught : $4 \%$ to $5 \%$ hook, 15 to 21 line. Bait: Conch; Crawfish. Edible, B.

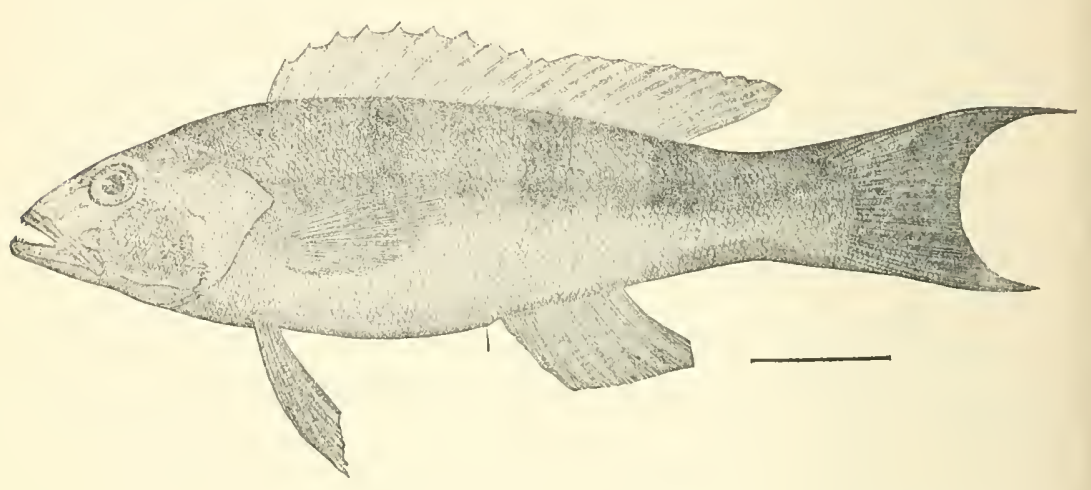

Illustration. Page.

41. "DIPLECTRUM FORMOSUM." $502 \quad 1207$

SquirRel-Fish; Caught same as above. A much smaller fish than SERRANO; last named, 6 to 10 inches long.

SAND-FISH.

Caught in Biscayne Bay. $\quad 1 / 8$ to 1 pound. Edi-

ble, A. 



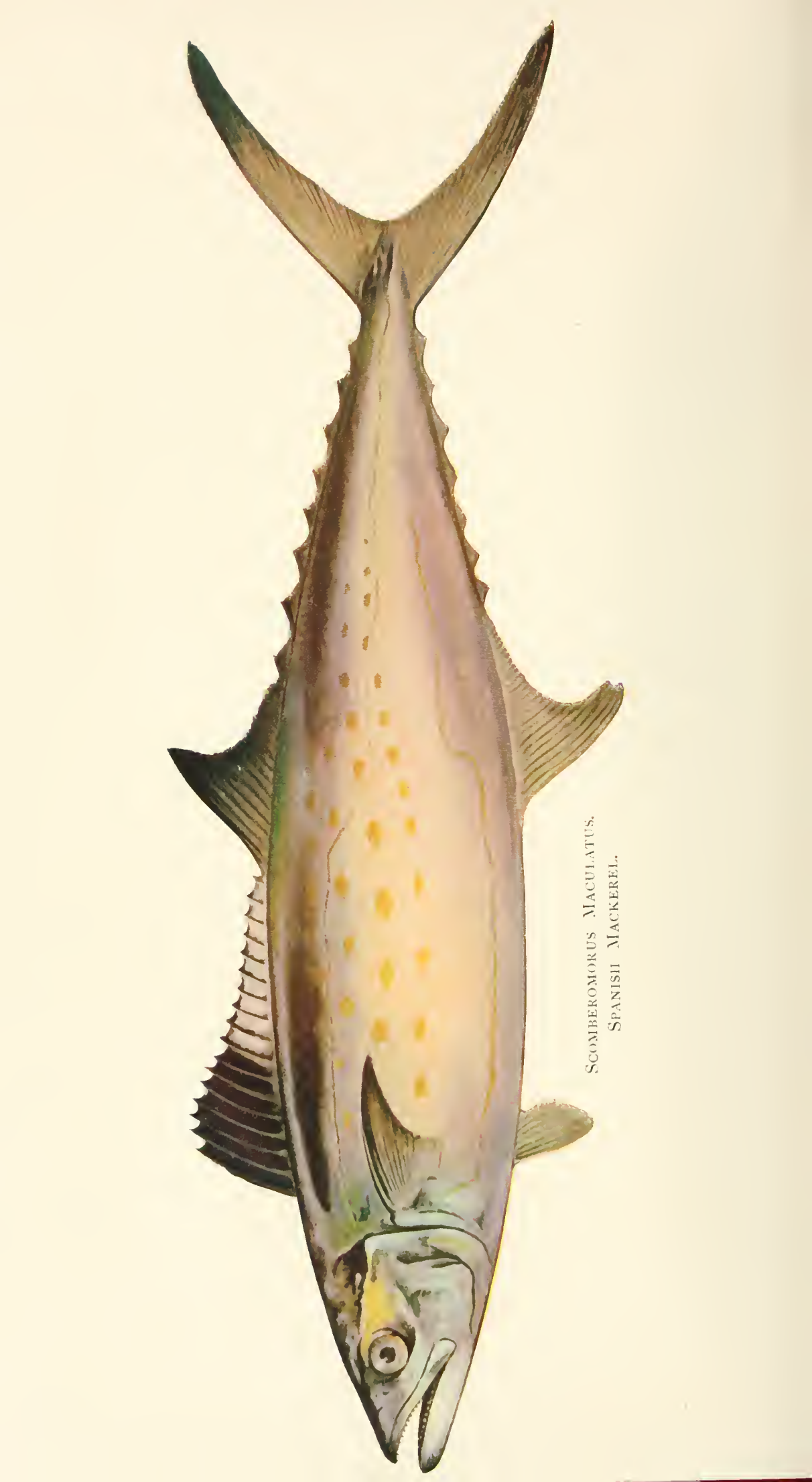




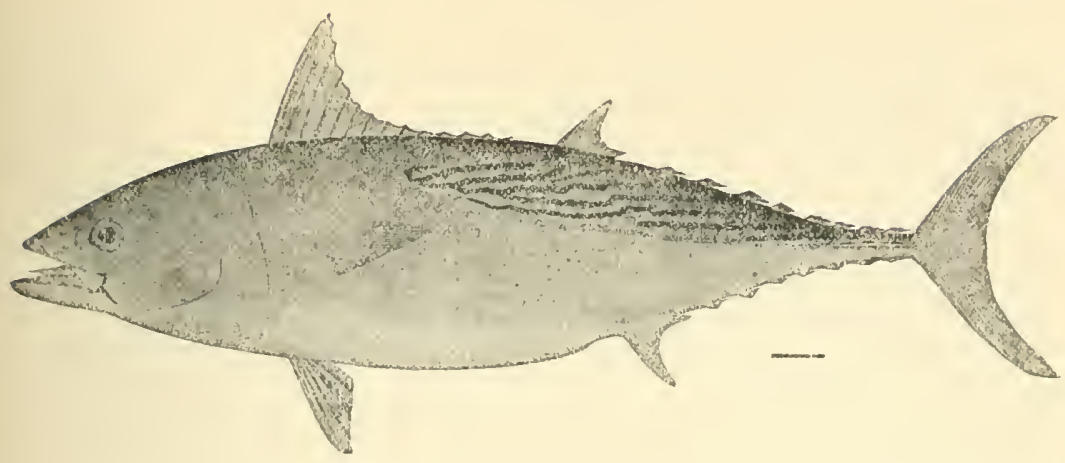

Illustration. Page.

42. "GYMNOSARDA ALLETERATA." $366 \quad 869$

BONITO;

LITTLE TUNNY;

Frigate MACKEREL; OCEanic Bonito;

Blue Bonito.

"Head 33/4; depth 41/4. D. XV-I, 12-VIII; A. 12-VII. Body fusiform, robust ; lateral line nowhere making a very distinct curve; corselet well developed, not covering the entire space between the diagonals connecting the posterior extremity of spinous dorsal and base of pectorals; posterior margin of preopercle about 2 in inferior margin ; pectorals reaching vertical from ninth dorsal spine. Bluish above; sides and belly silvery; no stripes of any kind below lateral line; above lateral line several wavy, oblique streaks; 5 round black spots about as large as pupil below pectoral."

I have seen this fish off the pier at Lake Worth (Palm Beach), but have never caught one.

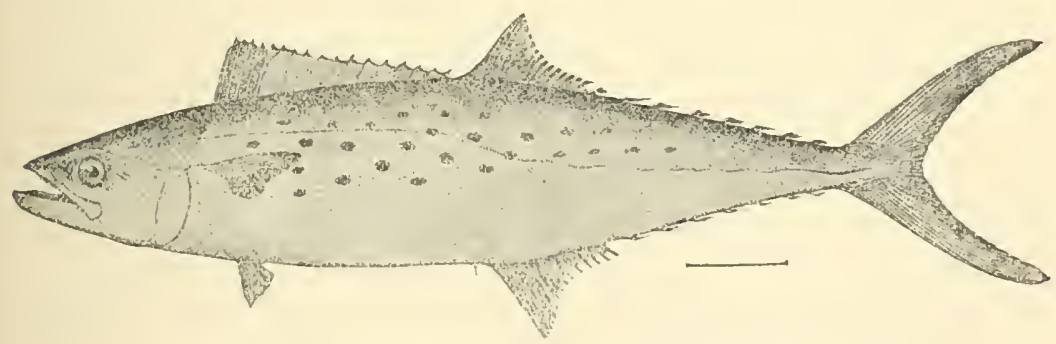

43. “SCOMBEROMORUS MACULATUS." 368 S74

Spanish MaCkerel; “Head $4 \frac{1}{2}$; depth $4 \frac{1}{2} 2$. D. XVII-18-IX; SiERRA.

A. II-17-IX; maxillary $1 \frac{4}{5}$ in head; eye $43 / 4$; pectoral $13 / 4$; ventral $41 / 2$; dorsal and anal lobes subequal 2 ; body 
elongate, its dorsal and ventral outlines equal ; profile straight from snout to dorsal; head small and pointed; mouth large, oblique, jaws equal; maxillary reaching posterior margin of orbit; teeth large, compressed and sharp, their formula being 24-24 to 32-32; gill rakers $2+11$; soft dorsal inserted in advance of anal a distance about equal to diameter of eye; lateral line undulating, with about 175 pores. Color silvery, bluish above; sides with many elliptical spots of dull orange color, two rows of these spots below lateral line and one row above; spinous dorsal white at base, black above; soft dorsal tinged with yellowish, its margins black; anal white; posterior side of pectoral black, anterior side yellowish with black borders; caudal blackish." Weight to 12 pounds ; average, 2 to 3 pounds.

Caught, usually, trolling with Mackerel squid, spoon, red and white rag, or fish bait. The squid preferred. Piano wire leader eighteen inches, hand line; or if you are in a school outside, rod and reel trolling, or floating in rowboat, or from sailboat or launch. Caught outside and inside at Indian River Inlet and Gilbert's Bar, mostly outside; Biscayne Bay, outside, and usually fewer inside, but some seasons good success inside. The fish change location from year to year. See "Indian River Inlet," "Biscayne Bay," and "Miami," in this book. A very gamy fish on rod and reel. Edible A.

44. "SCOMBEROMORUS CAVALLA." Not illustrated. 875

Kingrish ; “Head 5 ; depth 6 ; eye large, 2 in snout. D. XV-I, Cavalla: 15-VIII; A. II, 15-VIII. Mouth large, maxillary reaching Cero ;

SiERra;

Plntado. to below eye; lateral line descending abruptly below the second dorsal; teeth triangular, strongly compressed, about 30 on each jaw; pectoral 5 in body. Gill rakers very short, less than $1 / 3$ diameter of eye, about 8 below the angle. Adult iron gray, nearly or quite immaculate; young with the sides of body marked with darker yellowish spots; spinous dorsal without black blotch anteriorly." Weight up to 100 pounds; average about 15 pounds off Lake Worth and Biscayne Bay; at Key West, about 10 pounds.

Caught by trolling, hand line $\frac{3}{11}$, Kingfish squid, with copper, or piano wire leader, 13-in.; or rod and reel, Tarpon rig, 21 line, 10\% hook. Canght from Lake Worth to Key West, all outside. Bait: Whole or cut Mullet or other small fish, alive or dead. Fine sport 
outside with rowboat, rod and reel when sea is quiet enough to leave the large boat. Edible. Up to 6 or 8 pounds fine flavor, but rather tough. C. All sizes are dried at Key West for the home and Cuban markets.

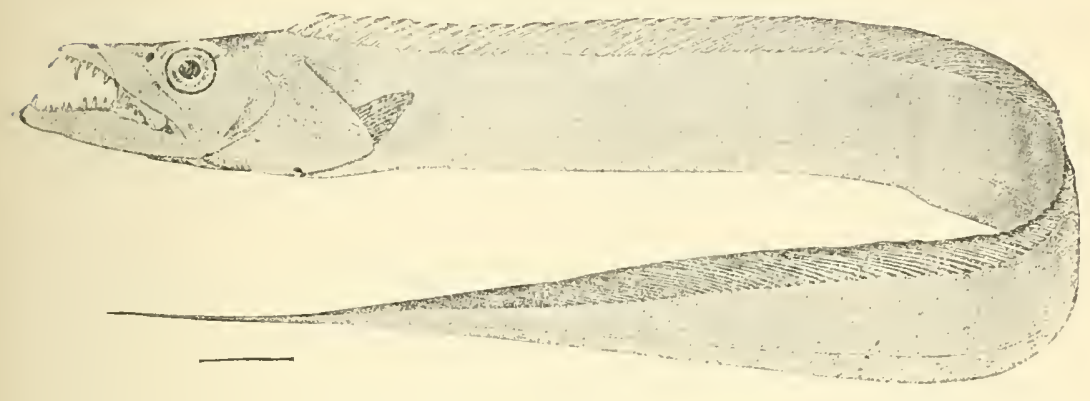

\section{5. “TRICHIURUS LEPTURUS.” $\quad 375 \quad 889$}

Cutlass Fish ;

"Head about $7 \mathrm{I} / 2$; depth about 16 ; eye 2 in SCABBARD Fish; snout. D. 135 ; A. about 100 ; snout long and SILVERFISH ;

SABLE;

SAVOLA. pointed, about as long as pectoral ; maxillary reaching nearly to pupil, concealed by preorbital. Uniform bright silvery ; dorsal dark edged."

This is a rare fish. Several were brought to the Royal Palm Hotel during winter 1901. Caught while trolling for other fish near Fowey Rock Light off Soldier Key. Beautiful silver fish, 4 to 6 feet long, 2 to 3 inches wide, 1 to 2 inches thick, shape of a scabbard. Usually caught while trolling off the Keys for other fish. Non-edible; supposed to be. 


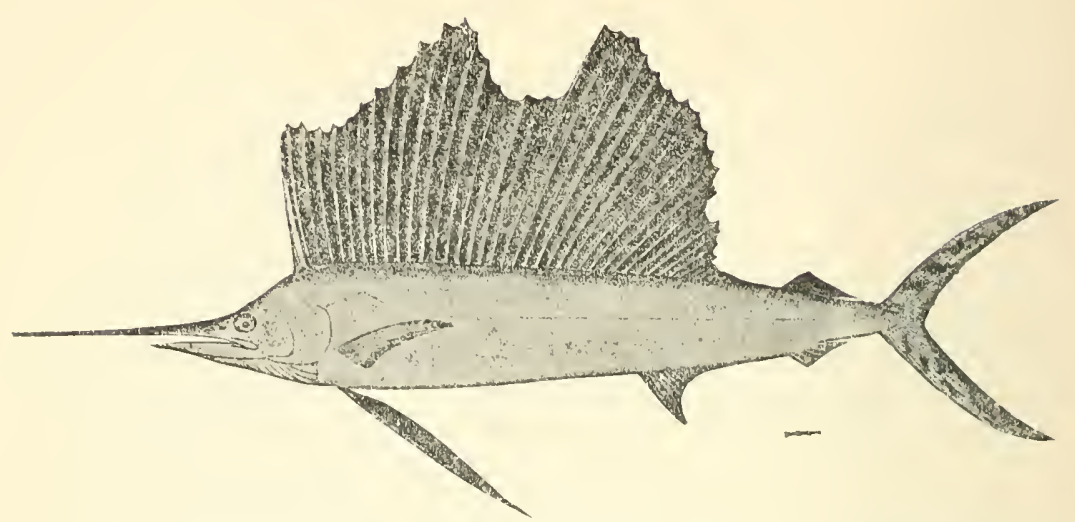

Illustration. Page.

SAILFISH ;

SPIKEFISIF ;

BoOHOo;

Guebucu ;

VOILIER ;

AgUja VOLADORA; Aguja Prieta;

Spearfish ;

BANNERFISH.

$376 \quad 891$

maxiliary reaching to slightly beyond eye, which is $2 \frac{1}{3}$ in postorbital part of head and 10 in snout; sword narrow, regularly tapering, depressed, its upper and lower surfaces both rounded, its edges blunt and rougher than its upper side; for its entire length it is nearly twice as broad as deep; breadth of snout at the middle point between its tip and the eye 25 times in its length from the eye. Bluish black, paler below; dorsal dusky bluish; its membranes with many nearly round black spots, from $1 / 3$ to $1 / 4$ diameter of orbit. Length of specimen described (obtained by Dr. Jordan at Key West) 6 feet." Weight to 150 , or more, pounds.

Caught trolling outside with sailboat or lannch, rod and reel 'Tarpon rig, or Kingfish rig. One of these fishes, and the only one I have seen, was taken, late in March, 1901, by a party consisting of Mr. and Mrs. Moore and Mr. Huling of Kansas City, Mo. 'The party were on a launch in charge of Charley Thompson, and were trolling with hand line and rod and reel near Fowey Rock Light off Soldier 
Key, and part of the time were fishing for these fishes, of which there was a school running at the time. One of the Sail-fishes jumped out of the water, some ten feet or more, almost perpendicularly, and very near where Mrs. Moore was sitting in the boat. She, almost instantly, jumped to the other side of the boat, and in a second or two the fish made another jump coming through between the deck stanchions, just where Mrs. Moore had been sitting, struck the iron door of the engine casing, smashing it in, and fell on the bottom of the boat, where he was killed with wrenches and hammers by Mr. Thompson and the engineer. As his spear was some eighteen inches, or more, long, Mrs. Moore had a very narrow escape. The fish was exhibited at the Hotel Royal Palm the evening of the day he was taken, measured 7 feet 2 inches from tip of spear to tail; weighed 87 pounds, and I think it was given to the hotel to be mounted. Two or three years before the above time, Mr. Armes, with Mr. Cameron as guide, caught one with rod and reel of about same size and weight. I have photograph of that fish. This fish is supposed to be non-edible, and of no value except the sport of catching, and as a curiosity.

After writing the above account of the Sail-fish jumping into the launch, not desiring to use the names of any parties without their consent, I wrote to Mr. George D. Huling of Kansas City, Mo., asking if it was agreeable to himself and the other parties on the launch to use their names, and also asking if I had given a correct account of the adventure. I received reply from which I quote as follows, viz: "I have seen all the people connected with that fish story, and they are agreeable to your publication of their names. Your story is mainly correct, with the exception that six of those fishes were jumping in the air when one landed in the boat.

"The boat was a forty-foot steam launch, owned by Mr. Moore. The parties in the boat were Mr. and Mrs. L. R. Moore, Mr. and Mrs. W. M. Reid, Miss Reid, Miss La Forge, G. D. Huling, Charles Thompson, captain, and one servant." 


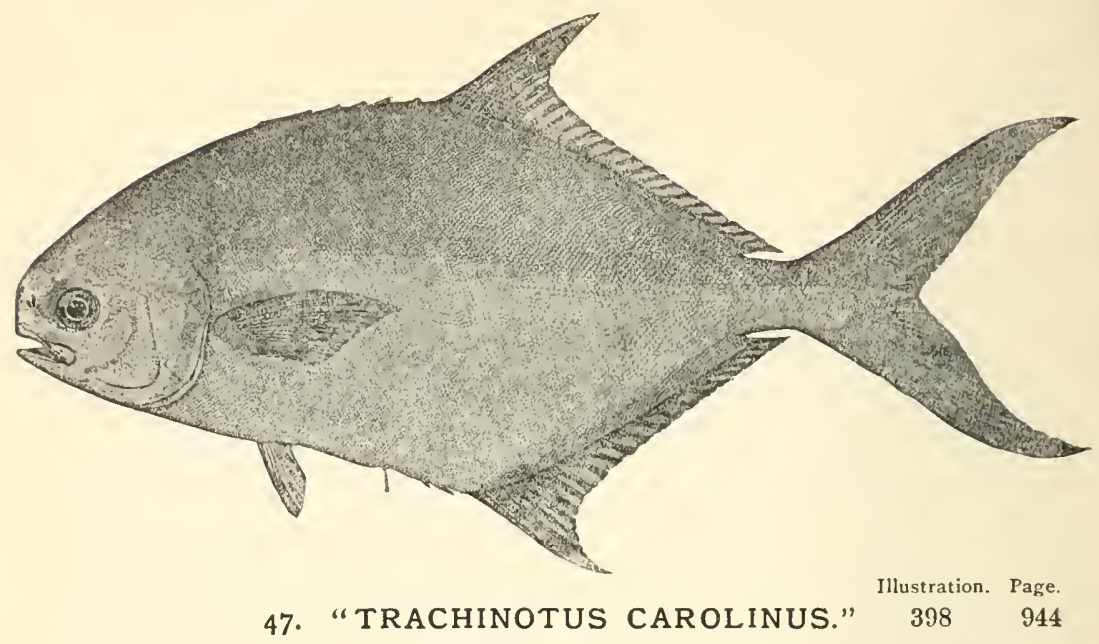

Pompano;

"Head 4 ; depth $2 \frac{1}{3}$ to $2 \frac{2}{5}$. D. VII-I, 25 ; Common Pompano; A. II-I, 23. Body oblong, comparatively robust; COBbLer. greatest thickness 3 in greatest depth; snout from mouth to horizontal from upper edge of eye nearly vertical, somewhat bluntly rounded; profile from upper edge of snout to procumbent spine evenly convex; mouth nearly horizontal, maxillary reaching to vertical from middle of eye, its length $27 / 8$ in head; eye $4 \mathrm{I} / 2$ in head, about as long as snout ; jaws without teeth in adult; ventrals reach $\frac{3}{5}$ distance to vent, about 2 in pectorals, $2 x / 2$ in head; dorsal and anal fins falcate, anterior rays nearly reaching middle of fins when depressed; dorsal lobe $4 \mathrm{x} / 2$ in body; anal $5 \mathrm{x} / 2$ in length of body. Color bluish above, silvery or slightly golden below; pectorals and anal light orange shaded with bluish ; caudal and upper portion of caudal peduncle with bluish reflections. Length 18 inches."

I quote from U. S. Commission Report 1896, page 233: "Pompano are taken occasionally, weighing 20 to 27 pounds, but none was seen during the investigation. The largest reported weighed 27 pounds. They are probably the same species of Trachinotus known about Key West as the 'Permit,' recently decided to be a distinct species and named 'Trachinotus goodei' by Jordan \& Evermann. 'They are, of course, not the 'Permit' of Indian River, which is a small fish. 'The true Pompano of Indian River does not exceed 7 or 8 pounds in weight." U. S. Commission, 1896, has plate No. 38 of the "Common Pompano." 


$$
\frac{y}{y}
$$



The market fishermen of Indian River and Lake Worth do think the "true" or Common Pompano have been caught weighing up to 27 pounds. I have often been told of specimens weighing 20 to 25 pounds. I am quite sure the one caught by Capt. Gardner at Lake Worth April 15, 1898, was a true Pompano, as he was compared with several undoubted Pompanos, by Mr. Cory the taxidermist (who had him mounted), by Mr. Allen of The Inn (now The Breakers), and ourselves. We all thought the agreement was perfect in every respect. In my estimate of weight of the Pompano, I will, however, be guided by the scientific people.

Weight 8 pounds; average about 2 pounds. Caught with rod and reel, 6 or 9 line, No. $2 \%$ or $3 \%$ hook, double gut snood 12 to 18 inches, small egg sinker, fish on the bottom. Bait: Sand fleas, or other Crustacea; they will not touch cut fish. Jupiter Inlet (when open), Lake Worth Inlet, and the beach of Lake Worth the best grounds I know of. Occasionally caught at Gilbert's Bar inside, and at Indian River Inlet. In May and June they run to the Carolina coast. In June of 1901, Capt. Gardner caught 25 in several throws with cast net, at Ponce Park. Edible, A 1.

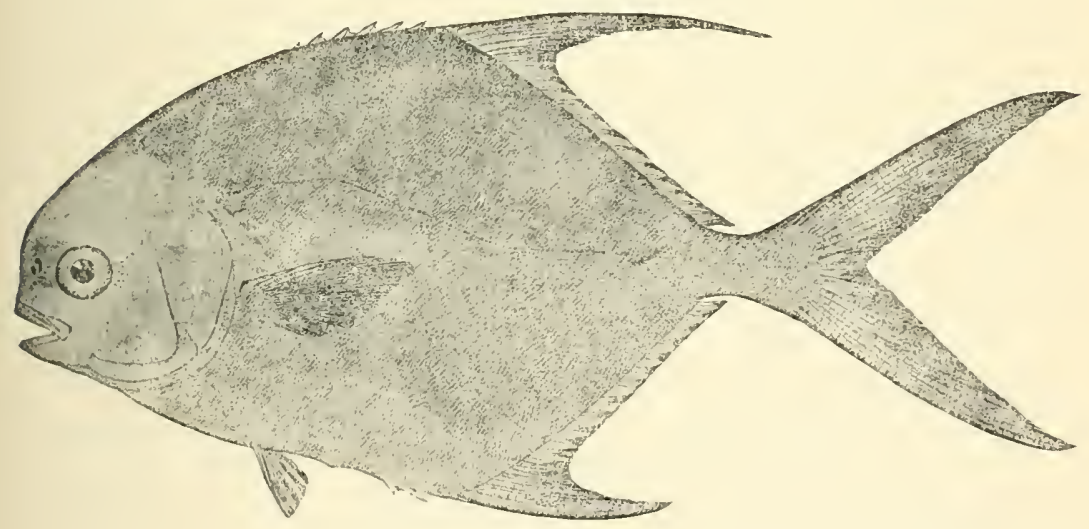

48. "TRACHINOTUS FALCATUS." " 396

POMPANO;

ROUNd POMPANO;

PAlometa;

Indian River Permit. where it descends almost vertically; the vertical portion is about $1 \frac{1}{3}$

"Head $33 / 4$; depth $1 \frac{3}{5}$. D. VI-I, 19 ; A. II-I, 18. Body broadly ovate, moderately compressed, profile very evenly convex from procumbent spine to level of upper edge of eye, 
times the eye ; length of snout nearly equal to eye ; mouth nearly horizontal; maxillary reaching to vertical from middle of eye, its length $22 / 3$ in head ; jaws without teeth in adult ; dorsal spines short and thick, not connected by membrane in adult ; ventrals short, their tips scarcely reaching halfway to anterior anal spine, 3 in head; caudal widely forked; lobes about $22 / 3$ in length of body; dorsal and anal fins falcate; anterior rays reaching almost to posterior end of fins; in adults, dorsal lobe $2 \frac{2}{3}$, anal lobe $4 \frac{1}{2}$, in length of body. Color bluish above, silvery below ; lobes of dorsal black in young; in adults the fins are all bluish with lighter tips. The young differ from the adult as above described in the following respects: The profile is scarcely convex; snout shorter and less vertical ; spines much longer and connected by membranes; lobes of vertical fins shorter; dorsal lobe with black; fins all much darker; jaws with bands of villiform teeth ; eye larger."

I presume the most of my readers who have visited Florida have heard wonderful stories of Pompanos jumping into boats. I will tell some true ones, and some others afterwards which have been told to me.

On my first visit to Lake Worth, before the Royal Poinciana and the railroad were built, while I was on the little steamer "Lake Worth" en route from Dimmick's Hotel to Juno, a Pompano jumped into the engine room of the boat.

On my cruise with Capt. Ward in 1885 , while at Jupiter trolling inside for Bluefish, etc., the Pompanos were jumping all over the little bay, and two or three went over the small boat we were towing behind the sailboat. I remarked to the captain: "I believe some of those fellows will land in our boat"; and he replied, "Sure, they often do, three jumped into boats yesterday afternoon." In a short time, one did jump into our boat and we cooked him for dinner.

At that time there was no market fishing at all on Indian River, and it is no exaggeration to say that at Jupiter I frequently saw fifty, or possibly a hundred, out of the water at one time.

During the spring of 1900 , while lying at same place, our mate was in a small boat cleaning it out, when a Pompano jumped, hitting him on the back and falling into the boat. The next morning he was washing the deck of the yacht, when a Pompano jumped onto the deck, the mate catching him.

One of the other stories was told by Capt. Bravo, then of the 
East Coast Railway steamer "Santa Lucia," now of the steamer "City of Key West," and probably is a "chestnut," but I have never seen it in print, and presume it is not copyrighted.

While on the river during winter of 1895 , I heard several times that a great many Pompanos had jumped on to the "Santa Lucia " just at the entrance to Jupiter Narrows opposite Gilbert's Bar. I have known the place very well, as the steamers almost every trip would ground there, from a few minutes to hours, and have a hard time floundering around trying to get off. And I had seen many Pompano jumping in the inside channel almost every time I was there.

I, naturally, after hearing the stories several times, began to be suspicious that they might possibly be true, although the number had grown from twenty or thirty on some trips, up to seventy-nine. I concluded to ask Capt. Bravo about it. Later, I was at the Royal Poinciana for a couple of months. At that time the bridge across Lake Worth had not been built, so the "Santa Lucia" had been brought down and was used as a ferry for passengers and freight from West Palm Beach to the Royal Poinciana. As this employed but a part of the day, the boat made excursion trips during the forenoon and afternoon to Pitts Island, north, and Lantana, south.

A party of a dozen or so of St. Louis people, including my daughter and myself, took the Lantana trip one afternoon. As we were all out in front on the cabin deck, and Capt. Bravo among us, I thought it a good time to ask him as to the truth of the Jupiter Narrows Pompano stories, which I did, in the presence of our party and other passengers. The captain immediately replied that the stories were true, and said: "You will believe anything Mr. Flagler will say, won't you?" We all replied, "Yes, of course we will." Then he went on as follows: "Uncle Henry was on the boat a while ago, and as we approached Gilbert's Bar from the north asked if these stories about Pompano were true, and I told him I would convince him. Night was coming on, so I had our large ice box, with some ice in it, placed right in the gangway aft, right near the opening, and just before we got to the Narrows put a lantern on each end of the box. We got into the Narrows just about dark, and the Pompanos began to jump into the box onto the ice, and never stopped until they filled it heaping full. We did not get aground that night, as we usually did. Now, if you don't believe me, ask Uncle Henry." I will leave the story with the reader, simply saying that, as far as I 
know, none of the party ever asked Uncle Henry to corroborate the story. I had slight doubts, however, about the not-grounding part of the story, as I had been over the route many times.

After writing Capt. Bravo's Pompano story I wrote him asking permission to publish the same, and received reply from which I will quote. The captain, in his modest way, is rather inclined to give Mr. Flagler the full credit for telling that Pompano story, but says he will vouch for it, and then goes on as follows, viz: "When I first came to Indian River the people there told me fish were so plenty that they need do no fishing at all ; all they had to do was to put a lantern in the boat and anchor it out; go to it in the morning and it would have all the fish in it they wanted.

"I worked for Mr. Flagler as captain on one of his steamers on Indian River for two years. During that time I fed the officers and crew of said steamer, and got so much per day for doing so. Now, if I got my fish for nothing it would be quite a saving to me, because everybody wanted Pompano, and Pompano was a high-priced fish. So when I got below Eden I called all the crew on and ran the steamer across the shoal, when the Pampanos, being frightened, started to jump onto the steamer. I have caught as many as eighty going across one shoal.

"Now, I believe any fish story anybody tells me after living on Indian River five years; but one day I had a passenger from the Columbia River, Oregon. I was showing him the great quantities of fish we had in Indian River, and told him some pretty strong stories that had been told to me. It did not seem to surprise him at all, like it did most tenderfeet, so he says to me, 'on the Columbia River, where I come from, we have salmon. I have looked at a school coming down the river, acres of them, and that is the greatest sight in the world. Sometimes, he said, one of them would jump out and when he fell back there would be no place for him but to fall on top of the school and die there.' I believe his story, though it is a hard one. I could continue telling some incidents in the fish line indefinitely, but I will close."

The captain said nothing in his letter about his statement, in his first Pompano story, that the "Santa Lucia" did not get aground that night. I may swallow his fish stories, but when he tells me he navigated the "Santa Lucia" into Jupiter Narrows without getting aground, I have, at least, faint doubts. I will say, however, that a fish 
book, or any other book, treating of the East Coast of Florida, which does not reckon with Capt. S. A. Bravo is not of much account.

Another story is that a Northern gentleman, who spent his winters at Eden, or Jensen, I forget which, had heard these Pompano stories, and thought he would try an experiment; which he did by building a small fire right near the water, at night, then taking a fry pan, with a piece of pork in it, and holding it over the fire. In a short time a couple of Pompanos jumped into the pan, where he fried them. Now, I do not believe this last story; but I do believe that in Yellowstone Lake, in Yellowstone Park, Trout are caught and without taking them off the hook are swung around into a boiling spring, where they are boiled to a turn. I have not seen that done, but have been there and have seen places on the lake where it can be done, and am sure it is done in a small stream near the Mammoth Spring Hotel.

49. "TRACHINOTUS FALCATUS."

(Repetition.)

Round Pompano;

(J. \& E., U. S. Commission, 1895,

Palometa;
Permit of Indian River; page 348.) (Evermann \& Bean, report Permit.

to U. S. Commission, 1896, pages 230, 235, 243), and Plate 39.

This fish is usually called " Indian River, " or " Small " Permit.

"The 'Permit' of Indian River is Trachinotus falcatus, a different species."

Report of H. M. Smith, B. W. Evermann, John N. Cobb, and W. C. Kendall, printed in U. S. Commission, 1896, page 285. Weight to 10 pounds. Edible, C. Occasionally and accidentally caught while fishing for Pompano or other fish.

1llustration. Page.

50. "TRACHINOTUS GOODEI." Not illustrated. $9 \pm 3$

PERMIT;

Palometa;

Great Pompano.
“Head 3 ; depth $2 \frac{3}{5}$. D. VI-I, 19 ; A. II-I, 17. Body oblong, elliptical, moderately compressed; profile nearly straight from procumbent spine to nostril, where it descends nearly vertically, forming an angle; vertical portion from angle to snout nearly equaling eye ; snout obliquely truncated; maxillary reaching slightly behind vertical from middle of eye, its length $2 \frac{3}{5}$ in head; jaws with bands of villiform teeth (these disappearing with age); ventrals reaching $\frac{4}{5}$ distance to 
vent; their length 2 in head; tips of pectorals reaching slightly past tips of ventrals; dorsal and anal fins falcate, their anterior soft rays less elevated than in Trachinotus falcatus, but extending beyond middle of fins when depressed, their length in the young 4 in length of body; caudal forked, lobes about 3 in body; lateral line nearly straight, slightly curved upward above the pectorals. Color bluish silvery above, silvery below ; dorsal, caudal and anal lobes black; no cross bars. Length 3 feet."

"Permit or Pompano. This large Pompano, which attains the weight of 25 pounds, is not uncommon along the Keys." (Report of Hugh M. Smith, U. S. Commission, 1895, page 174.)

"Key West Permit, or Permit of Key West, Trachinotus goodei." (Evermann \& Bean, report to U. S. Commission, 1896, pages 230, 243.)

"Permit, Trachinotus goodei, J. \& E. This species is not very common about Key West. It reaches a weight of 40 pounds, the average being about 8 pounds. It is taken in winter by hook and line and seine."

This fish is often called "Key West Permit," or "Large Permit." Weight to 40 pounds; average, 25 pounds. All I have seen were caught near Fowey Rock Light, trolling from naphtha launch. Quite a number of them were brought to Hotel Royal Palm, 1901. Edible. Barely edible, C.

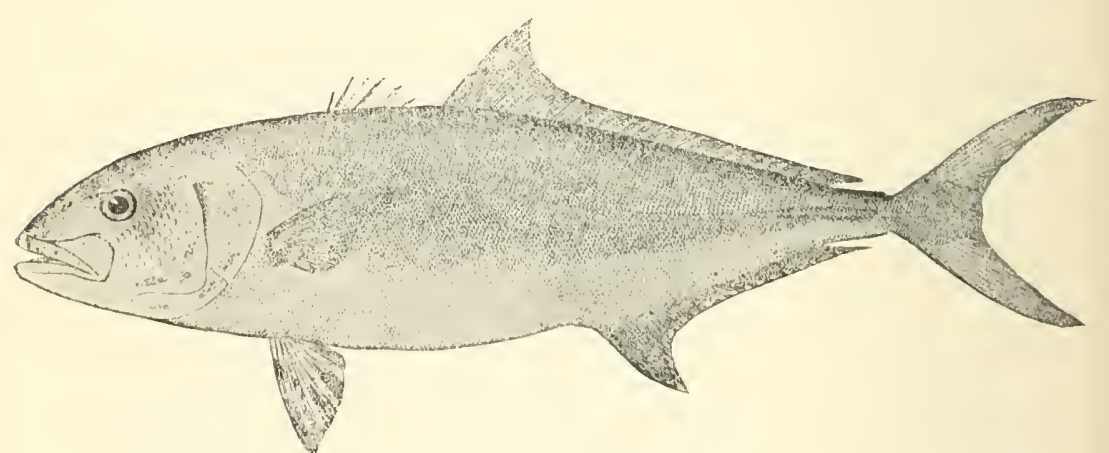

51. "SERIOLA LALANDI."

Hlustration. Page. $352 \quad 903$

AMBER JACK ;

"Head $33 / 4$ to $4 \frac{1}{4}$; depth $31 / 2$ to $33 / 4$. D. I, Great Amber-fisil; 34 ; A. I, 27 ; dorsal lobes $2 \frac{1}{3}$ in head; maxCoronamo. illary $2 \frac{1}{5}$. Body slender; dorsal fin dusky, with a light-yellow submarginal band; pectorals dusky yellowish; 
ventrals yellow and blackish; anal blackish, with pale edge. Young and old specimens have essentially the same general form, being in all stages more slender than Seriola dumerili. A food-fish of some importance, reaching a weight of 100 pounds and a length of 5 or 6 feet." Weight to 100 pounds ; average 25 pounds.

Caught still fishing, rowboat anchored, without sinker, Tarpon rod and reel, 10\% or Tarpon hook, No. 21 line, with wire snood $11 / 2$ feet long, Live Spot, Grunt, Mullet or other $1 / 4$ to $1 / 2$ pound fish. Keep the bait on or near the surface. When the fish bites, let him run ten or fifteen feet, then strike, and play the fish until he surrenders. Or trolling from rowboat, sailboat or launch, with rod and reel, same rig as above, or with hand line $\frac{3}{16}$ cotton line and squid, a live, or long cut dead fish. These fish are also grained by some of the guides of Biscayne Bay, and "Conchs" of the Keys.

On quiet days outside Biscayne Bay, around Fowey Rock Light, leave the large boat in rowboat, and fish with rod and reel as above. A very game fish. Barely edible, C.

During March, 1897, while I was at the Royal Poinciana, I strolled down to the pier just after an early breakfast. As I passed through the gate, the gate-keeper said to me, "There is a fine school of Mullets about 200 feet from the shore on the south side of the pier." I went out to look at them, and there they were about 75 feet from the pier, a round school of at least 100 feet diameter and quite solid, with Barracoudas and Amber Jacks surrounding and making dashes among them.

I went over for Capt. Gardner, who was on the "Hillsboro" in the lake. We picked up rods and went back to the pier. The instant John saw the school he said, "Those are not Mullet, they are Bluefish "; and, sure enough, they were, and on their migration north, the pier evidently having stopped them. John said, "Now is your chance, put on a piece of Mullet, cast into the school, a Bluefish is sure to take it, haul him out of the school, leave him there, and a Barracouda or Jack is sure to take him." I followed instructions, and it turned out just as John said, as I hooked an Amber Jack of fifty pounds or so, but at that stage the business had only commenced, as the Amber Jack had something to say (or do) about it. He charged around, taking and giving line for a few minutes, and then made a straight bolt for the spiles under us, ran around one of them, the bar- 
nacles on the spile cut my line, and there I was minus fifty feet, or so, of line. I repeated the above process four or five times with the same precise result in each case, and had less than 100 feet of line left out of 600. John, of course, in each case, would criticise my method of handling the fishes, saying in some cases, "You ought to have played him longer" ; then, in the next case, he would say, "You did not bring that fish in quick enough ; you gave him too much line," etc., etc. The onlooker always indulges in that kind of talk. I told John to just try it himself, which he did with another rod and 600 feet of line, and he came out of the fight just as I had, with about 100 feet of line. Of course, I got in my critical work on him. Revenge is sweet.

A day or two afterwards we had the same kind of a school of Bluefish at the Inlet, a little inside; followed the same tactics, and I hooked the "largest" Amber Jack I ever saw, played him half an hour, the hook wore a hole in his jaw and dropped out ten feet from the skiff. I said nothing, of course.

52. "ELAGATIS BIPINNULATUS." Not illustrated. 906

RUNNERS ;

YELLOW-TAIL RUNNER ;

Coginera.

53. "TRACHUROPS CRUMENOPHTHALMUS."

Goggle-eye Runner;

GOGgLeR ;

Big-eyed Scad;

GOGGLE-EYE JACK ;

CiICARRo ;

I IORSE-EYE JACK. 


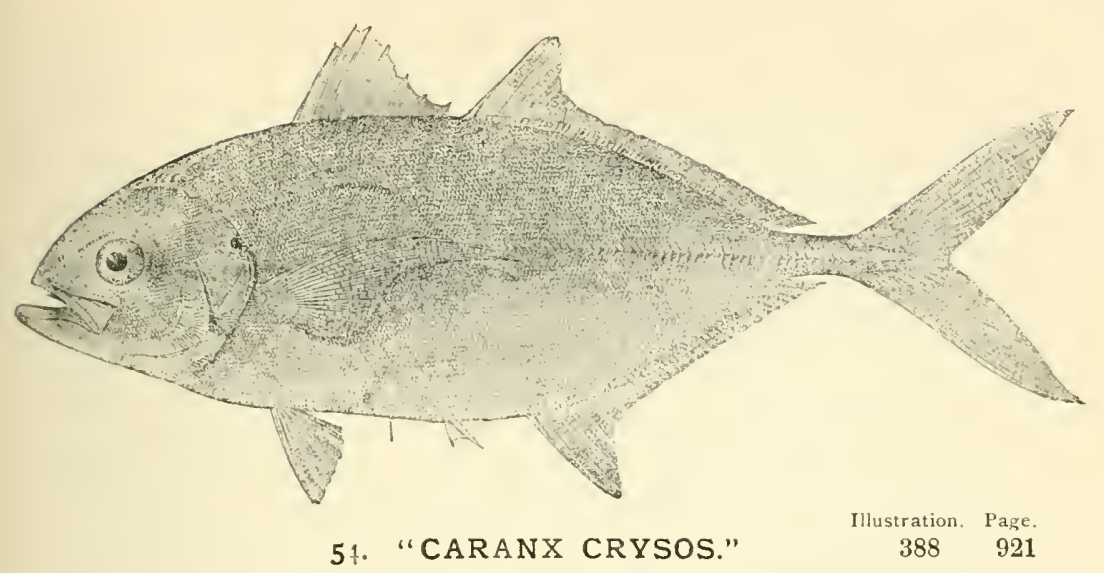

HARD TALl RUNNER;

"Head 33/4; depth $31 / 4$. D. VIII-I, 24; A. RUNNER;

JUREL;

Yellow Mackerel;

Crevalle;

RUNNING JACK;

DOLLAR-FISH ;

TIDE RUNNER;

Blue Runner.

II-I, 19; lateral line 50 (scutes). Body oblong, moderately elevated, the dorsal and ventral outlines about equally arched; profile forming a uniform curve; snout rather sharp; mouth slightly oblique, a little below axis of body; maxillary reaching about to middle of orbit; teeth comparatively large, a single series in lower jaw; upper jaw with an inner series of smaller teeth; no canines; teeth on vomer, palatines, and tongue; eye rather small, shorter than snout, $3 \frac{1}{2}$ in head; gill rakers long and numerous; pectoral as long as head, barely reaching anal; rarely longer than head in certain specimens from Key West, possibly referable to $C$. caballus; scales moderate; cheeks and breast scaly; lateral line with a weak arch anteriorly, which is about half length of straight portion; lateral scutes numerous, developed on whole straight part of lateral line. Greenish olive, golden yellow or silvery below ; a black blotch on opercle; fins all pale. Length 1 foot or more."

The above Runners are all classed under the "family Pampano," by Jordan \& Evermann, among the Pompanos, Crevalles, Permits and Jacks. They all resemble the Cavalla, Bluefish, and Pompanos. Weight to 5 pounds; average, $1 \mathrm{I} / 2$ pounds.

Caught trolling outside and inside ; Mackerel squid, spoon, red and white rag, or cut bait; and still fishing, bottom, or floating; usual tackle for the average weight fishes among the Keys. Usually caught while fishing for other fishes. Edible, C. Somewhat better than Cavalla. 
While on the subject of Runners I will make a few feeble remarks. It seems to me the Runners are hybrids from the Crevalle and Bluefish species or familics, as they certainly resemble both of those fishes.

At first glance when I have caught one he always looks like a Bluefish, but after examination resembles the Crevalle, and for this reason is called a "Jack" by the people where he is caught. I believe that every time I have visited the Keys I have caught one or more varieties which were new to me.

Jordan \& Evermann, in Bulletin 47, 1900, give eighteen species; Jordan \& Gilbert, Bulletin 16, 1883, give none under the name "Runners," but put in seven under their heading of "Crevalles." As the family seems to be increasing in variety they must propagate their own species and also must intermix with other fishes, notably with the Bluefish, Crevalle, and Pompano, from whom they probably sprang.

The Catfishes, Sharks, Carps, Suckers, Groupers, Parrot fishes, etc., etc., are largely increased.

I know there were formerly people who denied the Darwinian theory of the origin, differentation, and evolution of species, using as their argument the statement that hybrids do not propagate their own species, and stood pat on our humble and hard-working friend, the mule, as the only instance they could cite in support of their contention. They were undoubtedly correct in that one citation; but if any people of that way of thinking are left in the country, I would advise them to visit the Keys of Florida and study the fishes a little, and they will be convinced the fishes violate their rules and explode their theory. Another thought occurs to me, which is that the ichthyologists are to have a hard time in keeping up with the fishes. Jordan \& Gilbert (1883) classified 1,340 species, and Jordan \& Evermann (1900) classified 3,263 species, thus showing an increase of 1,923 species during seventeen years.

This large increase of about 150 per cent. is partly due, of course, to a closer investigation, and addition of some territory not investigated by J. \& G., but a larger proportion is probably due to finer lines of distinction having been drawn by J. \& E. Where the first party has described and classified, say, ten, more or less, in a family, it seems as though the latter has, with the same fishes, doubled or trebled the number, by finer distinctions.

Still, after all the above is admitted and accepted as true, there has undoubtedly been a large actual increase in species. 
If the scientific people continue to prepare new classifications every seventeen years, continuing their exceedingly fine lines of distinction, and do not do something to check the hybridizing of the fishes, the Greek, Latin, and all the modern European languages will not contain names enough to furnish many succeeding classifications.

IV. C. Harris, in his finely illustrated (in colors) "Fishes of North America," says : "Nearly 6,000 varietal forms of fishes are either native or transient visitors to American waters."

The above shows the formidable condition of affairs the future ichthyologists have to face.

On the above subject I will quote from Encyclopædia Britannica, article Ichthyology, Vol. XII., page 664, Scribner edition, 1881 :

"Hybridism is another source of changes and variations within the limits of a species, and is by no means so rare as has been hitherto believed ; it is apparently of exceptional occurrence, merely because the life of fishes is more withdrawn from our direct observation than that of terrestrial animals. It has been observed among species of serraranus, pleuronestæ, cyprinidæ, clupedæ, and especially salmonidæ. As with other animals, the more certain kinds of fishes are brought under domestication, the more readily do they interbreed with other allied species. It is characteristic of hybrids that their characters are very variable, the degree of affinity to the one or the other parent being inconstant; and as these hybrids are known readily to breed with either of the parent race, the variations of form, structure, and color are infinite." The contributor of above article is Albert C. L. G. Gunther, M. D., Ph. D., F. R. S., keeper of the Zoological Department British Museum. 


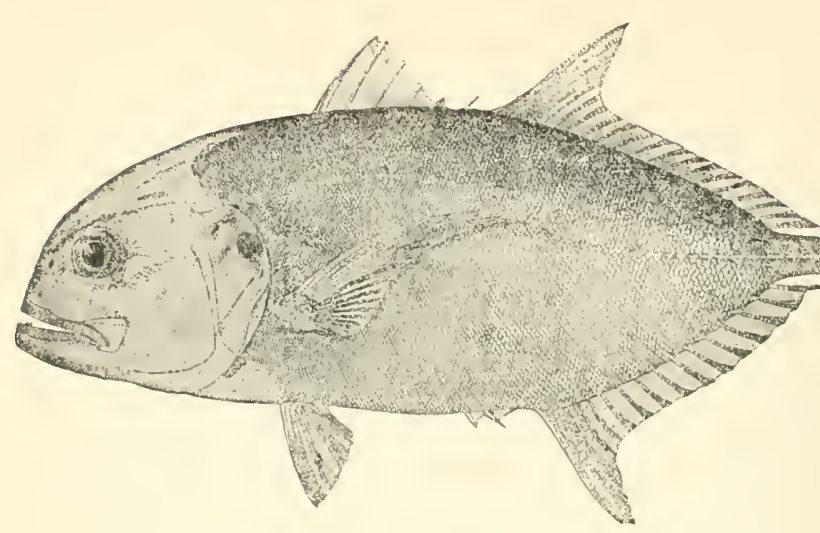

55. "CARANX HIPPOS."

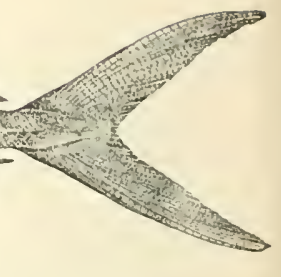

Illustration. Page.

387

920
Cavalle ;

Crevalle;

TORO;

Horse Crevalle;

JACK ;

JIGUAGUA ;

Cavally.

"Head $31 / 2$; depth $21 / 2$; lateral line (scutes) about 30 . D. VIII-I, 20 ; A. II-I, 17. Body oblong, the anterior profile very strongly arched. Head large and deep. Mouth large, low; lower jaw prominent; maxillary extending to nearly opposite posterior border of eye, $2 \frac{1}{3}$ in head. Teeth in upper jaw in a broad villiform band; an outer series of large, wide-set conical teeth; teeth of lower jaw in one row, a distinct canine on each side of symphysis; villiform teeth on vomer, palatines, pterygoids, and tongue. Lateral line with a wide arch, its length $1 \frac{1}{3}$ in straight part, the angle under fifth dorsal ray; plates not covering all of straight part. Dorsal spines short, rather stout; gill rakers stout, rather long, 15 below angle. Occipital keel sharp. Eye not very large. Pectoral falcate, $\frac{1}{5}$ longer than head. Breast naked with only a small triangular patch of scales in front of ventrals. Caudal lobes equal, nearly as long as head. Olivaceous above; sides and below golden; a large distinct black blotch on opercle, bordered behind with pale; a large faint black spot on lower rays of pectorals, the latter sometimes wanting in young; axil of pectoral with a black blotch; edge of soft dorsal black; upper edge of caudal peduncle dusky." Weight to 20 pounds; average, 5 pounds.

Caught: Rod and reel, 18 or 21 line, $6 \%$ hook, still fishing bottom, or floating. Bait: Live or cut fish ; Crab, Crawfish, Conch, or in fact most any bait. Trolling with any artificial, live or cut bait. 
$\mathrm{He}$ is a game fish and gives fine sport. Edible, C. Is barely an edible fish, but some folks like him.

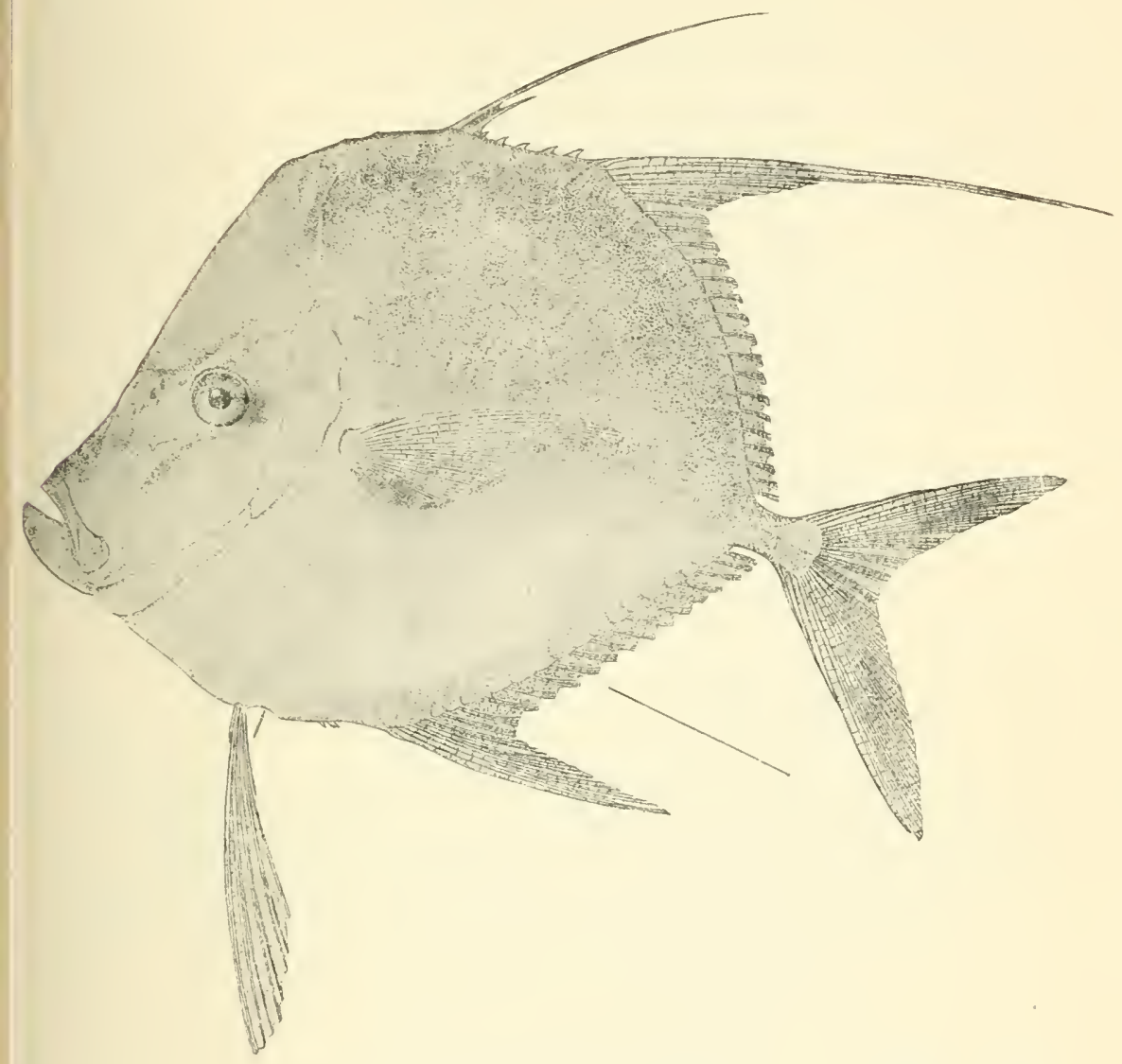

56. "SELENE VOMER."

Illustration. Page. $393 \quad 936$

MoOnfish ;

Blunt-nosen Shiner; JoROBADO ; HORSEFISH ;

Look Down ;

Old MAN OF THE SEA; Silver MOONFISH;

HORSEHEAD.
"Head 3; long dorsal rays 2; pectoral $23 / 4$; long anal rays $22 / 3$; depth $1 \frac{1}{2}$, the young much deeper. D.VII-I, 23 ; A. II-I, 18. Anterior profile from tip of snout to occiput almost perfectly straight in the adult. Diameter of eye, length of opercle, and distance from eye to profile about equal; eye 2 in maxillary, $2 \mathrm{x} / 2$ in preorbital; mandibles very deep, the dentary 
bones thin, approximate; one or two of the dorsal spines greatly elongate and filamentous in the young, short in the adult; ventrals variable in length, usually about as long as the eye in the adult, variously elongate in partly grown specimens. Color uniform silvery, in the adult. Our observations of this species tend to confirm the correctness of Dr. Lutken's views (Spolia Atlantica, 139) as to the transformations incident to its growth." Weight, 30 to 40 pounds.

I have known them caught only in trolling with launch near Fowey Rock Light off Soldier Key. Heavy tackle. Barely edible, C. I rank him with the Cavalla.

57. “CARANX BARTHOLOMÆI." No illustration. 919

Y'ELLOW JACK; This is one of the Jacks of the Pompano family, Cibi Amarillo. with the Amber Jacks, etc. Weight to 50 pounds. Caught outside trolling, same method and tackle as Kingfish and Amber Jack. Edible, C. Barely edible, small sizes.

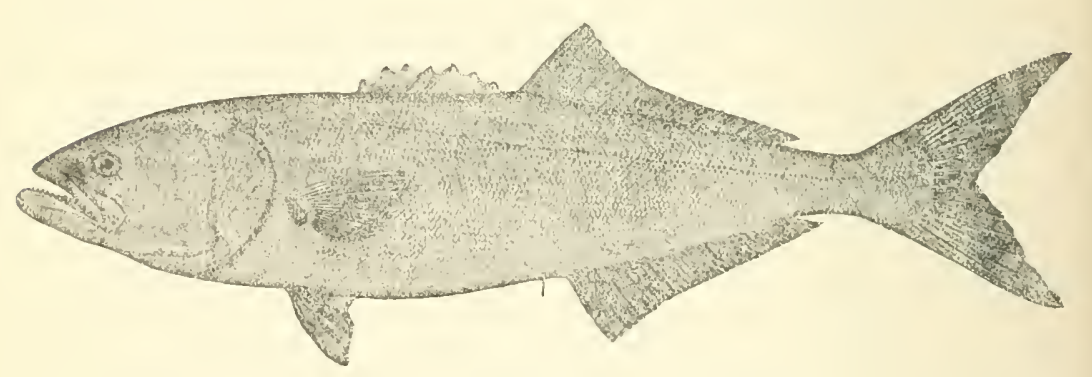

58. "POMATOMUS SALTATRIX." $400 \quad 946$

BLUEFISH ;

"Head $31 / 3$; depth 4. D. VIII-I, 25 ; A. II-I, Snap Mackerel; 26 ; scales 95 . Body robust, moderately comSkIP JACK; pressed; belly compressed to a bluntish edge. FAT-BACK. Head deep; top of head and a ridge on each side above the cheeks naked. Cheeks much longer than opercles. Pectorals placed rather low, their length a little more than half that of head. Coloration bluish or greenish above, silvery below; a blackish blotch at base of pectoral. Length 3 feet." Weight to $161 / 2$ pounds. 


$$
1
$$



I saw one of that weight caught at Jupiter Inlet, and I caught one weighing $12 \mathrm{r} / 2$ pounds. Average about 3 pounds.

Caught: Still fishing on bottom, and with floating bait. Rod and reel, 18 line, $6 \%$ hook, with piano wire 12 -inch leader, float, if desired. Bait: Menhaden, Anchovy, Sardine or other live Minnows, or cut bait. Trolling outside and inside, rod and reel or hand line, medium size block tin squid, bone squid, red and white rag on 10\% hook, or cutbait; always piano wire leader. Edible, A, if cooked few hours after caught.

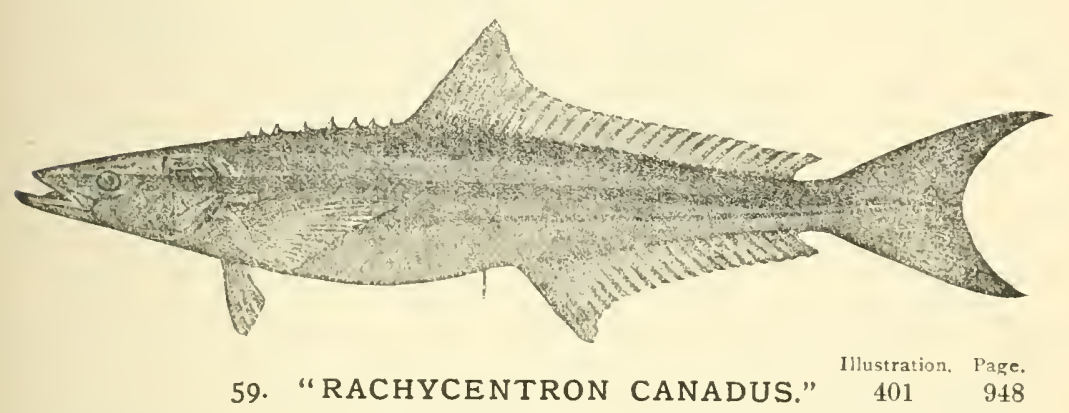

SERGEANT Fish ;

Crab Eater;

BONITO ;

SNOOK ;

CoBIA ;

BROCHET DE MER;

Rovalia ;

Robalo.
"Head $4 \mathrm{~T} / 4$; depth $52 / 3$.

D. VIII-I, $26 ; \mathrm{A}$. II, 25. Head much depressed; mouth moderate, the short maxillary reaching front of orbit. Pectorals broad and falcate; caudal deeply emarginate, the upper lobe slightly the longer. Lateral line wavy and irregular, descending posteriorly. Olive brown, sides with a distinct broad band of darker, and a less distinct band above and below it; silvery below. Length 5 feet." Weight to 20 pounds.

Caught: Still fishing, any bait, 15, 18 line, 5\% hook ; or trolling, any bait, spoon, phantom. Barely edible, C. 


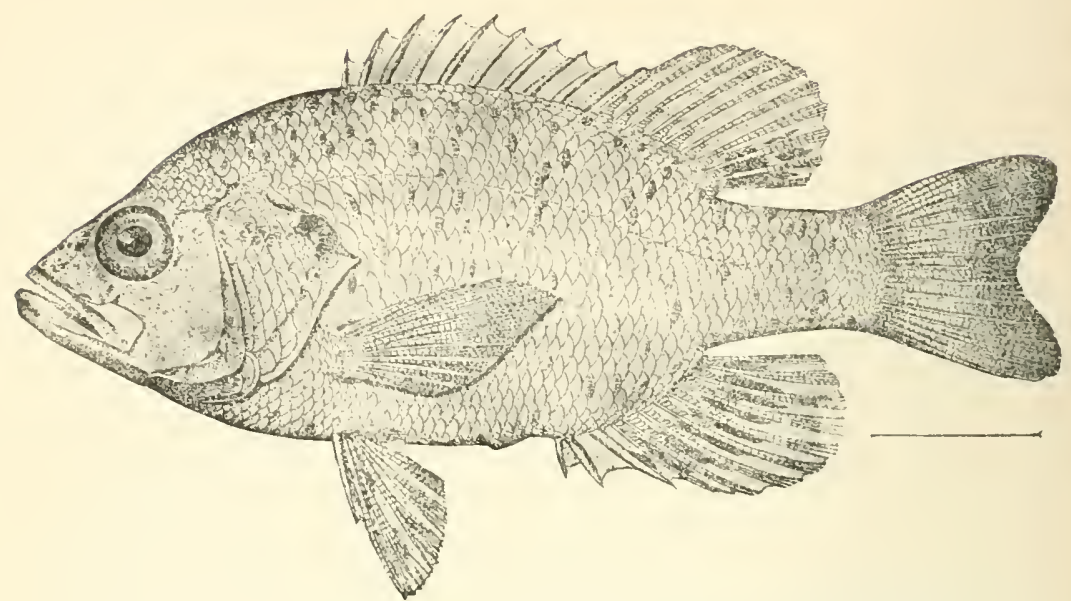

1llustration. Page.

60. “CHÆNOBRYTTUS GULOSUS." 421992

IVARMOUTH ;

"Head $2 \frac{1}{2}$ to $2 \frac{2}{3}$; depth 2 to $21 / 2$; eye 4 to $4 \frac{1}{2}$. Goggite-EyE. D. X, 9 or 10 ; A. III, 8 or 9 ; scales $6-40$ to $46-11$ or 12 ; 37 to 42 pores ; 6 to 8 rows on cheek. Body heavy, deep, more elongate than in Lepomis; head large; snout about equal to eye; mouth large, maxillary reaching posterior border of eye; opercular spot about as large as eye. Dorsal spines low, longest reaching to middle of pupil from tip of snout; pectoral not reaching origin of anal fin; ventrals nearly reaching anus, ventral spine about 2 in distance between origin of ventral and anus. Gill rakers 8 or 9 besides rudiments. Dark olive-green, clouded with darker, usually with red or blue, and brassy ; a dusky spot on each scale more or less distinct; vertical fins mottled with dusky; a faint spot on last rays of dorsal, bordered by paler; 3 oblique dusky or reddish bars radiating from eye ; belly yellowish or brassy. Length 8 to 10 inches."

Fresh-water fish. Caught: Same hook, line and bait as LargeMouth Bass. Edible, C. 


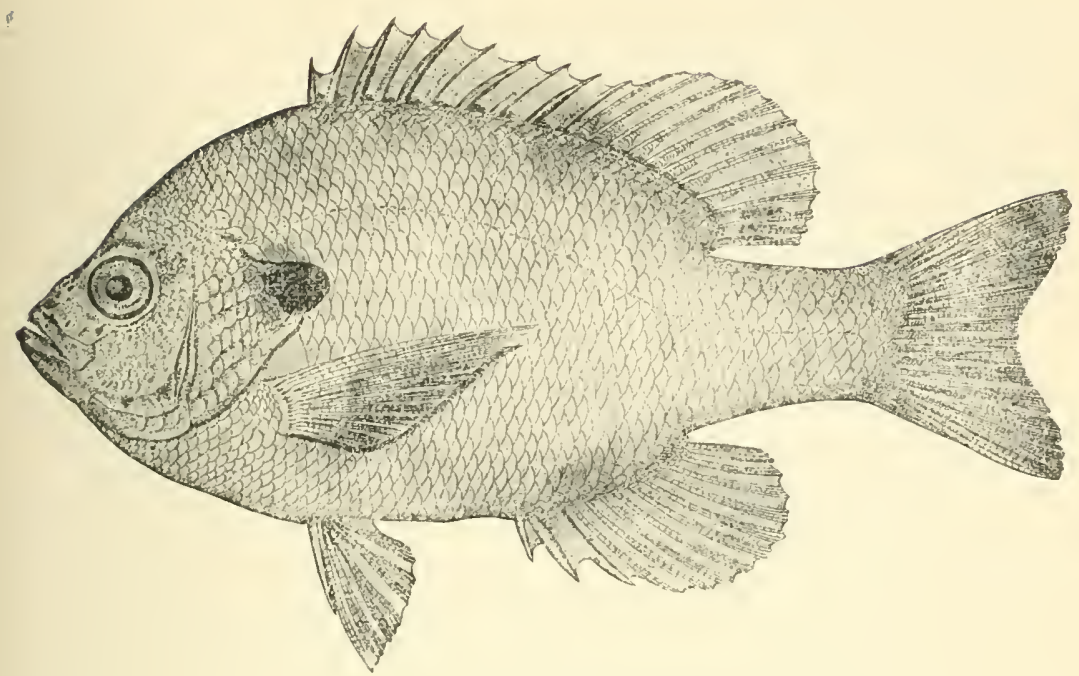

61. "LEPOMIS PALLIDUS." $\quad \begin{array}{cc}\text { Illustration. Page. } \\ 427 & 1005\end{array}$

SUNFISI ;

Blue Bream;

Blue Sunfish ;

COPPER-NOSED BREAII ;

Dollardee;

BLUE-GILL ;

RoACH BREAM.

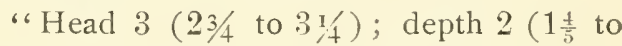
$2 \mathrm{x} / 4$ ); eye $3 \mathrm{x} / 2$ to 4 in head. D. X, 11 or 12 ; A. III, 10 to 12 ; scales $7-43$ to $52-16 ; 40$ to 50 pores; 5 rows of scales on cheek. Body comparatively short and deep, compressed; the young slender, the adult nearly orbicular. Caudal peduncle rather slender. Head not large, the projecting snout usually forming an angle above eye. Mouth quite small, oblique, the jaws about equal, the maxillary barely reaching the front of the eye. Opercular flap very short in the young; in the adult rather long and wide, without pale edge. Gill rakers moderately long, nearly terete, bent slightly downward, about $\mathrm{X}+11$ to 13 . Dorsal spines strong and high, the longest about half head, usually longer than snout and eye; ventral fins reaching anal ; pectorals very long, usually longer than head, reaching past base of anal spines. Olive green ; adults dark ; young more or less silvery, with a purple luster in life; sides with undulating, often chain-like, transverse greenish bars, which become obsolete in the adult; no blue stripes on cheeks; a diffuse black blotch at base of posterior 
rays of dorsal and anal, often obscure in young; no red on fins ; very old specimens often with the belly coppery red. Length, 12 inches." Weight average $1 / 4$ to $3 / 4$ pound.

Small fresh-water fish. Caught: Light rod and reel, silk line. Bait: Worms, grasshoppers, or worm out of top of rushes or saw grass. Edible, B.

\section{2. "EUPOMOTIS GIBBOSUS." Illustration. Page,}

SUNFISH ;

Common Sunfish ;

Caught same as above.

BREAM ;

PUMPKIN SEED;

SUNNY.

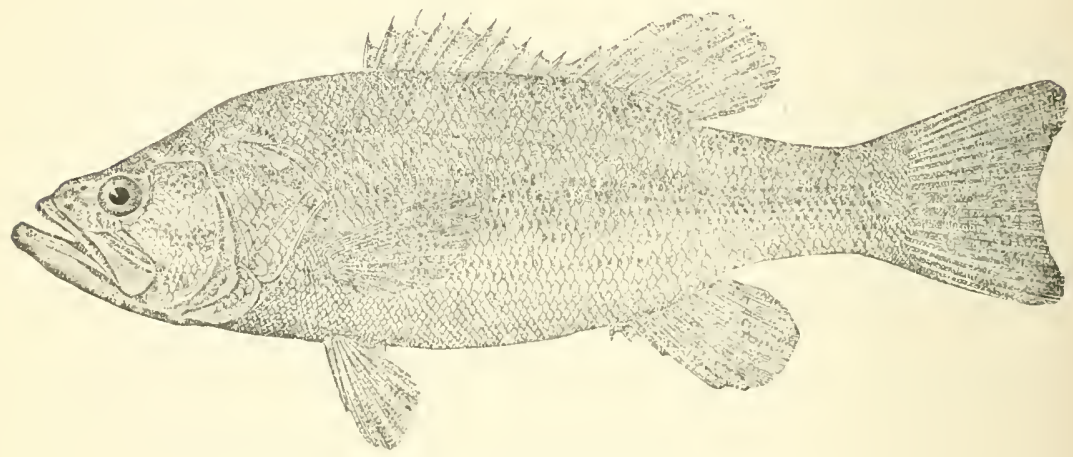

63. "MICROPTERUS SALMOIDES." $431 \quad 1012$

Black Bass, Large-Moutil ; OSWEgo Bass ;

Green bass;

BaYOU Bass;

OTSEgO BASS ;

Swamp Bass.
"Head 3 to $3 \frac{1}{2}$; depth 3 to $3 \frac{1}{4}$; eye $1 \mathrm{I} / 2$ to 2 in snout, 5 to 6 in head. D. X, 12 or 13 ; A. III, 10 or 11 ; scales $7-6.5$ to $70-18$; pores 58 to 67 . Body ovate-fusiform, becoming deeper with age, moderately compressed. Head large.

Mouth very wide, the maxillary in the adult reaching beyond the eye, in the young shorter. Scales on the cheek in about 10 rows; scales on the trunk comparatively large; tip of maxillary in adult as broad as eye. I.ingual teeth sometimes present. Gill rakers longer than gill 
fringes, $X+7$ or 8 , besides rudiments. Dorsal fin very deeply notched, its fifth spine $3 \mathrm{x} / 4$ in head. Coloration dark green above; sides and below greenish silvery; young with a blackish stripe along the sides from opercle to the middle of the caudal fin; three dark oblique stripes across the cheeks and opercles; below and above the lateral band some dark spots; caudal fin pale at base, then blackish, whitish at tip; belly white. As the fish grows older the black lateral band breaks up and grows fainter, and the color becomes more and more of a uniform pale dull green, the back being darker, a dark opercular blotch usually present. Length 18 inches or more."

This name corrupted in the South to "Trout." Weight in the North to 8 pounds, in Florida to 17 pounds. Caught: In fresh-water rivers and creeks. Rod and reel, No. 6 or a smaller silk line, No. $4 \%$ hook, gut snood, or without snood. Bait: Live Minnow, or small Bream, or cut bait. Small worms can be found in the decayed stems of the flags or saw grass, with which small Bream can be taken with Minnow hooks. Troll with spoon, phantom or bait. They will also take the fly. Red Ibis, Montreal,'Parmachene Belle, Seth Green and Brown Hackle are good as any. Edible, C.

While on the "Micropterus Salmoides" subject I wish to make a confession, which may read like a too late repentance for past errors or iniquities.

"Befo de wah," and for several years after, very many St. Louis families spent their summers at the lake resorts of Minnesota and Wisconsin, Lake Minnetonka and White Bear Lake in the former State, and the Oconomowoc lakes and Green Lake in the latter, being quite prominent fishing and family resorts, as they are at the present day.

My first visit to White Bear Lake was in 1857 , and I spent the summer of 1861 , and part of 1862 and 1863 , there.

I was at Lake Minnetonka through the summers of 1865 and 1866 , at which time the only route to the lakes was from Minneapolis by private conveyance, or stage three times a week to Excelsior, the only place of resort on the lakes, and only one small hotel, or boarding house, there. As there were only one or two small farms on the two lakes, called Upper and Lower Minnetonka, and possibly 100 residents in Excelsior, with the Bass, Pickerel, Rock Bass, Crappies, Sunfish, and Perch plenty in the lakes, it can be readily seen the visiting anglers had fine sport. 
During the first season I contented myself with catching the fish I needed for my family or that could be used by the hotel; but, as time wore on, fishermen came along who, in their rivalry and banter with each other, brought in large lots.

I saw over 500 Black Bass and Pickerel buried on the shore near the hotel many days in succession. Finally, once in 1865 and once in 1866 , I went out to see what I could do, and brought in 120 each day. I counted only the Black Bass and Pickerel, all others having been returned to the water.

All of the fishes of the lakes were of fine edible quality, as the water was clear, clean, and cold. I preferred the Sunfish, as they were of the large Blue Gill variety and would average three-fourths of a pound.

White Bear, War Eagle, and Birch lakes, from 1857 until 1862, were nearly as good as the Minnetonkas.

I first visited Green Lake, IVisconsin, in 1870, and spent many seasons there, sometimes remaining as late as November, the best Bass fishing being during the month of October. There nearly all are the Small-Mouth species, while at the Minnesota lakes nearly all are the Large Mouth. The catches, however, are much smaller, twenty-five to the boat in the best of seasons being a full average.

From 1882 until 1889, I camped from two to four months each year on the lines of the Milwaukee, Lake Shore \& Western Railway, and on those of the Northwestern Railway, in northern Wisconsin and the Northern Peninsula of Michigan, after Brook Trout, Large and Small-Mouth Bass, Pickerel and Mascalonge.

My best ground for Bass was Lake Gogebig, which I visited the first year the road was finished to that point. There I saw hundreds of Small-Mouth Bass brought and buried day after day, but I never indulged in any great number. As I was in camp where I could get Brook Trout to eat, I caught very few Bass.

On one occasion while camped with two friends on the east branch of the Ontanogan River, at that time almost a virgin Trout stream, we concluded we would try Duck Lake, which was the principal source of supply of water to the stream we were on. I had camped on the lake the year before and knew it well. We went up to IVatersmeet, taking along three Bond iron sectional boats and a fifty-four pound Rushton cedar, and put them on the train at $7 \mathrm{~A}$. M., having four guides with us. We ran six miles on the train, carried the boats 


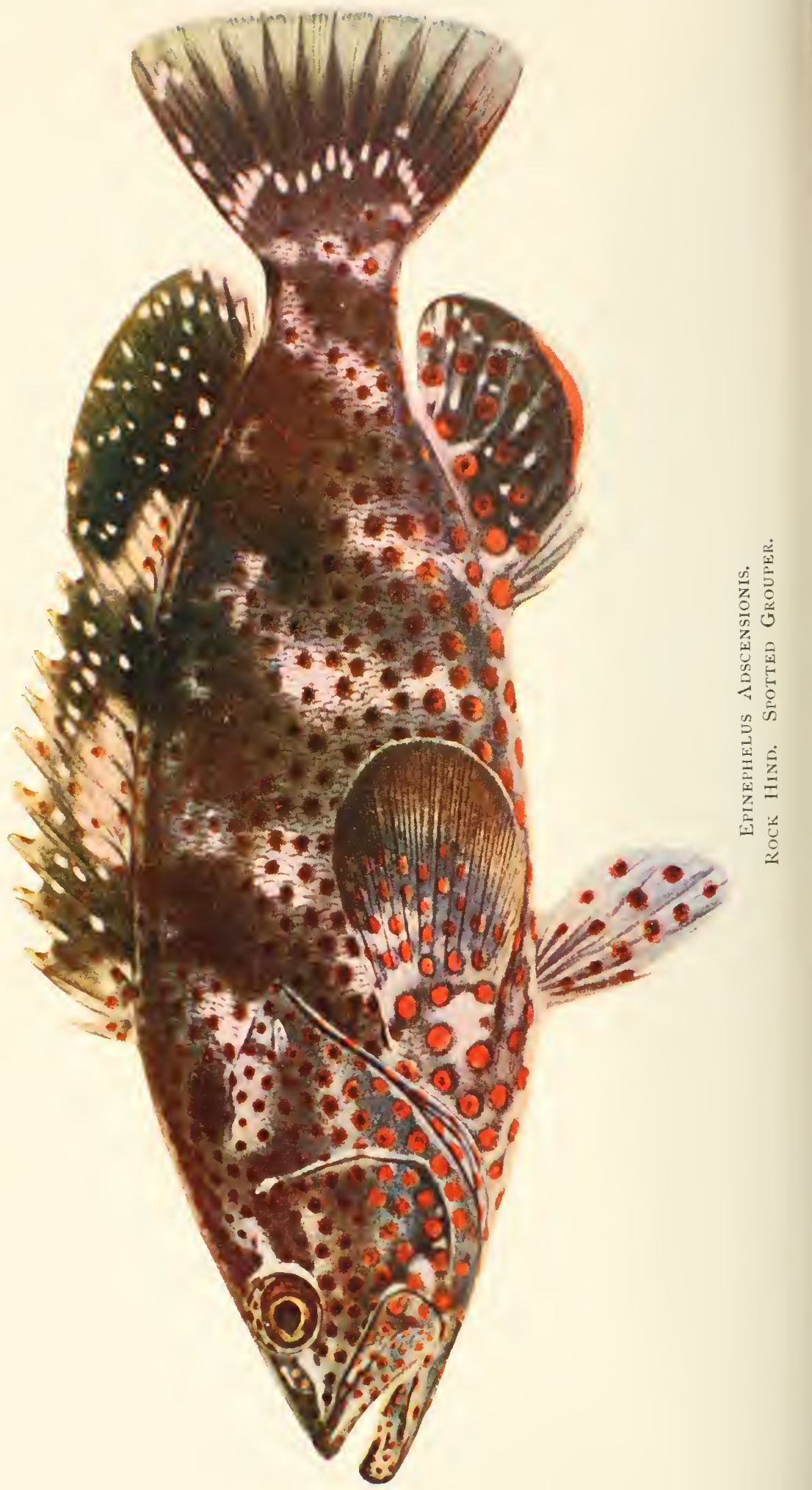


three-fourths of a mile into the lake, fished about three hours, landed and cooked our dinner, and were back at Watersmeet about 6 o'clock P. M. with 215 as fine Large-Mouth Black Bass as I ever saw.

Duck Lake is of the Lake Superior waters, and is very clear and cold. There was use for the fish, as we gave them to the hotel and railway men; so this can hardly be called a "Fish Hog" story. I promised to never do it again, and have kept my word.

\section{4. "EPINEPHELUS ADSCENSIONIS." $482 \quad 1152$}

GROUPERS ;

ROCK HIND;

Cabra MORA;

Polka Dot.

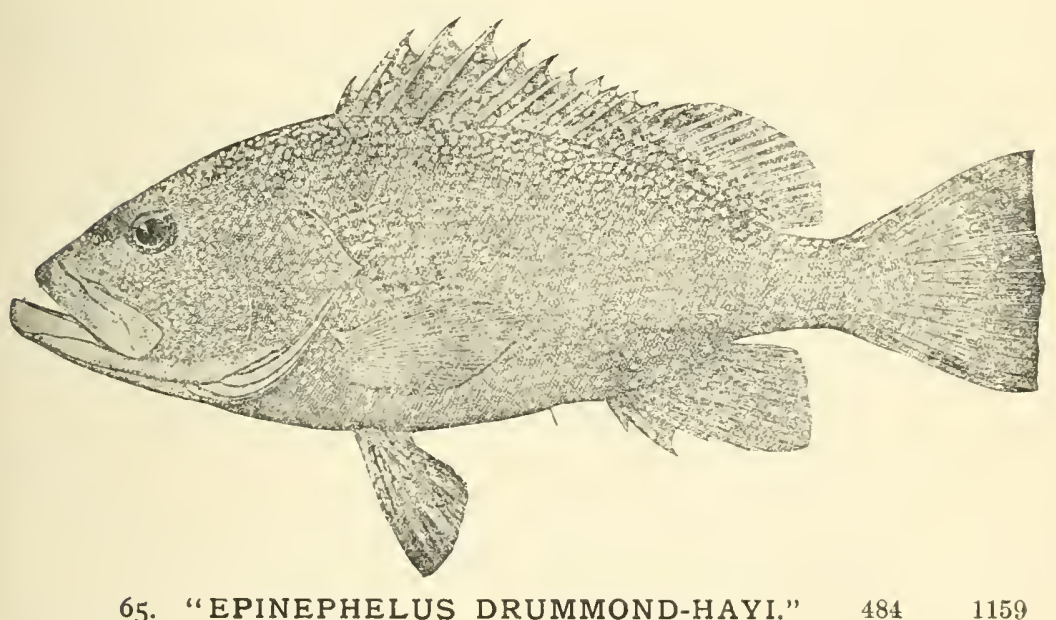

GROUPER ;

SPECKLED HiNi) ;

JOHN PAW ;

Polka Dot.

66. "EPINEPHELUS MACULOSUS." No illustration. 1158 GROUPER ;

CABRILlA ;

RED HiND. 


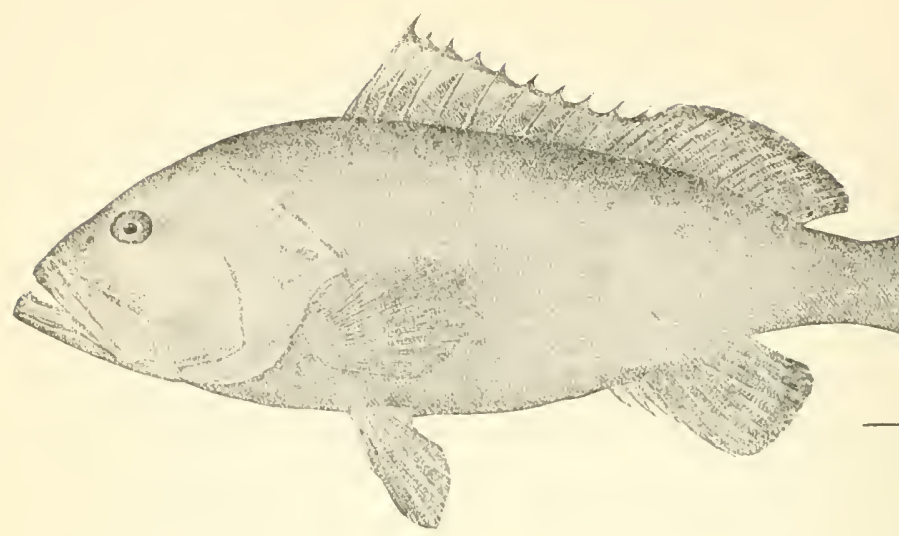

67. “EPINEPHELUS MORIO." $\quad 485 \quad 1160$

GROUPER ;

Red Grouper ;

Cherna Americana Cherna de Vivero;

NEGRE.
"Head 21/2; depth $2 \frac{4}{5}$; eye large, 5 in head (young). D. XI, 16-17; A. III, 9, rarely III, 8 ; scales 18 or $20-130$ to $140-60$; pores 60 to 65 . Body comparatively deep and compressed, highest under front of spinous dorsal, its greatest width $2 \mathrm{I} / 2$ in greatest depth. Head large, moderately pointed, the anterior profile rather steep and nearly straight. Mouth rather large, the maxillary reaching slightly beyond eye, its length $2 \frac{1}{6}$ in head. Lower jaw not strongly projecting. Teeth moderate, in rather narrow bands; 2 moderate canines in the front of each jaw, the lower smaller. Interorbital space narrow, its width $7 \mathrm{I} / 2$ in head, the outline of the bone (under the flesh) transversely concave. Nostrils small, round, subequal. Preopercle moderately serrate, its angle slightly salient; teeth at the angle a little enlarged. Gill rakers rather slender, about 15 below the angle. Scales small, mostly ctenoid. Dorsal spines high, slender but pungent, the first less than half the second, which is highest $2 \mathrm{r} / 3$ in head; the outline of the fin thence almost straight to the tenth spine, which is $13 / 4$ in the second; soft dorsal not elevated; caudal fin lunate, the outer rays a little produced, $12 / 3$ in the head; caudal peduncle comparatively slender ; soft part of anal rounded, its longest ray $23 / 4$ in head; second anal spine somewhat stronger but not longer than third, $4_{6 j}^{1}$ in head. Pectorals reaching slightly beyond tips of ventrals, $1 \frac{4}{5}$ in head; ventrals short, not reaching vent. Pyloric coeca 25 (according to Poey). Color in 



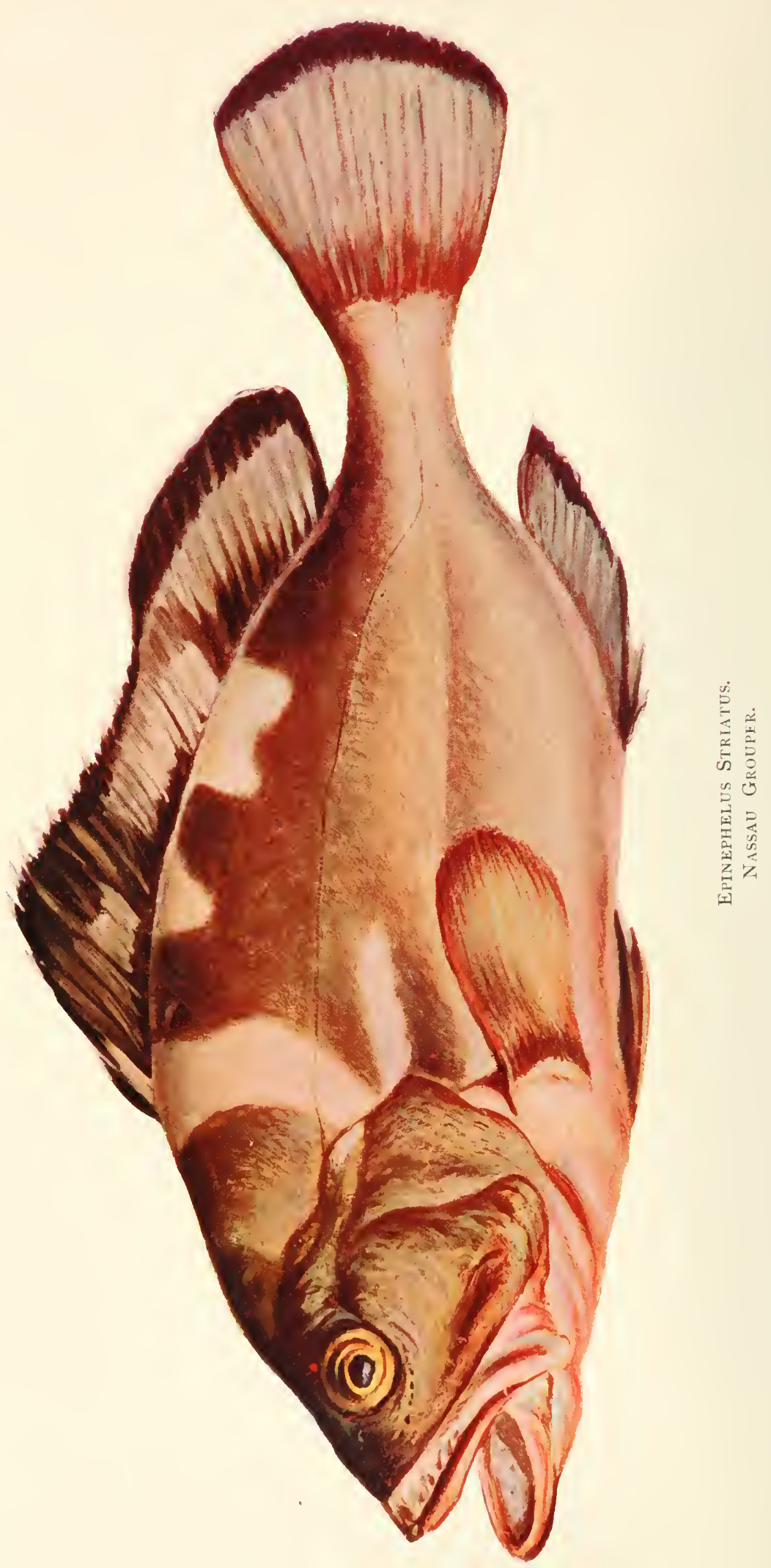


life: Olive gray or olive brown, clouded with paler olive, with no clear red shades except on jaws and lower part of sides of head and breast, these regions being usually a salmon color ; besides these, very irregular rounded blotches of grayish white over the body ; preorbital, suborbital region, and snout with numerous round points of dark orange brown, most numerous on preorbital, these points brown in spirits ; inside of mouth posteriorly bright orange ; iris gilt ; vertical fins colored like the body, the shades from the body extending on them; soft dorsal, anal, and caudal with a broad ridge of blue black, with a narrow whitish edge; spinous dorsal narrowly edged with blackish; ventrals slightly dusky ; pectorals light olive. With age this species becomes more and more of a flesh red, especially below and on mouth, the pale spots and blotches are less distinct in old examples. Length, 1 to 3 feet."

\section{8. "EPINEPHELUS STRIATUS." llustration. Page.}

GROUPER ;

"Head 24 Nassau Grouper; in head (young). D. XI, 17 ; A. III, 8; scales HAMLET ;

Cherna Criolla; 13 to $18-110$ to $125-45$ to 55 ; pores 55 to 65 . ROCKFISH.

Body rather deep, not strongly compressed, its greatest width $2 \frac{2}{5}$ in depth. Head somewhat pointed, the anterior profile nearly straight to the front of the dorsal. Mouth moderate, the lower jaw little projecting, the maxillary reaching posterior border of eye, $21 / 3$ in head. Teeth in moderate bands; 2 moderate canines in front of each jaw, the lower smallest. Nostrils close together, the posterior a little the larger, ovate. Interorbital space narrow, flattish, or somewhat concave, $81 / 2$ in head. Angle of preopercle slightly salient, a shallow notch above it, the teeth at the angle somewhat larger. Gill rakers slender, about 16 below the angle. Scales moderate, strongly ctenoid. Dorsal spines of moderate strength, higher than in most species, the second much higher than tenth, the third highest, $2 \mathrm{I} / 2$ in head; soft dorsal rather high ; caudal rounded, $1 \frac{5}{7}$ in head; soft anal rounded, the largest ray $21 / 4$ in head; second anal spine stronger than third and about as long, 4 in head; pectorals reaching tips of ventrals, $1 \frac{7}{9}$ in head. Ventrals short, barely reaching vent. Color in life: Rather pale olivaceous gray, paler below, and with obscure whitish clouds along sides; body with about 4 vertical bars, very irregular and undulating, of an olive-brown 
color, darker on the back, and all extending on the dorsal fin; a square blotch of jet black on back of tail; a band of dark olive through eye and on snout, meeting its fellow on shoulder just before dorsal; another on median line of snout, forking opposite front of eye, the 2 bands extending backward parallel and ceasing abruptly on occiput without reaching the other band; dark shades radiating from eye below; a ring of deep brown or blackish points around eye, the upper ones on eye, a deep orange-red stripe on lower edge of preorbital ; mouth within partly orange; lower parts of head and breast tinged with orange and with coppery cloudings; vertical fins colored like the parts of the body nearest them; edge of both dorsals yellow ; caudal and anal tipped with orange yellow; ventrals blackish; faintly yellowish at tips; pectorals chiefly light orange, dusky at base; bands and dark markings of body becoming fainter in old examples of this species, and almost disappearing in alcoholic specimens.",

Grouper ;

69. "MYCTEROPERCA VENENOSA." $\quad 491 \quad 1172$

ROCKFISH ;

YELLOW-FINNED GROUPER;

Bonaci de Piedra;

DOLLY VARDEN.

70. "MYCTEROPERCA BOULENGERI." 490

1171

GROUPER ;

Cabrilla de Raizero ;

Mangrove Grouper.

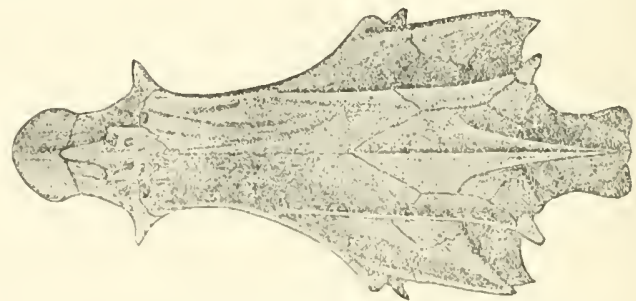

7x. "MYCTEROPERCA BONACI."

Grouper ; Skull illustrated.

Black Grouper;

Bonaci Arara;

Aguajl. 
GROUPER ;

72. "MYCTEROPERCA MICROLEPIS." $494 \quad 1177$

GAG ;

Aguajl.

73. "MYCTEROPERCA FALCATA PHENAX."

$494 \quad 1185$

Grouper; The Groupers run in weight from less than a pound to ScAMP; 50 or 60 pounds; so it is difficult to advise as to tackle, BACALAO. which will be all the way from No. 9 line to 21 , and the hooks from $2 \%$ to $10 \%$. Sportsmen will have to be governed by the fish where they are fishing.

As to bait: The Groupers will take cut fish, Crawfish, Conch, Crabs of all kinds, and will take a squid, spoon or phantom, trolling. For the largest ones on the " patches " and under the mangroves, hand lines must be used. They are caught in large numbers, and large sizes, on the "patches", off the shores all the way from Indian River to Key West. The large ones are very gamy, but the small ones are somewhat sluggish. I will treat them further in detail in giving the places to fish at. This applies to all the Groupers mentioned herein. Edible up to 10 pounds, B. Very good bakers and boilers.

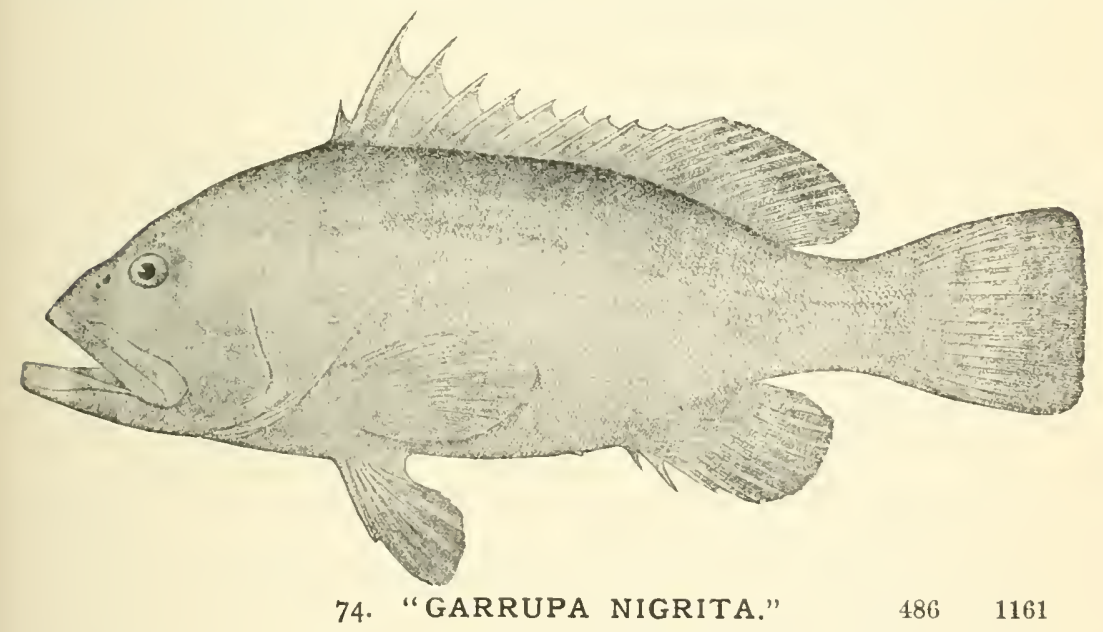

JEWFISH ;

" Head $21 / 2$; depth $21 / 3$; eye very small, 6 to 8 BLACK JEWfisir ; in head. D. XI, 14 (nigrita), or X, 14 (merus); Black Grouper; Mero de lo Alto. A. III, 9 ; scales 90 to 110 . Body very robust; teeth in broad bands, canines strong, but growing smaller with age. Interorbital width $4 \frac{1}{3}$ in head; lower jaw project- 
ing; maxillary scaly, about 2 in head, extending beyond eye; preopercle rounded, without salient angle, the young with enlarged teeth at the angle. Gill rakers short and thick, $X+12$ to 14 , the longest not twice as long as broad. Dorsal fin notched; second dorsal spine longest, its length 2 to 3 times in head, and half longer than third spine; caudal fin rounded; second anal spine shorter than third, 6 in head. Scales ciliated, those of lateral line of the ordinary type. Color, plain chocolate brown, varying to blackish gray, without markings, or with faint pale blotches, the lower parts scarcely paler, the distal part of the vertical fins darker; a dark streak along edge of maxillary."

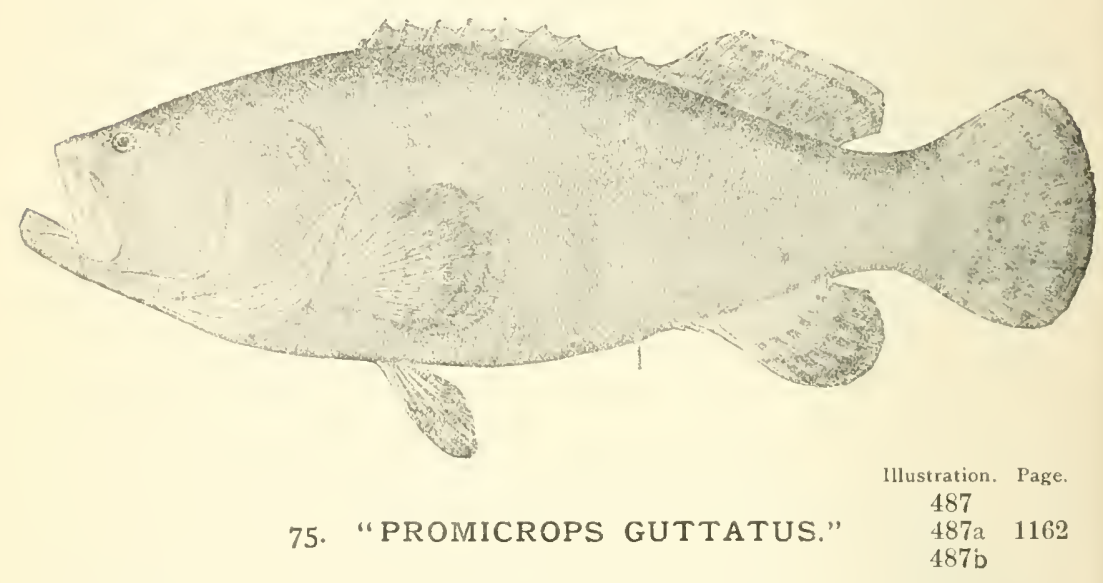

JEIVFISII ;

GUASA ;

SPOtTen JeIVFISII ;

NiERo.
"Head $2 \frac{3}{5}$ to 3 ; depth $3 \frac{1}{10}$; eye very small, 7 in head (in young), about 12 in adult. D. XI, 16 ; A. III, 8 ; scales $16-95$ to $135-40$; pores 60 to 70 . Body more robust than in any species of Epinephelus, its greatest breadth $12 / 3$ in the depth. Head very large, unusually broad, anteriorly obtuse, its profile depressed or slightly concave above the eye, convex at the nape. Snout very short, $43 / 4$ in head; lower jaw projecting. Maxillary scaly. Mouth large, the maxillary, even in the young, reaching much beyond the eye, 2 in head, its ti] in the adult as wide as eye. Teeth in broad bands, those of the outer series somewhat enlarged, the canines very small, scarcely differentiated, but present. Interorbital area flattish, very broad, its width 5 in head. Nostrils subequal, roundish, close to the eye. Preopercle convex, with a slight emargination, the angle a little promi- 
nent, with somewhat larger teeth. Opercular flap obtusely pointed, its upper edge curved. Opercular spines small and blunt. Gill rakers short and thick, few (about 12) in number. Scales comparatively large, mostly ctenoid. Scales of the lateral line each with 4 to 6 conspicuous radiating ridges separated by furrows. Dorsal spines low and strong, the third, fourth, and fifth subequal, 4 in head, the outline of the fin scarcely convex; second spine lower than tenth; caudal fin rounded, its outer rays very much shortened, little more than half the length of the middle rays, which are $1 \frac{1}{2}$ in head. Anal rounded, its longest rays $21 / 3$ in head; second anal spine rather shorter than third and a little stronger, $4 \frac{3}{5}$ in head; pectorals reaching a little beyond tips of ventrals, $12 / 3$ in head; ventrals 2, not reaching vent. Pyloric coeca excessively numerous and finely divided. Color of adult nearly uniform dull olive brown, the spots and bands faint or obsolete. Young specimens in life pale olive green, slightly yellowish on breast and lower jaw, the body with 5 cross bars of dark olive green, with irregular but rather sharply defined edges, and extending on the dorsal and anal fin; 2 under spinous dorsal, 2 between soft dorsal and anal, 1 on caudal peduncle ; these bars partially or wholly disappear in spirits; a dark blotch at nape; two shades down and backward from eye; a bar at base of caudal; round blackish spots smaller than pupil, of different sizes, scattered over the whole of head and nuchal region; a few along back; these smallest on upper part of head, largest on back and lower parts of sides of head; breast and belly plain; dorsal fin olive, with dark clouds like the body, a few spots on spines and tips of soft rays; caudal much clouded with dark, which form series of spots on the hinder parts, these spots smallest and best defined posteriorly. Anal similar to caudal ; pectorals light olive, profusely covered with large dark spots; ventrals similar to pectorals, with fewer spots. Tips of pectorals and caudal slightly reddish. In spirits the dark bands and blotches of body are more or less faded. Length, 2 to 6 feet."

The Jewfish is of the Grouper family. Weight to 500 pounds; average usually caught by sportsmen 1 to 10 pounds. Caught: Usual small sizes, rod and reel, hand line, same as Groupers, while fishing under mangroves for Snappers and Groupers. If large ones are wanted, $\frac{3}{16}$ hand line, shark hook. Bait: Fish $1 / 2$ to 1 pound. Fish where you have ascertained them to be, in channels, under mangroves, and around docks and piers, and on "patches." Edible, B, 
up to 5 or 6 pounds; very fair boilers, bakers, chowder, etc. Large ones worthless.

\section{6. "DIPLECTRUM FORMOSUM."}

SQUIRREL-FISH ;

Serrano;

SAND-FISH.

\author{
"Head 3 ; depth $3 \frac{2}{5}$; \\ D. $\mathrm{X}, 12$;
}

A. III, 7 ; scales $9-80$ to $90-22$; pores 54 to 60 . Body elongate, the profile strongly arched above eyes; mouth large, lower jaw slightly projecting; maxillary narrow, reaching middle of eye, $2 \frac{1}{5}$ in head; canine teeth small; eye placed high, shorter than snout, about 5 in head; preorbital broad, more than twice the width of maxillary; upper part of margin of preopercle finely serrate ; preopercle with two clusters of divergent spines, the one at the angle, the other higher (the two fascicles well separated in the adult, but smaller and coalescent in the young); distance from opercular flap to upper end of preopercle $1 \mathrm{I} / 2$ in rest of head; opercular flap short and sharp; gill rakers moderate, $\mathrm{X}+14$ or 15 ; top of head and preorbital region naked; smooth area on top of cranium very convex; 11 rows of scales on cheeks; fins, except caudal, scaleless; 15 scales before dorsal; dorsal spines low and slender, the first three graduated, the rest subequal; caudal deeply lunate, the upper lobe the longer, sometimes ending in a long filament; anal spines very weak, the third longest, $1 \frac{1}{2}$ in eye; pectoral $13 / 4$ in head. Color brownish, silvery below; sides with 7 or 8 longitudinal blue lines, bright blue above, pearly whitish below, and about as many dark cross bars, the last bar forming a large black blotch at upper base of caudal ; 6 of these present, with another at base of dorsal; a broken median stripe before dorsal ; stripes on head bright blue; spinous dorsal with 2 stripes of light blue, bordered with darker, and 3 of light orange yellow; 3 blue stripes and 4 yellow ones on soft dorsal; caudal with light-blue reticulations around light-orange spots; ventrals and anal bluish white, shaded with light yellowish; pectoral transparent; posterior part of mouth tinged with yellow; young with two broad, dusky longitudinal stripes, which become interrupted with age; 3 or 4 distinct blue stripes on sides and top of head; 2 across preorbital, the lower forked; fins with narrow, wavy bars of blue and pale yellow."

"Sand Perch," local name Biscayne Bay. "Goat Fish," local name West Coast. Weight up to $1 / 2$ to $3 / 4$ pound; average less than 
$1 / 4$ pound. I have caught them only in Biscayne Bay, on East Coast, inside near the passes, grass or sand bottom, 4 to 10 feet water, still, bottom fishing, or floating. Light tackle, rod and reel, 6, 9, line, No. 1, 2, hooks. Bait: Cut Mullet, or other fish, Crawfish, Conch. Edible, B, almost A. Fine pan fish.

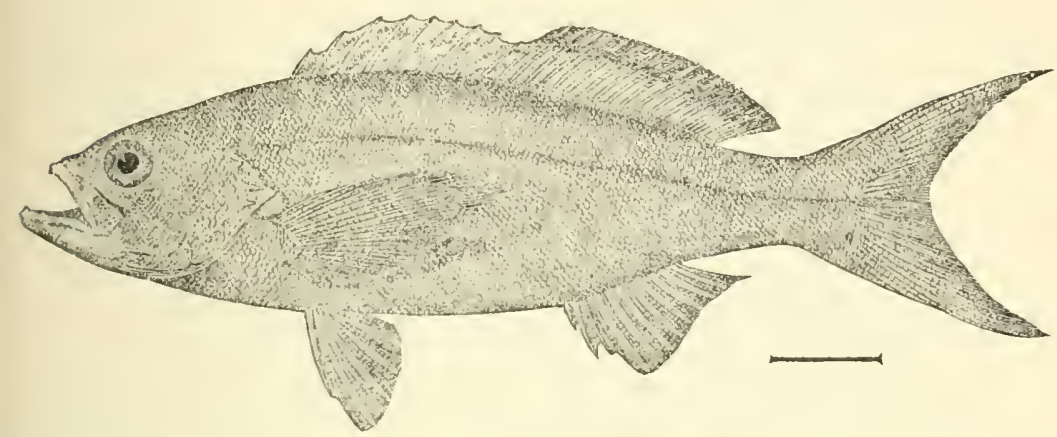

77. “PARANTHIAS FURCIFER." $\begin{array}{ccc}\text { Illustration. Page. } & 504 & 1221\end{array}$

RABIRUBIA ;

RabiRubia De lo Alto;

Creole Fish.
" Head $32 / 3$; depth 3 ; snout about 4 in head; eye about 4 . D. IX, 18 to 20 ; A. III, 9 or 10 ; scales $12-120$ to $135-35$; pores
derately elongate, strongly compressed; the 77 to 85 . Body moderately elongate, strongly compressed; the
profile convex and the snout short, as in Anthias; maxillary reaching to below middle of eye, $2 \frac{3}{5}$ in head; maxillary broadened posteriorly, its surface scaled, as in Anthias, its distal extremity $1 / 2$ to $\frac{3}{5}$ in eye ; teeth small, recurved, in a narrow band in each jaw, 2 to 4 straight canines near the front of each jaw; preorbital very narrow; preopercle finely serrate, with salient angle or enlarged teeth; gill rakers long, slender, and close-set, $12+20$ in number, the longest $3 / 4$ eye ; scales small, closely and regularly imbricated, most of them strongly ctenoid; dorsal fin low, the spines strong, the third longest, $2 \mathrm{I} / 3$ in head; soft rays of dorsal low, scarcely higher than longest spine; anal short, its longest (second) soft ray 2 in head, its third spine longest, $2 \frac{2}{3}$ in head; ventrals narrow, $1 \frac{1}{2}$ in head, not reaching vent; pectorals lanceolate, as long as head; humeral scale long. Color bright red, or salmon color, with 3 small violet spots, 1 on side of back and 1 or 2 on the tail; a bar of similar color extending from upper corner of pectoral across the humeral process; sides with 
faint oblique streaks along the rows of scales ; dorsal fin with a longitudinal blackish streak." Weight, average $3 / 4$ pound.

Caught: No. 6 and 9 line, No. $1 \%$ hook. Still fishing. Edible, A.

\section{8. "RABIRUBIA."}

Illustration. Page.

There is a fish caught at Ponce Park called by this name, which is of the Snapper species. It has all the especial features of the Snappers, and only varies in being brighter red than the Mangrove Snapper.

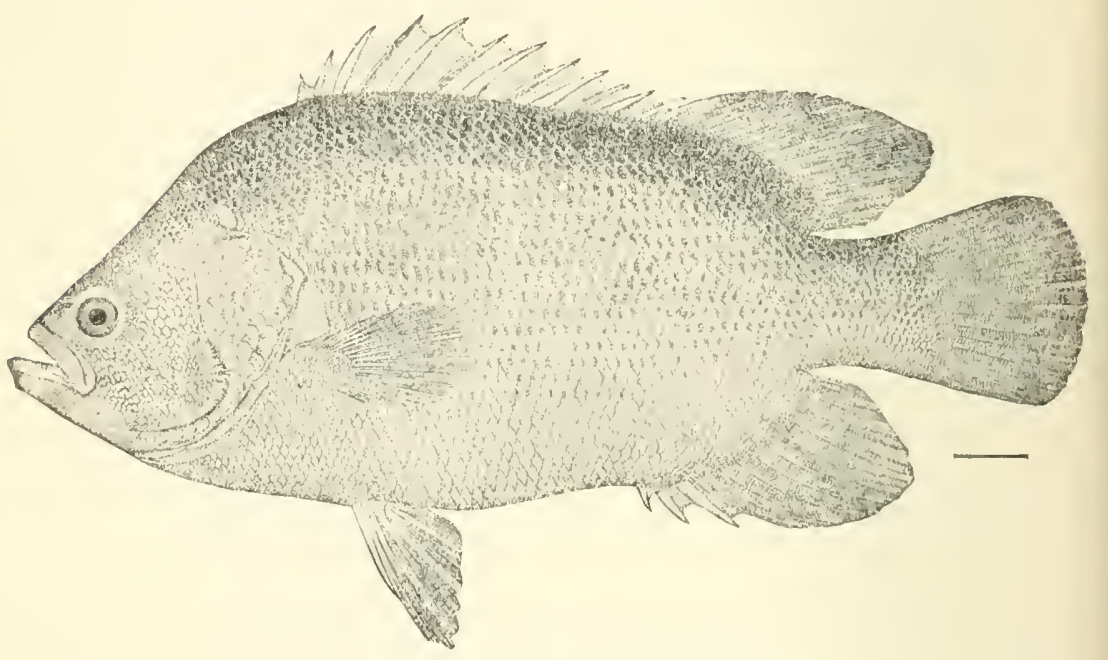

79. "LOBOTES SURINAMENSIS." $510 \quad 1235$

TRIPLE-TAIL;

FLASHER ;

DORMEUR ;

Chora ;

CHOFA ;

STAKE-FISII
“Head 3; depth $1 \frac{4}{5}$ to $21 / 4$. 11 ; scales 47 . Head small. Profile from dorsal to occiput strongly convex, from occiput to snout concave; maxillary reaching beyond middle of orbit. Scales around eye very small, those on opercle large. Eye small, much shorter than snout. Preopercular strongly dentate; teeth enlarged on angle, hooked upward on posterior limb. Pectorals shorter than ventrals, which do not reach vent; soft dorsal higher than the spinous portion. Small scales running up on the base of soft dorsal, anal and caudal. Blackish above, becoming silvery gray on the sides; often blotched and tinged with 
yellow; fins dusky gray; sometimes with yellow. A large fish of rather sluggish habits, reaching a length of 3 feet." Weight to 30 pounds; average about 6 pounds.

Caught: Rod and reel, or hand line, 18-21 line, 4\%-6\% hook. Still fishing, bottom and floating, around docks, bridges, beacon stakes, spiles, etc. Bait: Shrimps, Prawns and Crustaceans generally, cut Mullet and other fish. Edible, A 1. One of the very best edible fish up to 10 pounds.

\section{0. "NEOMÆNIS GRISEUS." 1llustration. Page. \\ No illustration. 1256}

SNAPPERS ;

GRAY SNAPPER ;

MANgrove SNAPPER ;

CABELLEROTE;

LAWYER. rather pointed, 3 in head. Eye rather small, $42 / 3$ in head. Interorbital space gently convex, 6 in head; occipital keel little prominent; preorbital rather broad, $5 \mathrm{x} / 2$ to $6 \mathrm{x} / 2$ in head. Mouth large; jaws subequal ; maxillary reaching front of pupil, $2 \frac{3}{5}$ in head; upper jaw with a narrow band of villiform teeth, outside of which is a single series of enlarged teeth ; 4 canines in front of upper jaw, 2 of them quite large, $1 / 3$ diameter of eye; lower jaw with a very narrow band of villiform teeth in front of jaw only; outside of these a single row of teeth larger than outer teeth of upper jaw, becoming canine-like in adult; tongue with an oval patch of teeth, its width about $1 / 2$ its length; vomer with an arrow-shaped patch of teeth, with backward prolongation on the median line, its length about twice its width in front. Gill rakers rather short and thick, their length about $1 / 3$ diameter of eye, about 8 on lower arch, with no rudimentary ones before them. Preopercle with its posterior margin nearly vertical, with a rather broad and deep emargination. Preopercle finely serrate above, the teeth coarser at the angle. Scales comparatively large, the rows in horizontal series below the lateral line, those above running parallel with the lateral line until below the soft dorsal, where they become slightly irregular and oblique ; 7 rows of scales on cheek; an embedded row on interopercle; one row on subopercle and 7 on opercle; temporal region with about 3 rows of large scales; top 
of head, snout and jaws naked; base of soft dorsal and anal scaly; tubes of lateral line branched. Dorsal spines rather strong, the outline of the fin gently convex, the fourth spine longest, $21 / 2$ in head; the tenth spine 4 in head; margin of soft dorsal rounded, the ninth and tenth rays longest, $1 \mathrm{r} / 3$ length of first, and $1 \frac{3}{5}$ last ray, $2 \mathrm{r} / 2$ in head; caudal emarginate, the upper lobe longest, $1 \frac{1}{3}$ length of middle rays, which are $13 / 4$ in head; anal fin high, its margin slightly angulate, the middle rays longest, 2 times length of last ray, $2 \frac{1}{6}$ in head, first ray reaching almost to tip of last ray, when the fin is depressed; second anal spine as long or slightly longer and stronger than third, $3 I / 4$ to 4 in head; ventrals $13 / 4$ in head; pectorals shortish, scarcely reaching vent, $1 \frac{4}{7}$ in head. Color in life, very dark green above, the middle part of each scale brassyblack, its edge broadly pearly whitish; below lateral line the duskiness of the middle of the scale passes into brassy, and below into bright coppery, the belly and lower parts of head being more or less distinctly bright coppery-red; the lower jaw grayish; no blue stripe below eye, except in the very young; top of head blackisholive; dorsal blackish, its margin darker and tinged with maroon-red; soft dorsal dusky, anteriorly slightly edged with whitish; caudal violaceous or maroon black; anal wine-color, edged with whitish; pectorals pale flesh-color; ventrals whitish, faintly marked with reddish. Young with a blackish band from snout through eye to nape, very distinct in life; a blue streak below eye; spinous dorsal with a dark maroon-colored band along edge. Described from a specimen from Key West, 11 inches in length. Fishes from deep water are much redder than those taken near the shore. In no case is the caudal yellowish or of any pale shade."

J. \& E. group this fish with the Mangrove Snapper. U. S. Commission, 1896, classifies each separate. 'They are very closely allied, but there are small differences in color and shape. Their habitat and habits are exactly the same. Weight to 14 pounds; average, 3 pounds. Caught: Rod and reel, still fishing, bottom, No. 15-18 line, No. $4 \%, 5 \%, 6 \%$, hooks. Occasionally one will take a troll. Bait : Crawfish, Mullet or other fish, Conch. Edible, A 1. A very game fish, and my favorite to eat of all fishes. 



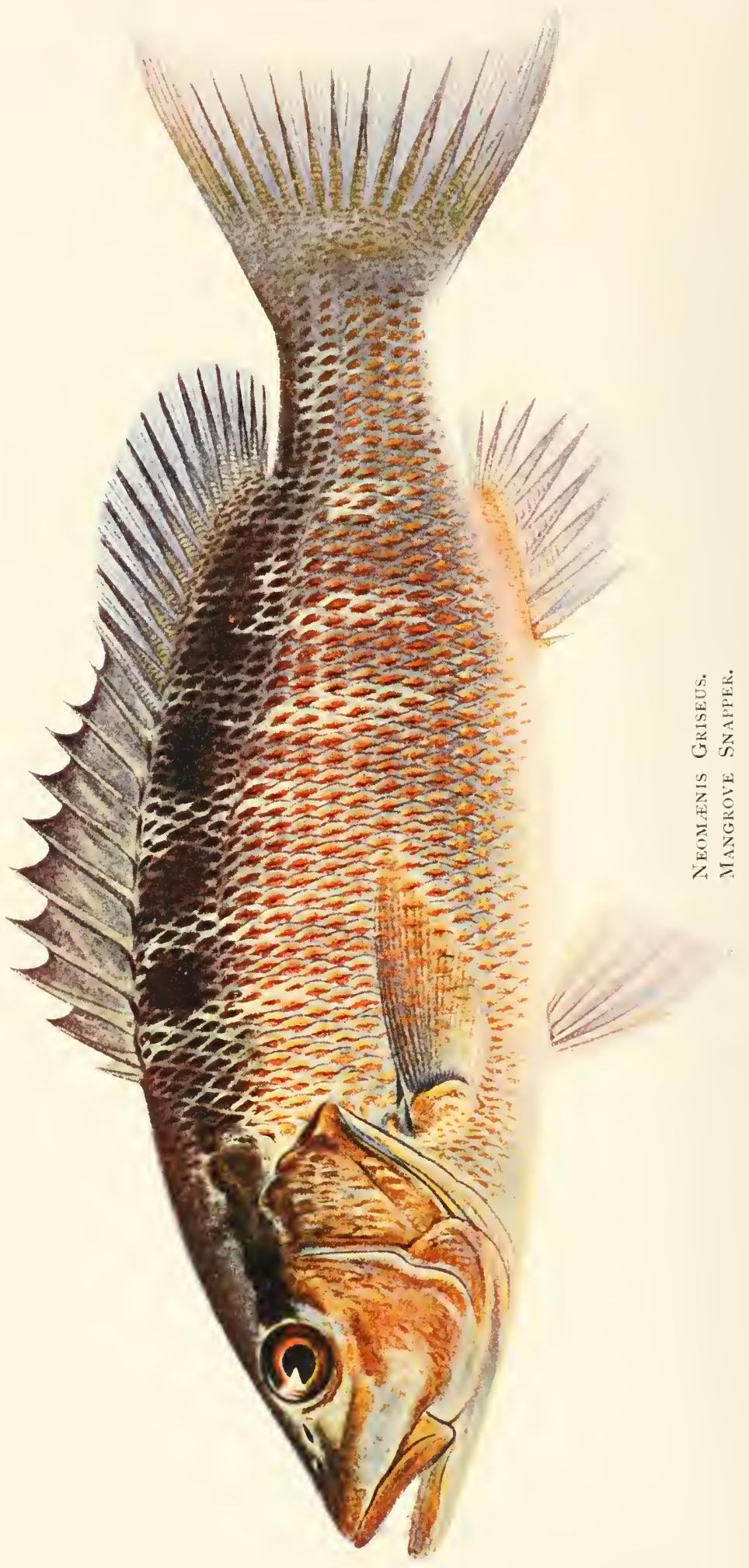




\section{1. "MANGROVE SNAPPER."}

In nearly all respects same as Gray Snapper, but there are slight differences. Caught same as Gray.

During March, 1897, while at Lake Worth, Capt. Gardner and I tested the Mangrove Snapper fishing off the end of the pier quite thoroughly. The water there is very clear, so that you can see the bottom twenty feet down ; consequently, all the fishes are exceptionally wary and shy, and, in the case of the Snapper, I would say cunning.

We cut Mullets into pieces from an inch to two inches long, throwing it down to the Snappers, of whom there were probably a dozen in sight, some of them "whoppers" of ten or twelve pounds.

They at first sailed around the bait, apparently studying the situation, and, finally, some would take it. We kept this up for fifteen or twenty minutes, by which time fifty or more had collected, eating the bait well. Then we put the same bait on as small a line as we dared to, No. 9, $4 \%$ hook, and dropped that down while they were busy eating our chum, and " nary one" touched it.

We tried that several times, always with the same result during the day. Just before dark we could sometimes get one or two, but never a large one, about five pounds being the largest we ever caught there.

While at Indian Key, in 1892, I asked the headkeeper of Alligator Light if there were any Mangrove Snappers around the light. He replied yes, but they were hard to catch, that they gathered under the lighthouse to eat the table refuse thrown down, but if you dropped a baited hook down, they would look up at you, wink their eyes at you and sail away. I presume this was, in the main, true; but in 1900 Professor Walker and I did well there, some ten or fifteen feet distant from the column of the light. It was quite rough that day, which may have been in our favor. 


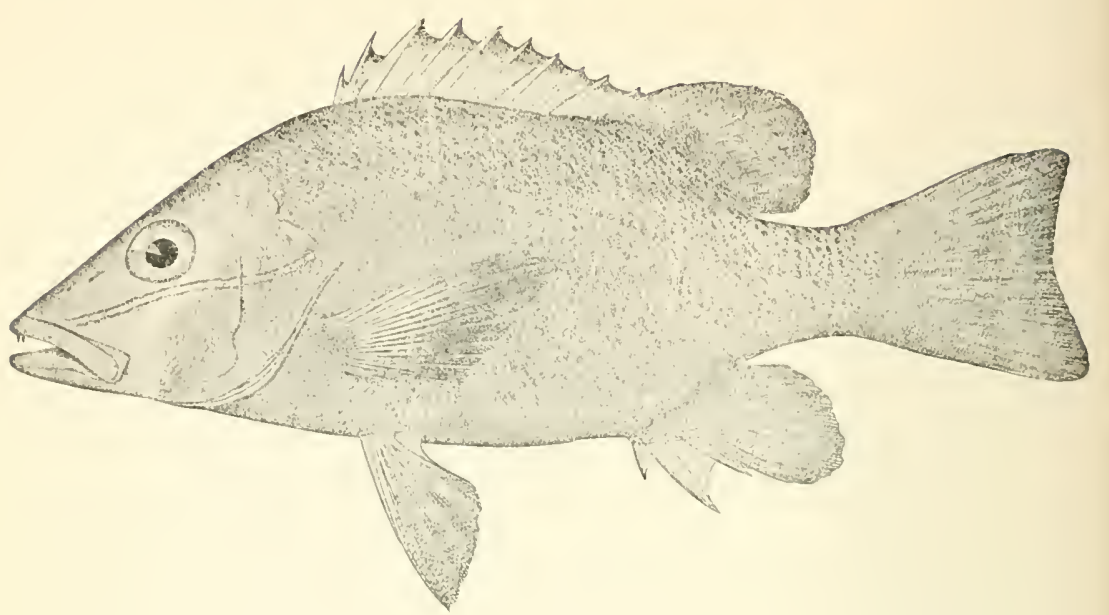

82. "NEOM ENIS APODUS."

Illustration, Page.

$515 \quad 1258$

SNAPPER ;

"Head $2 \mathrm{x} / 2$; depth $2 \mathrm{x} / 2$.

D. X, 14 ; A. III, 8 ;

Schoolmaster; scales (5) $6-42$ to $45-13$; 36 pores in lateral line. CAJ1.

Body comparatively deep, moderately compressed, the back considerably elevated; profile almost straight from snout to nape, the nuchal region rather convex; snout unusually long and pointed, its outline before eye a little depressed, its length $2 \frac{5}{7}$ in head; eye moderate, $4 \frac{1}{3}$ in head; interorbital space flattish or gently convex, $5 \mathrm{r} / 2$ in head; mouth large, maxillary reaching front of orbit, 23 in head; upper jaw with a narrow band of villiform teeth, outside of which is a single sseries of larger teeth; 4 canines in front of upper jaw; 1 of them on each side very large, almost as long as pupil; lower jaw with a narrow villiform band in front only, and an enlarged series outside, these largest on side of jaw, where some of them are somewhat canine-like; tongue with a single large oval patch of teeth, its length more than twice its width; teeth on vomer forming an arrow-shaped patch with backward prolongation on median line, the length of which is twice the width of the arrow-patch in front. Gill rakers rather short and thick, the longest about $1 / 3$ diameter of eye about !) on lower part of arch. Preopercle with its posterior margin directed somewhat obliquely forward, usually very weakly emarginate, finely serrate above, almost entire at the angle. Scales large, decidedly larger than in $N$. jocu; the series below the 
lateral line almost horizontal, those above in rows parallel with the lateral line, these becoming more or less irregular posteriorly and extending upward and backward below soft dorsal; about 7 rows of scales on the cheeks, 1 row on interopercle, 1 on subopercle, and 7 on opercle; temporal region with a few large scales in about 2 rows; base of soft dorsal and anal scaly; tubes of lateral line each with 4 or 5 branches. Dorsal spines strong, the outline of the fin not greatly convex, the fourth spine longest, $22 / 3$ in head, the tenth spine 4 in head; margin of soft dorsal well rounded, the middle rays longest ; twice length of last, $23 / 4$ in head ; caudal not deeply forked, the upper lobe longest, $1 \mathrm{1} / 2$ length of middle rays, which are 2 in head; margin of anal well rounded, its middle rays twice length of last $2 \frac{2}{7}$ in head, the first ray reaching about to middle of last when the fin is depressed; anal spines strong, the second larger than third, $3 \frac{1}{3}$ in head; ventrals 2 in head; pectorals reaching to front of anal, $1 \frac{1}{3}$ in head. Color of young in life greenish, with about 8 very narrow vertical paler bars on body; scales of lower part of sides with central orange spots, forming faint streaks along the rows of scales; belly pearly; head greenish; a blackish streak from snout through eye to nape; a narrow, sharply-defined blue stripe below eye from snout to angle of opercle; no lateral spot; spinous dorsal edged with orange; ventrals, anal, and caudal pale orange-yellow; pectorals paler. The adult examples differ from the young in the vertical bars being fainter or obsolete, and in the absence, usually, of the blue stripe below eye and the dark stripe on.temporal region; the soft dorsal, anal, and caudal are always yellow, of varying intensity, and the edge of the spinous dorsal is orange, not dusky; the whitish area below the eye, very constant in $N$. jock, is wanting in N. apodus."

This fish is usually called simply "Schoolmaster" by the residents of Biscayne Bay and the Keys. Weight to 3 pounds; average, 1 to $1 \frac{1}{2}$ pounds. Caught: Rod and reel, still fishing, bottom, No. 9-12 line, 2\%, 3\% hooks. Bait: Crawfish best. Edible, A. 


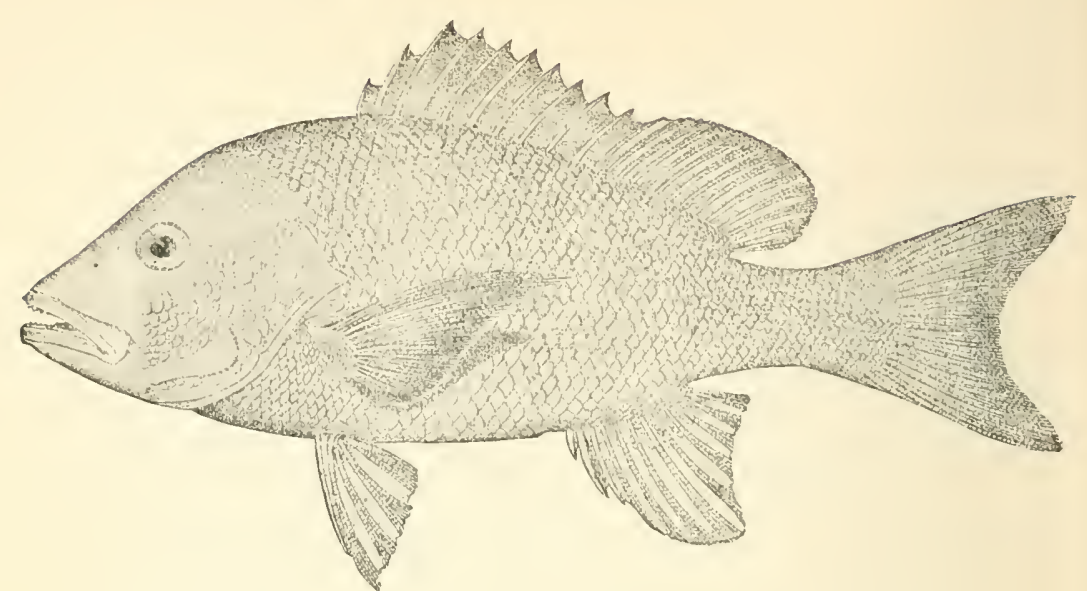

83. "NEOM ENIS AYA."

11lustration. Page.

$516 \quad 1264$

SNAPPER;

RED SNAPPER;

PARgo COLORADO;

Pargo Guachinango;

ACAra Aya.
" Head $2 \frac{3}{5}$; depth $2 \frac{3}{5}$. D. X, 14; A. III,

9 ; scales (7) 8-60-15; pores 46. Body rather deep, moderately compressed, the back well elevated, profile steep, and almost straight from snout to nape. Snout rather pointed, $2 \frac{4}{5}$ in head ; eye moderate, $5 \mathrm{I} / 2$ in head (larger in young). Interorbital space angulate or strongly convex, 5 in head. Occipital keel rather strong; preorbital rather broad, 5 in head; mouth rather large, maxillary reaching front of orbit, $2 \mathrm{I} / 2$ in head; upper jaw with a narrow band of villiform teeth, outside of which is a row of larger but comparatively small teeth; 4 canines in front, 2 (sometimes duplicate) of them larger, their length about $1 / 3$ diameter of eye ; lower jaw with a single row of rather small teeth, usually largest on side of jaw, where some of them are almost canine-like; within these is a very narrow band of villiform teeth in front of jaw only; tongue with a broad oval patch of teeth, scarcely twice as broad as long; in front of this patch is a small irregular patch ; vomer with a broadly arrow-shaped patch, with a rather short backward prolongation on median line, its length about equaling width of patch in front. Gill rakers moderate, their length about $1 / 2$ diameter of eye, 8 on lower arch. Preopercle with its posterior margin about vertical, its emargination deep, its edge rather finely serrate above, coarser at the angle, dentate on the lower border. Scales rather large, the rows horizontal 

below lateral line, the rows above running backward and upward; 6 rows of scales on cheek, 1 on the interopercle, 1 on subopercle, and 7 on opercle; bases of soft dorsal and anal scaly ; pores of lateral line branched; temporal region with a broad band of scales, with a few scattering ones below it; top of head, snout, and jaws naked. Dorsal spines rather strong, the outline of the fin moderately convex, the fourth and fifth spines longest, $2 \frac{t}{5}$ in head, the tenth spine about 4 in head; margin of soft dorsal nearly straight, the fin pointed behind; the middle rays little longer than first ray, $1 \frac{1}{2}$ length of last, 3 in head; caudal lunate, the upper lobe scarcely longer than lower, its length $1 \frac{2}{5}$ times length of middle rays, which are $1 \frac{6}{7}$ in head ; margin of anal strongly angulate, the middle rays reaching nearly to base of caudal, $2 \mathrm{I} / 2$ length of last ray, $1 \frac{1}{5}$ in head ; the first ray reaches abont to middle of last ray when the fin is depressed; anal spines strong, the second scarcely as long as third, 4 in head; ventrals $1 \frac{4}{5}$ in head; pectorals reaching to front of anal fin, $1 \frac{1}{5}$ in head. Color in life, deep rose-red, paler on throat; bluish streaks along rows of scales, above becoming fainter and disappearing with age; fins brick-red; dorsal bordered with orange, with a narrow, blackish edge; caudal narrowly edged with blackish ; eye red; a large blackish blotch above lateral line and below front rays of soft dorsal in young specimens, this spot disappearing with age; axil of pectoral dusky. Length, 2 to $21 / 2$ feet." Weight, 1 pound to 30 pounds.

Caught on reefs ten miles or more from shore. Rod and reel or hand line, heavy tackle. Not exactly a sport fish. Edible, A 1.

I do not know of a well authenticated specimen of this fish having been caught in any of the inside waters, or within five miles of the shore of the East Coast of Florida. The Mutton-fish and the Hog-fish are sometimes supposed to be the Red Snappers, but they are not similar. 


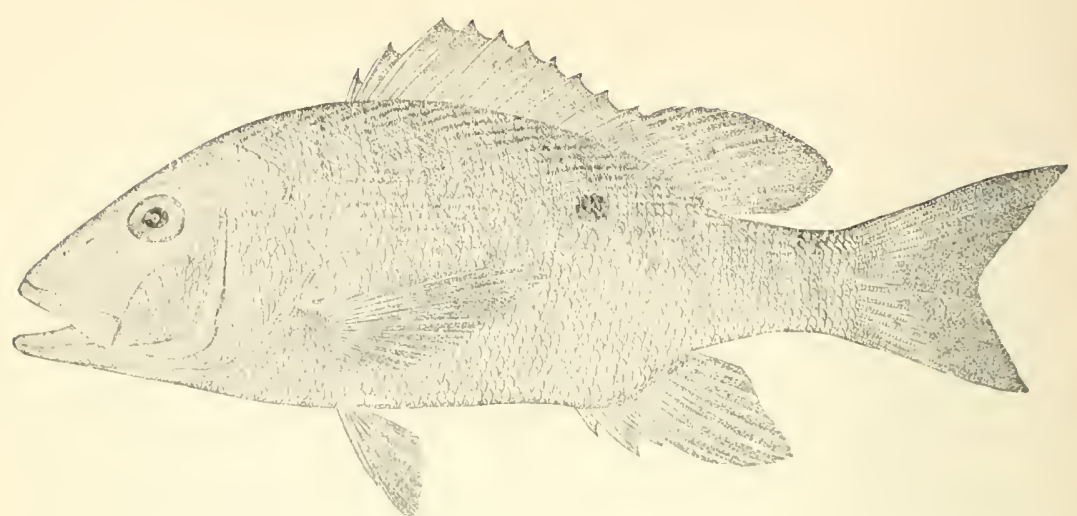

\section{4. “NEOMENIS ANALIS.'}

Illustration. Page. $517 \quad 1265$

SNAPPER ;

MUTTON-FISH PARGO ;

Pargo Criollo.
"Head $22 / 3$; depth $22 / 3$.

D. X, 14;

A. III, 8 ; snout rather long and pointed, $2 \frac{3}{5}$ in head; eye rather small, $5 \frac{2}{5}$ in head in specimens a foot in length ; interorbital space gently convex, $5 \frac{2}{5}$ in head; occipital keel moderate; preorbital very broad, its least width 4 in head; mouth moderate; maxillary scarcely reaching front of orbit, $2 \frac{5}{7}$ in head; upper jaw with a narrow band of villiform teeth, outside of which is a single series of larger but small teeth; 6 rather strong canines in front, 4 of them larger, about equaling in length $1 / 2$ diameter of pupil; lower jaw with a narrow villiform band in front only and a series of larger teeth outside; these unequal, largest on side of jaw, some of them almost canine-like; tongue with a single very small patch of teeth on its middle, this wanting in young examples; teeth on vomer forming a broadly $\wedge$-shaped patch, without backward prolongation on median line. Gill rakers moderate, $\mathrm{x} / 2$ length of diameter of eye, about 8 on lower arch. with no rudiments before them. Preopercle with its posterior margin almost straight, slanting gently downward and forward, the notch broad and very shallow; edge of preopercle rather coarsely serrate, most so at the angle; scales small, the rows almost horizontal below the lateral line, running backward and upward above; tubes of lateral line branched; about 7 rows of scales on the cheeks; 1 row on interop- 
ercle, 1 on subopercle, and about 9 on opercle; temporal region with about 8 rows of scales, which become smaller posteriorly; bases of soft dorsal and anal scaly. Dorsal spines weak and slender, the outline of the fin not greatly curved, the fourth spine longest, $22 / 3$ in head, the tenth spine $31 / 3$ in head; margin of soft dorsal angulate, the ninth ray longest, twice last and $1 \frac{1}{2}$ times first ray, 2 in head; caudal well forked, upper lobe the longer, $1 \frac{3}{5}$ length of middle rays, which are about $2 \frac{1}{6}$ in head; anal regular, similar to soft dorsal, the middle rays more elevated than in any other species, longest $2 \mathrm{x} / 4$ length of last, 2 in head; first ray nearly reaching tip of last when the fin is depressed; the second and third anal spines rather strong, of equal length, $33 / 4$ in head; ventrals $1 \frac{3}{5}$ in head; pectorals reaching slightly past origin of anal, $1 \frac{3^{*}}{10}$ in head. Color in life, dark olivegreen above, many of the scales with pale-blue spots, these forming irregular oblique streaks upward and backward; similar stripes more regular and numerous on caudal peduncle and above anal. In old fishes these blue spots and streaks disappear; belly white, strongly tinged with brick-red; about 6 narrow, dusky, vertical bars, a little broader than the interspaces and not well defined, between gill opening and anal; head bronze-olive, darker above; a broad, undulating, pearly streak from snout below eye to upper edge of gill opening; a narrow blue streak from eye to nostrils; iris fiery red; pectorals, caudal, anal and ventrals brick-red, the caudal narrowly margined with black and little bronzed above; dorsal reddish along the rays and tips of membranes, otherwise yellowish; distinct lateral blotch just above the lateral line and below the first soft ray on dorsal, about as large as pupil, smaller than in other species similarly marked, and seldom disappearing with age; axil and bar across base of pectoral above, pale or dusky olive. In spirits the markings become fainter, the lateral blotch and the bluish streaks on head usually persisting." Weight to 12 pounds; average, 5 pounds.

Usually called simply "Mutton-fish." Caught in the channels and cuts of Biscayne Bay, and on the " patches," to Key West, with rod and reel, line 18-21, hooks 5-6\%. Same bait as used there for other fish. Edible, B. 
85. “NEOM ENIS SYNAGRIS." No illustration. 1270

SNAPPER ;

LANE SNAPPER;

BIAJAIBA ;

Red-TAIL SNapper.

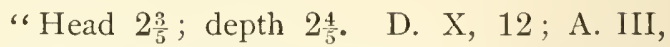
8 ; scales (7) 8-60-15; 50 pores. Body oblong, compressed, the back moderately elevated, profile almost straight from snout to nape; snout rather pointed, 3 in head; eye moderate, 5 in head; interorbital space gently convex, $53 / 4$ in head; occipital keel little prominent; preorbital rather broad, $43 / 4$ in head; maxillary reaching front of orbit, 23/4 in head; upper jaw with a narrow band of villiform teeth, outside of which is a single series of enlarged teeth; 4 rather small canines in front, 2 of them larger; lower jaw with villiform band in front only, the single row of larger teeth nearly equal in size, none of them canines; tongue with a single oval patch, its length more than twice its width; vomer with a $\wedge$ or $\mathbb{\wedge}$-shaped patch of teeth, without backward prolongation on median line, or with only a very slight one. Gill rakers rather long, their length slightly more than $1 / 2$ diameter of eye, about $5+9$, and no rudiments before them. Preopercle with its posterior margin slanting downward and forward, the emargination broad and moderately deep; preopercle rather finely serrate above, with coarser teeth at the angle. Scales rather small, the rows almost horizontal below the lateral line, above somewhat undulate, running upward and backward; tubes of lateral line simple ; 6 rows of scales on the cheek, 1 row on the interopercle, 1 on the subopercle, and 6 on the opercle; temporal region with a broad band of scales, arranged in several series; base of soft dorsal and anal scaly; dorsal spines rather weak and slender, the outline of the fin gently convex, the fourth spine longest, $2 \frac{2}{3}$ in head, the tenth spine $3 \frac{3}{5}$ in head; soft dorsal short, its margin somewhat angulated, the eighth ray longest, twice the length of last ray and $1 \frac{1}{2}$ first, $2 \frac{2}{5}$ in head; caudal moderately forked, the upper lobe the longer, $1 \mathrm{r} / 2$ length of middle rays, which are 2 in head; anal rather high, rounded in outline, its middle rays longest, $12 / 3$ length of last ray, $2 \frac{4}{7}$ in head, first ray reaching middle of last ray when the fin is depressed, second anal spine stronger than third and of equal length, $32 / 3$ in head; pectorals reaching front of anal, $1 \frac{1}{4}$ in head. Color in life, rosecolored, silvery tinged below, slightly olivaceous but not dark above; a large, round, maroon blotch, larger than eye, just above lateral line and below front of soft dorsal, always present; series of stripes of 



$$
\gamma
$$


deep golden yellow along sides; 3 on head, the upper from snout through eye; about 10 on body, the lower nearly straight and horizontal, the upper undulating and irregular, extending upward and backward; belly white, its sides largely yellowish; lips red; maxillary partly yellow; tongue yellowish; iris fiery red; caudal deep blood-red; spinous dorsal nearly transparent, with a marginal and basal band of golden; soft dorsal light red, edged with golden ; ventrals and anal golden; pectorals pinkish. Young quite green above. Similarly striped Cuban specimens are generally duller, with the yellow stripes decidedly coppery. In spirits the bright colors fade, only the lateral blotch and the streaks on the head being persistent."

Resembles the gray, but brighter colors. Weight, $1 / 2$ to 3 pounds. Same tackle and bait as Schoolmaster. Edible, A.

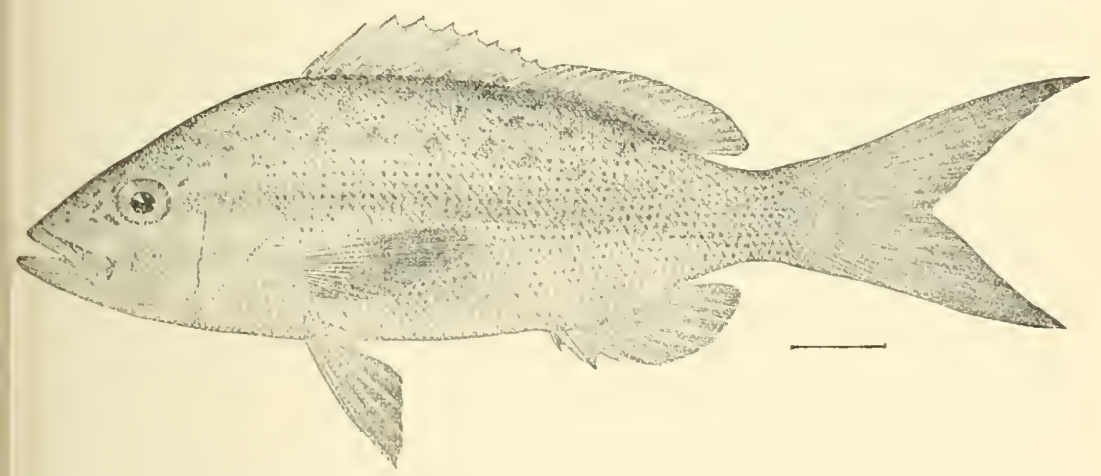

86. "OCYURUS CHRYSURUS."

Illustration, Page. $520 \quad 1275$

Yellow-TAIL; "Head 3; depth 3. D. X, 13; A. III, 9 ; scales Rabirubia. 7-65-16; 51 pores. Body elliptical, comparatively elongate, the back little elevated, the profile straight from the tip of the snout to the nape, thence rather strongly arched; caudal peduncle long and slender; snout pointed, of moderate length, 3 in head; eye small, 5 in head; interorbital space very convex, with a sharp median keel, 4 in head; preorbital narrow, its least width $62 / 3$ in head. Nouth small, oblique, the lower jaw projecting; maxillary reaching very slightly beyond front of orbit, $2 \frac{5}{7}$ in head; upper jaw with a narrow band of villiform teeth, outside of which is a single 
series of larger teeth, 5 or 6 of those in front being somewhat canine-like, but small; lower jaw with a single series of moderately strong teeth, none of them large enough to be called canines; tongue with a large, oval patch of teeth, in front of which is a smaller but similar patch ; teeth on vomer forming a broadly arrow-shaped patch, with a backward prolongation on the median line, which is nearly twice the width of the patch; a narrow band of pterygoid teeth behind the patch on the vomer, this not evident in young examples. Gill rakers rather long and slender, the longest about $1 / 2$ diameter of eye, about $8+21$, none of them rudimentary. Preopercle with its posterior margin almost vertical, with a slight, but distinct emargination above the angle; serrations of preopercle very feeble, the teeth at the angle scarcely enlarged; nostrils well separated; the posterior slit-like; scales small, those above lateral line arranged in very oblique series, those below in rows nearly horizontal; cheeks with 5 or 6 rows of scales, about two rows on interopercle; temporal region with 2 or 3 series of large scales, before and behind which are many small scales; top of head, snout, and jaws naked; bases of soft dorsal and anal scaly. Dorsal spines rather long and slender, the fin not deeply emarginate, fifth spine longest, $2 \frac{2}{5}$ in head; tenth spine $33 / 4$; soft dorsal and anal similar, their margins nearly straight, the last rays slightly shortened, median rays about 3 in head; caudal fin long, very deeply forked, the upper lobe longest, 3 times as long as middle rays, which are $2 \mathrm{I} / 2$ in head; pectorals long and slender, reaching vent, $1 \frac{\mathrm{r} / \mathrm{s}}{\mathrm{in}}$ head; ventrals $1 \frac{4}{7}$ in head; anal spines rather weak, the third $1 / 3$ longer than second, 4 in head. Color in life, olivaceous above, rather pale, and somewhat violet tinged; a number of large, irregular deep yellow blotches on sides of back; a deep yellow stripe from tip of snout straight through eye to caudal peduncle, there broadening and including all of tail above lateral line and behind dorsal fin; above this is a pearly-purplish area; below it a flesh-colored or rosy area or band, 2 scales broad, then a succession of about 16 narrow streaks alternating flesh-color and yellow, growing fainter progressively below; the yellow on the edges of the scales, the reddish on their middles; iris fiery red; lower parts of head flesh-color with some yellow spots; maxillary mostly yellow ; caudal deep yellow, its edges reddish; dorsal chicfly yellow; anal faintly yellow; ventrals and pectorals translucent. In spirits, all the markings fade, leaving the fins yellowish, the upper parts grayish, the 
lower rosy-silvery. Length, 2 feet." Weight to 3 or 4 pounds; average, $3 / 4$ pound.

Caught: Light tackle, No. 1 and 2, or ${ }^{*} 1 \%$ hooks, 6-9 line. Still bottom fishing among the Keys. Crawfish and Conch bait; around Key West, Pilchard and Sardine bait. Edible, A 1. At Key West considered the best table fish.

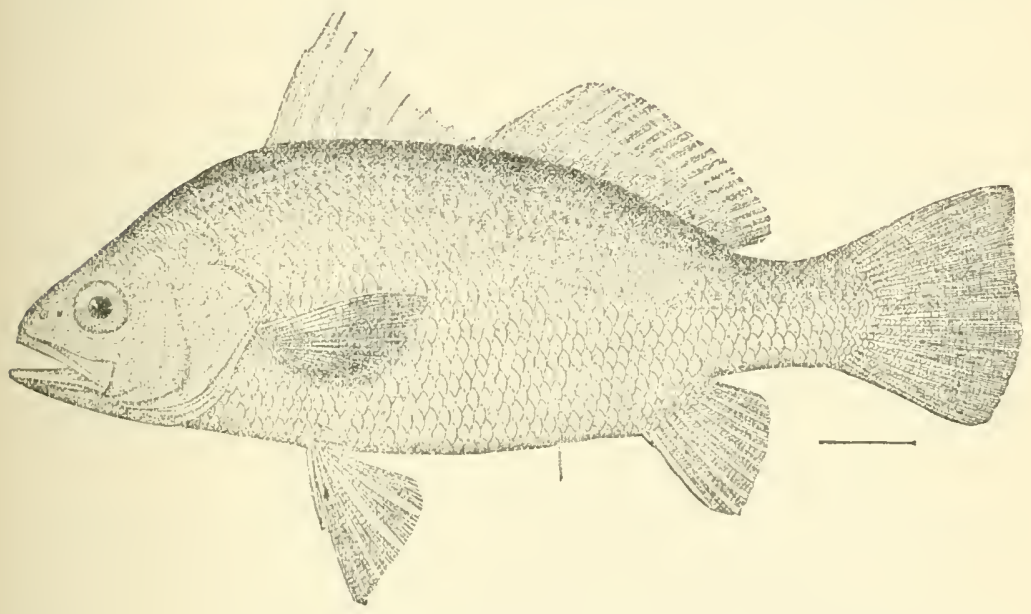

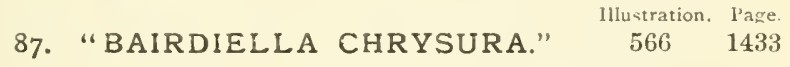

Yellow-TAlL; This fish is caught off Sebastian Bridge St. Mademolselle; Augustine, Mayport, and at Ponce Park, at times in White Perch. large numbers. It does not resemble the Yellowtail Rabirubia, except in having a yellow tail and some yellow on the body. Has a square tail. Weight, 1/8 to $1 / 4$ pound. No. 1 hook, No. 6 or silk line. Bait: Cut fish or Crab. Edible, B. 


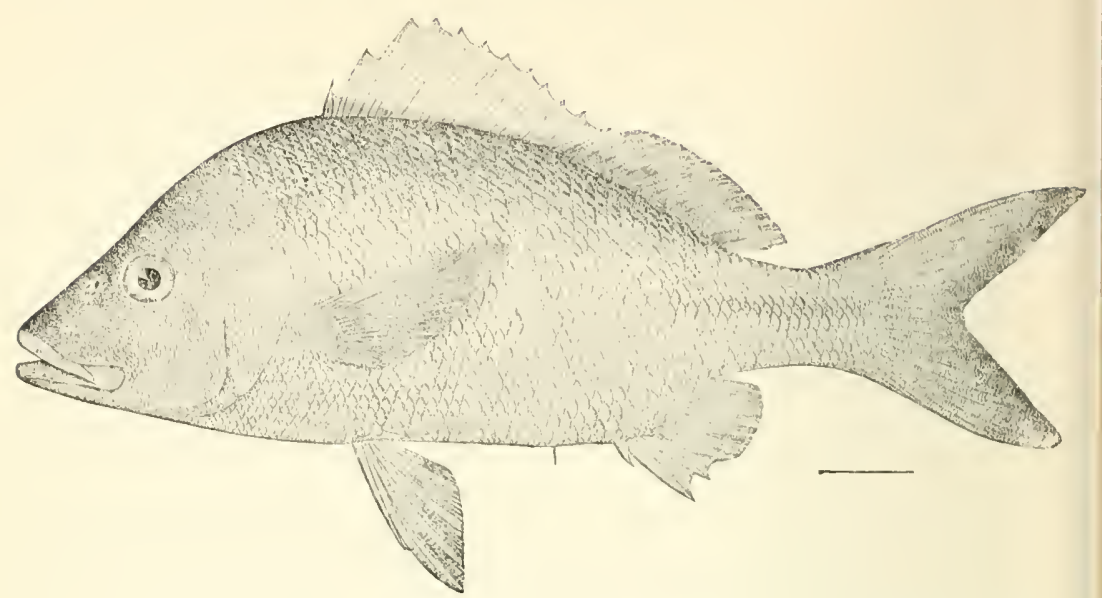

88. “HÆMULON ALBUM." $\quad \begin{array}{cc}\text { Illustration. Page. } \\ 528 & 1295\end{array}$

GRUNT ;

MARGATE-FISH ; JALLAO ;

MARGARET GRUN'T.

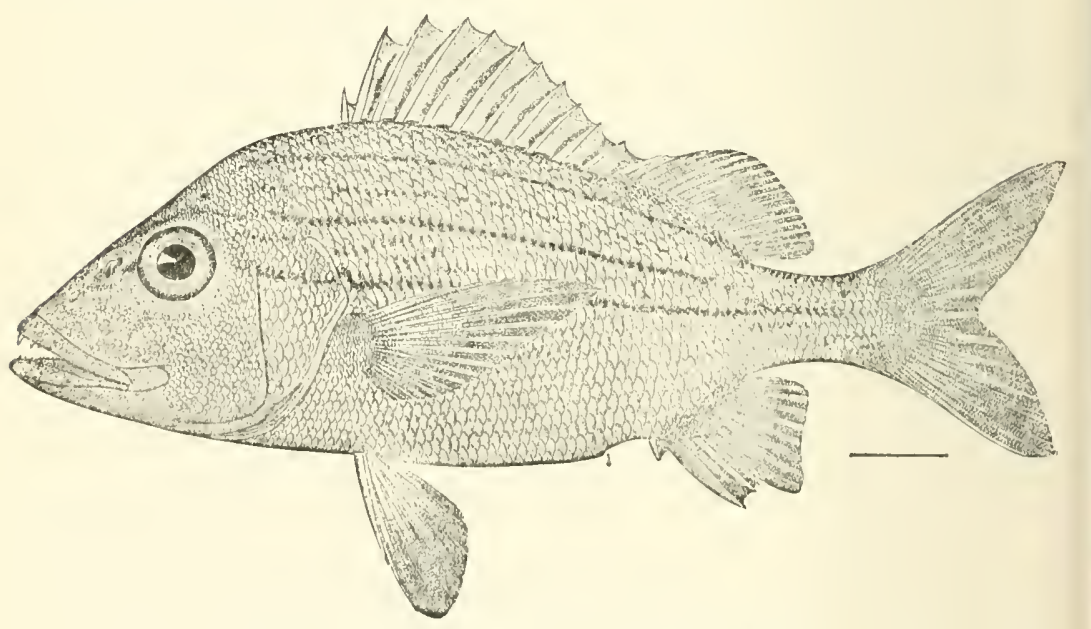

89. "HAMULON MACROSTOMUM." 5291296

Gray Grunt ; STRI'El GRUNT. 8 ; scales $7-51-1: 3$ (9 above in an oblique series). Body oblong, moderately compressed, the anterior profile almost 
straight; snout rather long and pointed, its length $2 \frac{1}{3}$ in head; eye large, $3 \frac{4}{5}$ in head; mouth rather large, the maxillary reaching front of pupil, $2 \frac{1}{6}$ in head; least width of preorbital about 5 in head. Teeth moderate, the outer row in the upper jaw and the posterior teeth in both jaws considerably enlarged. Preopercle moderately serrate. Gill rakers small. Scales moderate, those above lateral line not enlarged; those below very slightly enlarged; scales above arranged in very oblique series, the series below oblique anteriorly, becoming horizontal posteriorly. Dorsal spines strong, the longest $2 \frac{1}{4}$ in head; soft dorsal rather high ; caudal lobes subequal, $12 / 3$ in head; anal spines strong, the second longest and strongest, $22 / 3$ in head, its tip reaching, when depressed, beyond tip of last ray; soft anal very high, its free margin concave, its longest ray $2 \frac{3}{5}$ in head, reaching much beyond tip of last ray; pectorals $1 \frac{3}{5}$ in head; ventrals $12 / 3$. Color, in spirits, pearly gray, with conspicuous narrow dark streaks, arranged essentially as in the young of all the other species of Hamulon, but in this species persistent through life; a median streak from tip of snout to dorsal, 1 from snout above eye, along sides of back to last ray of soft dorsal, 2 below this from eye above to last ray of soft dorsal, the upper one more or less interrupted behind; a fourth streak from eye nearly straight to base of caudal; traces below this of a fifth streak; a short streak from eye to gill opening, between the third and fourth streaks; this is continued on the body in a series of irregular marks and dots; a large black blotch on opercle under angle of preopercle; fins all dusty olive, the pectorals palest ; ventrals darkest."

BLACK GRUNT;

$\begin{array}{ll}\text { 90. "HAMULON BONARIENSE." Illustration. Pake. } & 1297\end{array}$

RONCO PRieto.

GRUnT ;

SAILOR'S CHOICE;

Ronco Blanco;

Ronco Prieto;

Bastard Margaret. 


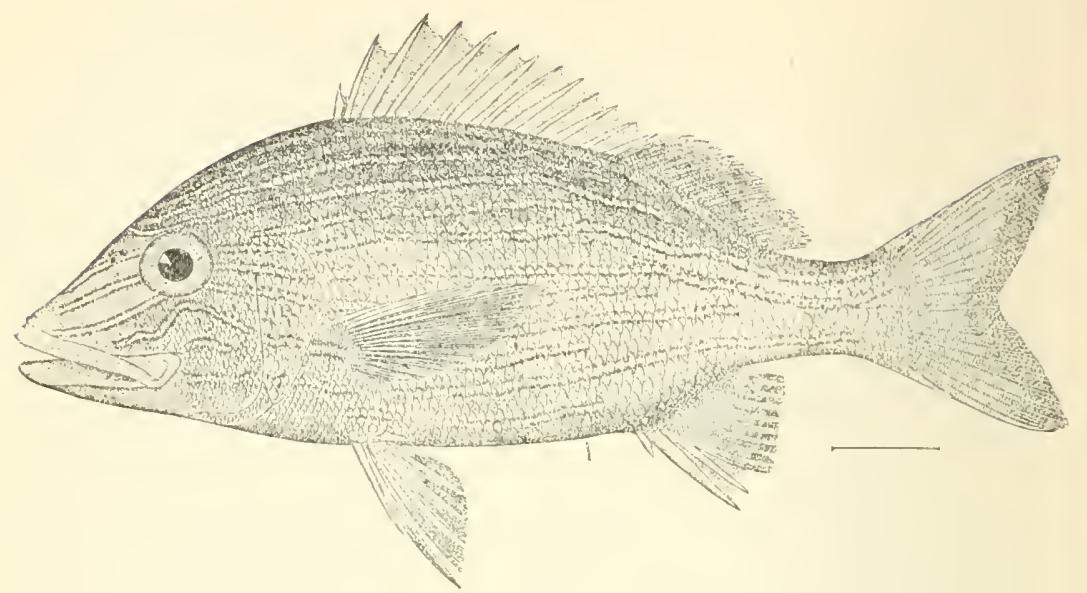

Illustration. Page.

92. "HAEMLON SCIURUS." $531 \quad 1303$

Yellow Grunt;

RONCO AMARILlo; BoAr Grunt.
"Head $23 / 4$; depth $2 \frac{3}{5}$.

D. XII, 16 ; A. III,

8 ; scales 7-53-14. Eye moderate, 4 in head; interorbital space convex, $3 \frac{5}{6}$ in head; preorbital moderate, its least breadth $62 / 3$ in head; preopercle finely serrate; gill rakers small, about $13+17$. Body oblong; the back not specially elevated; the profile nearly straight or slightly concave from tip of snout to before eye, thence a little gibbous to base of dorsal ; snout moderately acute, $2 \mathrm{I} / 2$ in head. Mouth large, the gape curved, the maxillary reaching a little past front of pupil, its length 2 in head; lower jaw slightly included; teeth strong; upper jaw in front with about 3 strong canines on each side, these stronger than any of the other teeth; front teeth of lower jaw rather strong, as also the antrorse teeth of the back part of both jaws. Scales moderate, those above lateral line not at all enlarged, arranged in oblicue series, those below in nearly horizontal ones. Dorsal spines rather slender, the fourth longest, $2 \frac{2}{5}$ in head; longest soft rays 4 ; upper caudal lobe longer than lower, $1 \frac{1}{3}$ in head; longest anal rays $2 \frac{1}{4}$ in head, their tips, when depressed, extending beyond the tips of the last rays; second anal spine stronger and longer than third, $2 \frac{1}{3}$ in head, its tip, when depressed, reaching past the middle of the last ray ; ventrals $12 / 3$ in head; pectorals $1 \frac{2}{5}$. Color, in life, deep brassy yellow, scarcely paler below or darker above; head and body with about 12 
conspicuous slightly wavy, longitudinal stripes of sky-blue, deepest on the snout, each with a very narrow edge of dusky olive; these stripes on the head curving upward below eye, the first stripe below eye forking near posterior margin of preopercle and inclosing an oblong area of the ground color; iris gilt, a dark spot under the angle of the preopercle; spinous dorsal edged and shaded with yellowish, its membrane mostly bluish; soft dorsal yellowish, caudal yellowish, broadly dusky at base, the degree of this duskiness being variable; mouth deep orange within ; pectorals pale yellowish; anal and ventrals deeper yellowish; the young have more yellow on fins and less on body, with traces of a dark caudal spot. The coloration becomes fainter in spirits, the blue lines becoming gray."

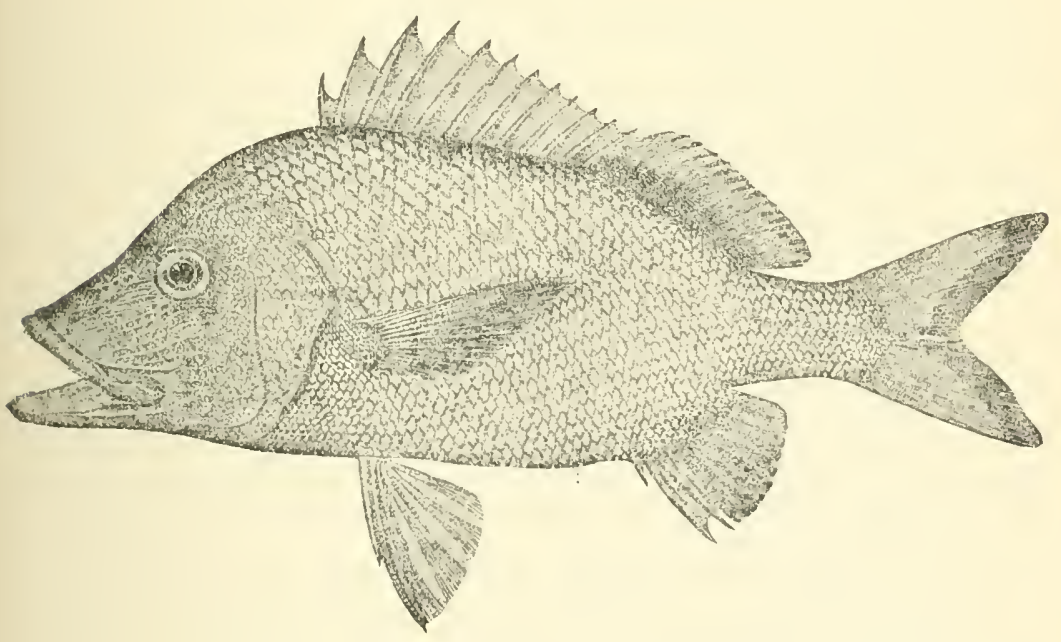

\section{3. "HEIMULON PLUMIERI." $532 \quad 1304$}

Common Grunt; Head $2 \frac{2}{3}$; depth $2 \frac{2}{3}$; eye small, 5 to 6 in Ronco Ronco; head. D. XII, 16 ; A. III, 8 ; scales 5-50-17. Body Ronco Arara. moderately elongate, the back elevated and somewhat compressed; head long, the snout sharp and projecting, its length $2 \frac{1}{5}$ in head; anterior profile more or less S-shaped, nearly straight from tip of snout to before eye, there concave, and thence gibbous to the front of dorsal, old specimens having the nape more gibbous than young ones. Mouth very large, the gape curved; max- 
illary reaching to a little beyond front of eye, its length $17 / 8$ in head ; lower jaw slightly included. Teeth strong, in rather broad bands, those of the outer series enlarged ; antrorse teeth of posterior part of both jaws strong. Interorbital space convex, 4 in head; preorbital rather deep, its least breadth 6 in head; preopercle finely serrate. Gill rakers small, about $12+15$. Scales rather large, those above lateral line anteriorly very much enlarged, arranged in irregular and very oblique series, those below also oblique. Dorsal spines stout, the fourth longest, $2 \frac{2}{5}$ in head; longest soft rays $33 / 4$ in head; caudal lobes subequal, 2 in head; longest anal rays $2 \frac{4}{5}$ in head, their tips, when depressed, about reaching tips of the last rays; second anal spine longer and stronger than third, $2 \mathrm{x} / 2$ in head, its tip, when depressed, at least reaching middle of last ray ; ventrals $13 / 4$ in head; pectorals $1 \frac{1}{2}$. Color, in life, bluish gray, the base of the scales above bright bronze, tinged with olive; bases of scales below lateral line also bronze, this color forming very oblique stripes, running upward and backward; anterior region above lateral line with 3 or 4 sky-blue stripes, ill-defined, apparently continuations of stripes of head; head golden-bronze with many narrow stripes of deep clear blue, as if painted on, these nearly horizontal, except before eye, where a few curved ones cross the forehead; also these lines curve slightly upward below eye. Lips dusky; inside of mouth deep orange, bordered anteriorly on the jaws by yellow; a greenish bar on opercle partly concealed by the preopercle; dorsals grayish, with a narrow yellow edge on spinous portion; caudal plain gray; anal gray, tinged with yellow; ventrals gray, with a clear blue luster which disappears after death; pectorals gray, a dusky bar at base. There is considerable variation in the depth of color in this species. The young is similar to the adult in color, but has traces of two lateral bands and a dusky caudal spot. The color in spirits differs only in the blue becoming dusky."

94. “HÆMULON FLAVOLINEATUM." No illustration. 1306 French Grunt;

Oren-mouthed Grunt ;

Ronco Conuenado. 


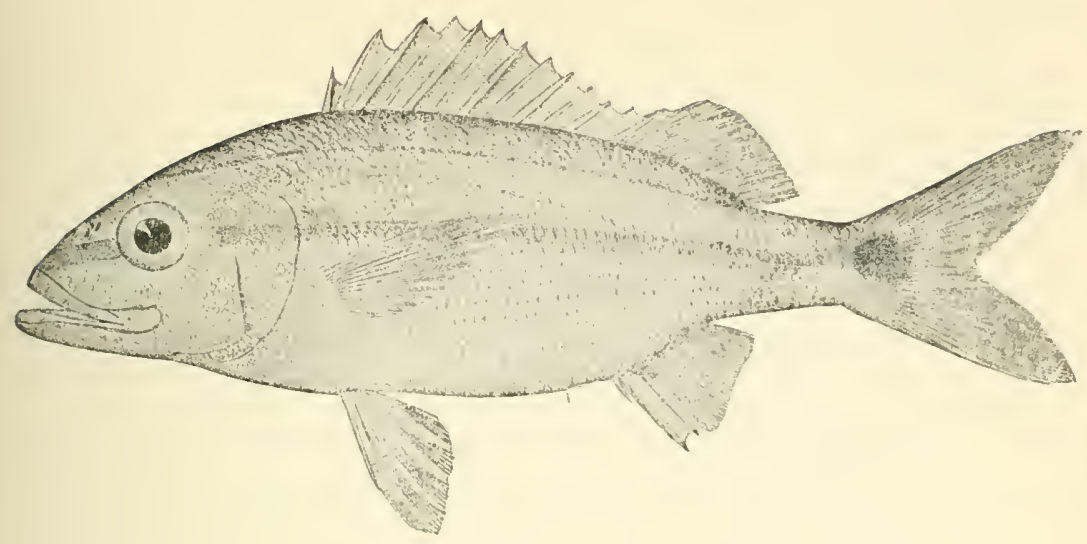

95. “BATHYSTOMA RIMATOR.” $\begin{array}{ccc}\text { Illustration. } & \text { Page. } \\ 534 & 1308\end{array}$

ReD-mouth GRUnt; "Head $2 \frac{5}{7}$; depth $2 \frac{5}{6}$; eye rather large, Tом TATE; $\quad 4 \frac{1}{4}$ in head; interorbital space convex, $33 / 4$ in CÆSAR. head; preorbital low, its least breadth 8 in head. Gill rakers small, about $11+16$. D. XIII, 15 ; A. III, 8 ; scales 8-51-13. Body rather elongate but not fusiform, the back somewhat elevated, the profile straight or slightly convex from tip of snout to behind eye, where it becomes gradually more convex ; snout short, rather pointed, about 3 in head. Mouth large, the maxillary reaching middle of pupil, its length 2 in head. Teeth not very strong, those of the outer series a little enlarged, the antrores posterior teeth rather large. Scales rather small, those above lateral line regularly arranged in oblique series, the series below nearly horizontal. Dorsal spines slender and high, the fourth 2 to $2 \mathrm{I} / 3$ in head; upper caudal lobe $1 \mathrm{r} / 2$ in head; longest anal rays 3 in head, their tips not reaching tips of last rays when depressed; second anal spine but little longer than third, $2 \frac{5}{6}$ in head, the two more nearly equal than usual in this genus, their tips, when depressed, reaching middle of last ray ; ventrals $13 / 4$ in head; pectorals $11 / 2$, their tips not reaching past tips of ventrals. Frontal foramina as in other species of the subgenus Bathystoma, long divided slits in front of the supraoccipital crest. Color, in life, silvery white, slightly bluish above, with iridescent reflections; edges of scales of body light yellow, these forming continuous light yellow lines, those below lateral line horizontal, those above very oblique; 
besides these, a narrow continuous streak of light yellow above lateral line, from head to end of soft dorsal, and another from eye to middle of caudal; head silvery-yellowish above; inside of mouth red; no black under preopercle; traces of black blotch at base of caudal; fins colorless, the lower slightly yellowish. Young are light olivaceous, grayish-silvery below; a dark bronze band, narrower than pupil, darkest in the younger specimen from snout through eye straight to base of caudal; above this, 2 or 3 dark streaks, the middle one most distinct, from eye to above gill opening; another, beginning on top of snout on each side, passing above eye, and extending parallel with the first-mentioned stripe straight to last ray of dorsal, where it meets its fellow of the opposite side; a dark streak from tip of snout along median line to front of dorsal; a large rounded black blotch at base of caudal, somewhat obscure dusky shading below soft dorsal and at base of pectoral ; fins all plain, upper slightly dusky; anal nearly white; pectorals, caudal, and ventrals light yellow ; lining of opercle plain orange; inside of mouth scarlet. In the large specimen (51/2 inches long) the dark stripes are fainter, paler, and more yellowish, several fainter bands occur between the broader ones, and faint oblique streaks of light bronze follow the rows of scales, those above lateral line oblique. In spirits the adult is plain silvery."

Here I will tell a "Grunt" story, in support of my statement that the fish is the most important one in Key West; which story is probably a "chestnut" in Florida, but was new to me a year or two ago, and will probably be the same to some of my readers.

A New York family were spending some time in Key West, and while there made the acquaintance of a family in which there was a young lady with whom they became intimate. They invited her to visit them if she should go to New York. The next summer she went there with her father, who was on business, and accepted her friends invitation to visit them.

After her visit she went to her father's hotel intending to make quite a stay. But in a day or two called on her friends to bid them good bye.

They were surprised, and asked what the reason was for changing her mind, and returning to Key West so soon. She rather hesitatingly said, that she did not like the food at the hotel, and that the fact really was that she wanted to get back to Key West and to her "Grits and Grunts." 
Since hearing that story, Capt. John and I when asked "What luck?" very frequently reply, "Oh! plenty of Grits and Grunts." Under my description of Mullets, I have given the status of "Grits" in Florida.

I really believe that the "Conchs" of the Keys, and a great majority of the residents of Key West, prefer Grunts to any other fish. At any rate very many boat loads are sold there every day in the year.

\section{6. “BATHYSTOMA AUROLINEATUM." $535 \quad 1310$} JENIGUANO.

97. "BATHYSTOMA STRIATUM." No illustration. 1310 White Grunt. Under family, "Grunters," J. \& E. have 55 species, and among them the Pig Fish, Pork Fish, Sailor's Choice, and Hog Fish; but I put under the heading "Grunts" only those usually called "Grunts," except the "Margate-fish." Weight to 2 pounds; average about $1 / 2$ to $3 / 4$ pound.

Caught: Rod and reel or hand line, No. 9-12 line, $2 \%$ hook, still fishing, bottom, channels, "patches," under mangroves, etc. The Grunts are the most important food fishes at Key West. Bait: Crawfish, Conch, Crabs, cut fish. Edible, A. 


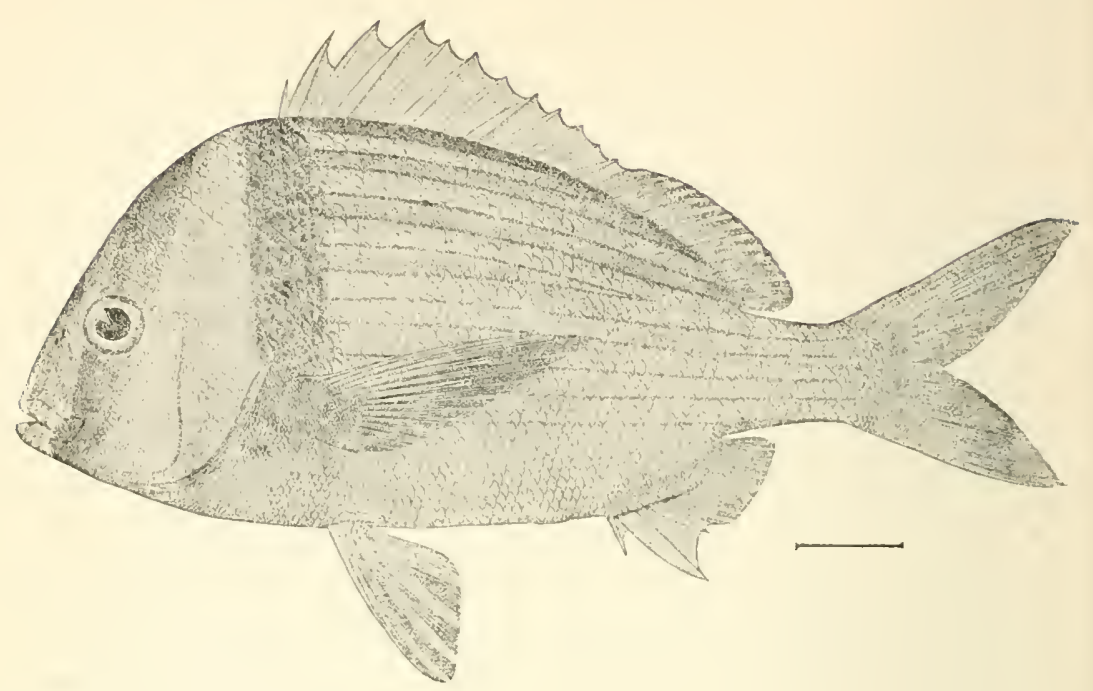

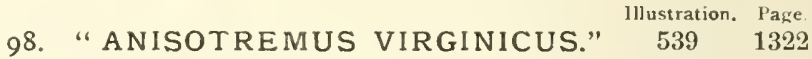 \\ Porkfish; “ "Head $31 / 8$; depth $2 \frac{1}{10}$. D. XII, 17 ; A. III, 10} Catalineta. or 11 ; scales $11-56-17$; eye $4 \frac{1}{8}$; snout $2 \frac{1}{2}$ to 3 ; preorbital 4; maxillary $31 / 2$; second anal spine $2 \frac{1}{10}$; third dorsal spine $2 \frac{1}{10}$; pectoral $7 / 8$; gill rakers $7+16$. Body ovate, the back very much elevated, the anterior profile steep, slightly convex along snout and over eye, very much arched at nape; mouth small, the maxillary extending to anterior nostril ; jaws subequal; outer row of teeth enlarged; about 6 gill rakers besides rudiments, below angle; dorsal fin low, emarginate, spines slender, the highest about equal in length to second anal spine, which is less than $1 / 2$ head; caudal forked. Oblique bar from nape through eye, and vertical bar downward from dorsal, jet black; space before anterior bar deep yellow ; interspace between bars pearly gray, with yellow spots, the spots confluent above into a yellow area; ground color of body plain pearly gray, with about 7 deep yellow longitudinal stripes; the pearly interspace not edged with darker and not distinctly blue; all the fins deep yellow; iris gilt gray. A very young specimen showed the following coloration in life: pale anterior region, from lower jaw and temporal region to spinous dorsal bright yellow; spinous dorsal ventrals, and front of anal deep golden; other fins pale; a large round 

jet black spot at base of caudal; a dark band from front of spinous dorsal downward, and 2 black stripes along sides, one from nape to last ray of dorsal and one from the eye nearly to the caudal spot." Weight to 2 pounds; average, $3 / 4$ pound.

One of the most beautiful fishes of the Keys. Caught same as other medium and small bottom fishes among the Keys. Edible, A 1.

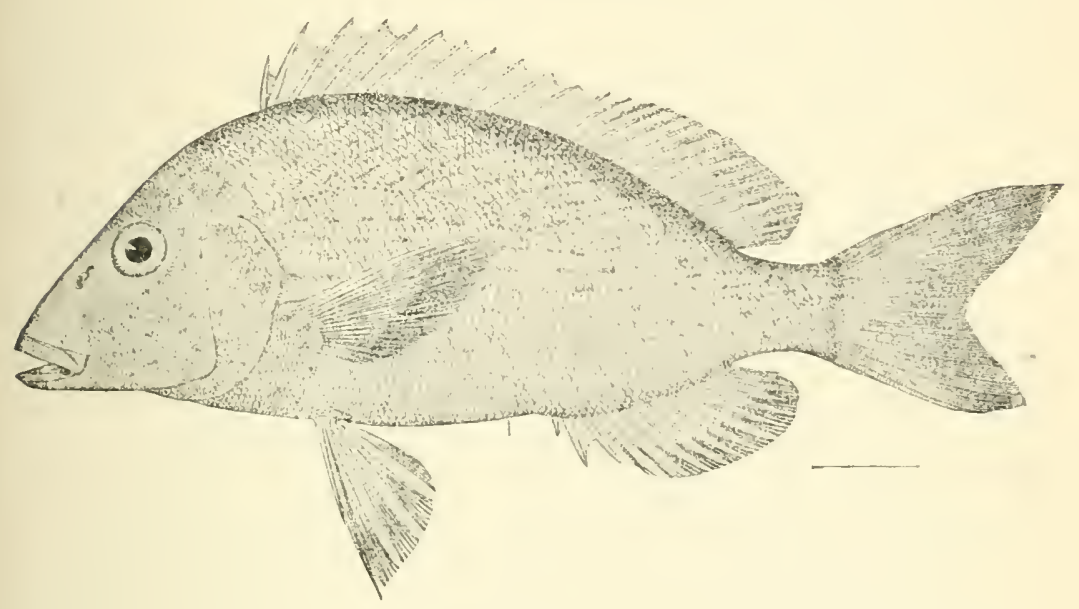

99. " "ORTHOPRISTIS CHRYSOPTERUS." 541 Illustration. Page.

Pigfish ;

SAILOR'S ChOICE ;

HoGFISH.
"Head $31 / 8$; depth $23 / 4$. D. XII or XIII, 16 ;

A. III, 12 or 13 ; scales $10-60-19$; maxillary $3 \mathrm{x} / 3$; eye 5 in head ; preorbital $3 \frac{3}{5}$; pectoral $1 \frac{1}{4}$; snout $2 \frac{2}{5}$; highest dorsal spine $27 / 8$; second anal spine $51 / 2$; longest anal ray 3 ; base soft, dorsal in spinous $1 \mathrm{1} / 4$. Body ovate-elliptical, somewhat elevated at shoulders, considerably compressed. Snout long and sharp, jaws equal, each with a narrow band of slender teeth, the outer above a little larger; maxillary not reaching to eye ; preopercle very slightly serrate above, the serrate blunt, obsolete below; gill rakers short and slender, $7+12$. The crown, cheeks, and pieces of the gill cover covered with small scales; snout in advance of the nostrils, suborbitals, and lower jaw naked; dorsal and anal spines inclosed in a deep scaly sheath, the soft rays naked. Outline of dorsal very slightly notched; anal rather high, second anal spine shorter than third; 
pectoral shortish, reaching past tips of ventrals; caudal well forked, the upper lobe the longer. Pyloric cæca 6 . Color, in life, light blue above, shading gradually into silvery below; preorbital and snout of a clear"sky-blue; a dash of blue on each side of upper lip; each scale on body with a blue center, the edge with a bronze spot, these forming on back and sides very distinct orange-brown stripes along the rows of scales, those above the lateral line extending obliquely upward and backward, those below being nearly horizontal; snout with bronze spots; 1 or 2 cross lines connecting front of orbits; 2 or 3 oblique lines on preorbital, besides numerous bronze spots larger than those on the body; preorbital also with dusky shades, one of which extends on upper lip; cheeks and opercles with distinct bronze spots, larger than those on body ; inside of mouth pale ; inside of gill cavity tinged with golden; dorsal translucent, with about 3 bronze longitudinal shades, composed of spots, those of soft dorsal most distinctly spot-like; edge of fin dusky ; caudal plain, yellowish at base, dusky toward the tip; anal whitish, its edge dusky, its base shaded with bronze; pectorals and ventrals yellowish, the latter darker at tip. Fresh specimens show no trace of vertical bands. In examples preserved in alcohol the yellowish and blue markings gradually disappear and dark cross shades become apparent. A specimen 5 years in alcohol shows the following coloration: Silver-gray, with faint streaks along the rows of scales; a distinct narrow dusky band from front of spinous dorsal through base of pectorals; behind this 7 or 8 cloudy, obscure bands, alternately broad and narrow; a horizontal dusky shade behind eye; spinous dorsal with a faint medium pale shade: soft dorsal with 3 rows of faint spots; other fins nearly plain. Length, 12 to 15 inches." Weight to 2 pounds ; average, $3 / 4$ pound.

Caught: Same as Pinfish. Edible, A.

\section{1llustration. Page. $544 \quad 1346$}

PokgY : $\because$ Head $: 31 / 2$; depth $2 \frac{1}{10}$.

D. XII, $12 ; \mathrm{A}$. III, Common Scup; 11 ; scales $8-50-16$; snout short, $21 / 2$ in head; eye SCUPPAUG.

small, narrower than preorbital, 4 to $41 / 4$ in head: fourth dorsal spine 2, third anal spine the longest, 3. Body ovateelliptical, the depth about the same from the first dorsal spine to the eleventh; anterior profile steep, nape convex, a strong depression above and in front of eye, straightish over snout; pectoral less than 
head, about $31 / 2$ in body, extending to first anal spine ; a scaly sheath very conspicuous at base of soft dorsal and anal fins; temporal crest obsolete; supraoccipital crest continuous with the frontal bones; incisor teeth very narrow, almost conical in appearance; molars in 2 rows above ; gill rakers small, about $6+10$; top of head, snout, orbitals, and chin naked ; scales on cheek extending from upper margin of eye, the anterior row composed of from 15 to 20 scales ; caudal fin forked, the middle ray about $2 \frac{1}{3}$ in longest ray. Color brownish, somewhat silvery below, everywhere with bright reflections, but without distinct markings in the adult ; soft parts of vertical fins mottled with dark in adult; young faintly barred; axil dusky. Length about a foot."
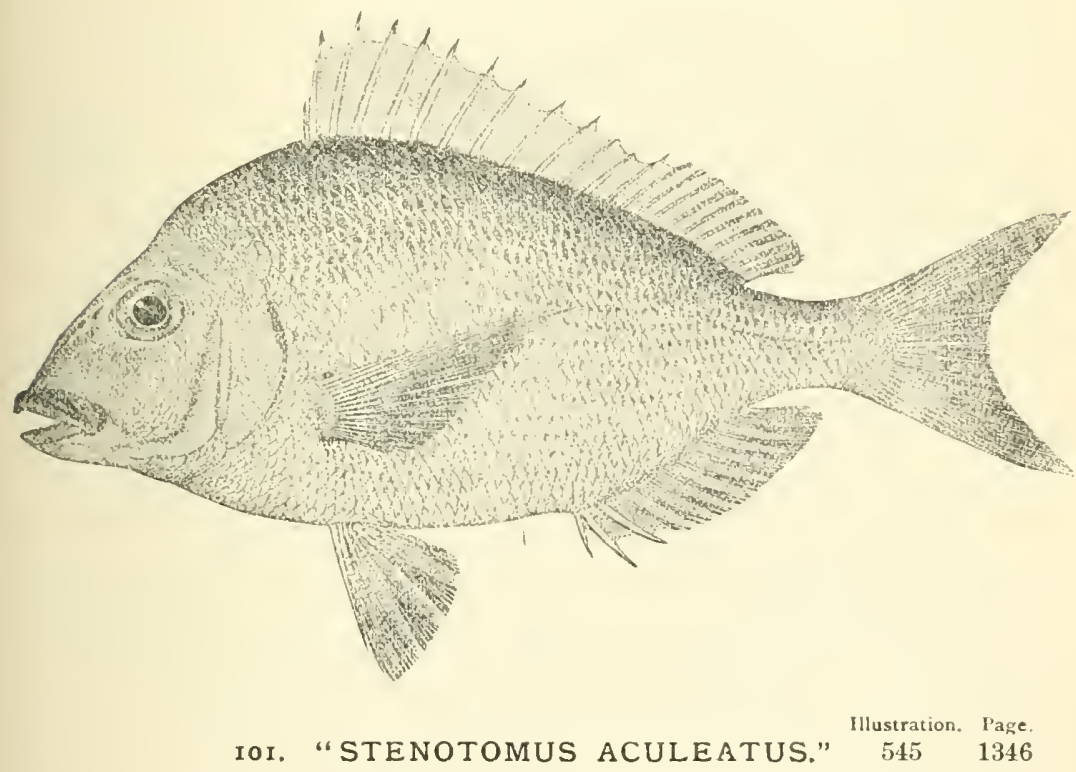

Southern Porgy. "Head 3 ; depth $2 \frac{1}{5}$. D. XII, 12 ; A. III, 11 ; scales $8-54-15$. Body elongate-ovate, the depth gradually decreasing from first dorsal spine to caudal peduncle; anterior profile not steep, nape slightly convex, a slight depression above and behind eye, convex over snout; pectoral about as long as head, $3 \frac{1}{5}$ in body; scaly sheath at base of soft dorsal and anal inconspicuous; snout 
long and pointed, 2 in head; eye large, less than width of preorbital, about $33 / 4$ in head; interorbital area very convex; 6 strong conical teeth in front of upper jaw and 8 in lower; molar teeth coarser and larger than in $S$. chrysops; scales on cheek reaching to top of eye, the upper rows less distinct than the lower, the anterior row of about 20 scales ; caudal fin moderately forked, the middle ray about $2 \frac{1}{4}$ in longest ray. First dorsal spine as long as eye, the second about as long as third, which is about 2 in head; temporal crest obsolete; frontal bones not gibbous or porous; antrorse spine attached to the fourth interneural by a downward projecting spur about twice as long as the spine. Color nearly plain dull silvery, with golden longitudinal streaks, following the rows of scales ; axil dusky ; ventrals dark."

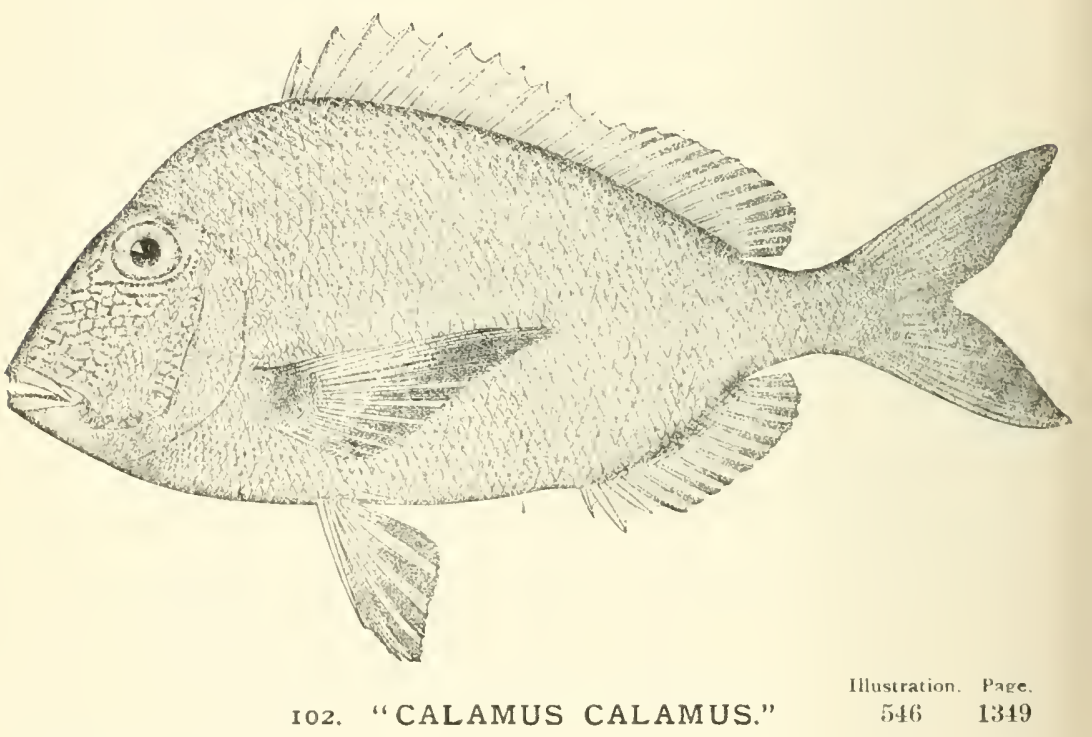

PURGY;

SIUCER-EYE PORGY ;

PE⿱ IE PI,UMA.

103. "CALAMUS PRORIDENS."

litTle-heal POKGy ;

PF.X DI: PI.UNA.

104. "CALAMUS BAJONADO."

JOLT-HEAD PORGY ;

B.IJONADO. 
105. "CALAMUS PENNA."

Little-mouth Porgy ;

SHEEPSHEAD PORgY.
"Head 3 to $3 \mathrm{x} / 4$; depth $21 / 6(23 / 4$ in total); eye rather small, $33 / 4$ to $41 / 3$ in head in specimens from 6 to 11 inches long. D. XII, 12 ; A. III, 10 ; scales 6-48-13. Body somewhat higher than in $C$. bajonado. Anterior profile evenly convex to front of dorsal, rising slowly and not strongly arched. Preorbital low, $2 \frac{3}{5}$ to 3 in head, about equaling interorbital width. Mouth moderate, the maxillary scarcely reaching vertical from front of orbit, $2 \frac{1}{2}$ to $22 / 3$ in head. Outer series of teeth anteriorly in both jaws somewhat enlarged, small and uniform in size, 8 to 10 in each jaw ; no accessory row of molars in either jaw. Dorsal low, the highest dorsal spine about $2 \frac{1}{3}$ in head; pectorals about reaching vertical from front of anal, $31 / 2$ in length; ventrals $12 / 3$ to 2 in head. Scales large, in about 5 vertical series on cheeks. Color, dull silvery with pearly markings, without blue stripes; a faint pale streak below eye; axil with a small inky black spot; ventrals blackish ; dark crossbars on body usually persistent."

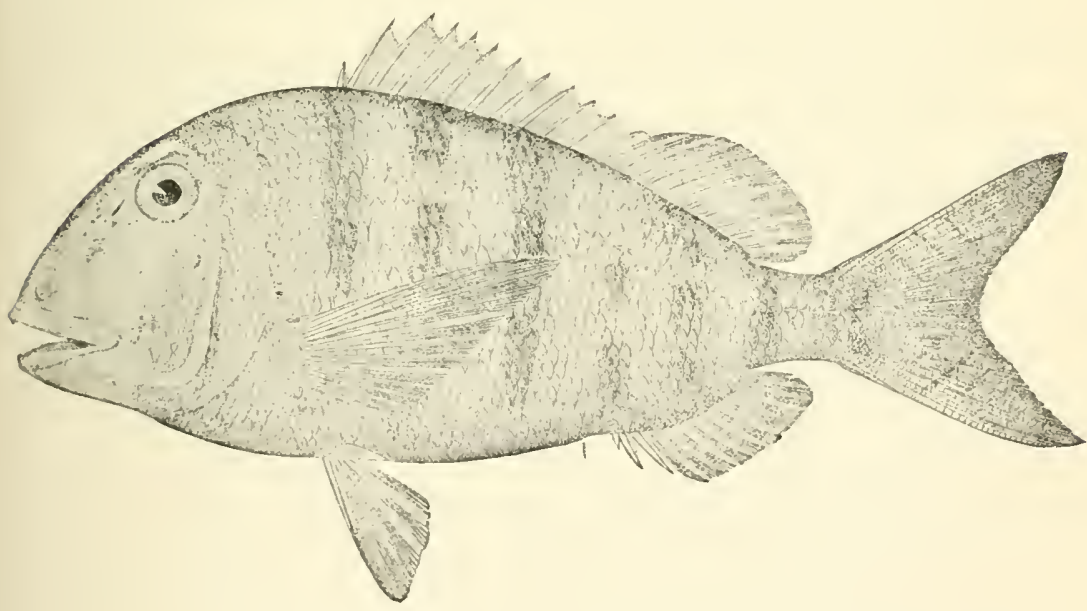

106. "CALAMUS ARCTIFRONS."

$550 \quad 1355$

Grass PokgY;

SILAD POKGY. 


\section{I07. "PAGRUS PAGRUS."}

lllustration. Page. $551 \quad 1356$

RED PORGY ;

Besugo ;

Pargo Colorado. back moderately elevated, the profile parabolic; preorbital deep, much wider than the small eye. Molar teeth in two series; teeth behind the canines slended; scales large. Dorsal spines not elongate, the front longest, about $2 \frac{1}{2}$ in head; soft dorsal and anal pointed behind; caudal well forked; second anal spine stronger but not longer than third, about 4 in head; pectoral fin elongate, longer than head, reaching about to fourth soft ray of anal. American specimens show in life the following coloration : Color, golden olive, the middle of each scale largely pinkish-red, giving a general reddish hue to the fish; sides and below silvery, flushed with red; many scales of back and sides each with a small round spot of deep purplish-blue, those forming distinct longitudinal streaks on the sides below lateral line, the series somewhat irregular, running along the margins of the scales; above the lateral line these spots are somewhat scattered, forming very irregular oblique series, running upward and backward; a few of these spots on nape and upper part of opercle ; a dark spot on upper part of orbital rim ; snout tinged with purplish, occiput with olive; edge of opercle dusky; vertical fins largely orange, their edges translucent; spinous dorsal somewhat dusky; ventrals pale, with a pinkish blotch at base; pectorals yellowish, especially at base, the axil somewhat dusky. Length, 2 feet." Weight to 3 or 4 pounds ; average about $3 / 4$ pound.

All Porgies caught same as other small bottom fish among the Keys. Edible, A. Some of them A 1. 

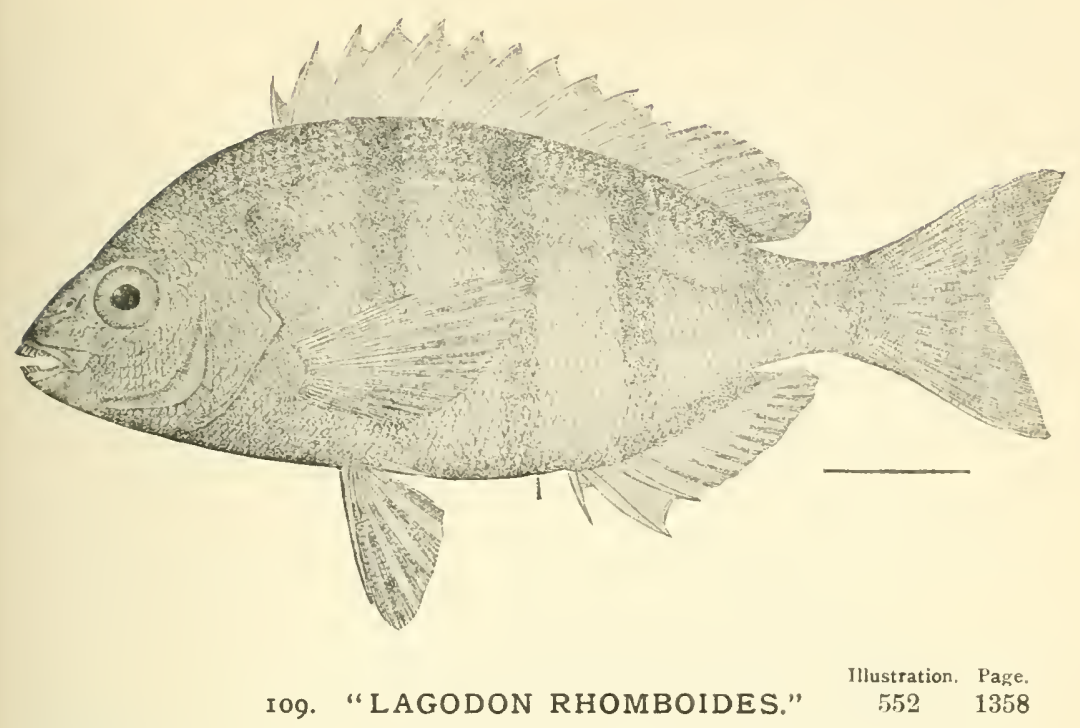

BREAM (SALT WATER); PINFISH ; SAII.OR'S ChOICE; ChOpa SPINA.

\section{"Head $3 \frac{1}{5}$; depth 2 to $22 / 3$; eye 4 . D.} XII, 11; A. III, 11; scales $10-65$ to $70-17$. Body elongate, elliptical ; head flattened, muzzle pointed, profile not very steep; eye moderate; $1 \mathrm{I} / 3$ to $1 \frac{1}{2}$ snout ; 1 in interorbital ; mouth moderate, maxillary not reaching front of orbit, $3 \frac{1}{3}$ in head; incisors $\frac{1}{4}$, all deeply notched; molars in two series in each jaw ; gill rakers $6+13$; dorsal spines all rather high, the highest about 2 in head: caudal deeply forked; second anal spine not longer than third; ventrals short and broad, pectorals moderate, upper rays reaching past origin of anal. Color, in life, olivacious, the sides bluich-silvery; a humeral spot and traces of 6 vertical bars; gilt stripes much less intense than in Archosargus unimaculatus, much broader than the interspaces; about 7 stripes below the lateral line, those above it more or less confluent; dorsal fin pale bluish, with a submedian gilt band and a gilt edging; caudal yellow, faintly barred; anal bluish, with a medium yellowish band; ventrals mesially yellowish; pectorals plain. Length, 6 inches." Weight, 2 pounds; average, 3/4 pound.

Caught in Halifax and Indian Rivers, Lake Worth Inlet, Biscayne Bay, and all the way to Key West, in the passes, channels and cuts, with rod and reel, or hand line, No. 6 or 9 line, No. $1 \%, 2 \%$, to $3 \%$ 
hook, still fishing on bottom. Bait: Crawfish, where obtainable, Crab, Conch, cut fish, Mullet preferred. Edible, B.

\section{IIO. BREAM (SALT WATER).}

Illustration, Pagc.

I have caught fish at Key West, called there "Salt-water Bream," and simply " Bream," which were entirely different from No. 552, in that they were striped yellow and red, but about the shape of No. 552 illustration. Weight, bait and method of catching same as other small fish among Keys. Crawfish best. Edible, B.

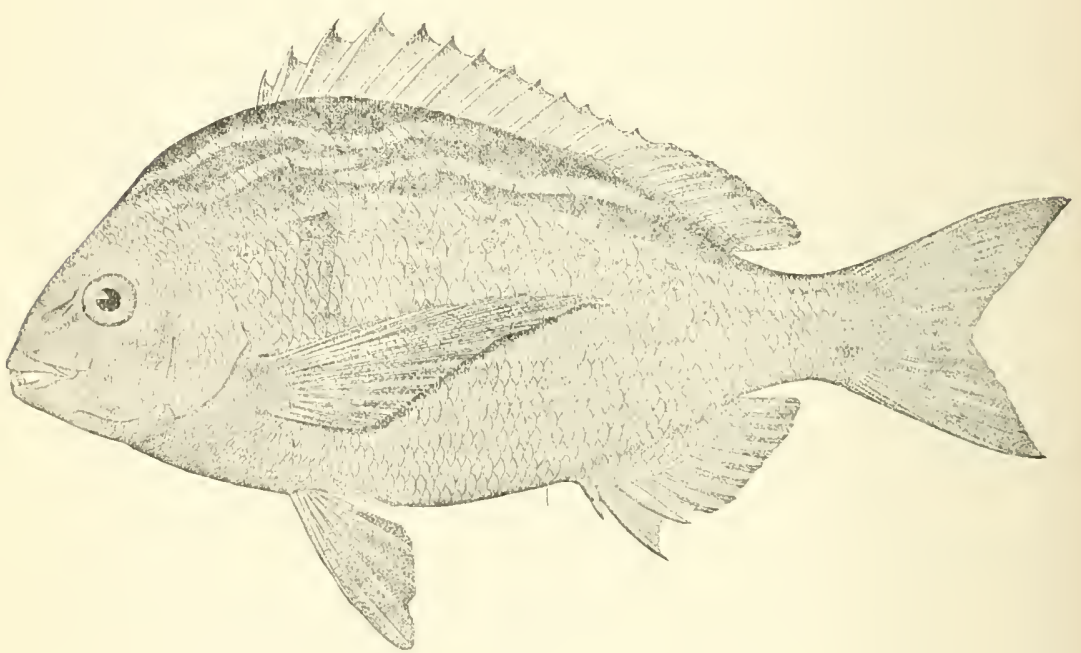

II " "ARCHOSARGUS UNIMACULATIS." $553 \quad 1359$

Shempheab; Said to be on Florida coast. Have never seen SAlema. them. 
. 


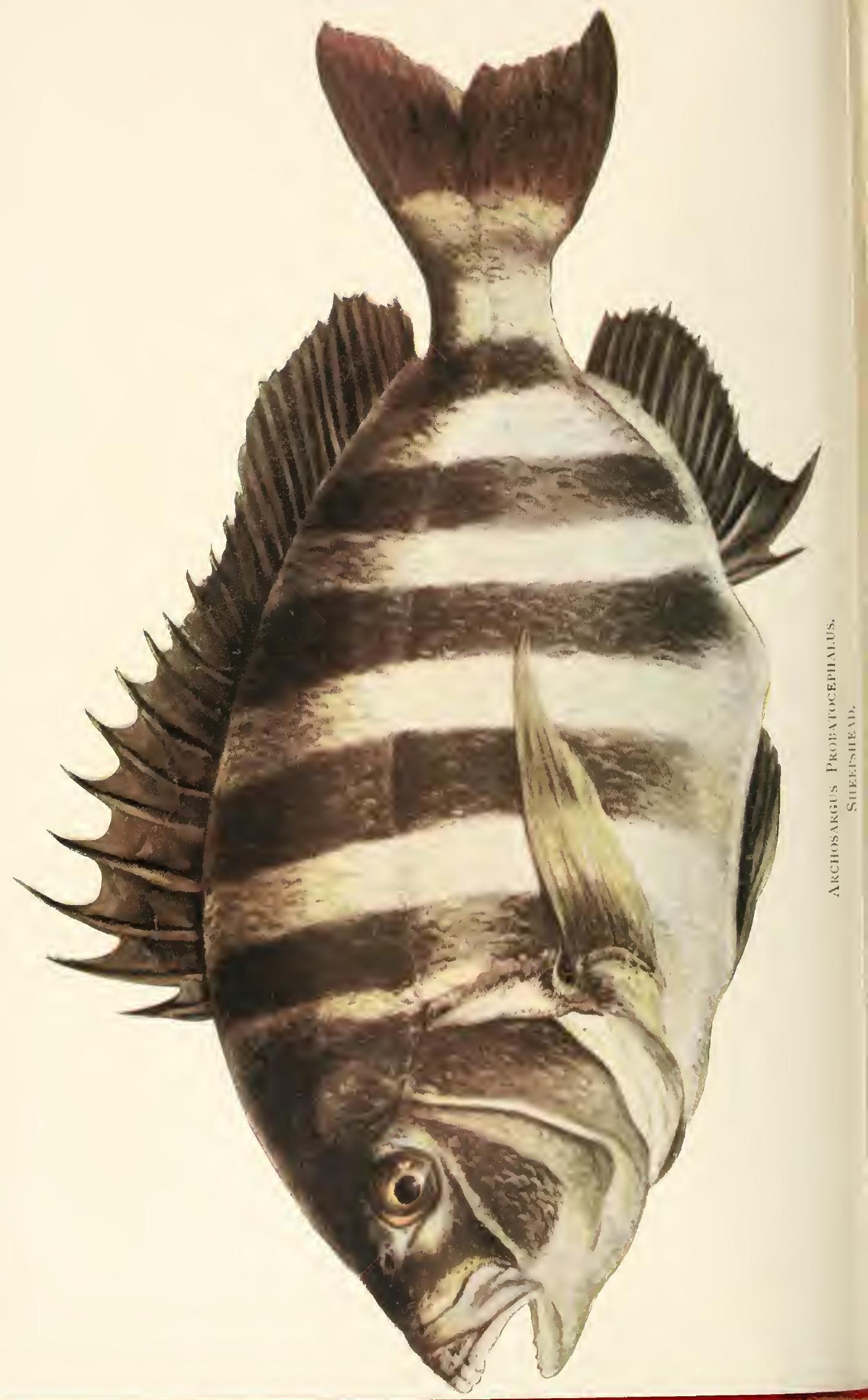




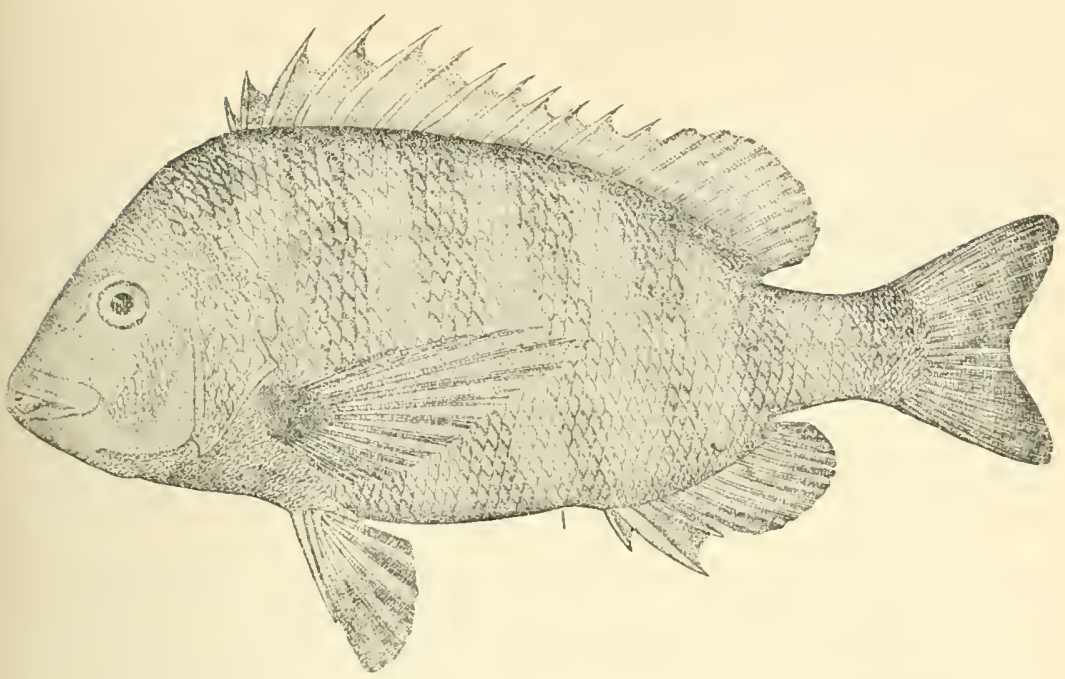

Illustration. Page.

II2. "ARCHOSARGUS PROBATOCEPHALUS." 5541361

Sheepshead; "Head $31 / 2$; depth 2 to $2 \mathrm{r} / 2$; eye large, $32 / 3$ to SARgo RAIADO. 4 = preorbital, or $1 \frac{1}{3}$ to $1 / 2$ in interorbital width. D. XIII, 10 ; A. III, 10 or 11 ; scales 8 or $9-45$ to $50-14$ to 16 . Body rather deep and compressed, profile rounded, steep; mouth moderate, maxillary not reaching front of orbit, 3 to $31 / 3$ in head; occipital crest rather thin, its honeycomb structure not exposed. Incisors $3 / 4$ on each side, entire, or with a shallow notch; molars 3 -rowed above, 2 -rowed below ; gill rakers small, about $6+8$; cheeks with 5 rows of scales. Fifth dorsal spine highest, 2 to $21 / 2$ in head ; second anal spine strong, recurved, 2 to $21 / 2$ in head; pectorals long, reaching to anal spines, about $2 \mathrm{r} / 2$ in body, ventrals moderate, $4 \frac{1}{2}$ to $4 \frac{4}{5}$ in length of body, not nearly reaching vent. Color, olivaceous, silvery below, the upper parts with golden longitudinal stripes alternating with bluish interspaces; a black humeral spot larger than eye." Weight to 15 pounds ; average about 3 to 4 pounds.

Caught: Rod and reel, still, bottom fishing, 18-21 line, sinker in weight according to tide, Virginia hook. Bait: Fiddlers, Oyster Crab, cut Sea Crab and other Crustacea bait. Edible, B. 


\section{II3. "DIPLODUS HOLBROOKII."}

SheEPSHEAd, Holbrook. The Sheepshead run in weight to 15 pounds; average, 3 to 4 pounds. Caught: Rod and reel or hand line, 18-21 line, sinker, fish on bottom, Virginia hook. Bait : Fiddlers, Sea Crab, Oyster Crab, or other Crustacea. Edible, B.

II4. "GERRES OLISTHOSTOMUS." $557 \quad 1376$ Irish Pompano; "Head 3 ; depth 2. D. IX, 10 ; A. III, 8 ; Mutton-Fish. scales 5-37-9. Body rhomboid, short and deep, the back elevated, the anterior profile short and very steep; mouth rather large; teeth slender, brush-like; preorbital entire; preopercle and interopercle serrate; groove on top of head, for reception of premaxillaries, broad, rounded behind, with a median linear depression, its surface completely covered with small deciduous scales which extend forward to just behind nostrils. Eye moderate. Gill rakers small, about 14 on lower part of arch. Dorsal spines high and strong, the second nearly or quite as long as head; second anal spine very strong, $1 / 2$ or more length of head; third spine slightly longer than second and very slender; caudal lobes long and slender, a little longer than head; pectoral long, nearly as long as head, reaching front of anal. Color, silvery olivaceous; scales with faint silvery streaks, but no dark ones; fins mostly pale or yellowish, the ventrals somewhat dusky. Length, 12 inches.'"

J. \& E. have, on page 392, U. S. Commission, 1895, " Irish Pompano" or "Mutton Fish" ; and Goode \& Beane, U. S. Commission, 1896, page 245, report in Indian River "Irish Pompano " or "Mutton Fish." Gardner has caught the fish in Indian River, and it is different from the Mutton-fish of the Keys.

Caught while fishing for other fish. Edible, C. 


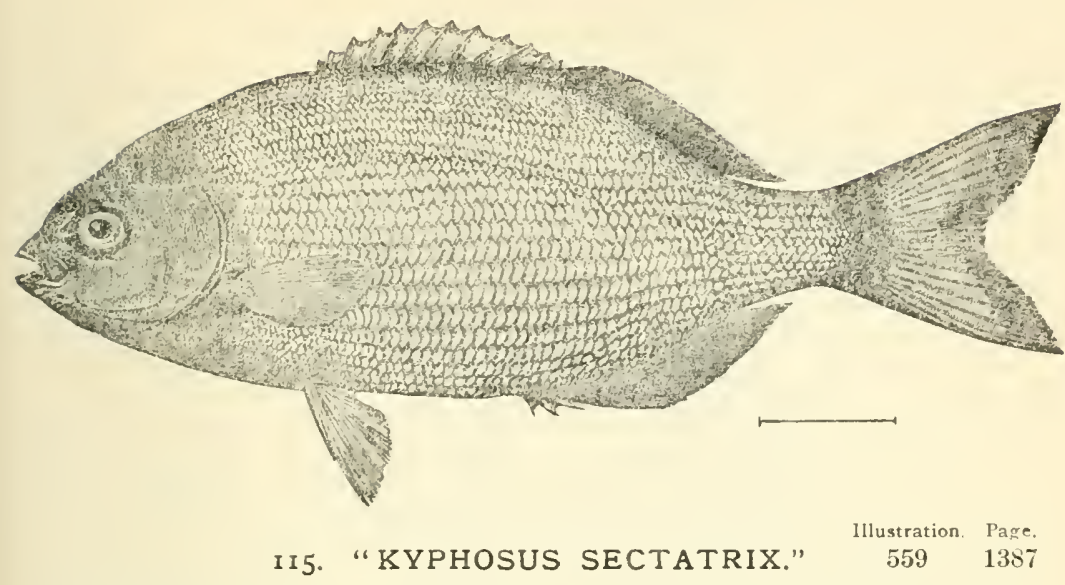

Chub (SALT WATER); RUDDER-FISH ;

Bermuda Chub;

Chopa Blanca.
"Head $33 / 4$; depth $21 / 8$. D. XI, $12 ; \mathrm{A}$. III, 11 ; scales $10-55-16$; vertebræ $9+16$. Body ovate, somewhat compressed; longest dorsal spine $\frac{1}{5}$ the height of body, rather higher than soft dorsal and nearly equal to longest ray of anal; teeth 35 to 40 on each side; horizontal process of the teeth not much longer than the vertical; interorbital space $2 \frac{1}{2}$ in head; top and sides of head finely scaled; interorbital region gibbous, below which point the snout is truncate; preopercle weakly serrulate; gill rakers long; soft dorsal and anal very low; the longest ray of anal $21 / 4$ in head, longest spine $21 / 4$; median dorsal spines highest; second anal spine highest; caudal well forked, the lower lobe longer. Color, in life, steel gray, very slightly bluish, not much paler below; the edges of each row of scales on back and sides slightly brassy, so that very faint yellowish stripes alternate with bluish ones of about equal width; a diffuse pale stripe below eye, a yellowish one above and below this; fins all dull grayish; ventrals and anal somewhat blackish; edge of opercle slightly darker." Weight to 9 pounds ; average, 3 to 4 pounds.

Caught: Still fishing, bottom, in channels, passes and cuts. Rod and reel, 9 to 15 line, $2 \%$ to $4 \%$ hooks. Edible, B.

II6. "CYNOSCION REGALIS."

562

1407

SEA TROUT ;

COMMON WEAKFISH;

Squeteague.

Said to be on the coast, but I have not seen them. 


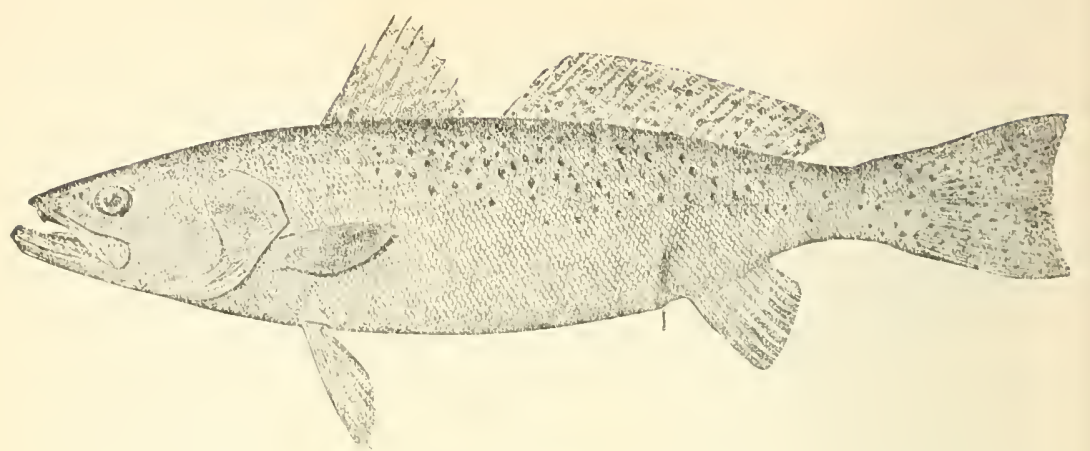

II7. "CYNOSCION NEBULOSUS." $\begin{array}{ccc} & \text { Mllustration. } & \text { Page. } \\ & 563 & 1409\end{array}$

SEa Trout ;

Spotted Sea Trout ;

SPOTTED Weakfisi.
Weight to 12 pounds; average, 4 pounds.

Caught: Rod and reel, still fishing, bottom, or floating; No. 12-15 line, 4 to $6 \%$ hook.

Trolling with phantom, spoon, or cut bait. Bait: Shrimp, Prawns, Crab, Crawfish, Conch, Minnows, cut bait. They will take any bait. Edible, B. Poor keeper.

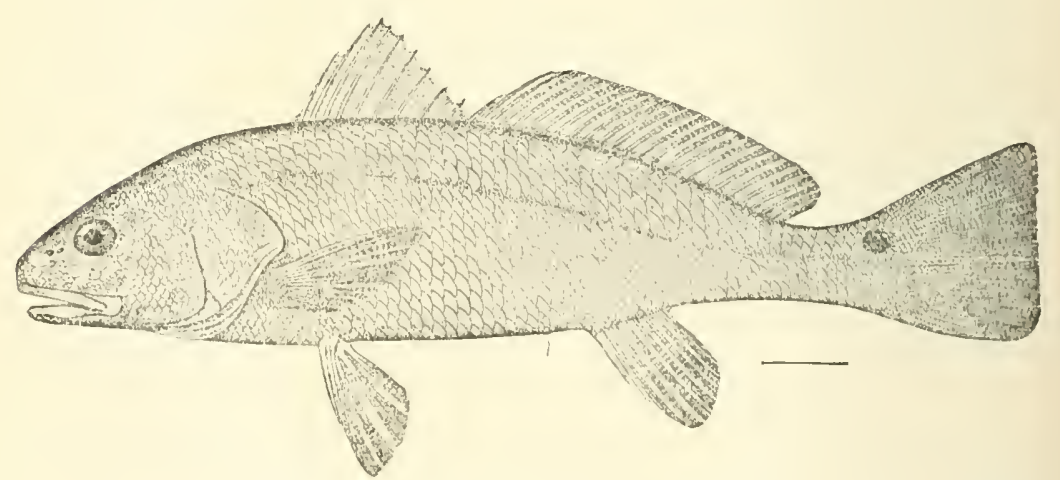

II8. "SCLENOPS OCELLATUS." $567 \quad 1453$

Channel. Bass;

RED DRUM ;

REI)-FISII ;

Pescano Colorado ;

BULL RED-FISII ;

BASS.
"Head $31 / 3$; depth $3 \frac{1}{2}$; eye 7 in head; snout 4 . D. X-I, 24 ; A. II, 8 ; scales $4-45$ to 50-12. Body elongate, rather robust, not much compressed; back somewhat arched; profile rather steep, somewhat convex; head long, 


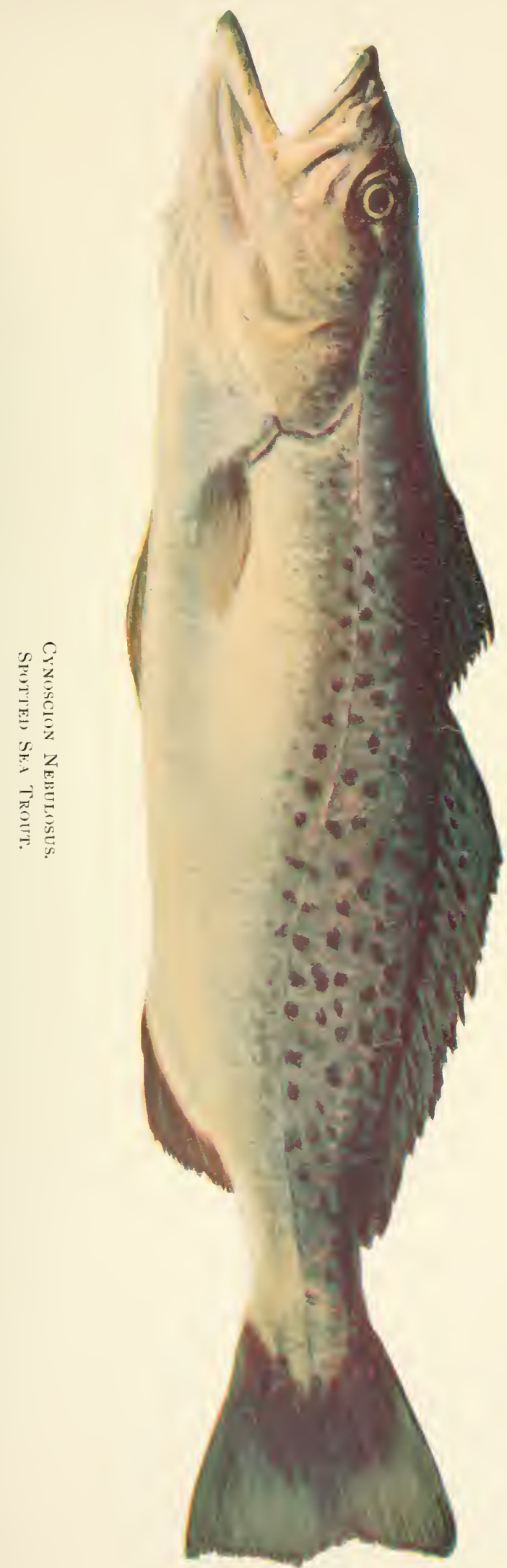



its bony margin sharply serrate in young examples, becoming entire with age, the serræe entirely disappearing in specimens of 20 to 30 pounds weight; in these the even edge of the bone is wholly covered by skin; mouth large, nearly horizontal; maxillary, not quite reaching posterior border of orbit, $21 / 2$ in head; teeth in both jaws in villiform bands, the outer series of the upper jaw much enlarged; lower teeth subequal; gill rakers $5+7$, shorter than the diameter of the pupil ; longest dorsal spine $2 \frac{1}{3}$ in head; second anal spine $1 \frac{2}{5}$ in the longest ray, $3 \frac{2}{5}$ in head; pectorals as long as ventrals, 2 in head; scales of the breast embedded, cycloid; soft dorsal scaleless ; caudal fin slightly concave, about $1 / 2$ as long as head. Color, grayish silvery, iridescent; often washed with coppery red; each scale with a center of dark points, these forming rather obscure, irregular, undulating brown stripes along the rows of scales; a jet black ocellated spot about as large as eye at base of caudal above, this sometimes duplicated; the body occasionally covered with ocelli. Length, 2 to 5 feet." Weight to 50 pounds; average about 6 to 8 pounds.

Caught: Preferably on banks near shores in shallow water, with light tackle. Rod and reel, 6 to 12 line, $4 \%, 6 \%$ hook. Bait : Live Menhaden, small Mullet or other small fish; Crab, or cut Mullet, bottom or floating bait, using float if desired. In shallow water they are obliged when hooked to make long runs, 100 to 300 feet, and afford fine sport. When fishing on or near oyster bars a float is necessary to keep the line off the oysters, where it may be cut. They take the same bait as above in the surf from Ormond to Indian River Inlet, at times, notably from April 1st to December 1st, and during long continued warm spells, between December 1st and April 1st. This is the case at Mosquito Inlet and New Smyrna south to Indian River Inlet, but not often much north of Mosquito Inlet, between these dates. Trolling: They will take a medium-size Mackerel or silvered phantom, a No. 5 or 6 Skinner spoon, Minnow or cut bait. Trolling should be near the shores where the fish are supposed to be. One of the best game fish. Edible, B. Up to 6 pounds they are a fine boiler or broiler; above that weight they are not desirable. 


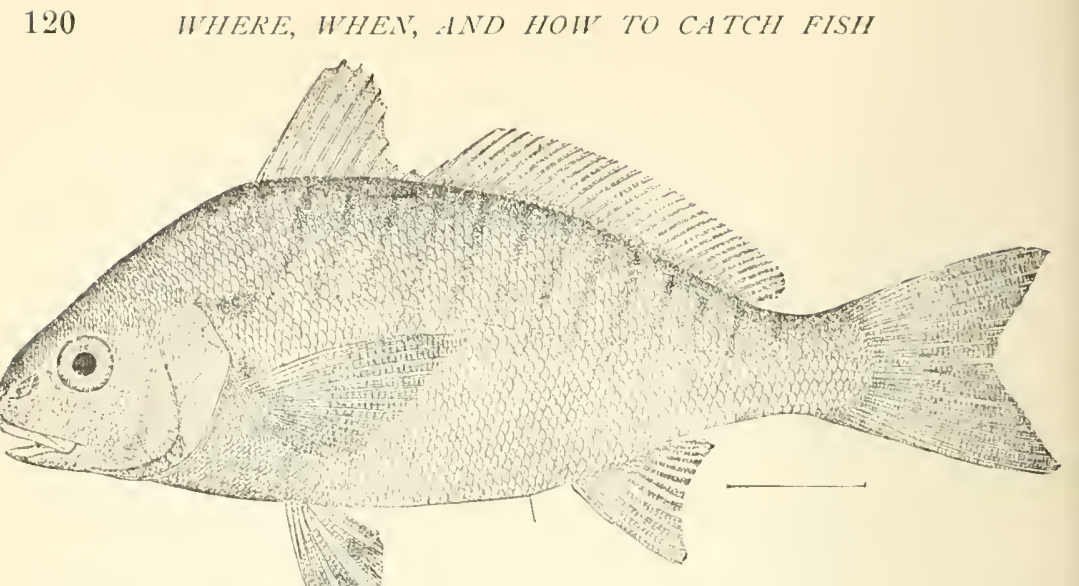

SPOT ;

GOODY ;

POST-CROAKER ;

OLDWIFE ;

LAFAYETTE;

Besouga (G.).

\section{II9. "LEIOSTOMUS XANTHURUS." $\begin{array}{cc}\text { Miustration. } & \text { Page } \\ 569 & \mathbf{1 4 5 8}\end{array}$}

“Head $3 \frac{1 / 3}{3}$ to $31 / 2$; depth 3 ; snout $31 / 3$ to $31 / 2$. D. X-1, 31; A. II, 12 ; scales $9-60$ to $70-12$. Body short, deep, much compressed; back in front of dorsal compressed to a sharp edge, profile steep, convex, depressed over the eyes; dorsal outline convex, highest at front of dorsal ; snout very blunt, as long as eye, $31 / 3$ to $31 / 2$ in head; mouth small, inferior, horizontal; maxillary 3 in head; extending to below pupil; no teeth in lower jaw, in the adult; upper jaw with a series of narrow minute teeth; gill rakers short, slender, $8+22$; lower pharyngeals small, with three series of molars posteriorly and many villiform teeth anteriorly; preopercle entire; preorbital broad, $1 \frac{1}{2}$ in eye; third dorsal spine highest, $1 \frac{1}{2}$ in head; soft dorsal with the sheath at its base formed by a single series of scales; caudal long and forked, as long as head; anal long and slightly falcate; second anal spine $21 / 2$ in the longest ray, 4 in head; ventrals $1 / 3$ shorter than pectorals, which are as long as the head; scales small, strongly ctenoid, extending on caudal and base of pectorals but not on other fins; lateral line little curved anteriorly; scales below lateral line in oblique series. Color, bluish above, silvery below; about 15 narrow dark wavy bands extending from the dorsal downward and forward to below lateral line; a round black humeral spot rather smaller than eye ; fins plain olivaceous, the caudal not yellow." 
There are several varieties of fishes called "Spots," some others of the name occurring in my list. The names are local, and they cannot be changed. The fish I have called "Spot" is also called Cuban Fish, Gulf Fish and Salt-water Bream. Is about the shape of a Saltwater Bream, all white, bluish cast, and a spot just below the gills. $\mathrm{He}$ is plentiful in Indian River, especially from Indian River Inlet to Jupiter. U. S. Commission Report, 1896, has "Spot," “Sailor's Choice," confused with "Croaker," and plate 50 called Pinfish, Bream. U. S. Commission Bulletin, 1897, "Spot," "Goody," probably the above Leiostomus Xanthurus. U. S. Commission Bulletin, 1898, "Spot," "Goody," probably same as Leiostomus Xanthurus. N. Y. Aquarium, "Spot," "Lafayette."

The "Spot," "Bream," and "Sailor's Choice" questions are decidedly mixed. The Spots are all small fish, $1 / 2$ to $11 / 2$ pounds.

Caught: No. 6 line, No. 1 or $1 \%$ hook, fish, or crustaceous bait. Still, bottom fishing. Edible, A 1 to $\mathrm{C}$, according to what kind of a Spot the specimen is. The Leiostomus Xanthurus is A 1. This fish received its name of "Lafayette" because it reappeared on the coast, after a long absence, during the visit of Lafayètte to this country in 1834 .

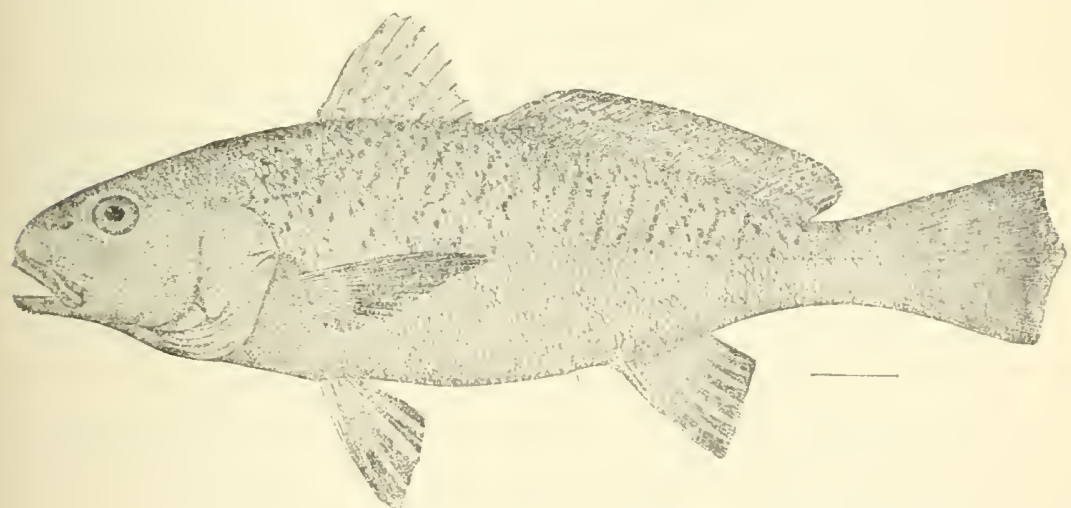

120. "MICROPOGstration. Page.

$570 \quad 1461$

Croaker: "Head 3 ; depth $31 / 3$. D. X-I, 28 or 29 ; A. II, RoNCADINA; 7 ; scales $9-54$. Body rather robust, the back someCorvina. what elevated and compressed, the profile rounded, not depressed above eyes; head long; the snout prominent, convex. 
Mouth rather large, nearly horizontal, the maxillary reaching to front of eye, 3 in head; outer teeth above enlarged; eye 2 in snout, 5 in head, rather less than interorbital width. Preopercle strongly serrate along its whole posterior margin, the spines near angle diverging; dorsals nearly separate, the first high, the third spine 3 in head; pectorals moderate, nearly reaching tips of ventrals; ventrals filamentous; anal inserted nearly under middle of second dorsal, the second spine rather weak, shorter than snout, $1 / 3$ length of head; caudal double truncate, $1 \frac{3}{5}$ in head; 16 scales in an oblique series from vent to lateral line, $12 \mathrm{in}$ an oblique series from dorsal to lateral line. Gill rakers slender, very short, $7+16$; сæca 8 . Color, brassy, paler below; middle part of the body with short, irregular dusky vertical bars crossing the lateral line; many dark brown spots on side of back, irregularly placed, and not forming continuous streaks along the rows of scales; usually some of these coalesce to form 2 dark streaks procurrent with the back. Length, 12 inches." Weight to $1 \mathrm{I} / 2$ pounds.

Caught: No. 6 line, No. 1, 1\% hook. Fish or Crustacea bait. Edible, A.

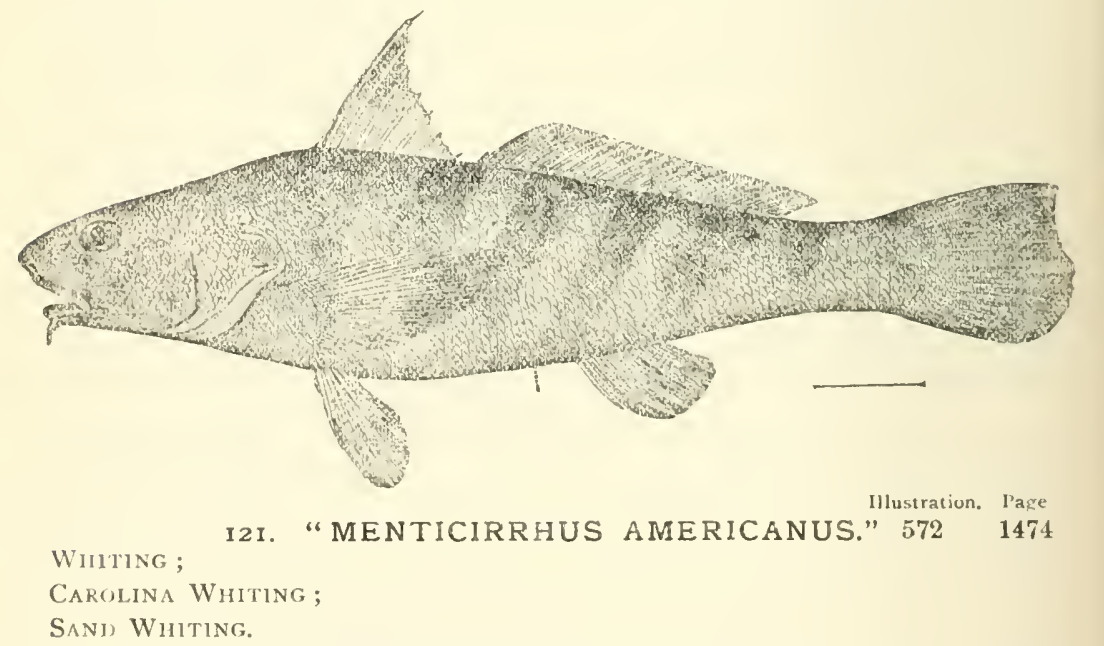

122. "MENTICIRRHUS SAXATILIS." $572 \quad 1475$

Whiting, Northern; "Head $33 / 4$ to 4 ; depth $4 \frac{1}{2}$ to $42 / 3$; eye KingFish (SMALL. G.); 7 in head; snout $33 / 4$. D. X-1, 26 or 27 ; SIEA MiNK.

A. 1,8 ; scales $7-53 ; 14$ pores. Outer teeth 
of upper jaw less enlarged; spinous dorsal elevated, the longest spine reaching past front of soft dorsal, its length $1 \mathrm{r} / 2$ in head; coloration strongly marked, body scarcely silvery. Profile slightly depressed above the eyes; eye small, $2 \mathrm{x} / 3$ in snout, 2 in interorbital area; snout long, bluntish; mouth large; maxillary reaching middle of eye, $2 \frac{4}{5}$ in head; ventrals $11 / 2$ in pectorals, which are $1 \frac{1}{7}$ in head; scales all ctenoid. Color, dusky gray above, sometimes blackish, the back and sides with distinct dark oblique cross bands running downward and forward, the anterior one at the nape extending downward, meeting the second and thus forming a $V$-shaped blotch on each side; a dark lateral streak bounding the pale color of the belly, most distinct posteriorly, and extending on lower lobe of caudal ; inside of gill cavity scarcely dusky; pectorals dark.",

I23. “MENTICIRRHUS LITTORALIS." No illustration. 1477 Whiting, Silver; "Head $3 \mathrm{I} / 2$; depth $4 \frac{2}{5}$; eye $6 \mathrm{I} / 2$ in head; Surf Whiting. snout $3 \mathrm{I} / 2$. D. X-I, 23 to $25 ; \mathrm{A} . \mathrm{I}, 7$; scales $6-5.3$; 12 pores. Upper lobe of caudal not longer than lower ; scales rather large, 15 to 18 in an oblique series from vent upward and forward to lateral line; axillary scale not $1 / 4$ length of pectoral; snout distinctly projecting beyond mouth; gill rakers larger than in other species, the longest about $1 / 2$ length of pupil, the number $\mathrm{X}+7$; lower pharyngeal bones broad, most of the teeth developed as coarse molars, only those along the posterior margin conical; maxillary reaching past front of orbit, $31 / 2$ in head; outer teeth of upper jaw scarcely enlarged; longest dorsal spines reaching past front of soft dorsal, the free margin of the fin concave; caudal rather deeply lunate, the lower lobe rounded, the upper pointed; ventrals $1 \frac{3}{5}$ in pectorals, which are $1 \frac{1}{3}$ in head. Color, silvery gray above, with bluish and bronze reflections, immaculate; a dark-bronze shade along sides on level of pectorals, extending to tail and along cheeks; belly below this abruptly white; dorsals light brown, spinous dorsal black at tip, the base narrowly white; caudal pale, its tip usually black; inner lining of pectoral and ventrals blackish ; gill cavity pale.' Weight, $1 / 2$ to 2 pounds; average, $3 / 4$ pound.

Usually caught on sandy bottom, inside and outside, rather shallow water. No. 6 line, $1 \%$ hook. Still fishing, in surf or inside. Bait : Cut Mullet or Crustacea. Edible, B. 


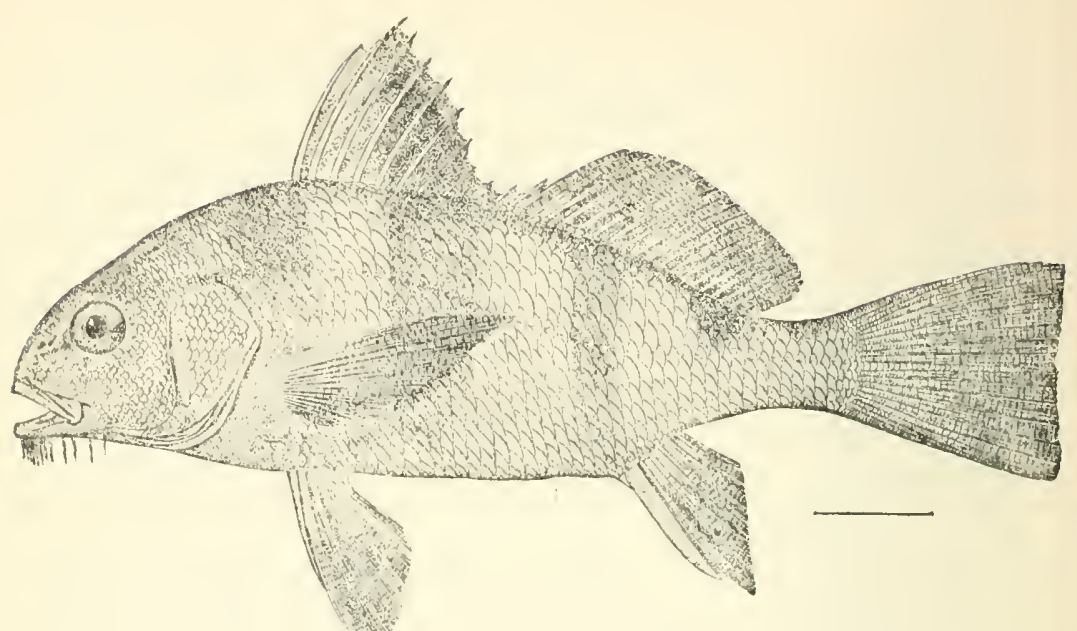

124. "POGONIAS CROMIS."

Illustration. Page. $573 \quad 1482$

DRUM ;

"Head $31 / 3$; depth $21 / 3$; snout $33 / 4$ in head. Common Drum (G.). D. X-I, 21 ; A. II, 5 or 6 ; scales 5-47-9. Body oblong, the back much elevated, ventral outline almost straight, the depth rapidly diminishing from the first dorsal spine backward; profile rather steep and slightly convex; mouth moderate, inferior, the maxillary not reaching middle of eye, $31 / 3$ in head; teeth in broad bands, the outer series above scarcely enlarged; snout blunt, longer than eye; lower pharyngeals large, completely united, covered with many blunt molars and a small patch of conical teeth at the outer posterior corner; gill rakers $t+12$, very short, slender ; dorsal spines high but slender, the fourth highest, 2 in head; caudal subtruncate; second arral spine very large, about 2 in head ; pectorals about as long as head; scales large, those on breast small. Color, grayish silvery, with 4 or 5 broad dark vertical bars, these disappearing with age, usually no oblique dark streaks along rows of scales above; fins blackish."

See J. \& E., page 1482. One of 146 pounds caught at St. Augustine. Up to 10 pounds this fish strongly resembles the Sheepshead. The very large ones non-edible. 


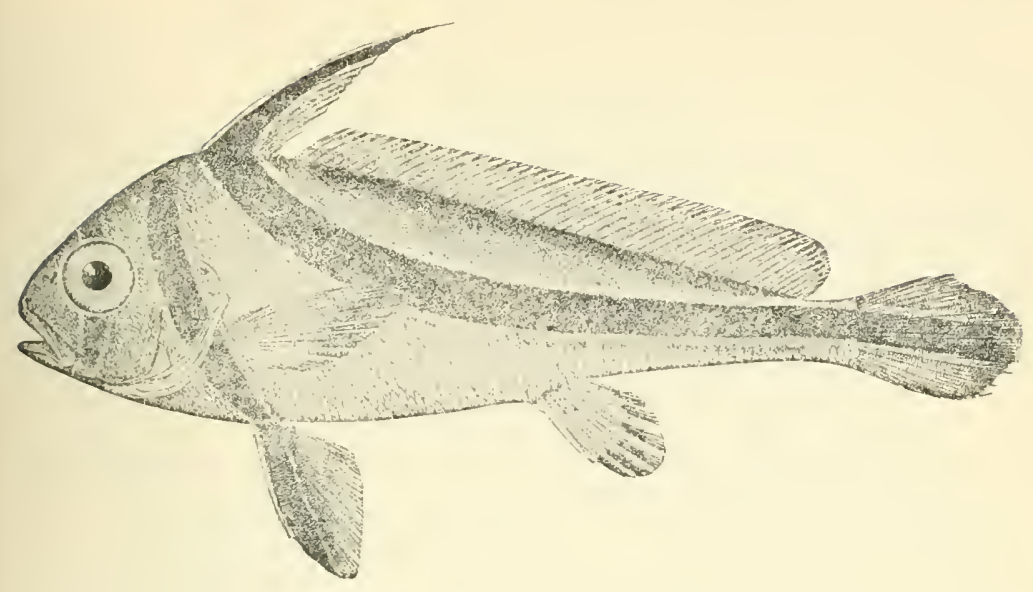

\section{5. "EQUES LANCEOLATUS." Illustration, Page.}

Ribbon Fish ; “Head 4 ; depth $2 \frac{2}{3}$; eye 4 . D. XIV to XVI-I, GUAPENA ; 53 ; A. II, 5 ; scales irregular, with smaller ones interSERRANA. mixed; about 12 of the anterior interneurals wedged in between the occiput and the neural spine of the third vertebra; distance from tip of snout to first dorsal spine much less than depth of body. Body deepest below first dorsal spine, rapidly tapering to the narrow caudal peduncle; profile very steep, little convex; eye little longer than snout; preorbital broad, nearly as wide as eye; mouth small, slightly oblique; maxillary reaching to below anterior fourth of eye; teeth all villiform in broad bands, the outer scarcely enlarged; preopercie with a fringed membranous border; gill rakers very short and slender, $6+9$; anterior dorsal spines much elongate, $13 / 4$ in body; soft ray's low, the membranes scaled to the tips; anal small, its second spine 3 in head; ventrals $1 \frac{1}{3}$ in head; pectorals scarcely shorter. Color, light yellowish; a narrow brownish band from the corner of the mouth up across the middle of the eye and meeting its fellow on top of head; another broader band edged with a narrow white line on each side from the nape down and back over opercie, meeting its fellow between the ventral fins and extending to the tips of their outer rays; a third and still broader band, also bordered by white, extending from the tips of the dorsal spines to their base, then downward and backward to the tips of the middle caudal rays; body below this band silvery white, above it somewhat darker.', 
This fish is very rare. A few are caught in Indian River, in seines, and while fishing for other fish, by sportsmen. A beautiful frosted silver fish. Long, flat, and slim, silver color. Non-edible. Simply a curiosity.

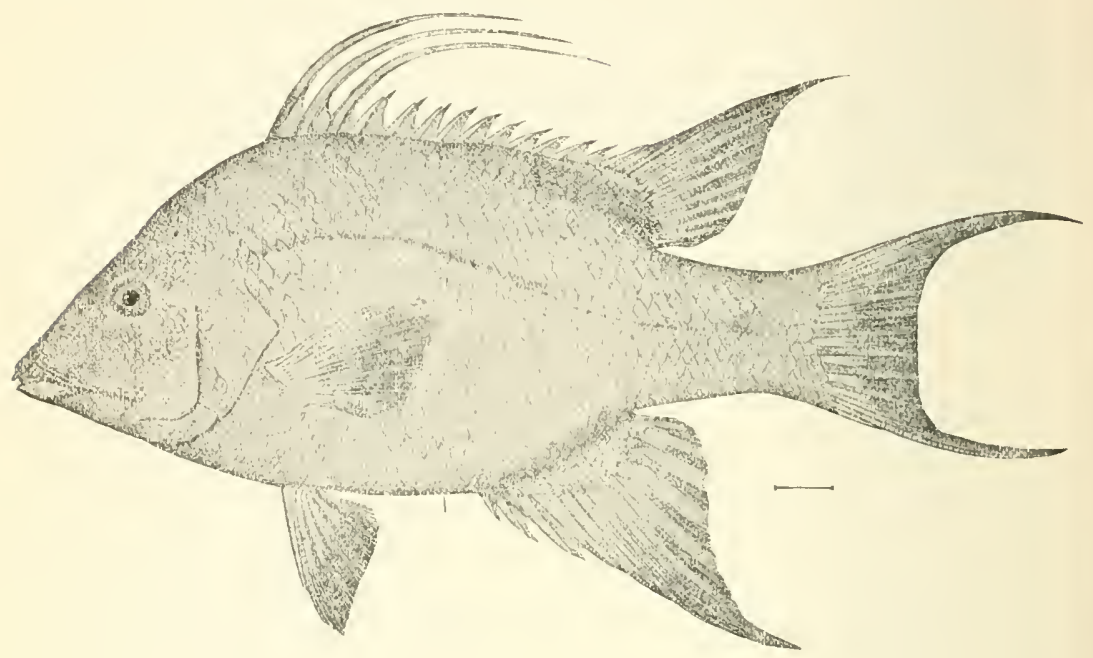

\section{I26. “LACHNOLAIMUS MAXIMUS." $597 \quad 1579$}

Hogrisu ; Weight to 8 pounds; average, 3 to 4 pounds.

Capitaine; Caught: Rod and reel, hand line, No. 15 line, Perro Perro. 5\% hook. Still fishing, bottom. Biscayne Bay to Key West, channels and "patches." Edible, A 1. (Ine of the very best table fishes.

127. "HARPE RUFA." No illustration. 1583

LADY-FISH ;

Entirely different from the Lady-fish, BoneSpanisiz Laly-Fish; fish, which see, page 411 , plate 179 . J. \& E. Spanisil Hogrisil; say caught at Key West.

P'UDIANO;

P'erRo Colorado. 


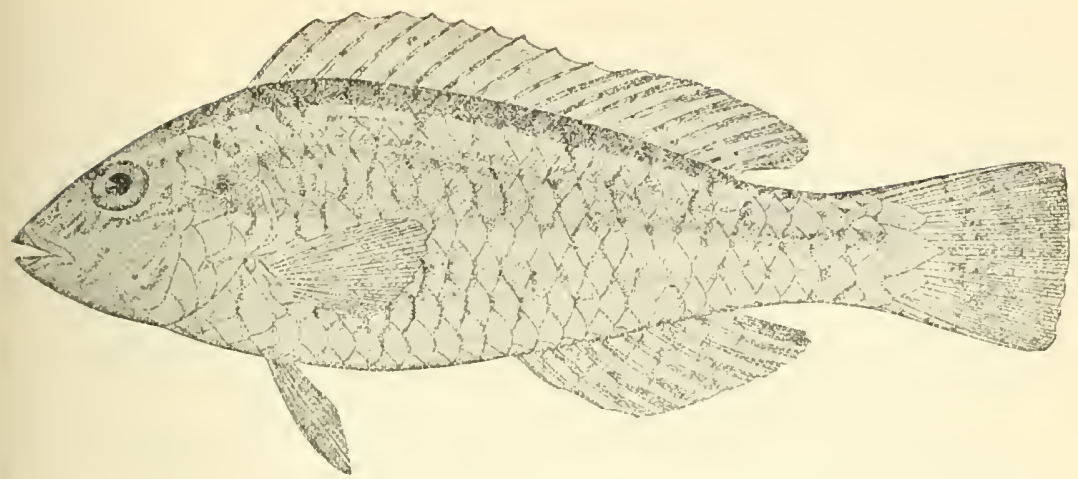

lllustration. Page I28. " CRYPTOTOMUS BERYLLINUS." $608 \quad 1625$ PARROT FiSH.

r29. “SPARISIMA CHRYSOPTERUM.” Noillustration. 1636 Parrot Fish, Blue; "Head $31 / 4$ ( 4 r $/ 4$ with caudal); depth $27 / 8$

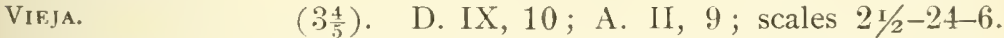
Body oblong ; a strong canine directed outward and backward toward angle of mouth in upper jaw; besides this about 3 smaller canines toward front of jaw, chiefly turned forward ; upper lip covering about $1 / 2$ of upper jaw. Eye 52/3 in head; snout not obtuse, 23/4; cheek with a single row of 3 or 4 large scales; each pore of lateral line ramose, many times forked, and covering most of the scale, the pores more branched than in any other of our species ; 4 scales on median line before dorsal. Caudal deeply lunate, the outer rays much produced, upper lobe the longer, twice as long as inner rays, as long as head. Color, in life, bright blue, almost everywhere tinged with green; head and portion behind pectorals brighter; an ill-defined pale band on lower part of side; dorsal and anal and middle of caudal brick red; edge of caudal blue; ventrals bluish green; pectorals greenish yellow, their base red around a large black spot; teeth bluish; jaws pale. In spirits the blue is more or less faded, leaving the fish chiefly green, darker on head; the red and yellow of fins become pale grayish. According to Poey, there is usually a dark blue horizontal stripe along sides behind pectoral fin."

130. "SPARISIMA VIRIDE." No illustration. 1638 PARKOT FISII, GREEN;

DARK GKEEN PARROT FISH, 
Illustration. Page.

13I. "SPARISOMA FLAVESCENS." No illustration. 1639

Parrot Fish ; MUD PARROT; Vieja Colorado; VIEJA MUGER.

"Head $31 / 3$ ( 4 with caudal) ; depth $2 \frac{5}{6}\left(3 \frac{1}{2}\right)$. D. IX, 10 ; A. II, 9 ; scales $2 \frac{1}{2}-24-6$; eye $5 \frac{1}{3}$ in head; snout $2 \frac{3}{5}$. Body oblong; no canine teeth ; upper lip covering most of upper jaw ; eye rather small; snout bluntish, cheek with a single series of about 5 large scales; tubes of lateral line dividing into about 5 branches, covering most of the scale; 4 scales on median line before dorsal; pectoral fin reaching past tips of ventrals; origin of ventral spine under middle of pectoral base; caudal fin slightly lunate, the upper lobe longer and narrower than the lower, $11 / 4$ in head; the prolongation of the outer rays varies somewhat and is greatest in the adult; the concavity of the fin is evident in specimens 3 inches long, but in the very young the fin is truncate or even slightly convex. A few specimens of 6 to 8 inches are in the collection in which the caudal fin appears fairly truncate when spread open, the angles remaining acute. In most cases, however, the fin is slightly concave. Color of adult, in life, olivaceous, somewhat clouded with light and dark, and usually flushed with pinkish, especially below, the edges of the scales more yellow olive; scales of belly and lower parts light orange red toward their bases, giving a decidedly reddish cast; dorsal mottled with different shades of olive; caudal creamy, mottled and barred with darker orange, the markings more distinct on the outer edge; ventrals and anal rich cherry red, mottled and barred with brown; pectorals light orange red, the color formed by narrow orange cross streaks on a paler ground, a light band across lower jaw, which is otherwise brown; teeth white; a dusky or black blotch at base of pectoral ; sometimes blackish spots on the scales at the base of the soft dorsal. In spirits the red of body and fins and yellow on scales becomes pale. Young individuals have small, bright, rosy spots on sides of back ; 2 faint, darker, longitudinal shades along side." 


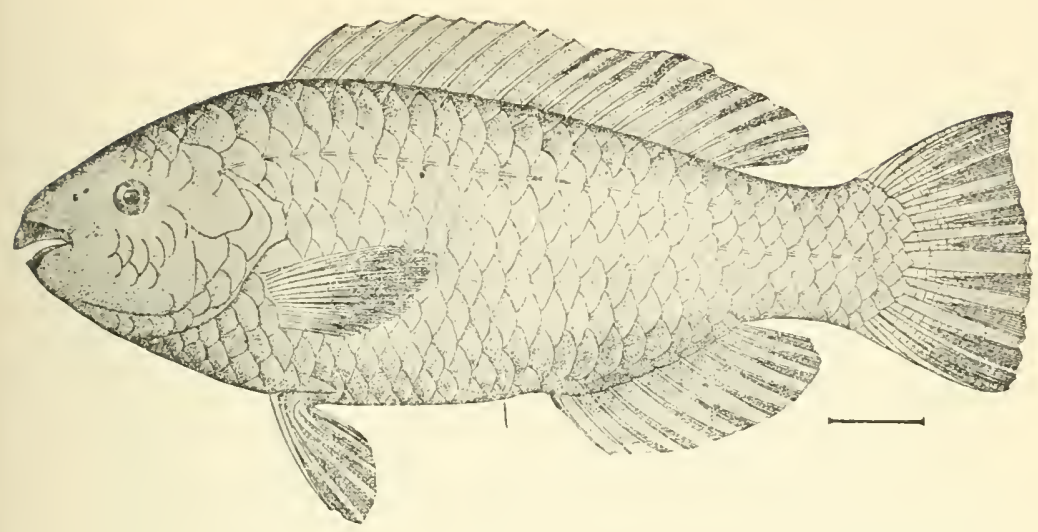

132.

"PSEUDOSCARUS GUACAMAIA."

Illustration. Page $617 \quad 1657$

PARROT-FISH ;

Guacamaia ;

GREeN PARROT-FISH.

133. "SCARUS CROICENSIS."

1650

PARROT FISH ;

BULLON,

No illustration.

134. "SCARUS CERULEUS."

(Illustration of jaws only.)

PARROT Fish ;

Blue Parrot-fish; or less.

LORO ;

Clamagore.

Caught: Same as bottom small fish, Biscayne Bay, the Keys and Key West. No. 6 line, 1\% hook. Bait: Crawfish, Conch, Crustacea, or cut bait. Non-edible, or barely edible.

135. "UPENEUS MARTINICUS."

GontFISH ;

Caught in Biscayne Bay, and Keys to Key YELLOW GOATFISH ; SALMONETE. West. No. 6 line, No. 1 hook. Bait: Crawfish, Crustacea, cut fish. Still fishing, drifting. Edible, B. 


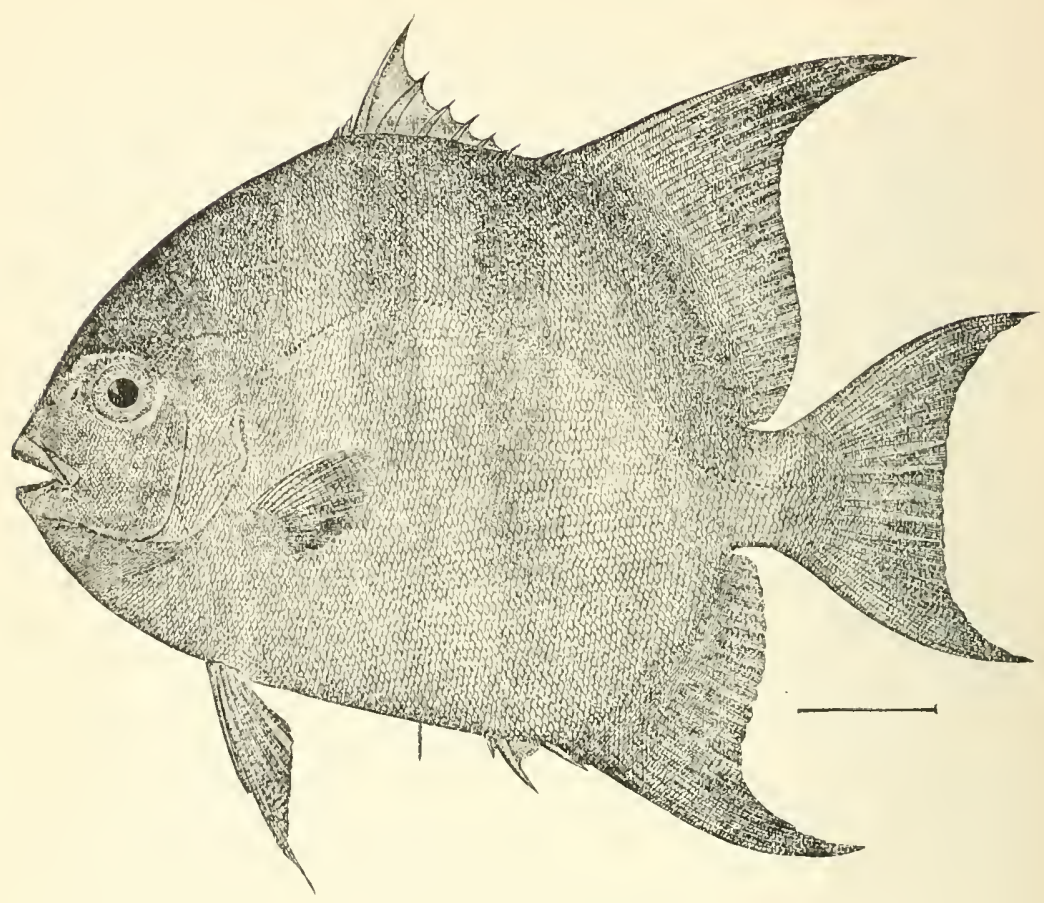

\section{I36. “CH ETODIPTERUS FABER." $\begin{array}{cc}\text { Illustration. } & \text { Page. } \\ 619 & 1668\end{array}$}

SPADE-FISH ; "Head 3 to $3 \mathrm{I} / 2$; depth 1 to $1 \mathrm{I} / 2$. D. VIII-I, ANGel-Fish. 20 ; A. III, 18 ; scales 60 ; cæca 4 to 6 . Vertical fins low in the young, falcate in the adult. Third dorsal spine more than $1 / 2$ in head, in adult about as long as from tip of snout to edge of preopercle, its membrane blackish, more produced in the young; chin with a row of pores; preorbital nearly as wide as eye ; pectoral considerably shorter than ventrals, the first soft ray of the latter filamentous. Color, grayish; a dusky band across the eye to the throat; a second similar band, broader, beginning in front of the dorsal and extending across base of pectoral to the belly; a third band, narrower, extending to middle of sides, from the base of fourth and fifth dorsal spines; a fourth broader band from the last dorsal spine to the anal spines, the remaining bands alternately short and long; 
all of these bands growing obscure and disappearing with age; ventrals black." Weight to 4 pounds; average, $2 \frac{1}{2}$ pounds.

These fish are of same family as the Angel-fish, but are sombre hued and very plain. Caught from Norris Cut to Key West, occasionally one farther north. Caught: Same as Angel-fish. Edible, C.

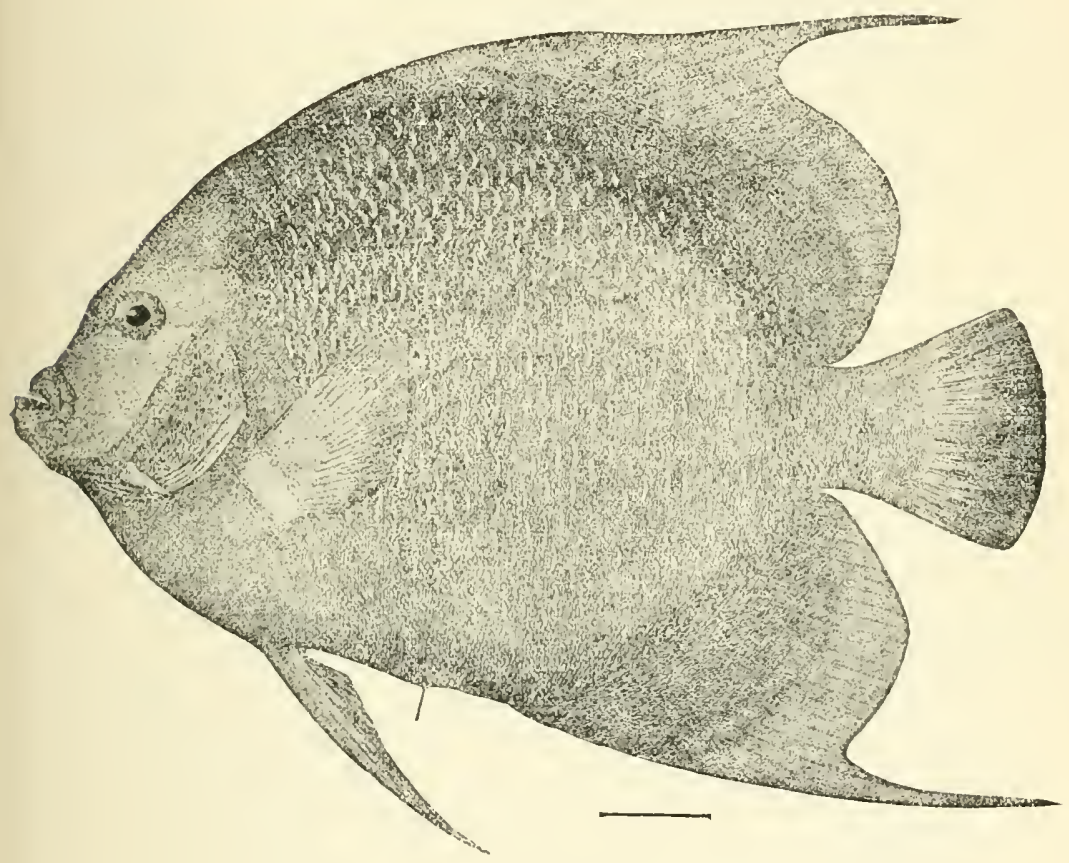

137. "POMACANTHUS ARCUATUS." $623 \quad 1679$

ANGEL-FISH ;

BLACK ANGEL-FISH;

Chirivita ;

Portugais. 


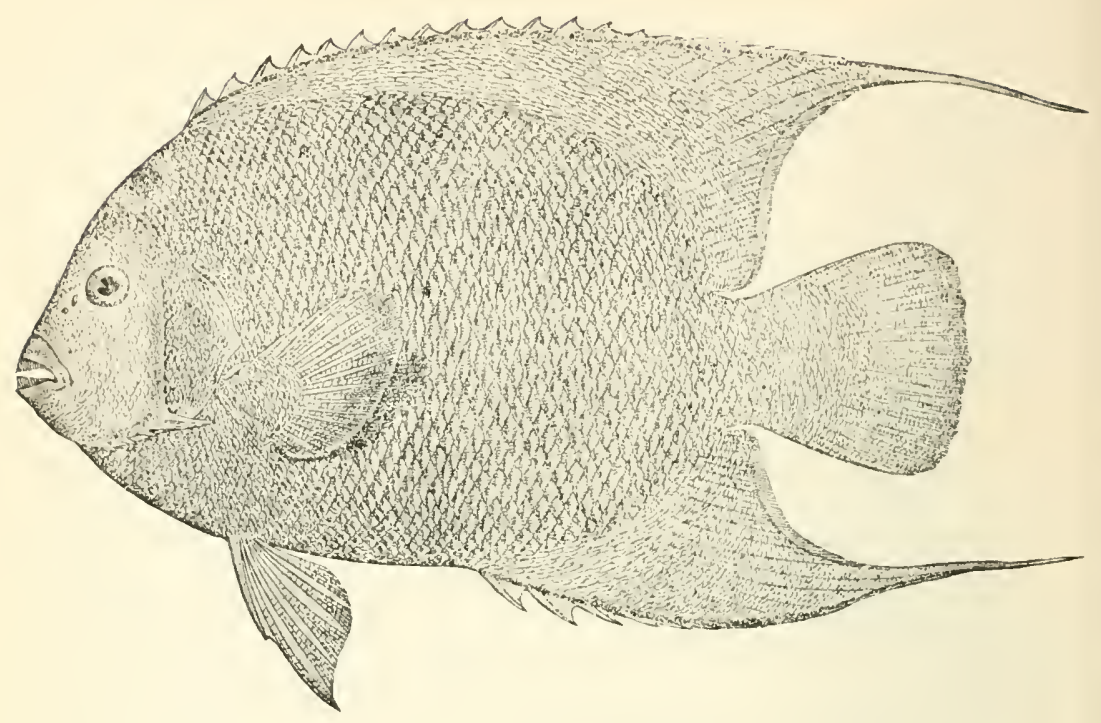

\section{8. "ANGELICHTHYS CILIARIS." $626 \quad \begin{array}{cc}1684 \\ \end{array}$}

ANGEL-FISII ; “Head $31 / 2$; depth $17 / 8$; eye $41 / 2$ in head; snout IsABELITA. $2 \mathrm{I} / 2$. D. XIV, 21 ; A. III, 21. Body oblong, oval; anterior profile straight, steep, sharply convex in front of dorsal ; anterior dorsal outline and ventral outline nearly parallel ; jaws projecting. Length of head equal to its depth from anterior margin of blue ring in front of dorsal; the preorbital $1 / 3$ broader than eye, with 1 or 2 indistinct spines; preopercle with a strong, grooved, slightly curved spine at angle, about as long as orbit; 5 or 6 short, blunt spines with intermediate minute ones on upper limb, the longest of these spines 6 in the spine at the angle; 2 or 3 short, strong spines on lower limb; interopercle with 1 or 2 short spines; premaxillary very thick, its width above equal to orbit; a furrow from front of eye below nostrils ; interorbital greater than preorbital, equal to distance between eye and upper end of gill opening. Soft dorsal and anal falcate, the filamentous tips reaching much beyond the caudal; pectoral broad, obliquely rounded, $1 \frac{2}{5}$ in head; ventrals long, the spine long, $12 / 3$ in head, the rays slightly filamentous, not quite reaching anal, equal to head; caudal rounded, equal to head behind premaxillary ; lateral line ceasing before reaching end of dorsal, the scales below 


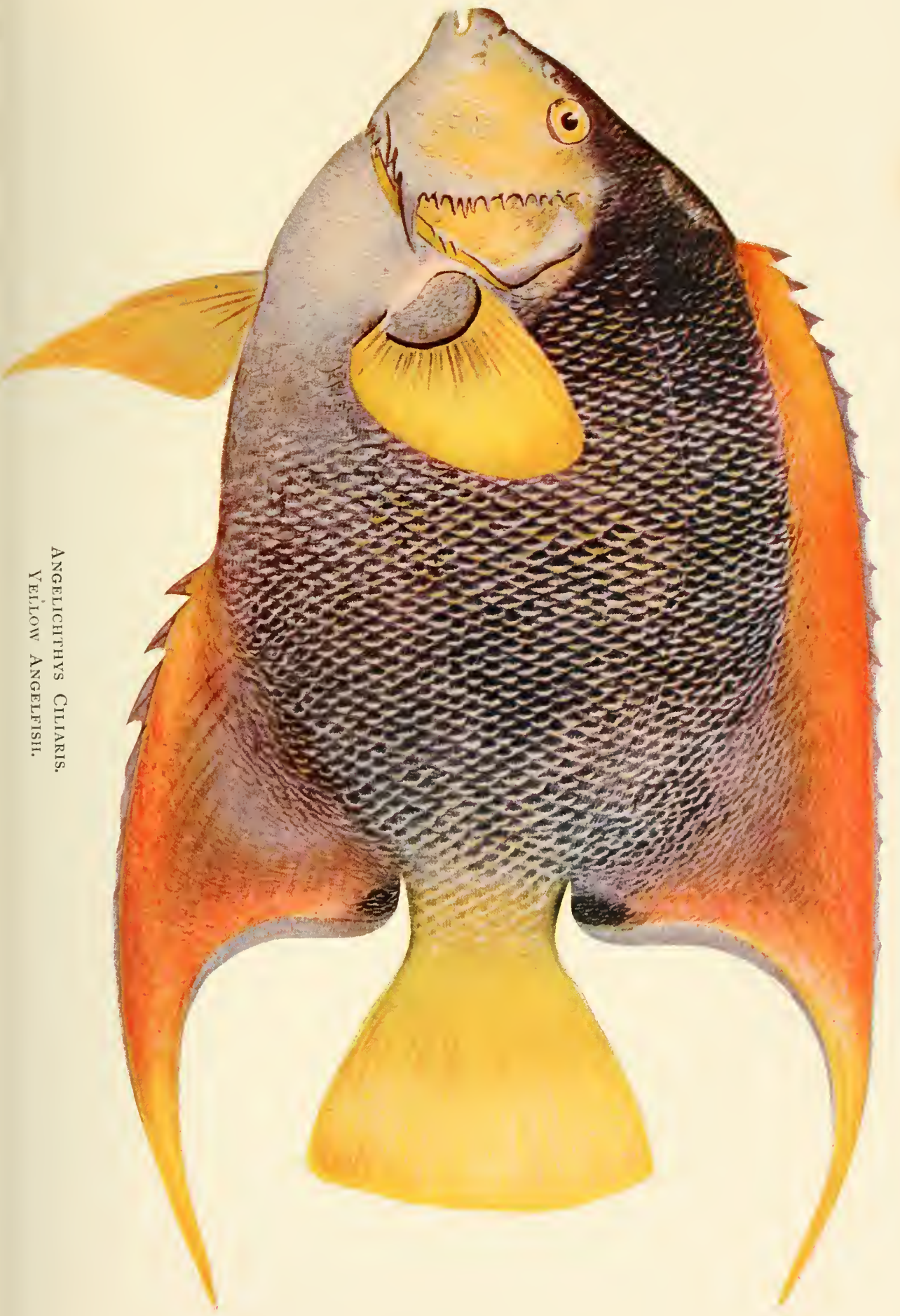



regularly arranged, those above irregularly. Ground color olive, terminal half of scales on sides yellow, side of head yellowish olive, top of head dusky; a blue ring in front of dorsal surrounding a black spot containing a few pale-blue specks; iris yellow, blue above and below, upper jaw blue-black, some yellow at corner of mouth; lower jaw, lower side of head, and breast dusky olive; a dark blue margin to opercle much broader above than below ; upper edge of preopercular spine pale blue ; edge of dorsal fin blue black, a black blotch on last rays, the fin otherwise reddish or orange, becoming paler toward tip of filament; anal similar to dorsal, but darker ; caudal entirely pale orange or clear lemon yellow ; pectoral lemon yellow, the base with a brown blotch bordered anteriorly by a narrow blue stripe; ventrals lemon yellow, somewhat dusky at base."

ANGEL-FISH ; Weight to 8 pounds ; average, $21 / 2$ pounds. Common Angel-fish (G.). U. S. F. Commission, 1896, says to 20 pounds. Caught: Still, bottom fishing; rod and reel, No. 6 line, No. 6 hook with gut snood. Bait: Cut Crawfish, cut Conch, small shell fish out of shell, cut fish, Fiddler Crab. The natives of the Keys grain them. By many considered the handsomest fish in the world. Edible, C.

I40. "BALISTES CAROLINENSIS." 6321701

TRIGGER-FISH ;

"Head $31 / 4$; depth $13 / 4$.

D. III, 27 ; A. 25 ;

LeAther Jacket ; scales usually about 60 (55 to 63 ); about 35 scales Cucuyo ;

TURBOT. in an oblique series from vent upward and forward. Third dorsal spine shorter but stouter than the second and remote from it; plates on head similar to those on body; caudal lobes produced in adult; soft dorsal high, its longest rays elevated but not filamentous, in adult $1 \frac{1}{4} 4$ in head. Ventral flap large, supported by several slender pungent spines, resembling fin spines. Lateral line very slender, showing only as the scales begin to dry, its course everywhere undulating and very crooked; it extends from eye backward to interspace between dorsals, then bends abruptly and obliquely downward to opposite first third of anal, then forms a $\mathrm{V}$-shaped figure, returning back to level of middle of caudal peduncle, 
whence nearly straight to base of caudal; a branch from behind eye extends obliquely downward and forward to the breast below pectorals; a cross branch at the nape connects the lateral lines of the two sides. Color, in life, olive gray ; a more or less distinct darker cross bar under front of second dorsal and 1 under last ray; some small violet spots on upper part of back; usually a ring of blue spots, alternating with olive-green streaks, about eye; violaceous marks on sides of snout ; first dorsal spotted and clouded with bluish; second dorsal pale yellowish with clear sky-blue spots separated by olivegreen reticulations, the spots arranged in rows; blue markings all fading in alcohol, leaving the olivaceous streaks; base of dorsal with 3 or 4 dark diffuse shades in the young; base of pectoral bluish, with olive spots ; anal colored like soft dorsal ; pectoral greenish."

TRIGGER-FISH ;

Illustration. Page. OLD WIFE;

OLD WENCH ;

Cochino.

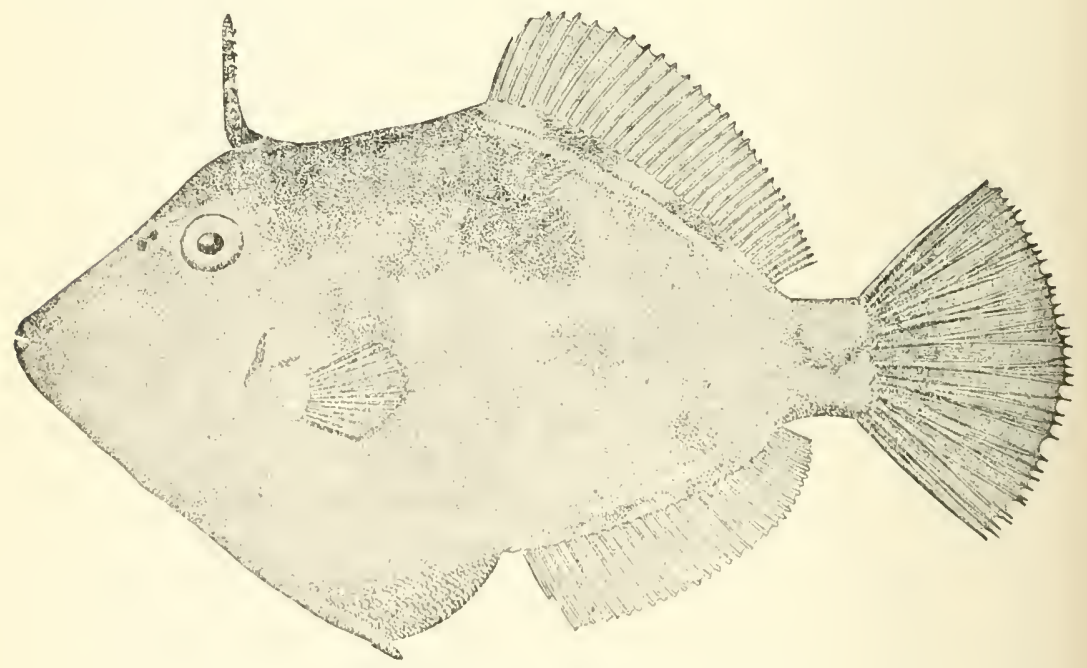

I42. "MONOCANTHUS CILIATUS." 6341714

TRIGGER-FISII ;

"Head $31 / 2$; depth $13 / 4$; young $11 / 2$.

D. I, 30 ;

LeATIIER Fish; scales very small, without median crest. Spines Lija. becoming longer on caudal peduncle, which has in addition 2 or 3 pairs of strong spines curved forward, these prominent 
only in adults; ventral flap longer than head, about $1 / 3$ length of body. Scales on ventral flap developed as flat plates, with their free margins pectinate. Snout pointed, the upper profile concave. Dorsal spine strong, nearly as long as head, armed behind with 2 rows of retrorse barbs; ventral spine small, rough. Color varying very much with the surroundings of the fish, from dull olive gray to the most vivid grass green ; the markings not well defined and not very constant; green, with white cirri on sides; a whitish longitudinal cloud behind pectorals ; a pale band downward and forward from eye ; lower side of head with darker cross bands ; dorsal and anal pinkish, with (usually 3 ) darker spots at base; ventral flap edged with scarlet; caudal greenish, mottled with darker and pale; some specimens show neither red nor green shades, and have vague, dusky, longitudinal stripes."

\section{I43. "MONACANTHUS HISPIDUS." $\begin{array}{ccc}\text { lllustration. } & \text { Page. } \\ 635 & 1715\end{array}$}

Turbot; "Head $3 \frac{2}{5}$; depth $13 / 4$. D. I, $32 ;$ A. 32. Trigger-Fish ; Young slightly deeper ( $1 \mathrm{I} / 2$ ) proportionally than adult. FOOL Fish ;

F1LE FISH ; Body rather deep. Jaws subequal; eyes large, about Leather Fish ; 3 in snout. Gill opening about as long as eye, sepHORNY CONY; arated from the eye by an interspace nearly equal to Lija. its length. Anterior profile slightly concave. Dorsal spine somewhat shorter than snout, more than $1 / 2$ head, inserted above posterior part of eye, stout, rough, armed behind with 2 rows of retrorse barbs; first ray of soft dorsal often filamentous in the adult (male?), its length varying from that of snout to that of depth of body (longest among specimens seen by us is 1 from the Canary Islands); pectorals small. Pelvic bone long, ending in a short, blunt, movable spine, beyond which the abdominal flap does not extend. Scales minute, each with a crest of about 3 prickles, those on caudal peduncle villous, those on ventral flap larger, elongate; no naked areas; no recurved spines on tail. Color, grass green or olive; back and sides with faint, irregular whitish spots; head plain; spinous dorsal and caudal green; second dorsal and anal translucent; adult less variegated; dull olivaceous, mottled with dusky. Length, 10 inches." Weight to 4 pounds ; average about 2 pounds.

Caught among the Keys, 9 to 12 line, $1 \%$ hook. A game fish. Bait: Crawfish, Crustacea, cut fish, Conch. Edible, C. 


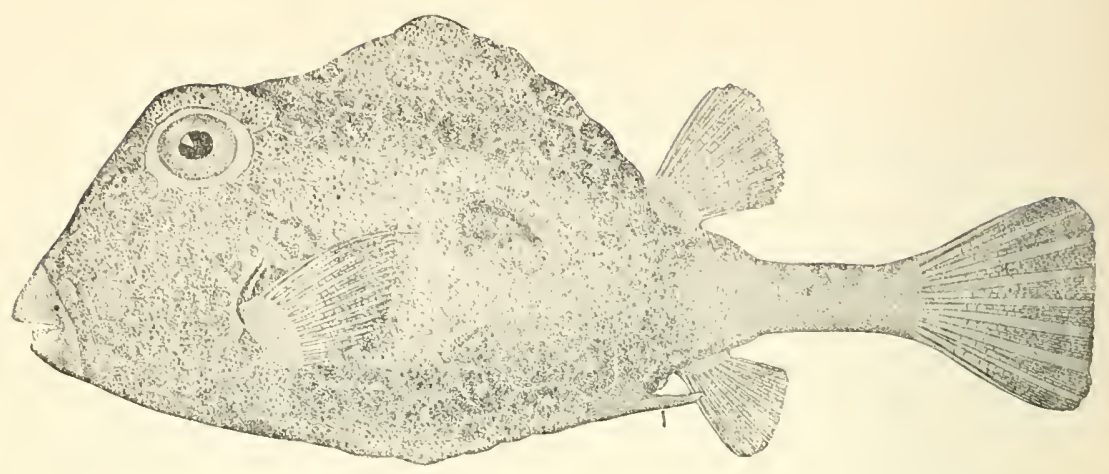

Jllustration. Page. I44. "LACTOPHRYS TRIGONUS." $\quad 641 \quad 1723$

TRUNK-FISH ;

CIIAPIN ;

SHELLFISH.

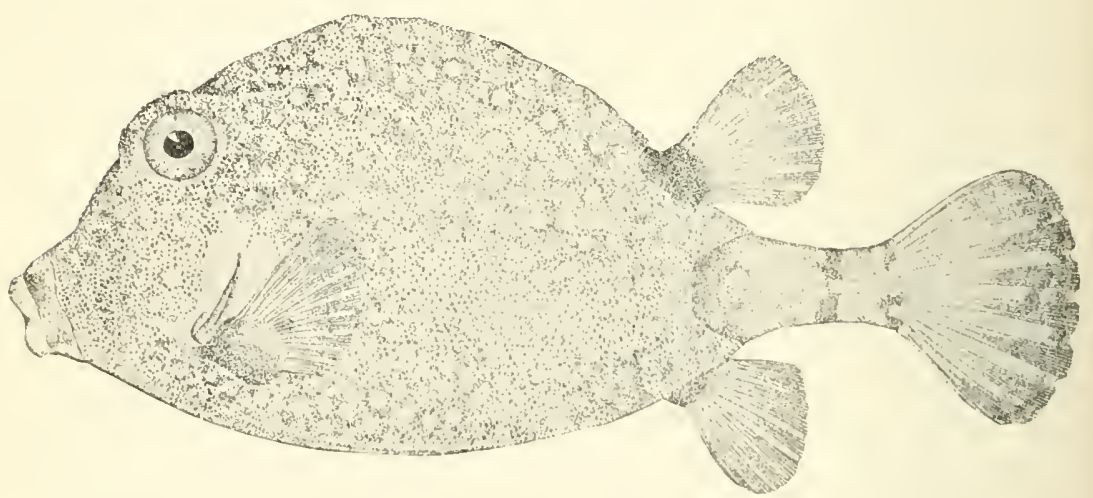

I45. "LACTOPHRYS TRIQUETER." $638 \quad 1722$

TRUNK-FISII .

" Head 4 ; depth $2 \frac{1}{5}$; eye 8 to 9 in total length, Rock Shellfisir; 4 to $4 \frac{1}{2}$ in height of side. D. 10 ; A. 10 ; P. 12 ; DRUNKEN-FISII ;

Chapin ;

Plate-fish. scales 9. Carapace trigonal, without spines; breadth equal to $1 / 2$ length of body in adults, greater in young. Ventral surface of carapace convex anteriorly, concave posteriorly. Back elevated, compressed, sides joining at an angle of about 30 degrees. Carapace continuous behind dorsal fin. Interorlital space concave. Upper surface of snout concave. Teeth long, spike-like, 8 to 10 in each jaw. Scales of the sides 
hexagonal, in young with strix radiating from center to angles of each scale, in adult armed simply with tubercules, 9 to 10 in longitudinal series from gill opening to tail, 8 in median line of ventral surface, 8 between ventral keel and angle of back; posterior dorsal scute unarmed. Branchial aperture oblique, its length greater than diameter of eye, descending before base of pectoral. Fins obtusely rounded; caudal of moderate length and rounded. Color, dark brown, thickly studed with circular spots of yellowish white, each about $1 / 6$ of an inch in diameter; the position of these spots appears to have no relation to the shape of the plates of the carapace; ventral surface lighter and spotless; epidermis often abraded, leaving the shell uniform tawny white; lips, bases of the fins, and tail stem brown like the ground color of the body. In dried specimens the epidermis dries and loses its color, and the shell shows through with a lighter shade. Günther states that the lips, roots of the fins, root of the tail, and tip of the caudal are black. (Goode.) Length, $10 \frac{3}{5}$ inches. Young, in life, light olive, covered everywhere above and below with round darker spots of greenish blue about as large as pupil ; fins plain ; caudal peduncle with a few spots."

\section{I46. “LACTOPHRYS TRICORNIS." $\begin{array}{ccc} & & \\ \text { Illustration. } & \text { Page. } & 1724\end{array}$}

Cow-Fish; All of the so-called shell-fishes are usually caught Cuckold; while fishing for other fishes, and are only curiosities. TORO.

The meat is said to be sweet, but I will leave that to persons who desire to try them.

Siooth PUFFer.

I47. “LAGOCEPHALUS LEVIGATUS." 6421728

148. "LAGOCEPHALUS PACHYCEPHALUS."

1728 JUG-FISH.

No illustration.

\section{I49. "SPHEROIDES SPENGLERI." $644 \quad 1732$}

Swell-fish. "Head 3. D. 7 ; A. 6. Head compressed, SOUTHERN PUfFER; narrow; interorbital space very slightly concave, $\begin{array}{ll}\text { SWELl TOAD; } & \text { or flattish with a slight median ridge, narrow, } \\ \text { TAMBOR. } & \end{array}$

about $1 / 2$ as broad as eye, its width 5 to 6 in head, $2 \mathrm{I} / 2$ to 3 in snout, which is 2 in head; profile of snout not steep. Body 
variously prickly, sometimes smooth, usually a patch of minute spines from occiput halfway to dorsal fin ; belly spinous to near the vent ; skin of head, tail, and most of the skin of the sides smooth ; sides usually with small dermal cirri, especially in the young, these not very conspicuous. Young examples have the back and belly covered with rather large, not close set, stellate prickles as described in the original account of Tetrodon nephelus. Of the larger individuals, some have prickles only on the back, others on the belly only; 1 or 2 only on a small area behind the eyes near the median line, while the majority of the largest are entirely smooth. There is no doubt that these all belong to one species. The loss of the prickles is probably to some extent dependent on age. Adult olive brown, with numerous small light-bluish or greenish spots everywhere, many of them forming ocelli around darker spots of the ground color; numerous scattered black spots as large as the pupil, one in axil below most distinct; some obscure dark spots along sides of belly, this region being flesh color, with pale rivulations; pectorals yellowish; caudal pale, usually with 2 dusky shades. Young, gray and olive above, much mottled with blackish; back with numerous irregular blue spots; iris coppery, the pupil green; belly white, grayish brown along the sides; 12 round blackish spots along the boundary between sides and belly; a whitish bar at base of caudal; caudal with 2 bars of blackish olive and 1 of white; other fins plain; back and sides with whitish cirri.",

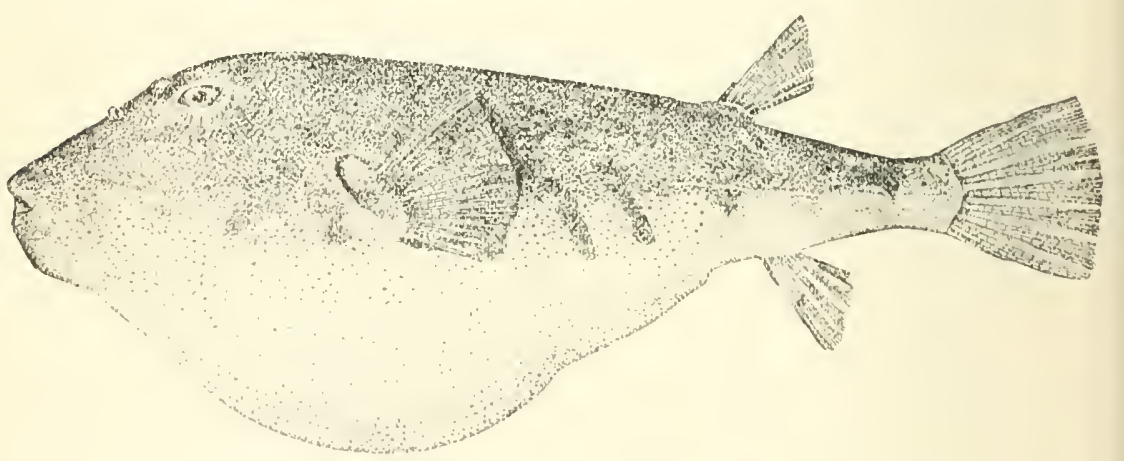

SWell TOAD ; I50. "SPHEROIDES MACULATUS." 645 PUFFER ;

BLOWER. 
ON THE EAST COAST OF FLORIDA.

r51. "SPHEROIDES MARMORATUS."

1733

BLOW-FISH ;

No illustration.

SPINY-BACK.

SWELl-fish ;

I52. "SPHEROIDES TESTUDINEUS." $646 \quad 1734$

TAMBOR ;

GLOBE F1Sh.

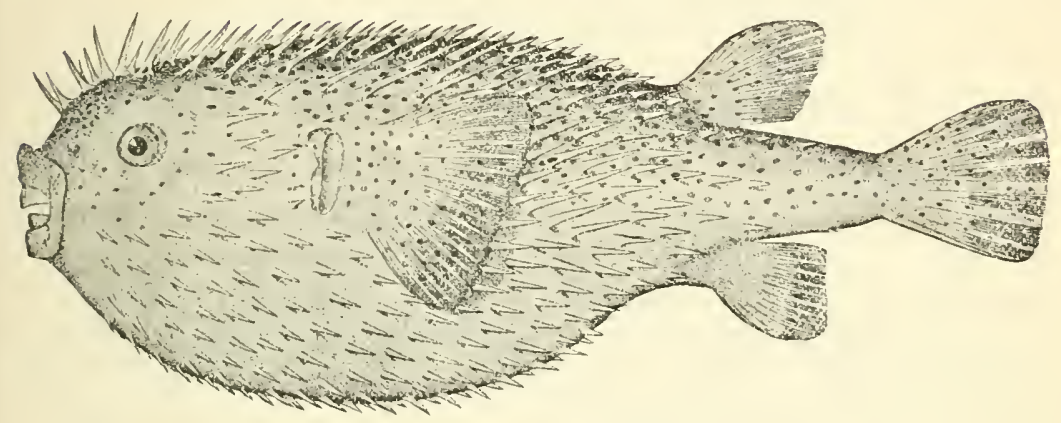

I53. "DIODON HYSTRIX." $648 \quad 1745$

PORCUPINE-FISH ;

"Head 3 ; depth $3 \mathrm{I} / 2$. D. 13 to 15 ; A. 13

Erizo ;

to 15 . Spines strong, dilated at base, with a pair Puerco Espino. of basal grooves; frontal spines not as long as post-pectoral spines (in adults not $1 / 2$ as long, about as long as eye) ; post-pectoral spines longer than any others, especially in the adult, usually about as long as pectoral fin, those of the posterior part of back and tail short and broad, 3-rooted, and therefore not erectile; predorsal spines very short, 3-rooted, fixed or nearly so; about 20 spines in a series between snout and dorsal; upper lobe of pectoral little longer than lower; upper and lower part of tail with 2 or 3 pairs of 3-rooted, immovable, recumbent spines. Adult above everywhere covered with small round black spots, these largest in front of dorsal, smallest on naked area about mouth; white below; fins all more or less spotted in the adult, nearly plain in the young. Length about 3 feet."' 


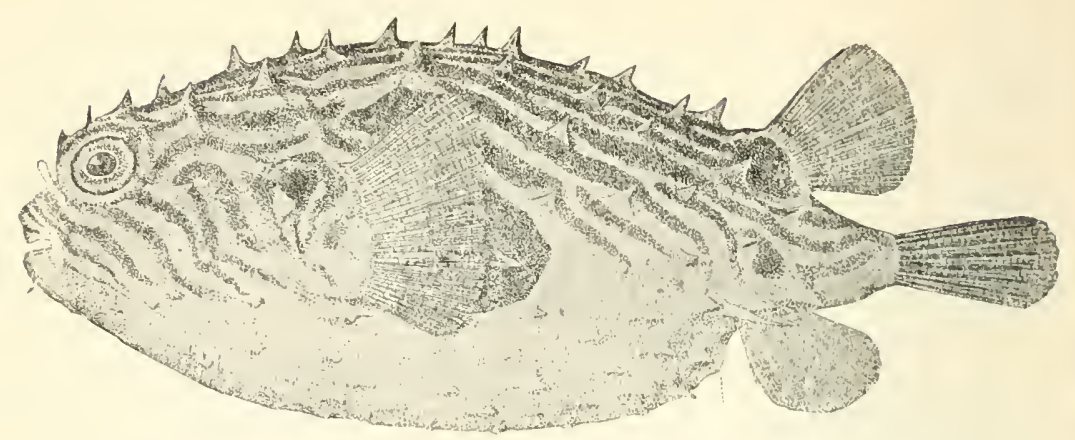

Illustration. Page. 154. “CHYLOMYCTERUS SCHCEPFI." $649 \quad 1748$

BURR-FISII ;

COMMON BURR-Fish;

RABBIT-FISH ;

SWELL-TOAD;

Swellfish.
"Head 23/4; depth 3. D. $12 ;$ A. 10 . Body a little broader than deep at gill openings; interocular space broad, concave; eyes large, lateral, nearly as long as snout, each with a cirrus above it, longer than pupil ; gill opening about as wide as eye, opposite upper anterior part of pectoral. About 9 spines between eye and tail, their height equaling diameter of pupil; spines on belly much smaller, partly imbedded in skin; some of the posterior with cirri; spines on caudal peduncle; anterior root of each spine little if any larger than others. Pectoral fin deeper than long, the margin undulate, the upper lobe longest. Color, greenish, belly pale; a round, black, ocellated spot above pectorals, not as large as eye, a larger one behind pectorals, another at base of dorsal, with a smaller one below it; back and sides with parallel black stripes of uniform width, about as wide as the interspaces, those on the back running longitudinally, those on sides obliquely downward and backward, those on front of head running crosswise, a dark bar at base of dorsal; belly pale in the adult, often black in the young; other fins plain. Length, 6 to 10 inches.'

Blow-fishes. On page 425, U. S. Commission, 1895, in check list of North American Fishes, Jordan \& Everman, under "family" name of "Puffers," give the various names of several varieties of Blow-fish, Swell Toads, etc., which frequent the East Coast, and which I have caught. I conclude to group them under the general name of "Blow-fish," as alove. They are the Toad-fish, Smooth Puffers, Swellfish, Southern Puffers, Swell Toads, Tambors, 
Puffers, Blowers, Globe-fish, and Blow-fish, Bladder-fish (local), Porcupine Fish, etc. Weight to 3 pounds; average about 3/4 pound.

Caught only when fishing for better fish. Non-edible. Worthless, foul fishes.

SEA Robin.

I55. "PRINOTUS SCITULUS." $\quad \begin{array}{cc}\text { Illustration. Page. } \\ 769 & 2157\end{array}$

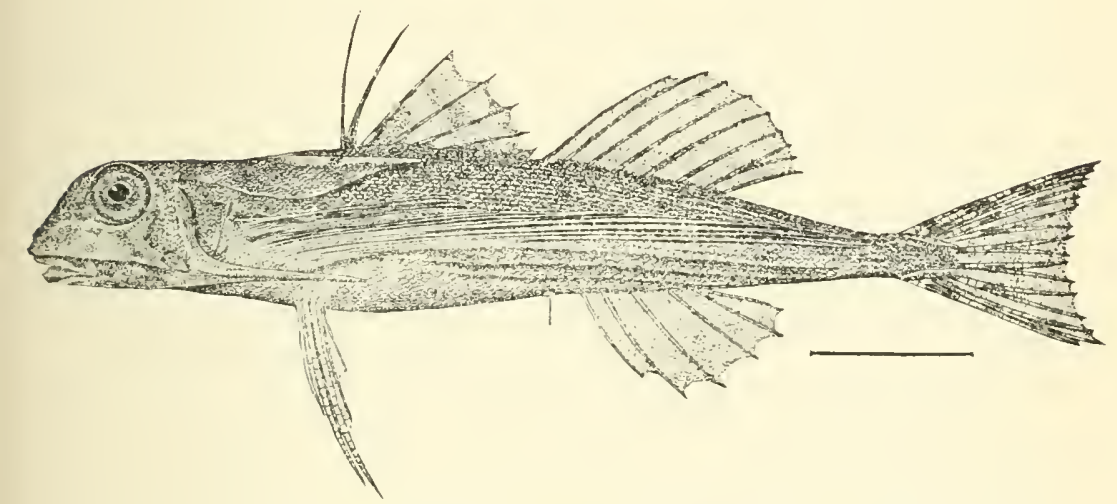

I56. "CEPHALACANTHUS VOLITANS." 7782183

SEA ROBIN ; FLYING ROBIN ; BAT-FISH ;

VOLADOR ;

Murcielago.
"Head 4 1/3 ; depth $5 \frac{1}{2} 2$. D. II-IV, 8 ; A. 6 ; P. $28+6$. First 2 dorsal spines free, slightly connected by membrane at base; preopercular spine reaching beyond base of pectorals, not to end of occipital spine; pectorals reaching nearly to base of caudal in adult, very much shorter in young; in the young the spines of the head are much longer. Color, greenish olive and brown above, of varying shades; below pale, marked irregularly with dusky and bright brick red, varying to salmon yellow; pectoral fins mottled with bright-blue streaks near the base and blue spots and bars toward the tip; their under sides glaucous blue, edged with darker; caudal fin with about 3 brownish-red bars; coloration extremely variable. Length, 12 inches."

Only occasionally and accidentally caught, and only a curiosity. 


\section{7. “LOPHOGOBIUS CYPRINOIDES." $\begin{array}{ccc}\text { Illustration. Page. } & \text { Par } & 2209\end{array}$}

Goble.

"Head $3 \frac{2}{5}$; depth $3 \frac{3}{5}$; greatest width $5 \mathrm{x} / 2$ to $6 \frac{1}{2}$. D.

VI or VII-10 or 11 ; A. 9 or 10 ; scales 26 to 30 ; vertebræ $11+15$; eye $31 / 2$ to 4 . Body short and deep, little compressed, formed much as in Cyprinodon; head naked, a prominent naked dermal crest extending from above middle of eye to near front of spinous dorsal; interorbital width slightly less than diameter of eye; profile convex; snout short, bluntish, about as long as eye; mouth very oblique, the gape slightly curved; front of upper lip on level of lower border of eye ; lower jaw somewhat projecting; teeth in both jaws in bands, the outer series erect and somewhat enlarged, those of the inner series small; scales large, reduced on breast and nape; a few scales on upper part of opercle; median line before dorsal naked; dorsal spines produced in short filaments; last rays of soft dorsal reaching caudal; caudal rounded; pectorals lanceolate, reaching beyond insertion of anal, the upper rays not silk-like; skull very broad and short, with low, median crest, highest behind; double crests of temporal region joining at the upper posterior angles of the eyes and forming a bridge over the interorbital area, the crests ending abruptly above the anterior part of the orbit, forming a decided angle, the bridged interorbital leaving a large foramen in front of this angle. Color, blackish green in life ; spinous dorsal black; soft dorsal, ventrals, and anal dark, plain ; pectorals lightish, plain ; caudal finely mottled. Length, 2 inches. Recently taken by Dr. Evermann in brackish water at Biscayne Bay."

I believe this small fish to be the "Stuffonier" of Mosquito Inlet, there used as Snapper bait.

158. "GOBIUS STIGMATICUS." (POEY.) $787 \quad 2224$ Gobies. "Head 4 ; depth 5 to 6 ; eye $31 / 3$. D. VI-12;A. 12 or 13; scales 27. Body a little deeper and less compressed than in Gobius encaomus. Anterior profile moderately decurved; back slightly arched; skull flattish behind, much broader than in $G$. boleosoma, with an evident median ridge; mouth oblique, large, lower jaw thin and flat, maxillary reaching to below pupil. Teeth above uniserial, some of them enlarged and recurved; lower teeth in a narrow band, males sometimes with the hindmost of the outer series a strong, exserted, recurved canine (present in Poey's type). Anterior half of 
body scaled except region between nape and dorsal, which is naked; breast naked. Longest dorsal spine $2 / 3$ head, sometimes elongate; caudal $3 \mathrm{x} / 2$ in body. Color, light greenish, sides of male with 5 or 6 narrow, straight, whitish or yellowish cross bars, regularly placed; 4 dark bars on head, 3 below the eye and 1 on opercle; a small, dark spot behind and above opercle; ventral fins barred; female with a row of irregular dark spots connected by a dusky streak, the pale cross bars obsolete."

Page 2217, "The commonest of all shore fishes in tropical America." With few exceptions small fish, or Minnow, used as bait.

There are 120 species of this fish in Bulletin 47, but I describe only two, as they are used in Florida only as bait, although some of the species are edible in other localities. All the Gobies, except one or two, are Minnows, and can be caught with cast nets and used as bait. They are plenty in brackish water in Biscayne Bay.

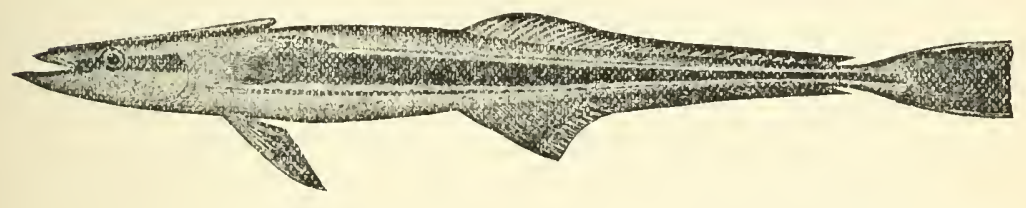

I59. “ECHENEIS NAUCRATES." (PILOT.) $796 \quad 2269$ SHARK-SUCKer; This is the locally-called "Pilot Fish," attached REGADOR ; to Shark. Frequently as many as five or six on one Sucking-Fish. Shark when the latter is caught. 

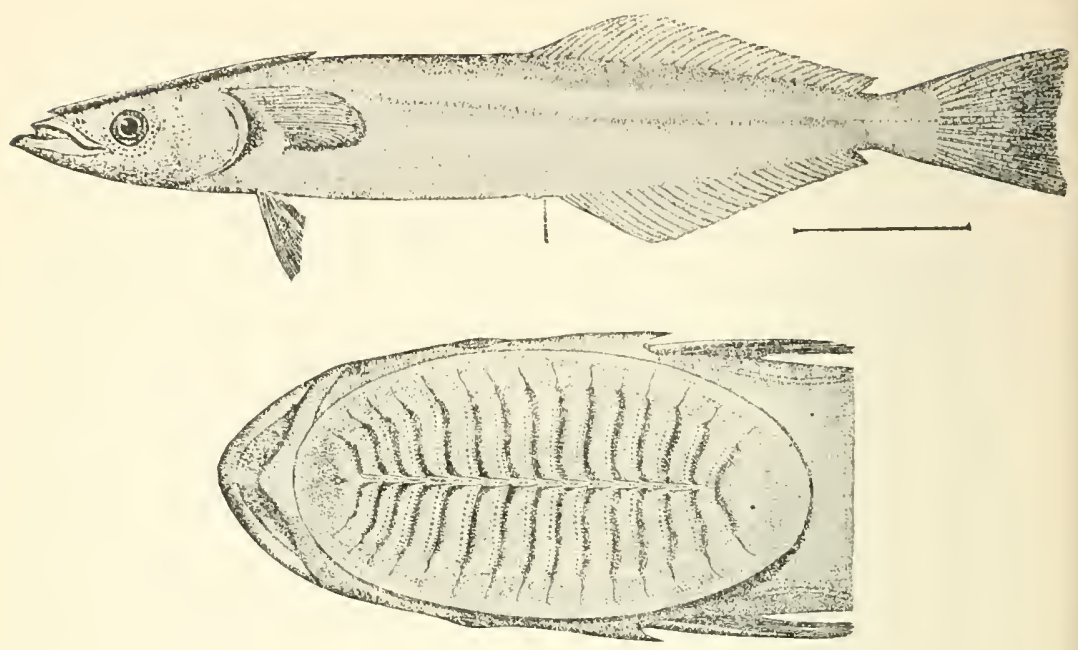

$797 \mathrm{a}$

160. "REMORA BRACHYPTERA."

Illustration. Page. $797 \quad 2272$

REMORA; Pilot Fish (G).
797 a shows the "sucker" by which the fish at taches and holds himself to Shark or other large fish.

I6I. "OPANSUS TAU." No illustration. 2315

TOADFISH ;

SAPO;

SLIMER ;

OYSTER-FISH. See Blow-fish, Burr-fish, etc.

Tondfisi ; See Blow-fish, Burr-fish, etc.

SAPO.

\section{2. "OPANSUS PARDUS."}

I63. "MERLUCCIUS BILINEARIS." No illustration. 2530 Hakes (OR Winting. G.); See Whiting, Kingfish. (Small.) Silder Hake;

WIITING ;

NeW ENGLANd HAKE. 


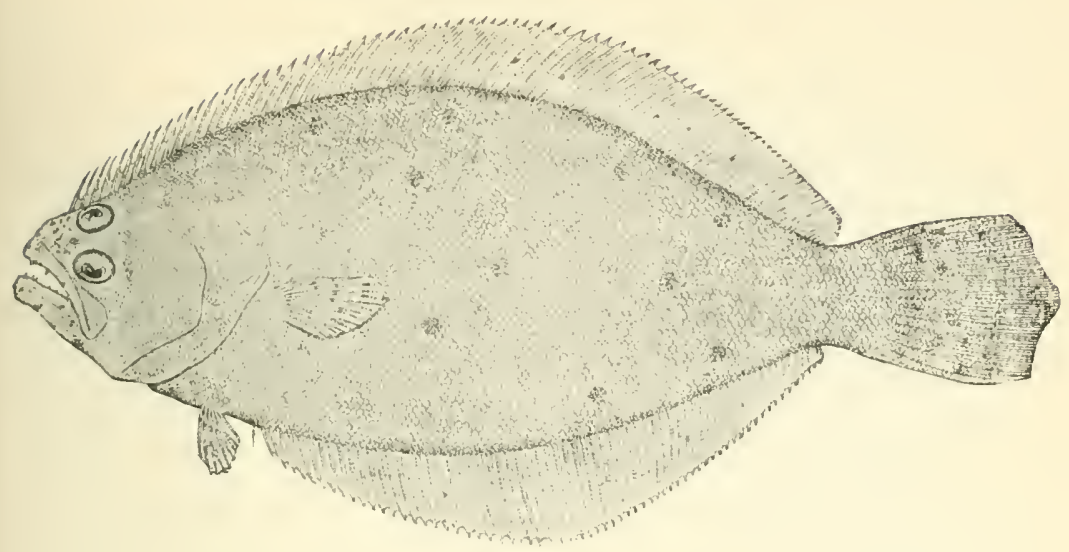

\section{I64. “PARALICHTHYS DENTATUS." $\begin{array}{cc}\text { Illustration. } & \text { Page. } \\ 922 & 2629\end{array}$}

Flounders ;

"Head $31 / 2$ to 4 ; depth $2 \frac{2}{5}$; eye 6 in head; Summer Flounder. maxillary 2 ; pectoral $2 \frac{1}{5}$; ventral $31 / 2$; caudal peduncle 4 ; caudal $1 \mathrm{~T} / 4$. D. 86 to 91 ; A. 65 to 71 ; lateral line 108 (tubes). Curve of lateral line $32 / 3$ to $4 \frac{1}{3}$ in straight portion ; body ovate: maxillary about $1 / 2$ head, reaching past posterior margin of eye ; month large, oblique, the gape curved; canines large, conical, wide set; gill rakers comparatively long and slender, longest $2 / 3$ eye, $5+15$ to $6+18$ in number; interorbital area a rather flattish ridge, in the adult about equal to vertical diameter of eye, narrower in the young, forming a bony ridge; scales cycloid, each with numerous small accessory scales; vertebræ $11+30=41$. Color, in life, light olive brown; adults with very numerous small white spots on body and vertical fins; sometimes a series of larger white spots along bases of dorsal and anal fins ; about 14 ocellated dark spots on sides, these sometimes little conspicuous, but always present; a series of 4 or 5 along base of dorsal, and 3 or 4 along base of anal, those of the 2 series opposite, and forming pairs; 2 pairs of smaller less distinct spots midway between these basal series and lateral line anteriorly, with a small one on lateral line in the center between them; a large distinct spot on lateral line behind middle of straight portion; fins without the round dark blotches."

165. "PARALICHTHYS LETHOSTIGMUS." No illustration. 2630 SOUTHERN Flounuer. 
I67. “PARALICHTHYS ALBIGUTTUS." No illustration. 2631 Gulf Flounder.

168. "ANCYLOPSETTA QUADROCELIATA." 925

2634

Flounder.

" Head $33 / 4$ to $3 \frac{4}{5}$; depth $12 / 3$. D. 70 to $76 ; \mathrm{A} .57$ to

59 ; pores in lateral line 83 to 90 ; vertical series of scales 70 ; fourth or fifth dorsal ray longest, nearly $2 / 3$ length of head. Caudal $1 \frac{1}{5}$ in head; ventral of colored side 12/3. Body oval, compressed, very deep; an abrupt angle above eye; mouth very small, the maxillary reaching to below middle of orbit, $2 \frac{1}{2}$ in length of head; teeth comparatively small, about 14 on each side of lower jaw; no strongly differentiated canines in either jaw. Eyes moderate, separated by a very narrow, sharp, scaly ridge; gill rakers very short, thick, few in number, $2+6$ or 7 , the longest less than $1 / 2$ diameter of pupil; scales rather small, very strongly ctenoid, those on blind side also rough; curve of lateral line rather low; tubes of lateral line simple; dorsal beginning in front of pupil, its anterior rays long and filiform, much exserted; caudal short and rounded, $1 \frac{2}{7}$ in head; ventral fin of colored side rather long, as long as pectoral, $1 / 2$ length of head; anal spine wanting. Color, brownish olive, with 4 large, oblong, ocellated spots, the first above the arch of the lateral line; the 3 posterior forming an isosceles triangle, the hindmost being on the lateral line, the ocellated spots are frequently furnished with a bright white center, and the sides and vertical fins have often a few scattered white spots; a small, indistinct, dark spot on middle of each eighth or tenth ray of dorsal and anal. Vertebræ $9+26=35$.'" 


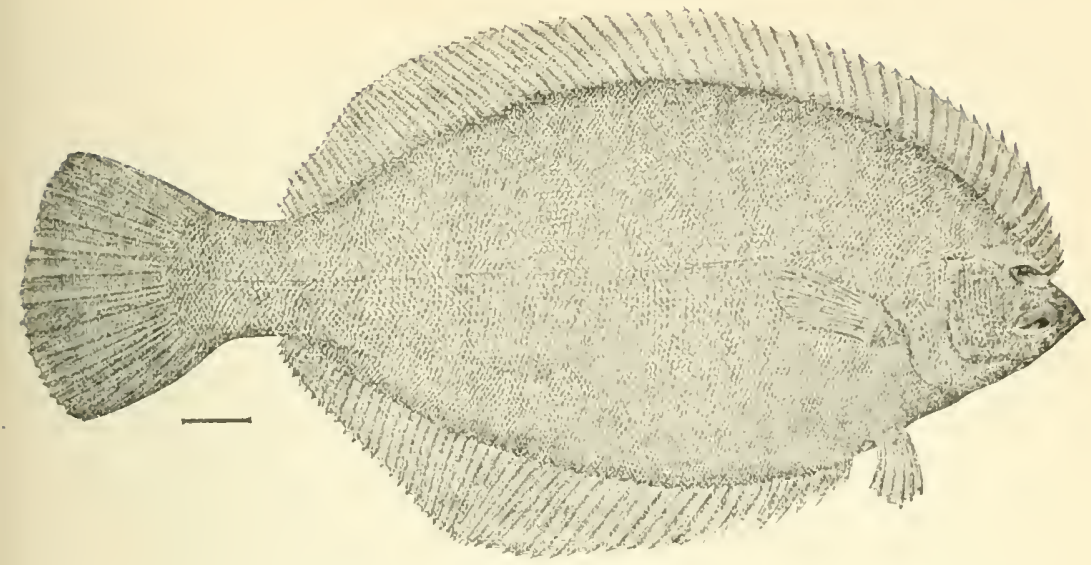

Illustration, Page.

169. "PSEUDOPLEURONECTES AMERICANUS." 9332647 Winter Flounder;

Common Flatfish.

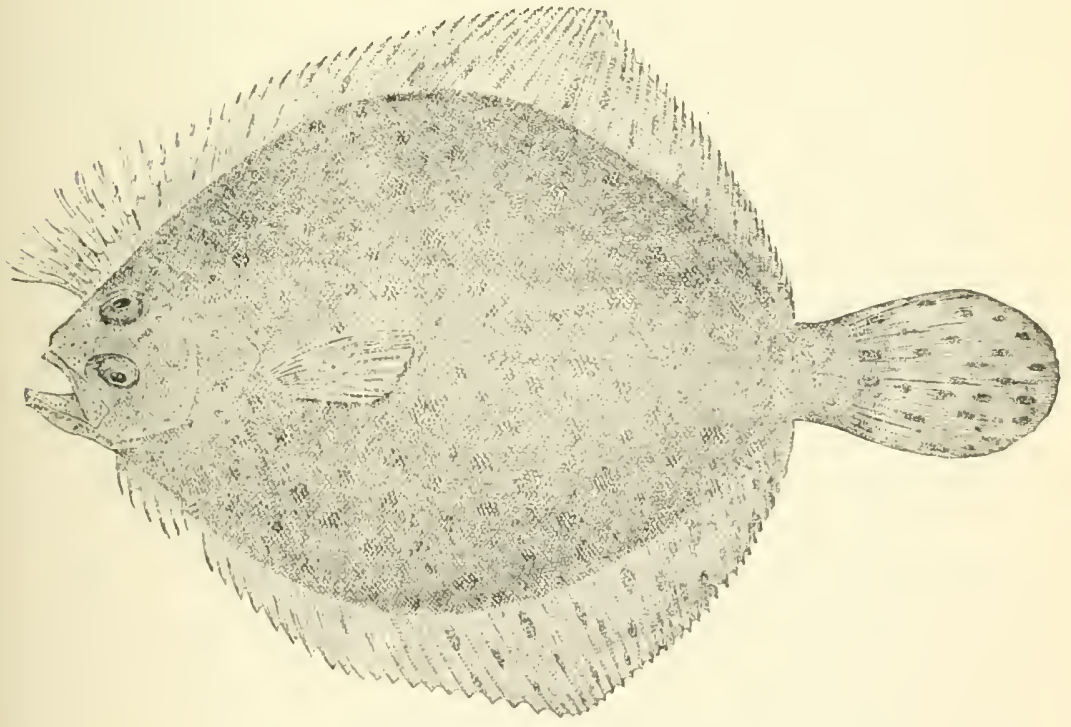

I70. "LOPHOPSETTA MACULATA." $938 \quad 2660$

Flounder (SPOTTEd, G.);

WINDOW PANE. 


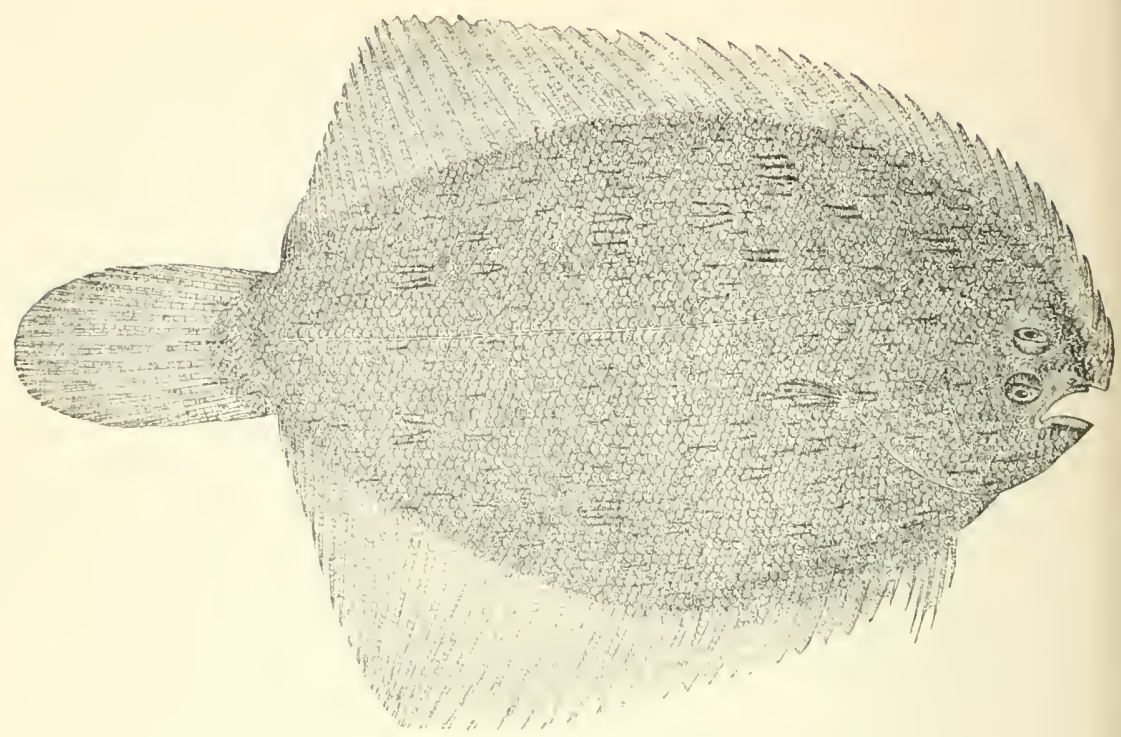

\section{I71. “ACHIRUS LINEATUS.” $\quad \begin{array}{ccc}\text { Illustration. } & \text { Page. } \\ & 947 & 2697\end{array}$}

Sole, American. "West Indies, Brazil, Florida Keys." "Specimens received from Key West."

172. "ACHIRUS INSCRIPTUS."

2696

Sole, American.

"Head $33 / 4$ in body; depth $13 / 4$. D. 53 to 57 ;

A. 40 ; scales 75 to 80 ; interorbital width less than eye; upper eye in advance of lower. Pectoral fin present on each side, that of the left side rudimentary, of a single ray; that of the eyed side with about 3 ; left ventral with 1 or 2 small rays, in some specimens entirely absent; right ventral joined to anal. Scales smaller and less rough than usual in this genus, those of nape scarcely enlarged on eyed side, those of blind side much fringed; scales of colored side with scattered hair-like appendages, some black, others pale. Color, olivaceous; head, body, dorsal, and anal fins covered with a network of dark lines; traces of about 8 dark cross streaks sometimes present; candal fin yellowish, nearly plain, or with a few dark dots or reticulations, its base dusky. Vertebre $8 \quad 20=28$." "'Specimens taken at Key West by Dr. Jordan." 


\section{ON THE EAST COAST OF FLORIDA.}

\section{r73. "ACHIRUS FASCIATUS."}

"The species is best known of American Soles.

AMERICAN SOLE;

HOG CHOKER

Head 4 in body; depth $1 \frac{4}{5}$.

D. 50 to 55 ; A. 37 to 46 ; scales 66 to 75 ; eye 7 in head; height of dorsal and anal nearly 2 ; caudal 11/6. Body broad, regularly elliptical; mouth moderate, reaching just past front of lower eye; right lower lip fringed; eyes very small, the upper one in advance of the lower; nostril ending in a wide tube, nearer lower eye than tip of snout ; interorbital space with scales, more than $1 / 2$ eye; head and body scaled with strongly ctenoid scales, none of them with hair-like appendages; lateral line nearly straight ; gill opening short, about twice as long as maxillary. Origin of dorsal on tip of snout ; last few rays of dorsal and anal rapidly decreasing, giving the fins a truncate appearance posteriorly; pectorals wholly wanting; caudal rounded. Color, dusky olive, more or less mottled, and with about 8 dark, vertical stripes, these varying very much in width and in number; vertical fins with the membrane of every second or third pair of rays blackish, besides dark cloudings at base of fin; caudal with numerous longitudinally oblong spots; blind side often with round, dark spots, especially in northern specimens, usually immaculate in southern ones (var. browni). Vertebræ $8+20=28 . "$

Flounders and Soles.

Weight to 10 pounds; average about 2 pounds. Caught with rod and reel, cut bait. Do not take bait readily. 2\% hook, No. 6 line. Are taken in Halifax and Hillsboro rivers, at night. Sharpen a stick, carry a lantern along the shores, in 6 inches to 2 feet water, and spear the fish with the stick. Large numbers are caught at Ponce Park when wanted. The Soles and Flounders are of same family. Edible, B. 


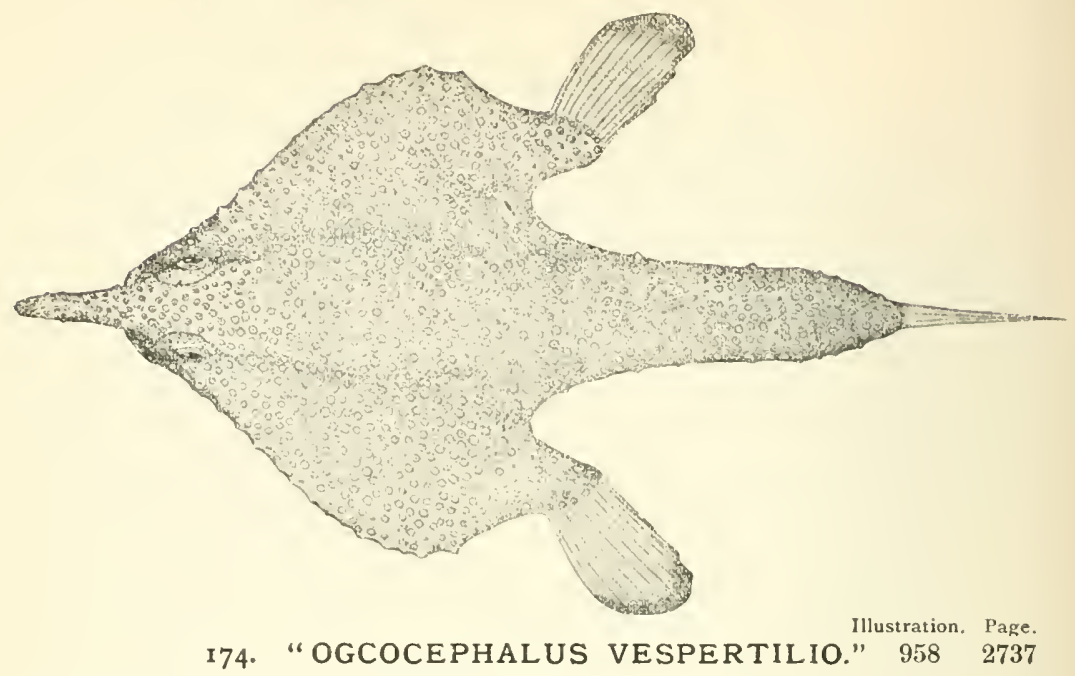

Bat Fisil; I have never seen this fish.

Diablo.

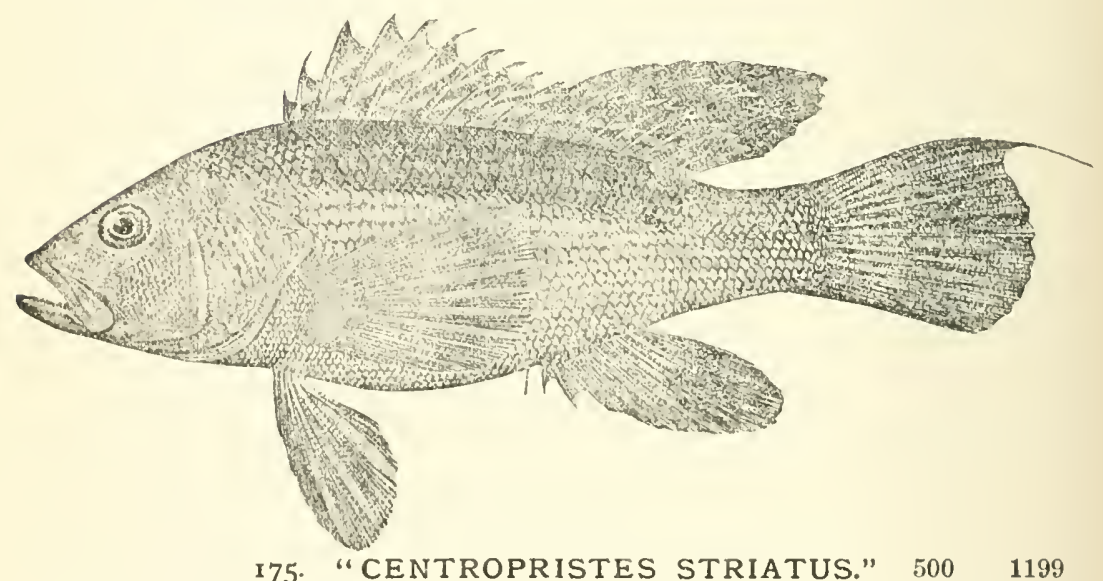

SEA BASS;

This fish goes by the local names of Sea Bass and Black Sea Bass; Black-fish, at Mayport, St. Augustine, and Ponce Black-FisiI ; Park. Not usually found south of latter point, but TAlly-Wag; Gardner caught one at Bears Cut, Biscayne Bay, winHaunabill; BLACK WILL; Biack Harry. ter 1901. He has never caught one in Indian River. Weight in Florida $1 / 4$ to $11 / 2$ pounds. Caught with No. 6 line, 1\% hook; Crab or cut fish. Edible, A. 

I76. “PAGRUS PAGRUS." $551 \quad 1356$

Besugo; This fish is also entered in my list among the RED PORgY ; Porgies, but I repeat here in order to show there Pargo Colorado. are two Besugos. See below.

I77. “LEIOSTOMUS XANTHURUS.” $569 \quad 1458$ (Repetition.)

Besouga (G.); This fish is also entered in my list as a Spot. He Spot; is called Besouga at Ponce Park, New Smyrna, and Goody; at Indian River Inlet. I repeat him here to put POST-CROAKER ; the above on record. He is one of the many "Spots."

OldwifE; $\quad$ Edible, A 1 ; which some of the other "Spots" are not. 


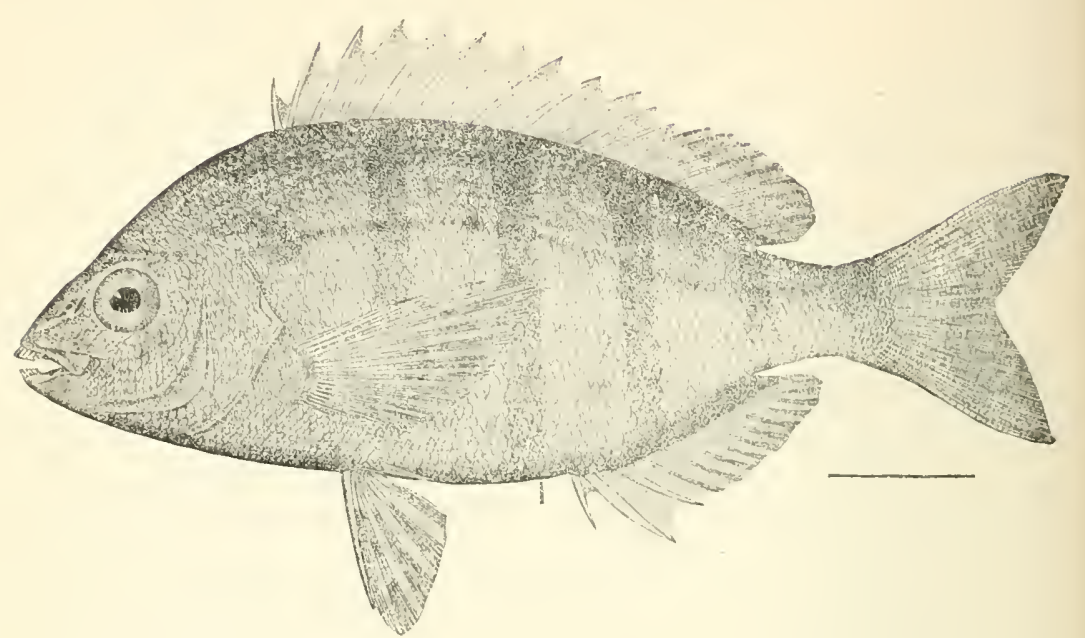

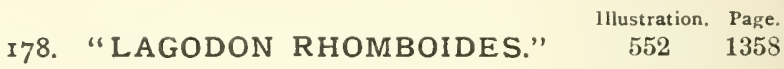
(Kepeated.)

SAlloR's CHOLCE;

RONCO Blanco;

Ronco Prieto;

Bastard Margaret;

Pigfish ;

Hogfish ;

Pinfish ;

BREAM ;

Chopa Spina (J. \& E.);

SaILOR's Cholce;

Sрот (U.S. Commission, 1896, pages 230,245 , plate 48 );

SAILOR'S ChOICE;

Pinfish ;

SHINY Scup (Bulletin U. S. Commission, 1897).

“" Head $3 \frac{1}{5}$; depth 2 to $22 / 3$; eye 4 . D. XII, 11 ; A. III, 11 ; scales $10-65$ to 70-17. Body elongate, elliptical; head flattened, muzzle pointed, profile not very steep; eye moderate, $1 \frac{1}{3}$ to $1 \frac{1}{2}$ in snout, 1 in interorbital; mouth moderate, maxillary not reaching front of orbit, $31 / 3$ in head; incisors $\frac{4}{4}$, all deeply notched; molars in two series in each jaw ; gill rakers $6+13$; dorsal spines all rather high, the highest about 2 in head; caudal deeply forked; second anal spine not longer than third; ventrals short and broad, pectorals moderate, upper rays reaching past origin of anal.

Color, in life, olivaceous, the sides bluish-silvery; a humeral spot and traces of 6 vertical bars; gilt stripes much less intense than in Archosargus unimaculatus, much broader than the interspaces; about 7 stripes below the lateral line, those above it more or less confluent; dorsal fin pale bluish, with a submedian gilt band and a gilt edging; caudal yellow, faintly barred; anal bluish, with a medium yellowish 
band; ventrals mesially yellowish; pectorals plain. Length, 6 inches." Weight to 2 pounds; average about $3 / 4$ pound.

Caught: Rod and reel, still fishing, bottom; No. 9 line, 1\%, 2\% hooks. Bait: Cut Mullet, Crustacea. Edible, C.

This is the only fish I know as the "Sailor's Choice."

\section{9. “HAMULON PARRA." $\quad \begin{array}{cc}\text { Illustration. Page. } \\ 530 & 1297\end{array}$} (Repeated.)

SAILOR'S CHOICE ; (2) OR

"Head 3 ; depth $22 / 3$; eye large, 4 Key IVest SaIloR's Choice. in head. D. XII, 17 ; A. III, 7 ; scales 5-50-14. Body comparatively deep, the back compressed and arched ; anterior profile rather steep and convex, steep and nearly straight from tip of snout to opposite front of eye ; here an obtuse angle is formed, and to the base of dorsal there is a rather even curve. In other specimens there is little or no prominence before eye. Snout comparatively high and obtuse, its length in specimens of moderate size 3 in head; snout shorter in young specimens than in the adult, the maxillary in the young extending farther back although proportionately shorter; mouth rather small for the genus, the maxillary usually extending a little beyond vertical from front of eye, in young nearly to middle of eye, its length $2 \frac{3}{7}$ in head; maxillary in adult barely reaching front of eye; jaws subequal, the lower slightly included. Teeth rather strong, in moderate bands, the outer large, the antrorse teeth of the posterior part of lower jaw well developed. Interorbital space convex, its width $4 \frac{1}{3}$ in head; preorbital rather deep, its least breadth $5 \frac{2}{3}$ in head; preopercle finely, but sharply serrate, the teeth near the angle farther apart than the others, but scarcely larger. In regard to the serration of the preopercle we find much variation among our specimens, some of those from Cuba, corresponding more or less perfectly to $H$. serratum, Poey, have the preopercle always strongly serrate ; while others, certainly corresponding to $H$. acutum, Poey, have the serrations very inconspicuous. The Key West specimens are in this respect mostly intermediate, and none of them show any other distinctive character correlated with the differences in the preopercle. Gill rakers small, about 15 on lower part of arch. Scales rather large, those above lateral line not especially enlarged, arranged in very oblique series; those below more nearly horizontal ; soft fins well scaled; series of scales from scapular scale reaching fourth to sixth dorsal spine. Dorsal spines stout, the fourth highest, 
$2 \frac{1}{5}$ in head; longest soft rays $33 / 4$ in head; upper caudal lobe rather longer, $1 \frac{2}{5}$ in head; longest anal rays $21 / 3$ in head, reaching when depressed beyond the tips of the last rays; second anal spine stronger and longer than third, $2 \frac{2}{5}$ in head, reaching when depressed nearly to the tip of the last ray; ventrals $1 \frac{5}{6}$ in head; pectorals short, $\mathbf{1} \frac{4}{7}$. Color, in life, dull pearly-grayish; belly plain grayish, each scale on body above with a conspicuous spot of dull olive-brown, these forming interrupted, oblique, and wavy streaks; head not spotted; mouth not much red, usually faintly orange near the angle in young specimens, a black spot on opercle under angle of preopercle; iris gilt ; fins all dull, blackish-gray, the ventrals more or less tipped with blackish. Younger specimens have dark lateral stripes arranged precisely as in H. macrostomum and H. rimator, and also a dark blotch at base of caudal. In the very young, the spots on the scales are indistinct."

"This species, which is not the Sailor's Choice of the South Atlantic Coast, is abundant about Key West." (U. S. Commission, 1896, page 282.)

Weight, 2 pounds; average, $1 / 2$ pound. Caught: Same tackle and bait as other small fish among the Keys, and at Key West. Edible, C.

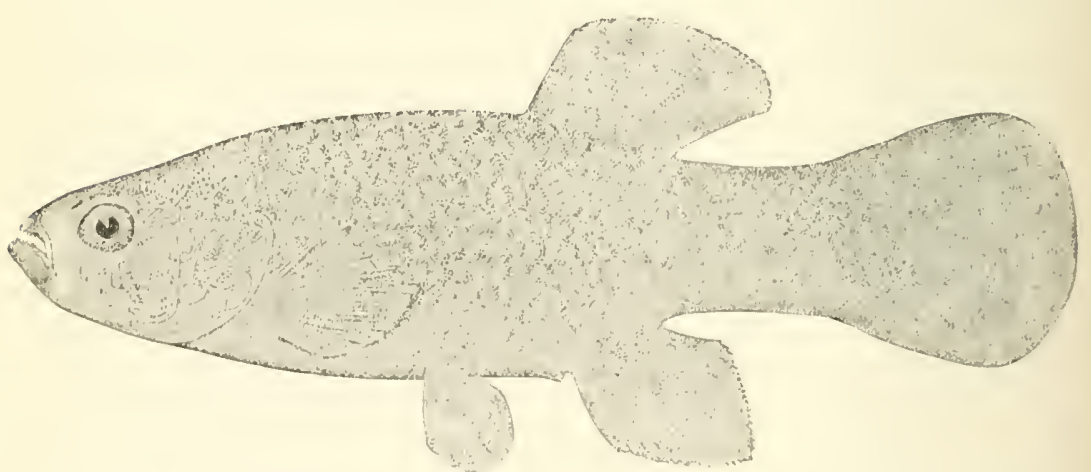

I80. "FUNDULUS HETEROCLITUS." $273 \quad \begin{array}{cc}\text { Illustration. Page. } \\ 240\end{array}$

MUd Fish ; This is a worthless fish, caught up the Miami River. Mud Sucker (G.). 


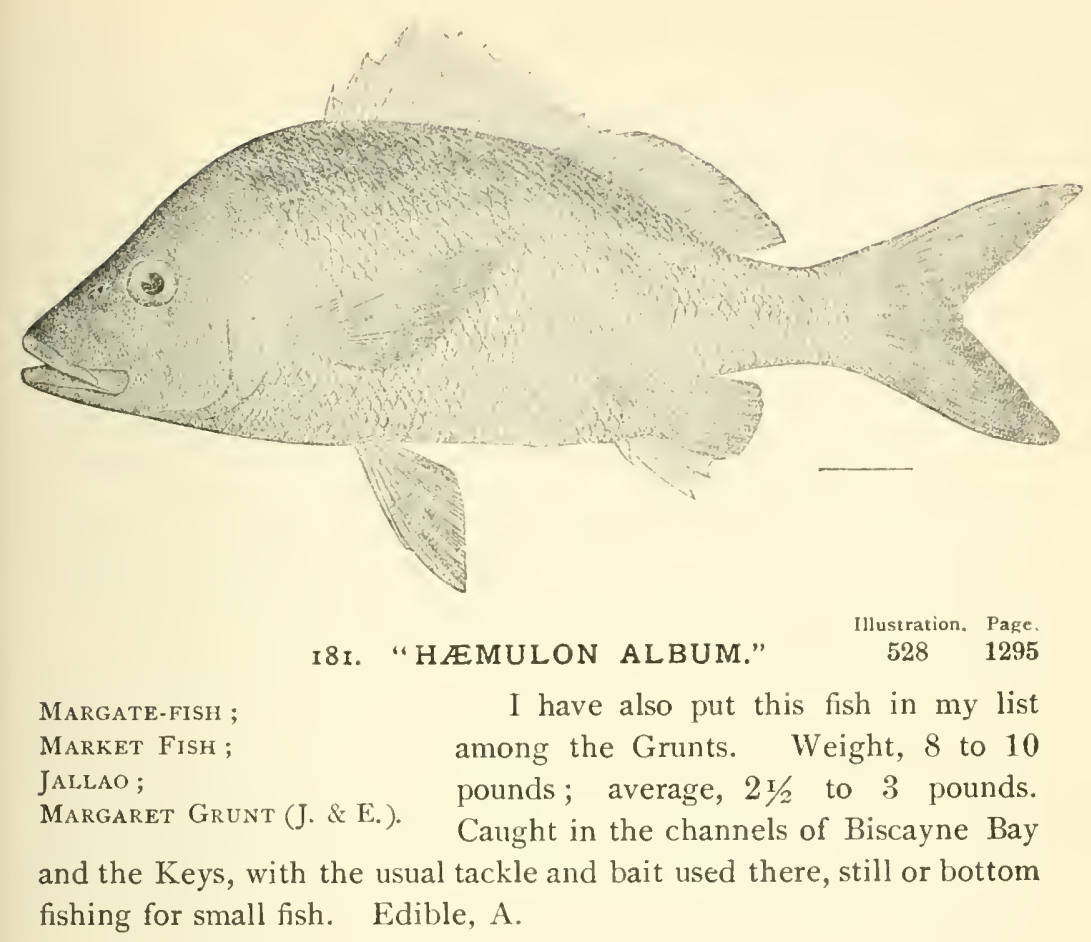

\section{PILCHARD.}

I presume local name taken from English pilchard. Small fish, used as bait at Key West.

\section{STUFFONIER.}

A small fish, caught at Mosquito Inlet and used as bait, especially for Mangrove Snappers. I have not been able to classify him, but presume he is a Gobie. 
184. "TAUTOGA ONITIS."

Illustration. Page.

$596 \quad 1578$

Black-Fish; The Tautog or Black-fish of the North. J. \& E. Tautog; state, "New Brunswick to Charleston, S. C." Some Oxster-Fish. people claim to have caught him in Florida. I think confused with the "Sea Bass" Black Fish. Have never seen him in Florida.

185 .

Cutthe Fish; INK FISII.

This is not a fish, but locally among the Keys is called by the above name. It is a Jelly Fish, so called. Is caught in nets. I have caught them in my landing nets. It is called Ink Fish, because when caught it exudes a large quantity of dark purple liquid. It is simply a curiosity, especially well to the south among the Keys. I mention it because it is a curiosity, not from an angling standpoint.

\section{CRAB.}

Common Sea Crab.

This is a Crustacian, and only important to the angler as bait. I need not describe it, as it is well known. Edible.

\section{I87. SHRIMP AND PRAWNS.}

Crustaceans, used as bait. About the best "all-around" bait for use on the entire coast, but scarce below Mosquito Inlet. Everything will take it.

\section{I88. CRAYFISH OR CRAWFISH.}

This is not a fish at all, but is of the Crustacea order. To the angler it is important only as bait, as it is the best " all-around" bait from Biscayne Bay to Key West. It may be said that all the fishes of that region will take it. The Key West market fishers use it more than any other one bait. They cut out the meat to use, and hang the remainder of the shell, antennæe, head, etc., alongside their boats in strings of two or more reaching nearly to the bottom, so as to attract the fish desired, and it has that effect. It is grained (speared) among the sponges, sea fans, and rocks, in the channels and 
cuts, on the bottom, and under the mangroves along the shores. By some people it is considered equal to the Lobster as food, as it belongs to same order, but I do not consider it equal to the Lobster in edible qualities. There are vast numbers of them caught and used as food and bait between Biscayne Bay and Key West.

It is hardly germane to my subject, but I must digress a little from the angler's standpoint, and call the reader's attention to the beauty, wonderful complexity, and high organization (physically) of the animal he is using as bait, the Crayfish.

Huxley, one of the great naturalists of our age, and the greatest zoölogist and biologist of any age, devoted a book of 381 pages and 81 illustrations to the description of the Crayfish. The title to the book, "The Crayfish, an Introduction to the study of Biology," shows how important he considers the family.

In his preface he says: "My purpose, in the present work, is to exemplify the general truths respecting the development of zoölogical science which has just been stated by the study of a special case; and to that end, I have selected an animal, the common Crayfish, which taken altogether is better fitted for my purpose than any other." And: "The Crayfish is obviously a very complicated piece of living machinery."

He quotes from Rosel von Rosenhof as follows: "Common and lowly as most may think the Crayfish, it is yet so full of wonders that the greatest naturalist may be puzzled to give a clear account of it." 


\section{CHAPTER III.}

\section{LIST OF BAITS.}

Clams, Fiddler Crabs, Hermit or Soldier Crabs, Oyster Crabs, Sea Crabs, Sand Crabs, called among the Keys "Sprite"; Stone Crabs, Crayfish or Crawfish, the latter obtainable only from Biscayne Bay, south ; Conchs, obtainable only from Lake Worth, south ; Shrimp and Prawns, rather scarce south of Daytona.

Menhaden, Anchovies, Alewife, Sardines, Pilchards, Gobies, small Mullets, Stuffoniers.

Cut Mullets, cut Sailor's Choice, cut Kingfish, cut Grouper, or cut pieces of any other fish when the last mentioned four are not obtainable.

Small Grunts, Porgies, Spots and other one-fourth to one-half pound fishes, used whole for Sharks, Saw-fish, Amber Jacks, Barracuda, Yellow Jacks, Sail-fish, and large Jewfish. Still fishing or trolling.

I carry a can or two of canned Oysters, Clams and Shrimp, which come handy at times, as starters, when I cannot readily get any of the aforementioned baits.

In the account of the different fishes and localities I have indicated, and will indicate, the appropriate bait to be used in each case.

\section{ARTIFICIAL BAITS.}

One each Nos. 4, 43/4, 6, Skinner's fluted or silver-plated, or nickel-plated spoons.

One each $31 / 2$-inch and 4 -inch calico phantom Minnows, and one each $31 / 2$ and 4 -inch silvered or white Minnows.

Six each 3 -inch, $31 / 2$-inch, $41 / 2$-inch, 5 -inch, $51 / 2$-inch block tin squids for trolling for Spanish Mackerel, Bluefish, Kingfish, Groupers, Amber Jacks, Barracuda, and other large fishes. The measurement is of the tin part of the squid only. 
Red and white cloth cut in strips, laid together four to five inches long, fastened on to a $10 \%$ hook, makes a fine trolling bait for Groupers and Bluefish ; and other fish take it well.

A long strip of Kingfish, cut to resemble a fish, fastened firmly on a large hook, does well.

Some sportsmen use a piece of red cedar, cut to resemble a fish, which is a good trolling bait. For Spanish Mackerel, the 3 -inch squid is the best of all. 


\section{CHAPTER IV.}

\section{LIST OF FISHING TACKLE.}

In naming the tackle for each kind of fish I give the size of the line and hook to be used. Please remember, however, that in fishing in salt water you cannot know "what you will draw," that is, you cannot usually know what kind, or size, fish will take your bait. You may be fishing for Porgies, small or medium sized Snappers, etc., and a Shark, Ray, or other large fish will take and walk off with your bait, hook and line. Usually, if fishing for small fish you should use small bait, as you are less apt to get hold of large fish than if using a large bait. You will have to use the size and kind of bait and tackle herein indicated for each fish and locality ; and if your fishes are larger, or smaller, than you want, you will have to change your hook and bait to meet the situation the best you can at the time. By using a medium-size hook you will be able generally to handle a large fish if one takes your bait, and you can change your hook to suit the case. On the "patches" and reefs outside, you should always use 18 to 21 line, and $4 \%$ to $6 \%$ hooks, hereafter mentioned.

I advise that you provide yourself with the following tackle :

One fishing rod butt with cork covered handle, patent lightest weight reel seat, and three full-length good cane joints; each joint to fit into the one butt, but tapering to different diameters at the tips. Butt to be $\frac{11}{16}$-inch, inside measurement, one joint $1 / 8$-inch at tip, one $\frac{3}{16}$-inch and one $\frac{5}{16}$-inch diameter. The total length of the rod should not be over seven feet. If desirable, you can have each of the joints made in two lengths instead of one, which will be easier to travel with, as the rod can be packed in a good-sized trunk, or can be carried in a canvas bag.

You thus have three rods of different weights and strengths, well adapted to all the fishes of the East Coast, except 'Tarpon, Barracudas, Amber Jacks, Sharks, Rays, etc., etc, and the outfit should not cost more than five to seven dollars, made of the very best materials. If you desire to fish for the above mentioned large fishes, I would 
advise you to buy a Tarpon rod of some one of the many tackle dealers. The price varies from ten dollars to as high as you may want to go. You will also need a Tarpon gaff, for landing the fish.

The next item is, one each Julius or Edward Vom Hofe reels, 3 -inch and $21 / 2$-inch diameter of plate, and a Tarpon reel, if you are to fish for Tarpon, etc.; they are made in three or four different qualities and prices. Or you can buy a No. 3 and No. 5 Frankfort reel, made by B. C. Milam \& Sons of Frankfort, Kentucky, which are all metal, and are quadruple multipliers, while the Vom Hofe's are partly rubber. The Frankforts are much higher priced.

Two spools each of 600 feet Hall's linen Tarpon or Bass fishing lines, Nos. 9 and 18 ; and if you are to fish for Tarpon, etc., and troll with rod and reel for Kingfish, Amber Jacks, etc., you will want a spool of No. 21.

From 25 to 100 (a full box) each of Harrison's blued ringed, Sproat hooks, $8 \%, 6 \%, 5 \%, 4 \%, 3 \%, 2 \%, 1 \%$, and Nos. 2, 4 and 6 . The $\%$ hooks commence with $1 \%$, the smallest size; while the numbered commence with the larger size, No. 1, and run to the smallest, No. 10. Say 25 each Nos. 4 and 7 , which are really Minnow hooks. For Tarpons, Amber Jacks, etc., a few regular Tarpon hooks and snoods, and 25 each Nos. 3 and 4 Virginia hooks for Sheepheads. I use the expression $10 \%$ to indicate the size for large fishes other than Tarpon.

Egg-shaped sinkers, 25 each Nos. 4, 5, 6, 7, and 8 ; these have holes through them, through which the line is run with a wood toggle made of half a match looped on at bottom of sinker about 14 inches above the hook and bait. As the line will run through the sinker when you have a bite, it offers no resistance to the fish. Add 25 ordinary long sinkers, assorted sizes, as they come handy in some kinds of fishing.

Brass box swivels, 6 each Nos. 1, 2, 3. These are to attach to line when you troll with it, to prevent twisting and kinking.

A few thumb stalls to put on your thumb while playing large fishes. These are made of cotton twine, knit in different sizes.

Shark hooks and chain, if you desire to fish for Sharks and large Jewfish. Two or three sizes.

A few extra tips and guides for your rods, as you are sure to lose some.

About 600 feet strong Cod line, for hand-line trolling for Spanish Mackerel and Bluefish, and 20 feet or so of steel piano wire for 
leaders, which should be about 3 feet each. The dealers have them of proper length.

About 600 feet $\frac{3}{16}$ white cotton line for hand line trolling for Kingfish, Barracuda, Amber Jack, large Groupers, etc.

I have given the artificial bait to be used in trolling in my list of baits.

One each 4 and 5 -inch Barrel-shaped Cork floats, and one each 2 and $21 / 2$-inch Egg-shaped Cork floats. These are necessary when fishing over oyster beds in Halifax and Indian rivers, and in places amongst the Keys, when over jagged coral reef bottoms. I do not use a landing net, as it tangles the hook, and is superfluous if your guide knows his business.

A tackle box, if you want one. Do not buy one made of or lined with tin, as it will rust in "no time" and give you trouble; one made of wood, plush lined, is the only one fit for salt water.

At the close of this chapter the reader will find illustrations of nearly all the above tackle.

The above list is calculated as ample to last one person through a season of three or four months on the coast; but each person will, of course, judge for himself as to his prospective stay, and buy or leave out accordingly.

I give the list because it is an important and necessary factor in the "how" to fish on the East Coast.

I strongly advise you to buy no "Cheap Johnny" or "good as" fishing tackle, as it will surely bring you to grief. Remember, that salt-water fishes are two or three times (if not more) as strong, weight for weight, as those of fresh water, and need the very best tackle. I have none but a trading acquaintance with any makers of, or dealers in, fishing tackle, and in mentioning brands, have been governed entirely by my experience of sixty-four years as an angler, which has taught me to buy the best tackle I can get.

I do not know "Mr. Sproat," if there is, or ever was, such a person, but must say I prefer the fishhook bearing that name to any other shape, for each and every species of fishes I have ever caught, from Minnows and one-ounce Brook Trout up to Tarpon.

And I have never found any make of hooks which suits me as well as Harrison's.

In advising the use of Virginia hooks for Sheepsheads I conform to the usual custom, but the Harrison "Sproats" will do just as well. 
E. VOM HOFE, NEW YORK.
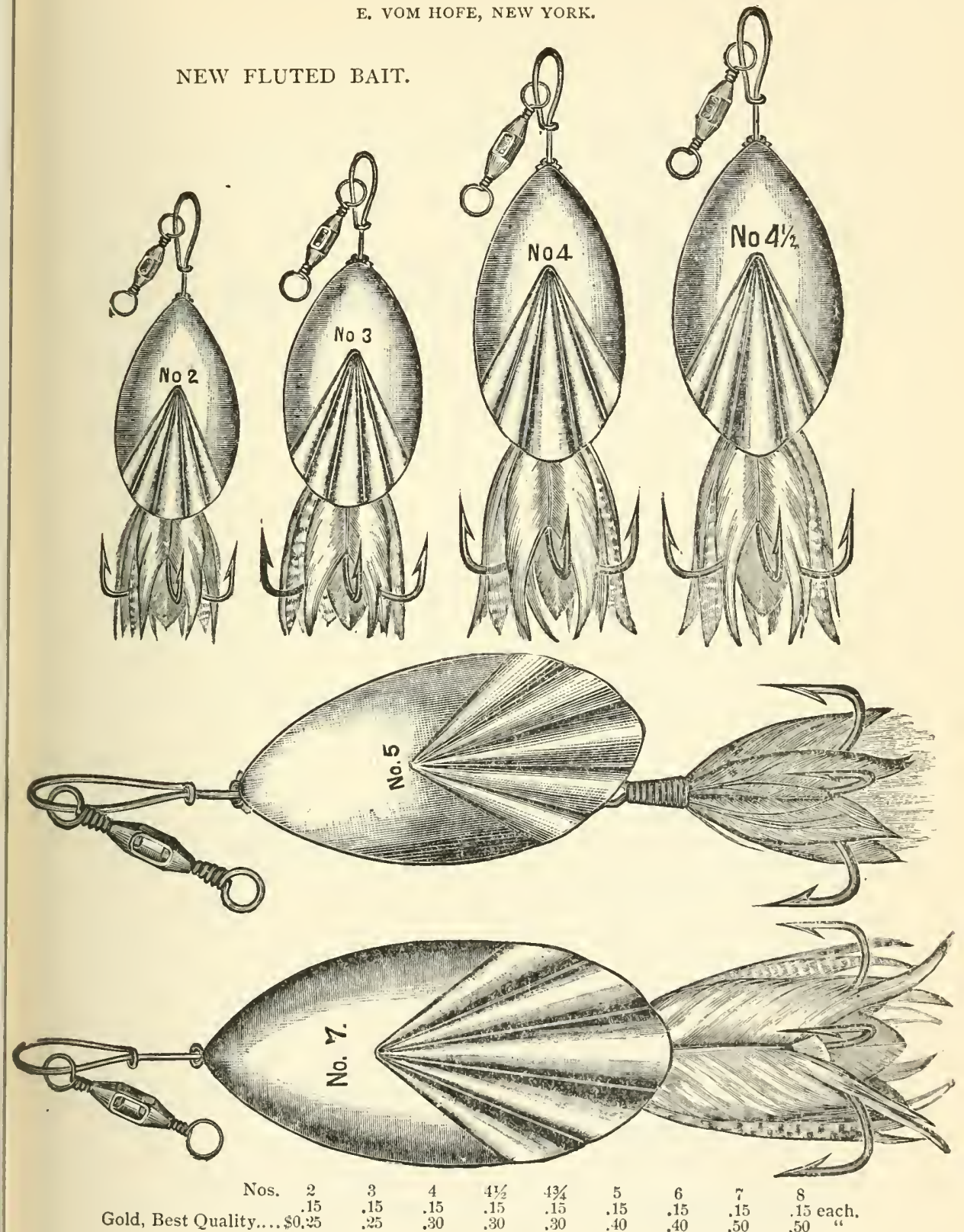
E. VOM HOFE, NEW YORK.

BUEL'S SPOON BAIT.

Nos. $\quad 2 \%$ $1 \% 0$
.35

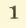

30
2

.30
3

.30 each.

CELEBRATED PHANTOM MINNOW.

Made of Silk, coated with nubber, very light, desirable Bait for Black Bass and Pickerel.

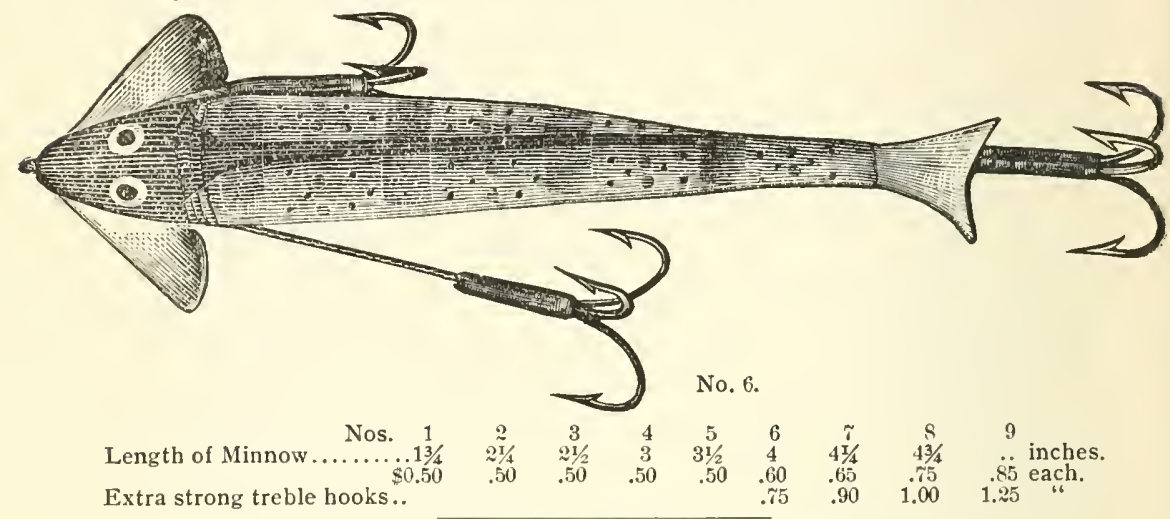

E. VOM HOFE'S NEW WHITE PHANTOM.

The most Killing Bait for Black Bass.

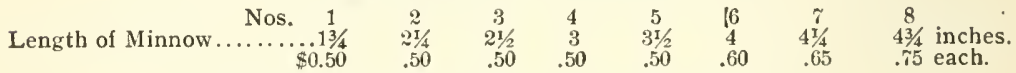

E. VOM HOFE'S SOLE SKIN PHANTOM.

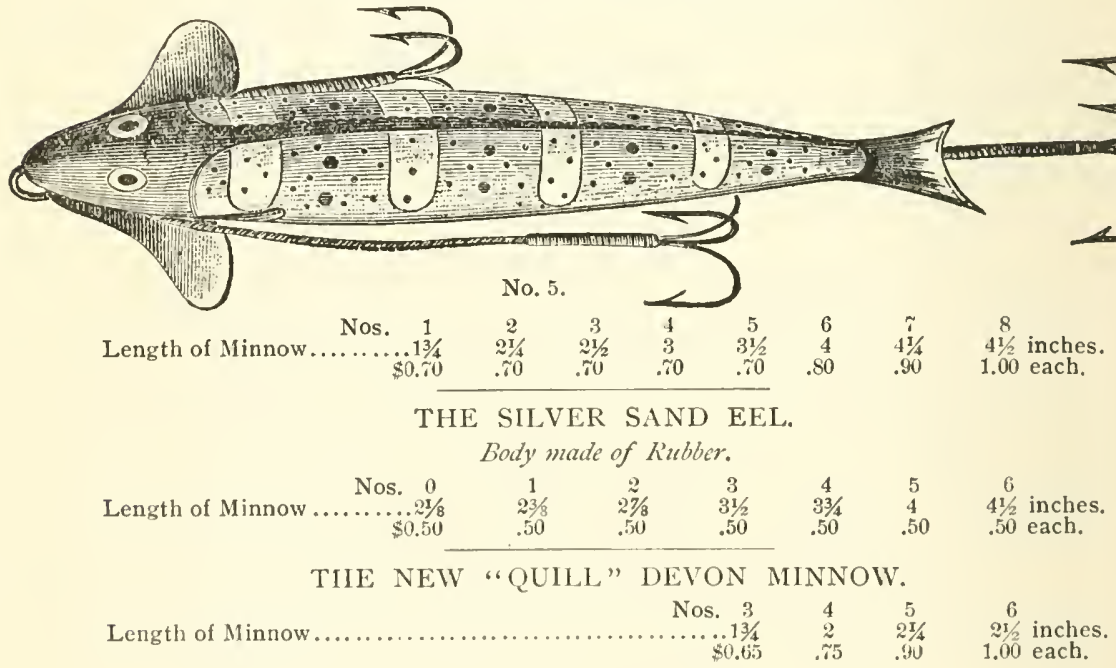


E. VOM HOFE, NEW YORK.

$$
\text { SQUIDS. }
$$

BLOCK TIN BURNISHED, WITH PATENT SIVIVEL.

$\begin{array}{rccccccc}\text { Nos. } 8 & 7 & 6 & 5 & 4 & 3 & 2 & 1 \\ \text { Length of Tin......23/8 } & 25 / 8 & 3 & 31 / 2 & 4 & 41 / 2 & 5 & 51 / 2 \text { inches. } \\ \$ 0.15 & .20 & .25 & .30 & .35 & .40 & .45 & .50 \text { each. }\end{array}$

ROUND BONE, MOUNTED WITH SWIVEL.

$\begin{array}{rcccccccc}\text { Length } \ldots \ldots \ldots \ldots .2 & 21 / 2 & 3 & 31 / 2 & 4 & 41 / 2 & 5 & 51 / 2 & 6 \text { inches. } \\ \$ 0.20 & .25 & .30 & .35 & .40 & .45 & .50 & .55 & .60 \text { each. }\end{array}$

ROUND WOOD, MOUNTED WITH SWIVEL. Length........................ $4 \frac{1 / 2}{1 / 2} \quad 51 / 2 \quad 61 / 2$ inches. $\$ 0.40 \quad .50 \quad .60$ each.

PEARL SPANISH MACKEREL SQUID. (No.3.) Same size Hook as Block Tin.

$\begin{array}{rcccccc}\text { Nos. } & 7 & 6 & 5 & 4 & 3 & \\ \text { Length of Pearl........... } & 31 / 4 & 33 / 4 & 41 / 8 & 41 / 2 & 5 \text { inches. } \\ & \$ 0.75 & .85 & 1.00 & 1.15 & 1.25 \text { each. } \\ \text { With Pearl Spinners....... } & 1.40 & 1.50 & 1.75 & 2.00 & 2.25 \text { " }\end{array}$

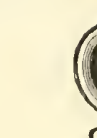


E. VOM HOFE, NEW YORK.

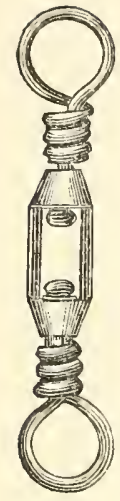

栬

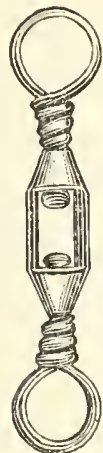

$3 \%$

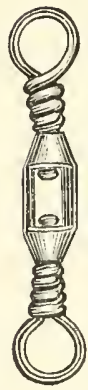

$\%$

S IV I V E L S.

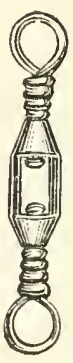

$1 \%$

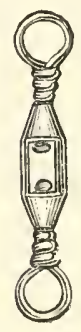

1

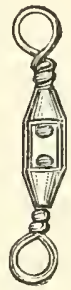

2
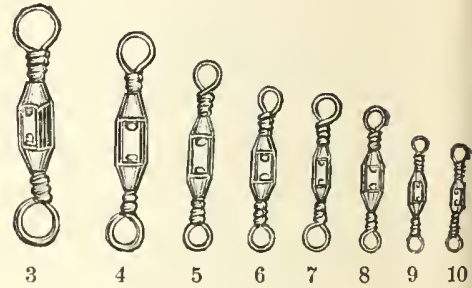

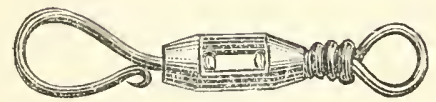

STEEL HOOK.

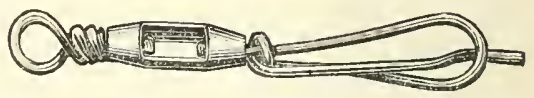

BRASS TO BUCKLE.

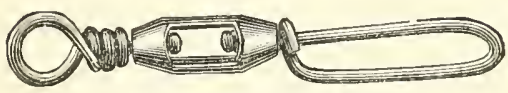

BRASS AND STEEL SPRING.

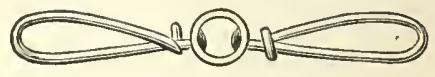

ADJUSTABLE SWIVEL-NO. 1.

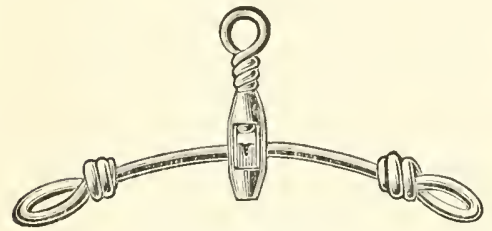

BRASS SPREADER.

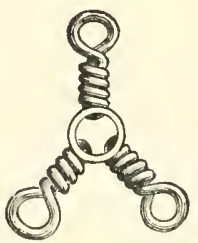

BRASS TRIPLE ACTION -NO. 1 .

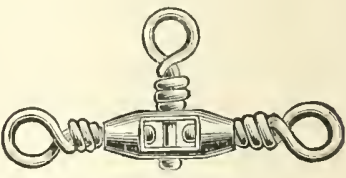

CROSS LINE SWIVEL.

Nos. $5 \% \quad \% \quad 3 \% \quad \% \quad 1 \% \quad 1$ to 10

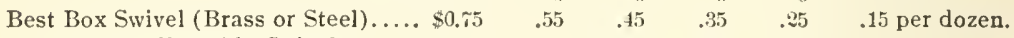

"Brass Adjustable Swivel.......

" " Triple Action Swivel.....

" " and Steel Spring Swivel...

" Steel Hook Swivel..............

" Brass to Buckle Swivel.........

" Barrel Swivels, bronzed.........

$1.10 \quad .80 \quad .65 \quad .55 \quad$ ".

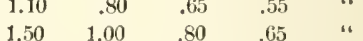

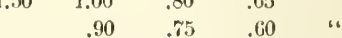

$.75 \quad .65 \quad .45 \quad .35 \quad$ " $\quad .6$

Rotary Link Swivel....................................each 10 cents, 3 for .25

Brass Swivel Spreader................................ " 6 " 5 " 5 " 6

Cross Line Swivel, Size 1 and $2 \ldots \ldots \ldots \ldots \ldots \ldots \ldots \ldots \ldots \ldots \ldots \ldots \ldots$ " 5 " 5 " 6 " 5.25 
E. VOM HOFE, NEW YORK.

PATENT SWIVEL SINKERS.

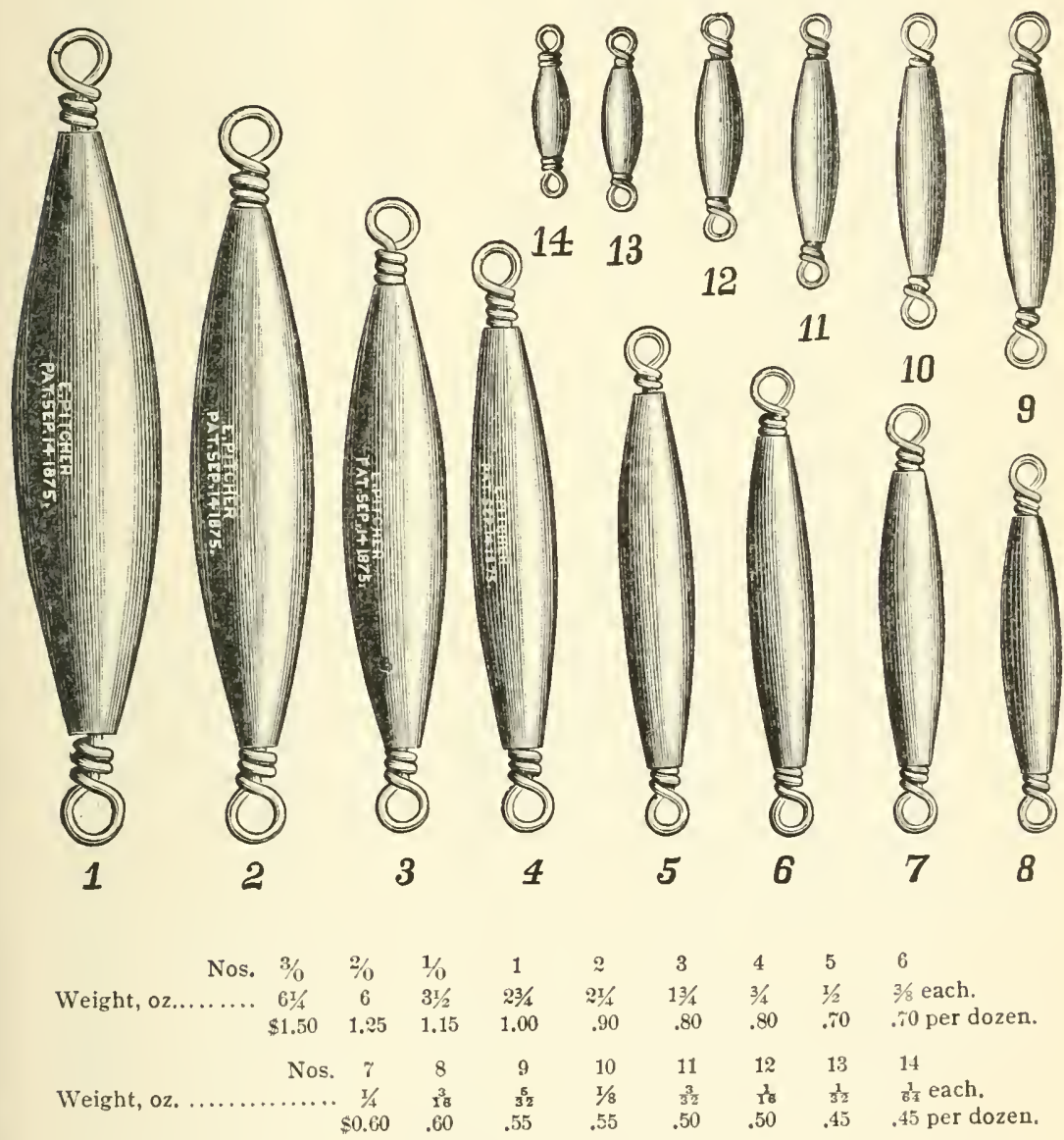



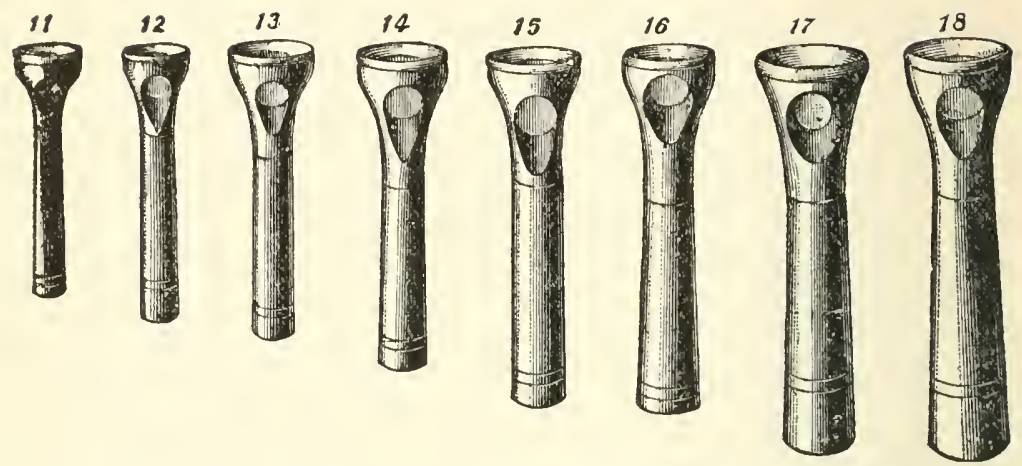

Nickel-plated, Nos. 11 to 18 , 5c. each.
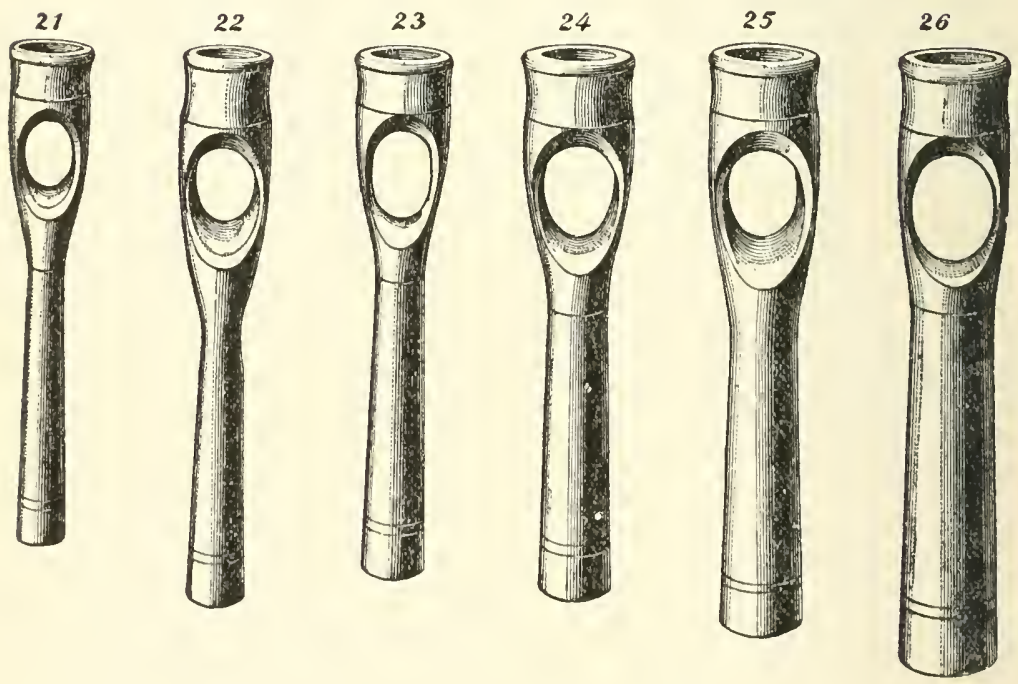

Nos. 21

Size of Ferrule, inches $5 / 32$

22

23

24

25

26

Nickel-plated 15c. each. German Silver 30c. each. 


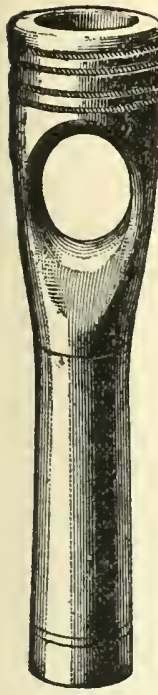

SOLID.

THE H. H. KIFFE COMPANY, NEW YORK.

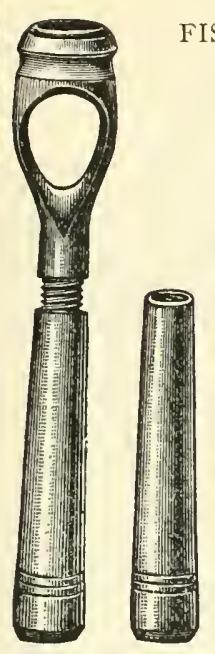

SCREW-OFF.

AGATE TIPS. (German Silver Mountings.)

Size of Ferrule, $\gamma^{3}, 1 / 4, \frac{5}{16}, 3 / 8,1 / 2$ inch. Screw-otf with extra Ferrule, 85c, each. Solid, 65c. each.

"VOM HOFE'S" PATENT RUBBER AND GERMAN SILVER, FIRST QUALITY MULTIPLYTNG STEEL PIVOT REELS.

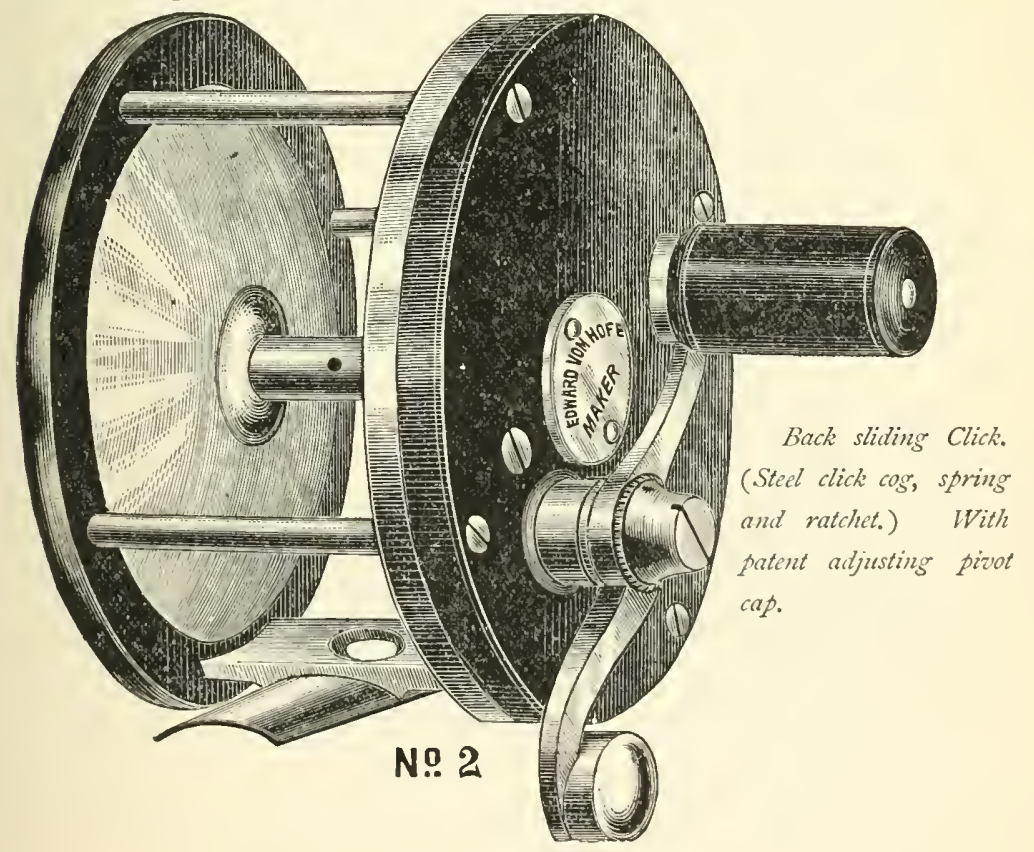


E. VOM HOFE, NEW YORK.

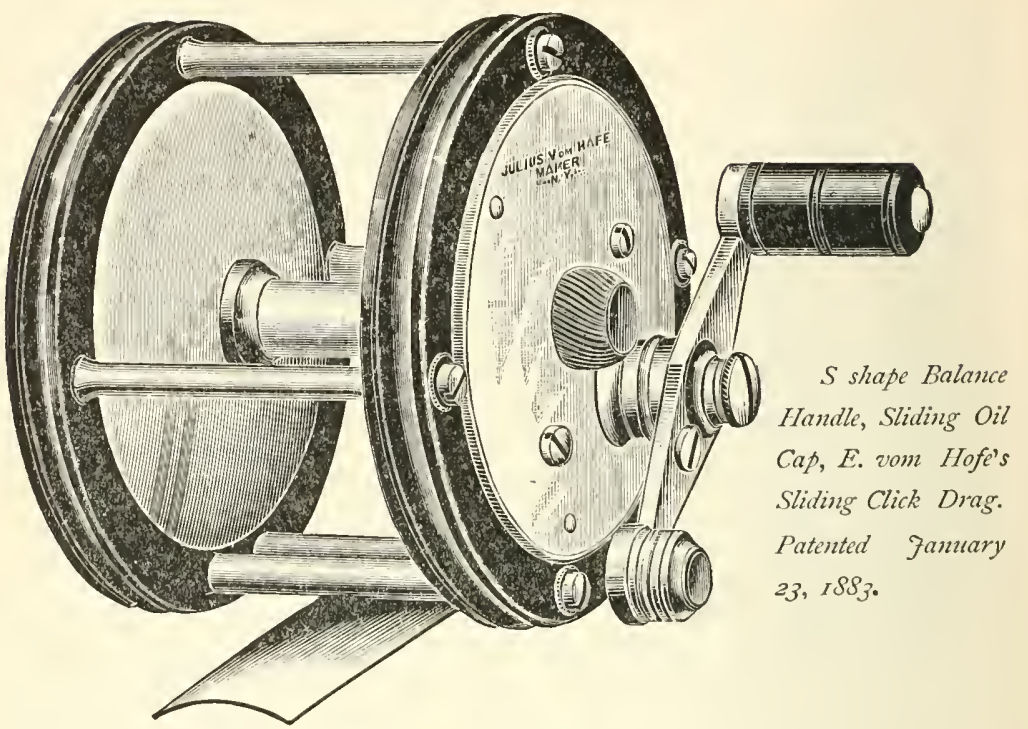

No. 2 .

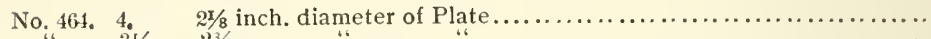
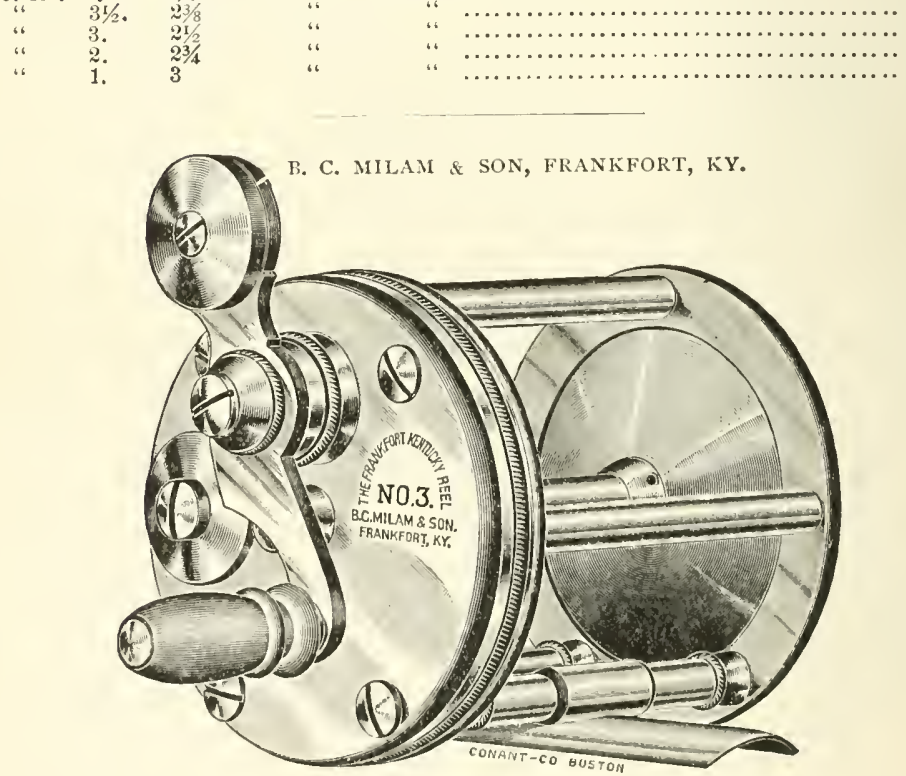
E. VOM HOFE, NEW YORK.

$S$ shaped Balance Handle to screw off, Sliding Oil Cap, E. vom Hofe's Sliding Click Drag. Patented Fanuary 23, 1883 .

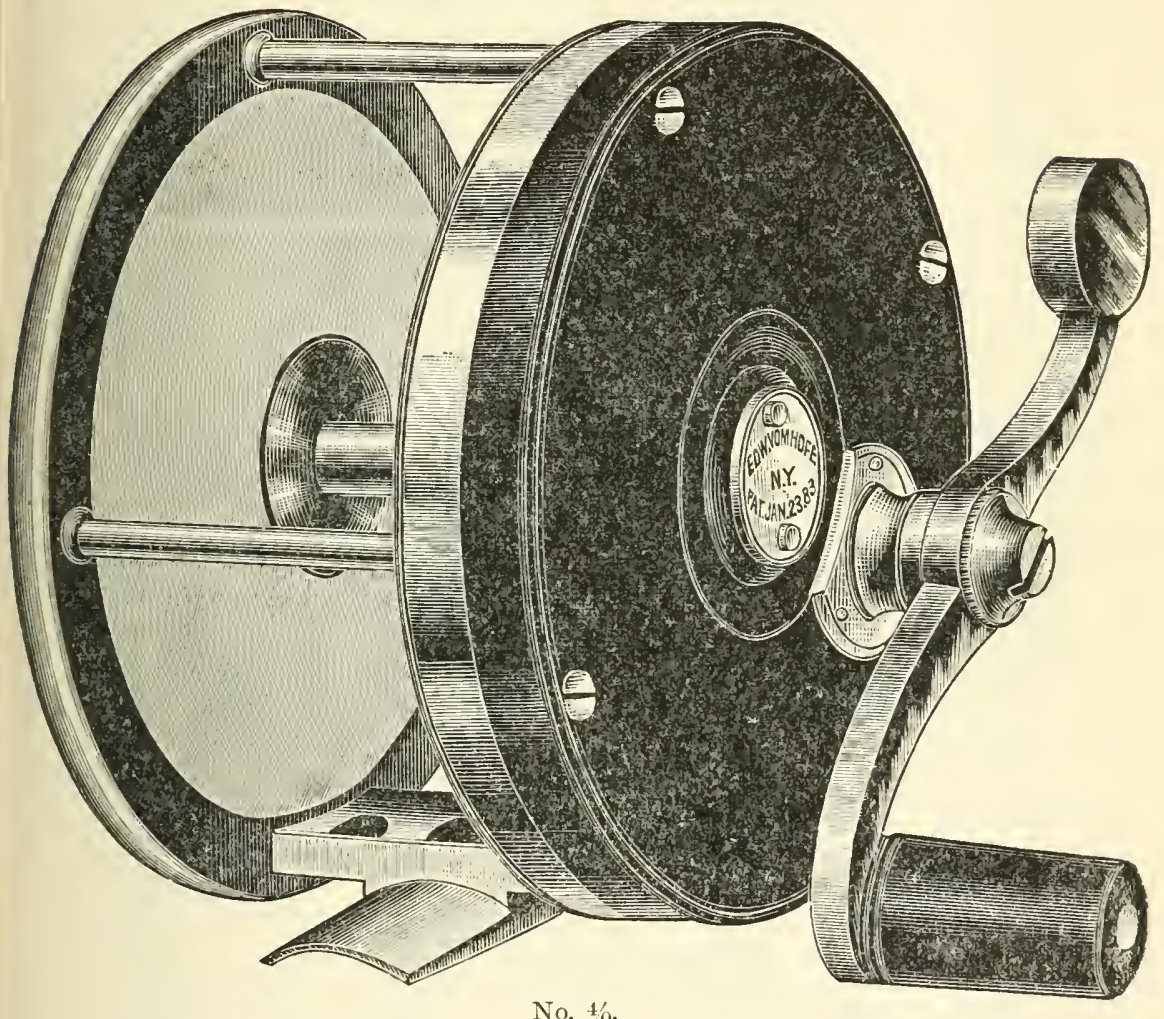

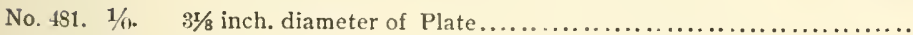

\begin{tabular}{|c|c|c|c|c|c|c|}
\hline " & 20 & $33 / 8$ & “ & “ & “" & $\ldots \ldots, \ldots, \ldots$ \\
\hline “ & $\%$ & $35 / 8$ & ، & " & “. & \\
\hline ، & 地. & $37 / 8$ & “ & “ & “. & $\ldots \ldots \ldots \ldots \ldots \ldots \ldots \ldots \ldots \ldots$ \\
\hline “6 & 6. & $41 / 4$ & " & “ & “" & \\
\hline
\end{tabular}

The above Reels are strong and durable. For their lightness and free running qualities they are surpassed by no other make.

The No. \% Reel being specially adapted for Tarpon Fishing. 

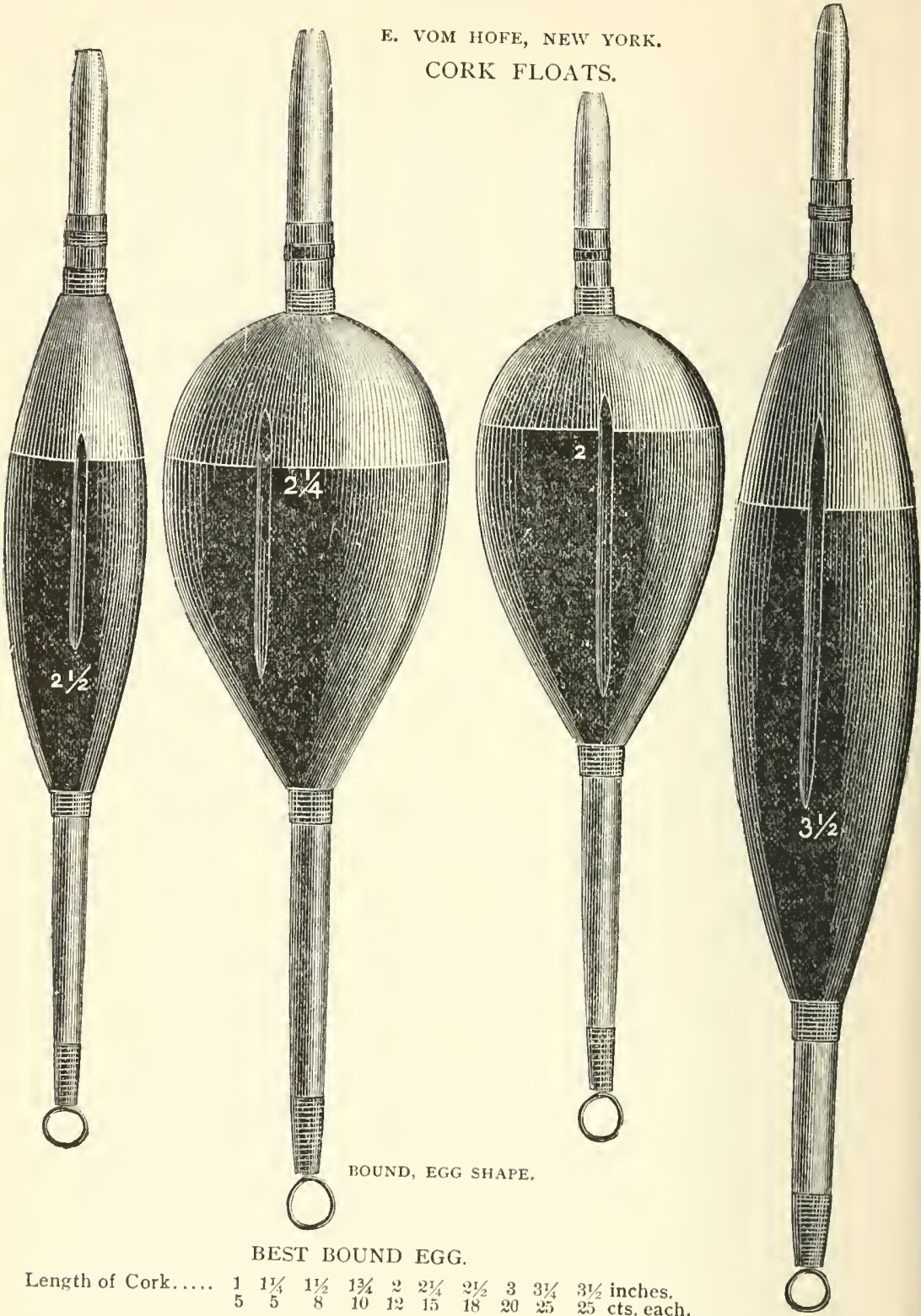

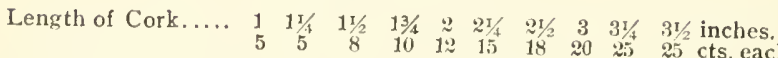

BEST BOUND BARREL $\{$ Length of Cork, $21 / 2 \quad 3 \quad 31 / 2 \quad 4 \quad 41 / 2 \quad 5 \quad 53 / 4 \quad 6$ inches.

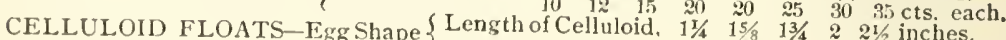

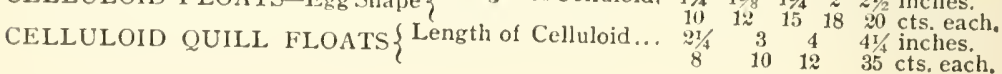


SPROAT - HIGHEST GRADE, BLUED AND RINGED. ENG.

Quality No. $56303 / 4$.

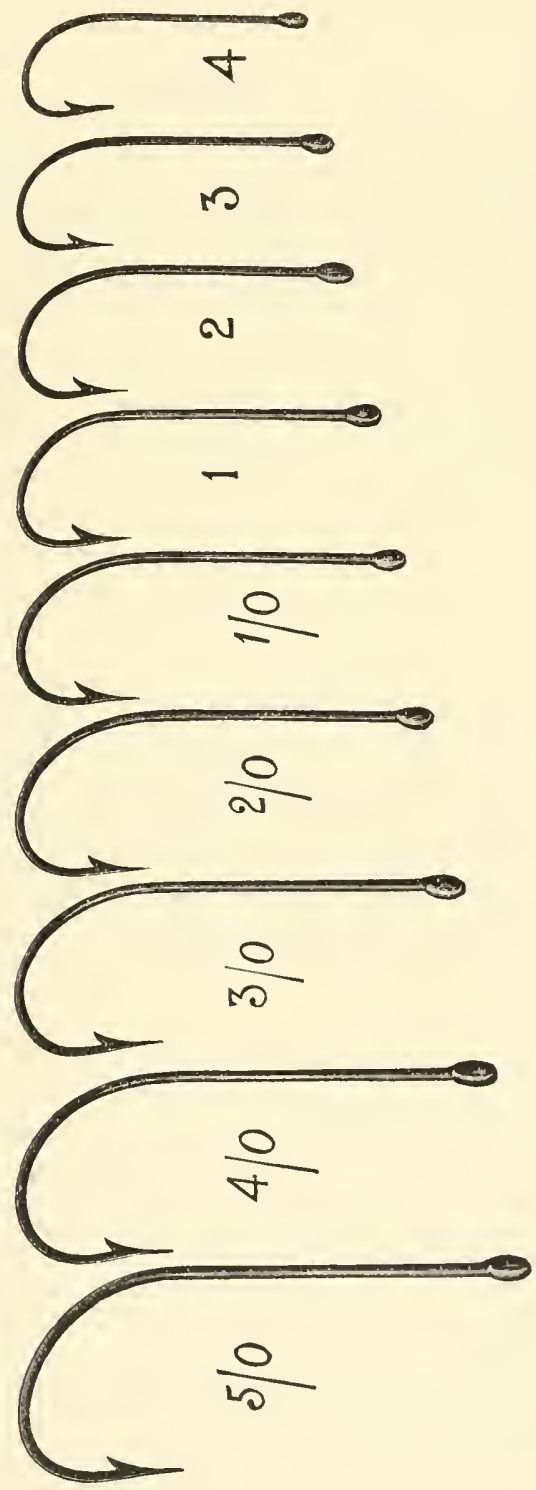


E. VOM HOFE, NEWV YORK.

ROD MOUNTINGS.

FINE GERMAN SILVER BELL GUIDE.
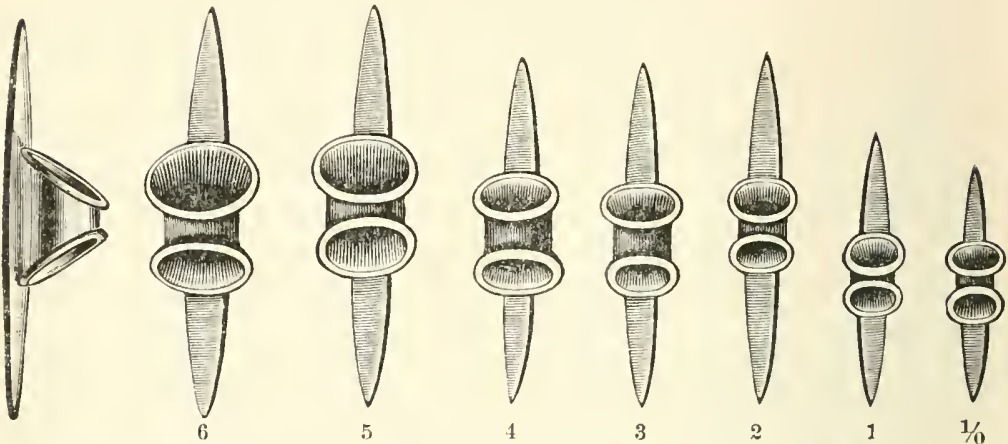

German Silver Belı Gujde, $1 / 0$ to $6 \ldots \ldots \ldots \ldots \ldots \ldots \ldots \ldots \ldots 15$ cents each, $\$ 1.50$ per dozen.

Not less than $1 / 2$ dozen at dozen rate.

E. YOM HOFE'S ACME GUIDES.

These Guides are by far superior to any ever placed before the public. For their Neatness, Lightness, Finish and Easy Rendering of the Line they are unsurpassed. (None Genuine unless name, E. vom Hofe, is stamped inside of Guide.)

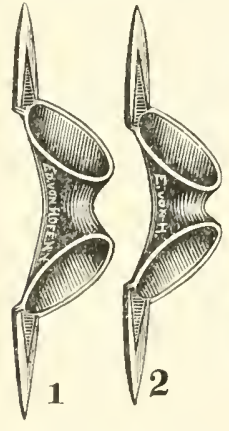

Best Brass Acme Guide, Best Nickeled Acme Guide, Best German Silver Acme Guide,

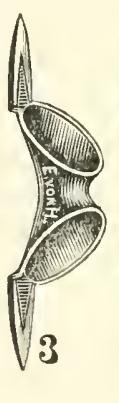

1 to $8 \ldots$

"

،.

$\ldots \ldots \ldots \ldots \ldots 20 . \ldots \ldots$

10 cents each, $\$ 1.00$ per dozen.

E. VOM HOFE'S AGATE GUIDES.

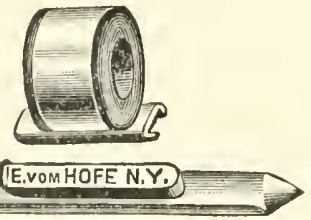

German Silver Agate Guides, Nos. 1, 2, 3 and 4. No. $1, \$ 1.00$; No. $2,90 \mathrm{c}$; No. $3,80 \mathrm{c}$; No. 4, r0c. each.

German Silver Agate Guides and two bars, Nos. 1 and $2, \$ 1.75$ each. 
E. VOM HOFE, NEIV YORK.

\section{EGG SINKERS.}

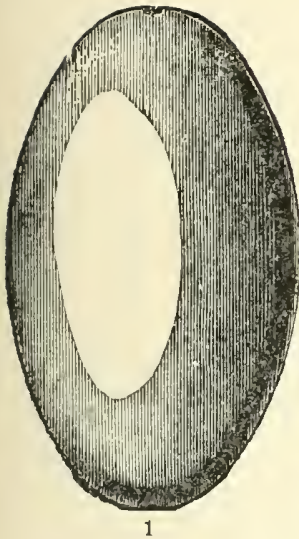

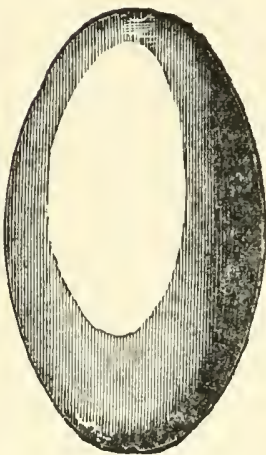

2

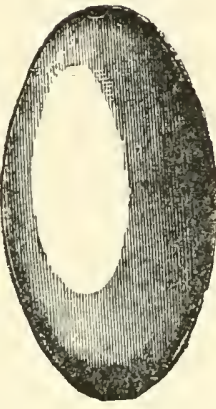

3

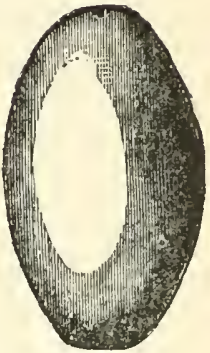

4

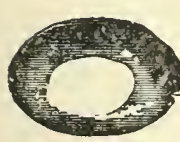

8

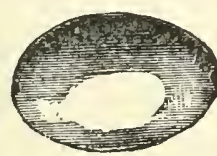

\%

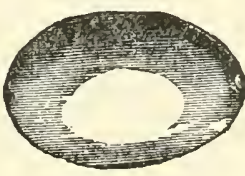

6

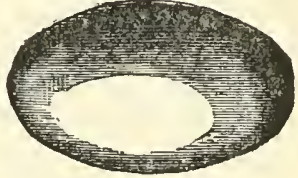

5

\begin{tabular}{|c|c|c|c|c|c|c|c|c|c|}
\hline & Nos. & 1 & 2 & 3 & 4 & 5 & 6 & 7 & 8 \\
\hline Weight, oz.. & $\ldots \ldots \ldots \ldots$ & $10 \mathrm{~T} / 4$ & $63 / 4$ & $41 / 4$ & $31 / 4$ & 2 & $13 / 8$ & 1 & $5 / 8$ each. \\
\hline & & $\$ 0.70$ & .60 & .45 & .35 & .25 & .15 & .10 & .10 per dozen. \\
\hline
\end{tabular}

For the benefit of my readers in the South and West, and the dealers in those sections, I will say that the Simmons Hardware Company of Saint Louis keep a full assortment of Hall's lines, Harrison's hooks, the Vom Hofe's and Milam's reels, and a full line of all other first-class fishing tackle.

I mention the above because the best brands are not always obtainable in the smaller cities and towns. If your local dealer does not carry the brands or articles you want he can order as above and be sure of getting them. 


\section{CHAPTER V.}

\section{LIST OF FISHING LOCALITIES ON THE EAST COAST.}

Before entering upon "where to fish," I wish to state, and emphasize the fact, that the season of the year, and the weather at all seasons, must be reckoned with by the angler, as they have a most decided effect upon fishes as well as upon all other animals.

It does not follow that because you have visited a certain place at one time and had abundant success that you can at any time afterward visit the same place and do well, unless you happen to meet like conditions, especially in the weather and tides. As a general statement for the entire coast, at the beginning of a "Norther," or during its continuance, you may as well "hang up your fiddle and your bow," as regards the greatest variety of fishes, still or bottom fishing; and generally an unusual cool or cold winter lessens the number of fishes caught with hook and line very materially.

I have known winters during which there were very few fish caught in the months of January and February at Mosquito Inlet and Indian River Inlet, while during the preceding and succeeding winters the anglers had great success in the same months.

From Jupiter Inlet south the above does not hold good to the same extent, owing, I presume, to the proximity of the Gulf Stream to the shore line, as it comes very near to the shore at Jupiter, and from there gradually leaves it until at Biscayne Bay it is four to five miles off shore; still, it makes quite a difference all the way down. I have, however, been at the cuts and passes, south of Miami, many times when I had difficulty in getting enough fish to eat; while after two or three warm days I could "load a boat" at the same places, if I desired.

There are, however, some exceptions to the above, as Kingfish, Spanish Mackerel, and some of the other fishes will take a troll outside Biscayne Bay and north to Jupiter just about as well (and I have sometimes thought better) in cool weather as in warm; and the same is true with Bluefish in Lake Worth, and inside at Jupiter. I have often trolled in Lake Worth in cold weather for Bluefish and have 
done well; this was the case before and after the "freeze" of February 8,1895 .

The tides also must be reckoned with by the angler, especially on the bars, and in the passes, inlets, and creeks, leading from the inside waters out into the ocean.

In all of them, from the north end of Biscayne Bay to Mayport (mouth of the St. Johns River) on the north, more fish can usually be caught on the last two hours of the "ebb" and the first two hours of the "flow" than in all the balance of the day; this is a well-known fact among all sea-fish anglers, North and South. However, as you go south from Miami the above is not quite as important as to the north, and its effect lessens very materially among the inside waters of the Bay of Florida, of which Biscayne Bay is really the northern end. And as you get beyond the influence of the tides coming in at Mosquito Inlet and Indian River Inlet, the fishing is not so much affected.

It is well for me to here explain that the openings from the inside waters out into the Atlantic Ocean are called by many different names, as follows, viz: The mouth of the St. Johns River is called "St. Johns Bar"; at St. Augustine, the opening is called "Saint Augustine Inlet "; then, to the south, the next is "Mosquito Inlet"; then " Indian River Inlet," with " Fort Pierce Cut" (now closed), "Nigger Cut," "Garfield Cut," and "Blue Hole Cut," leading from the river to the inlet; then, twenty miles south, "Gilbert's Bar"; then "Jupiter Inlet" (now closed), "Lake Worth Inlet," "Hillsboro Inlet," and "New River Inlet." Then, from Biscayne Bay, "Norris Cut," "Bears Cut," "Cape Florida Pass," "Soldier Key Passes," " Ragged Keys Passes," "Sands Cut." The next ones are called creeks, as " Cæesar's Creek," " Broad Creek," "Angel Fish Creek," and "Tavernier Creek," the latter at south end of Key Largo.

From the latter point the openings are called channels, such as "Upper Matacumbe Channel," " Boca Chica Channel," etc., etc.

At the close of the list of "Fishing Localities" I have placed a list of hotels and boarding houses, nearly all of which are taken from the folder of the Florida East Coast Railway, season of 1900-1901, entitled "East Coast of Florida Hotel List and Information Folder," that Company having kindly given me permission to use the same. I also desire to acknowledge my obligation to the same Company for the use of the map which is a part of this book. 


\section{CHAPTER VI.}

\section{MAYPORT, MOUTH OF SAINT JOHNS RIVER.}

This place is about twenty miles east of Jacksonville, on the Florida East Coast Line.

The best season here is from April 1st to November 1st. The fishes are, Mullet, Channel Bass, Spotted Sea Trout, Drum, Sheepshead, Cavalle, Bluefish (small and medium size), Blackfish (Sea Bass, not the Tautog), Whiting, Croaker, Yellow Tail (the Mademoiselle Yellow Tail), Pigfish, Sailor's Choice, Spots, Flounders, Sharks, Rays, Catfish and Shad; the last named, during the winter, caught with nets and seines.

From November 1st to April 1st, Sheepshead, Blackfish, Whiting, Drum, Sailor's Choice, Flounders, Pigfish, and the foul fishes, such as Sharks, Rays and Catfish, are caught, but in far less numbers than between April 1st and November 1st. After June 1st, and during the summer months, the Tarpon frequents the river for a short distance above the bar, and Pompano are caught during the same time with cast nets and seines, mostly in the surf outside.

The best fishing is at the jetties, standing on the rocks, or a few feet from them in a rowboat, or small sailboat; this especially for Sheepshead and Blackfish, but while after them you are apt to catch any of the others. In fishing, especially for Channel Bass and Whiting, you want to fish in the swash channels and on or near the sandy bars or bottoms. In September and October, however, the Channel Bass are plenty and will take the bait almost anywhere inside the bar, and especially surf fishing, that is, standing on the beach, or wading out a short distance, casting your bait out as far as you can into the surf. This is one of the most successful methods of Channel Bass fishing on the coast from Mayport south to Gilbert's Bar. On most beaches you will need a pair of hip rubber boots, or a regular mackintosh wading suit. Some sportsmen prefer to wade without them. This method of fishing can be done with hand line, or rod and reel, as each sportsman may prefer. In August, September and October, Mayport is one of the very best localities on the East Coast 
for Channel Bass, large and small. Large-mouth Black Bass are taken in nearly every fresh-water stream emptying into the St. Johns from its mouth to its source, some of them near Mayport.

\section{ATLANTIC BEACH.}

This place is seven miles south of Mayport, is the site of the new Continental Hotel of the Florida East Coast Hotel system, and is, of course, a railroad station. Channel Bass can be caught here during the summer months, either off the pier, "heaving and hauling," as the hand-line method in the surf is called, or with rod and reel, or by same methods in the surf. Occasionally while fishing for Bass you will get some of the other fishes mentioned at Mayport. Pompano can be taken in nets through the summer months.

Sportsmen staying here can take the train to Mayport, at several different hours during the day, and can "fish the tide," or remain longer if they please, and return to the hotel for dinner; or they can drive to and from Mayport, if they prefer.

\section{SAN PABLO OR PABLO BEACH.}

This place is three miles south of Atlantic Beach, on the railroad, and has long been an "all-the-year-round" resort. The fishing is the same in the surf as at Atlantic Beach, with the same facilities for the trip to Mayport. I was there about the middle of May this year, 1901, when the hotel was being supplied with Pompano caught in the surf with nets. 


\section{CHAPTER VII.}

\section{SAINT AUGUSTINE, THIRTY-SEVEN MILES FROM JACKSONVILLE.}

The best season here is from March 15th, or April 1st, to November 1st, and the fishes are the same as at Mayport. From November 1st to April 1st the same fishes are caught, but in less numbers.

The best ground is in the North River, in the inlet alongside of the jetties near the outside, on the beach, surf "heaving and hauling," or with rod and reel. In the river north or sonth of the bridge, the north preferred, for Drum and smaller fish.

From the Matanzas and Sebastian River bridges. At the latter bridge there is usually very good fishing on the incoming tide, for small Bluefish, small Spotted Trout, and Yellow Tails (the small, or Mademoiselle), and occasionally a Channel Bass or Drum is taken. Whiting and small Blackfish are very numerous, but run quite small. Sheepsheads are quite plentiful around the jetties. The fishing in the river is done from the sailboats, of which there are so very many for hire, by the hour or day. Rowboats can be hired, but the distance to North River and the jetties is a long row.

A very pleasant way of spending the day at St. Augustine is to provide yourself with a cheap cooking outfit, consisting of a wire gridiron, frying pan, coffee pot, and cups and saucers, plates, knives and forks, spoons, etc. Go to Corbett's and buy some Oysters, or you can depend upon picking up all the "Coon " Oysters you will need. Take one of the sailboats, go to the North River, or other place recommended by the boatman. Catch your fish, land and cook them with such other edibles as you choose, and roast your Oysters in their shells over a wood fire. Oysters cooked in this way suit me better than in any other style, but, as I have before said, "tastes differ." Try it once and see what your judgment is. Oyster roasts are quite a feature at St. Augustine from November to March or April.

At Matanzas Inlet, eighteen miles south of St. Augustine, there 
is very good fishing, with a larger proportion of Channel Bass and Sheepsheads than near the city; and when the Bass are running, good success may be expected all along the beach from opposite the city to the inlet, surf fishing.

Boats can be chartered for the trip to the inlet at reasonable rates. Some seasons a steamboat makes regular trips. 


\section{CHAPTER VIII. \\ ORMOND ON THE HALIFAX RIVER. \\ ORMOND BY THE SEA.}

ONE HUNDRED AND FIVE MILES SOUTH OF JACKSONVILLE.

Here the best season is the same as at St. Augustine, and the fishes are Channel Bass (usually quite small), Sea Trout, Sheepshead, Mullet.

The fishing is mostly done by walking to and fro on the bridge, with rod and reel, trolling with phantom Minnow, spoon, live Minnow, Shrimp, or cut Mullet, or from the bridge, still fishing, with Shrimp, Fiddlers or other Crustacea bait, for Sheepshead. A moderate number of fishes can be caught here all the year round, but, as stated above, the best season is from April to November.

The Tomoko River and Smith's Creek, each about four miles north from Ormond, afford some Large-mouth Black Bass fishing, and the rivers are reached by launches from Ormond.

At Ormond-by-the-Sea, or Ormond Beach, there is fair Channel Bass fishing in the surf, hand line, or rod and reel; and Pompano run there through the summer months.

I think it well to here say that the term "river," as applied to the so-called Halifax, Hillsboro, and Indian rivers, is a misnomer. They are salt-water lagoons, bays or arms of the sea, with a few freshwater streams emptying into them; and are connected and continuous from four miles north of Ormond to Jupiter, counting the Haulover Canal (one-half mile long) between Mosquito Lagoon and Indian River as part of their water, which it really is. They are navigable for light-draught boats (say three feet) the entire distance of 182 miles (railroad measurement). They have four inlets from the Atlantic Ocean, namely, Mosquito, Indian River, Gilbert's Bar, and Jupiter, the latter temporarily closed.

DAYTONA, WEST SIDE OF THE HALIFAX RIVER.

ONE HUNDRED AND TEN MLES FROM JACKSONVILLE.

Season about the same as at Ormond, but the best fishing commences a little earlier and lasts longer. 
Very many sportsmen, and some colored market fishermen, troll from the North and South bridges, with Shrimp, Prawn, phantom, spoons and cut bait, and still-fish with the above natural baits and Crabs and Fiddlers. Shrimp, Prawn, Fiddlers and Mullet are usually kept for sale by a colored man near west end of South Bridge. The fishes are more numerous in species than at Ormond, and are as follows, viz: Mullet, Channel Bass, Bluefish, Sheepshead, Tripple Tail, Drum, Cavalle, Whiting, Flounders, Sailor's Choice, Catfish and other foul fishes.

The Tripple Tail, a game fish, and one of the very best edible fishes, is caught off the bridge around the spiles, up to thirty pounds weight. The colored brothers here call him "Chofa," and "Chopa." Many sportsmen prefer to fish near the bridges, from rowboats, which is the case with myself. During October, 1900, I spent much of the time at Daytona, having Professor Walker as guest on my boat. $\mathrm{He}$ and Capt. Gardner caught sixty-five Spotted Sea Trout in one day, from rowboat, anchored at different places, east and west, and usually about 100 feet south of the South Bridge. All rod and reel, Shrimp bait. I caught twenty-five Trout on each of several days. During the month we caught there Bluefish, Channel Bass, Sheepshead, Sailor's Choice, etc. There is use for fish at Daytona, in the absence of which we would not have caught so many; only fished two or three hours at a time and not every day; and possibly struck it better than we can again.

On the ocean beach opposite Daytona, at Sea Breeze Pier, there is good Channel Bass fishing between April and November, and occasionally fair catches between November and April. One party caught seventeen off the pier one day in May of this year, 1901. The surf fishing from the beach is good there during the proper season.

Trolling for Channel Bass and Sea Trout with rowboat, sailboat or launch, between Daytona and Ponce Park on Mosquito Inlet, twelve miles south, meets with more or less success, depending upon the season and weather.

\section{POR'T ORANGE.}

ONE HUNDRED AND FIFTEEN MILES SOUTH OF JACKSONVILLF.

This place is situated on the west bank of the Halifax River, five miles south of Daytona and same distance north of Mosquito 
Inlet. Seasons and fishes the same as at Daytona, with the addition of some of the smaller varieties caught at Ponce Park mentioned below. The fishing is done mainly from rowboats.

A network of salt-water creeks begins here and continues on south nearly to Oak Hill on Mosquito Lagoon, a distance of twentytwo miles, which creeks in their windings form islands, on which there has been a growth of mangrove bushes, which were killed by the freezes of 1886 and 1895 . A new growth has started, which in time will cover the island, unless frozen out again.

Beyond New Smyrna, south nearly to Oak Hill, there are islands on both sides of the main river, which is there called the Hillsboro.

Port Orange is very near good Channel Bass and Sea Trout ground, as well as that of many of the smaller fishes; fine trolling ground, both north and south of the village.

\section{PONCE PARK A'T MOSQUITO INLE'T.}

Flag Station, Spruce Creek, two and one-half miles distant, and 120 miles from Jacksonville.

Regular station for Ponce Park, New Smyrna, five miles distant south, and 125 miles from Jacksonville.

This place is on the peninsula (so called) on the east side of Halifax River, and faces Mosquito Inlet on the south and southeast. Here all the salt water of Halifax River flowing to the north and that of the Hillsboro River flowing to the south enters from the Atlantic Ocean; the Halifax having three fresh-water tributaries - the Tomoka, Smith Creek, and Spruce Creek, the latter directly opposite Ponce Park.

Owing to the above conditions the fishing season here is longer than farther to the north or south (until Indian River Inlet is reached), with a greater variety of fishes; and owing to presence of fresh water there are vast beds of Oysters, many of them of the very best quality.

The best season is from March 1st to Deccmber 1st, but during an average warm winter it is very fair all winter. Quite cold weather interferes here, as it does everywhere on the coast, except with a few of the fishes. Nearly all the fishing is done from rowboats, and within onc-fourth mile, or even less, to three miles from the hotels; sailboats and launches, therefore, are unnecessary for this purpose.

The fishes caught are: Besougas, Black Bass (up Spruce Creek), 
Blackfish (Sea Bass), Bladder-fish, Bluefish, Bream (up Spruce Creek), Catfish, Cavalle, Channel Bass, Croaker, Drum, Flounders, Groupers, Gulf-fish, Jewfish, Ladyfish, Mullet, Moon-fish, Needlefish, Mutton-fish (not the Pargo variety), Pigfish, Pilotfish, Pompano (during spring and summer), Porcupine-fish, Sawfish, Sharks, Sheepshead, Sailor's Choice, Sea Robbin, Sargeant-fish, Snappers (Mangrove), Snappers (Gray), Snappers (Rabirubia), Sand Conger, Skate, Spadefish, Spanish Mackerel (occasional schools traveling north), Tarpon (spring and summer), Spotted Sea Trout, Tripple Tail, Whiting, Yellow Tail (Mademoiselle). From here the sportsman has all of the network of creeks and islands within a day's row to fish in, as well as the two rivers and the surf, both north and south of the inlet.

The surf fishing has always been reasonably good, either with hand line or rod and reel, for Channel Bass, from April to December, and nearly every year, for a short time during the spring, for Pompano and Bluefish.

The latter are especially plenty in October and November inside, along the sandy banks near the inlet, in fact, along nearly all the shores. At that time there are millions of Menhaden in the river, and they make the best of bait for Bluefish.

During the last October and early November I frequently caught twenty-five to thirty in an hour or two, rod and reel, small line, 4\% hook, wire snood, a float, and no sinker, small Menhaden bait, sometimes from boat, and oftentimes standing on the sand bank one-fourth mile from the turn of the river from the inlet to the north. The fish run small, very few over two pounds; average somewhat over one pound.

This is one of the very best places for Sheepshead on the coast, is exceeded by none, unless it be Indian River Inlet. All kinds of Crabs are plentiful here as well as Mullet, so the sportsman rarely lacks bait.

Do not forget that the "Oyster Roast" is a very pleasant and desirable feature here. I spell it with a big $\mathrm{O}$ and $\mathrm{R}$.

Parties fond of fresh-water Black Bass fishing can do fairly well by going up Spruce Creek from eight to fifteen miles, the distance depending upon the amount of rain and the consequent supply of fresh water in the creek. I have been up there twice, and did next to nothing, but am satisfied that under proper conditions a reasonable number can be caught. 
Some four or five years ago the people of Hillsboro River residing in Volusia Co., the southern limit of which is a few miles north of the Haulover, voted against seine and net (except cast net) fishing in their river. This is done under a State law allowing each county or town to settle that question for themselves by vote, which might be called a sort of local option. Before that time the waters had been very much depleted by the market fishermen, who had the very best kind of a show, as they could take nearly every fish out of the very numerous creeks, which were easily fished. In a year or two afterwards, the people living on Halifax River, north of the inlet, voted to close their river to the net fishermen.

The creeks and the river are still fished for market with cast nets, but they are not so destructive as the seines were. In addition to the above, the State law forbids net fishing within one mile of any inlet, pass or channel, inside or outside. Both laws are observed at Mosquito Inlet.

Notwithstanding all of the above favorable conditions, sportsmen go to Ponce Park, Port Orange, and New Smyrna and are disappointed, and they will be when they strike a cold winter, or strike a spell of cold weather during an average warm winter.

Mr. S. C. Clark of Boston spent a great deal of time at Ponce Park, and has written a great deal about the place, mostly in periodicals. 


\title{
CHAPTER IX.
}

\author{
NEW SMYRNA.
}

ONE HUNDRED AND TWENTY-FIVE MILES FROM JACKSONVILLE.

New Smyrna is one of the oldest places in Florida, and for many years was the only accessible resort south of St. Augustine.

It is five miles south of Ponce Park, is on the Hillsboro River and has all the advantages and facilities for fishing, in the very many creeks north of the town, that Ponce Park has.

In addition to the river and creeks to the north, it has many creeks on the east side of the river, as well as on the west, for about twelve miles to the south.

The sportsmen use rowboats generally, and sailboats are not necessary unless long trips are to be made.

All of the fishes named at Ponce Park are caught here, many of them within half a mile of the hotels, across the river and north and south.

At the bridge across the Hillsboro, less than a mile from town, there is excellent Sheepshead fishing from the bridge draw, with hand lines and rod and reel, or from rowboats alongside of the bridge spiles. Fiddler bait, 15, 18, or 21 line, Virginia hooks.

I think I am within bounds in saying that I have seen fifty men and women fishing from the bridge on several different occasions. On many days during the height of the winter season over 1,000 pounds of Sheepsheads are caught per day. Of course, many other kinds are caught from the bridge, but the greatest number are Sheepsheads. Many people come down from Daytona to fish here, and at the inlet, during the day and return in the evening.

At Coronado Beach, opposite New Smyrna, on the ocean front, Channel Bass are plenty, April to December, and a few at other times, heaving and hauling, or with rod and reel from the beach.

The beach is about two miles from New Smyrna, across the bridge above mentioned and across the Peninsula. Oysters and Clams are abundąnt around New Smyrna. 


\section{HAWKS PARK.}

ONE HUNDRED AND TWENTY-EIGHT MILES FROM JACKSONVILLE.

Hawks Park is three miles south of New Smyrna, is on the river, having all the facilities for fishing among the islands and in the river. However, as the distance from the inlet increases, the variety and number of the fishes decrease.

Between Hawks Park and the Mosquito Lagoon there are very fair grounds for Channel Bass. On the ocean beach opposite, Channel Bass can usually be taken by surf fishing.

\section{MOSQUITO LAGOON.}

This body of water commences eighteen miles south of New Smyrna and extends at its southeastern end eighteen miles, to within four miles of the Banana River, which is the eastern arm of the Indian River. The seasons here are the same as at Ponce Park and New Smyrna, and the fishes are: Channel Bass, Cavalle, Besouga, Croaker, Drum, Flounders, Gulf Fish, Ladyfish, Mullet, Pigfish, Sheepshead, Sailor's Choice, Sea Trout, Tripple Tail, and Whiting.

The localities to fish here are at south end of Elbow Canal, among the islands toward the eastern end of the lagoon, and at each end of the "Haulover Canal," and in the canal. More than half of the lagoon (to the south) has no law against net and seine fishing, so is kept partially depleted, especially during the winter season, when the demand for fish is heaviest.

From November 1st to spring there are millions of ducks in the lagoon. It is known to be one of the best duck hunting grounds in the United States.

\section{OAK HILL.}

ONE HUNDRED AND THIRTY-SEVEN MILES FROM JACKSONVILLE.

This place is on the west side of the lagoon, and was the site of the Oak Hill Hotel, one of the old-time sportsmen's resorts, recently destroyed by fire. Oak Hill is the only railroad station on the lagoon, and is comparatively a convenient point for duck hunters and anglers to stop at. Oysters are plenty from New Smyrna to this place.

For accommodations, see hotel list. 


\section{THE “HAULOVER."}

This is the canal, about three-fourths of a mile long, between the lagoon and Indian River. Before the marketmen commence their work in the fall, usually about November 1st, there is very good fishing in the canal, and at its northern entrance; usually not good at its southern entrance. Formerly I have caught Channel Bass up to twenty-five pounds and Spotted Trout up to twelve pounds in the canal. Recently, success can be expected only at season above stated. 


\section{CHAPTER X.}

\section{INDIAN RIVER.}

There are no laws against the use of nets and seines in Indian River, except the one applying to the inlets. For this reason the river is kept partially depleted, but as the large Channel Bass are not considered a choice food fish, the market fishermen usually return them to the water; large numbers of Sea Trout escape, so, as nearly all the fishes mentioned at Mosquito Inlet are more or less numerous, moderate sport can be had at all points on the river. I consider the above a fair statement of the present condition of the sport fishing on Indian River from the Haulover to Indian River Inlet. As the above conditions prevail at all the towns and stations for the distance named, I will have to group them under the one heading of "Indian River," as above. They are Titusville, 155 miles from Jacksonville; Faustina, 168; City Point, 170; Cocoa, 175; Rock Ledge, 176; Eau Galle, 190; Sarno, 191; Melbourne, 195; Malabar, 200; Micco, 209; Roseland, 213 ; Sebastian, 215. These points are all on the west side of the river, and are railroad stations. In addition, there are on the east side of the river the following small places, viz : Courtney, Indianola, Merrit, Doctor Whitfield's Fairy Land, and Georgiana, all on Merrit's Island, so called.

The sport fishing is almost entirely done from rowboats, trolling with phantoms, spoons, red and white cloth, live Minnow, or cut fish. The phantom, in my opinion, is far the best. The fishes caught in this way are mainly Sea Trout, with an occasional Channel Bass, or Cavalle. The latter will generally tear a phantom into ribbons.

Channel Bass can nearly always be caught (from one to three or four) by anchoring row or sailboat on any sandy point projecting into the river, on either shore, hand line, or rod and reel, 18, 21 line, 5 or $6 \%$ hook, cut Mullet bait; cast as far as you can and let the bait lie. I have always had some success on the sand point a few rods below Doctor Whitfield's, some six miles below Rock Ledge.

Whiting can be caught on the west sandy shores nearly the entire 
length of the river, but not in profusion, because the marketmen get them.

Formerly there was very good sport at the mouth of Banana River, opposite Eau Galle. Channel Bass, Trout, Cavalle, etc.; but I have not done well there the last five or six years. I hear of others doing well. Banana River, so called, extends from very near Mosquito Lagoon, on the north, to its mouth opposite Eau Galle, where it discharges into Indian River; the strip of land between it and Indian River being called "Merrit's Island." There is a shallow, narrow creekreaching from opposite Titusville through the neck of land to near the head of the river, called Banana Creek. Capt. Gardner has not visited Banana River far above its mouth for several years past, and I have never visited it, so we can give no opinion as to the fishing except at the mouth. We do not get good reports, although several years ago there were fine Channel Bass near the head, and even in some parts of Banana Creek.

To return to the Indian River: Turkey Creek, for a mile above where it empties into the Indian River, was formerly a good place for Sea Trout, and occasional Channel Bass; but of late years I have not done well there. Mouth of Sebastian River, or "Sebastian Bay," as it is often called, was fine ground for Sea Trout, Channel Bass, Sergeant-fish (snooks), Tarpon of ten to twenty-five pounds, and other smaller fishes, and up the south branch for Large-mouth Black Bass and Bream; but during the past two years I have not done well there. The marketmen get in their work there quite thoroughly. This is one of two "Sebastian" rivers on the East Coast, the other one coming into Mantanzas River at St. Augustine.

It was at Sebastian River that I figured in my first, last and only alligator story, which I will here proceed to tell.

Some seven or eight years ago I was at the mouth of the river with Capt. B. J. Pacetti on the sloop "Hillsboro" for several days. One warm, nice morning we concluded to go up the south fork eight or ten miles after Black Bass. We started in the rowboat and had gotten to an island where the river forks, when I saw within two or three hundred feet of the boat some pieces of bark (as I supposed) floating on the water. I called Pacetti's attention to them, and he said, "Those are not pieces of bark, they are alligators' noses "; and sure enough they were, and there were probably twenty or thirty in sight. Pacetti said, "Now is your chance to kill an alligator"; I re- 
plied, "Not much; I would as soon kill a hog, cow, or manatee." He finally convinced me that he could show me how to kill one and still preserve my dignity as a sportsman.

He saw one near the little island and made for him, and, as he knew would be the case, the alligator sank down quietly in about six feet of water. We moved over until within a few feet, where we saw him lying still on the bottom. Pacetti took the grains, which were on a pole twelve or fourteen feet long, with a $\frac{3}{16}$ or $1 / 4$-inch cotton line twenty or twenty-five feet long. We moved quietly over the 'gator, when the grains were driven down into him just behind his head. The pole was quickly drawn from the socket in the grains, leaving the line in my hands. Well, that 'gator rushed for everywhere at a lively gait, and before Pacetti could get his oars fairly in hand. We went stern first a few feet, when Pacetti got partial control.

We were towed around in the river in all directions for ten or fifteen minutes, when our victim began to play out. We finally landed on the south shore and pulled him out, pounded him quite a while with some pieces of board, drew the grains out of hin, pounded him some more and left him for dead some ten feet from shore. He was eight feet long.

We went on up the river, caught our Black Bass, and about 5 P. M., on our way back to the sloop, stopped to take a look at our alligator, and found he was not there. What became of him we could not imagine; no footsteps around, but the grass and ground did look a little as though he had crawled back into the water. That was the only 'gator I ever killed, or tried to kill, in all my experience in Florida, and I hereby pronise to never try to kill another one. It is a mean business, unless you want his hide to sell.

Eight miles below Sebastian the "Indian River Narrows" commence and are about eight miles in length. Channel Bass are tolerably plenty at the northern and southern entrances. Good Oysters can be gathered at the southern end. 


\section{CHAPTER XI.}

\section{INDIAN RIVER INLET.}

Post-office at Saint Lucie, on the west bank of the river, formerly called Fort Capron, and "Paines," 242 miles from Jacksonville.

This inlet is approached by three "cuts" from the river, called Nigger Cut, Garfield Cut, and Blue Hole Cut. Until the past year there was another cut called Fort Pierce Cut, running into it from the river, which has recently closed, near the inlet, thus destroying it and its tributary cuts as fishing ground.

Season here same as at other points on Indian River. Fishes: Besouga, Bluefish, Carvalle, Channel Bass, Croaker, Drum, Flounders, Groupers, Gulf-fish, Jewfish, Kingfish, Ladyfish, Mullet, Moon-fish, Pigfish, Pompano, Saw Fish, Sheepshead, Sailor's Choice, Sergeantfish, Snappers (Mangrove, Gray, and Rabirubia), Spadefish, Spanish Mackerel, Tarpon, Sea Trout, Tripple Tail, Whiting, Catfish, Sharks, Toadfish, and all other foul fishes.

Large Channel Bass are caught in the river, about one-fourth mile from the east shore, and about the same distance south of the entrance from the river into Nigger Cut, called "Quays Canal."

I have caught a great many here during the past three years and often before, weighing from six to thirty-seven pounds, fishing with light tackle, No. 6 line, and small reel. The Snappers and Groupers are caught along in the channels of the cuts, in the deep water near the shores, near the mangrove bushes or trees, as also in deep water where there are no trees. The other fishes are caught all through the cuts. Sheepshead are especially plenty, are caught with Fiddlers, Oyster Crabs, or Sea Crab bait, along the deep shores, usually within a few feet. Strong rods, reels and lines are necessary, with Virginia hooks.

From about March 15th till May 1st to 15th, the Spanish Mackerel come in schools outside the inlet, and the trolling with hand line, or rod and reel, with three-inch Nackerel squid is grand; of course, sailboat or launch is necessary for this sport. Usually a few Bluefish will also be taken. 
During the present season (1901) I have seen many catches of 100 to 800 Mackerel per boat, made by the market fishers, there being eighteen to twenty boats engaged in the business. Their market is Fort Pierce, four miles distant to the south. From March 15 to May 10, 1901, about 100,000 pounds of Spanish Mackerel were shipped North from Fort Pierce, which is also the largest shipping point on the East Coast for a great variety of fishes caught in nets in the river a considerable distance north and south of the inlet.

Kingfish are also frequently taken, trolling with $\frac{3}{16}$ line and large squid; or rod and reel, if you are willing to take the time to luff up when you get one on. A Kingfish cannot be held with rod and reel with the boat under way. If you are on a sailboat large enough to tow a rowboat, you can leave the large boat, if the sea is quiet enough. This is the scientific way to catch Kingfish.

Indian River Inlet is noted for its fine Oysters. I believe there are none better in the world. The Oyster Roast comes in here to a charm.

Here the first Tarpon caught with rod and reel was taken by Mr. S. H. Jones of Philadelphia, Capt. John Gardner being his guide.

\section{FORT PIERCE.}

TWO HUNDRED AND FORTY-TWO MILES FROM JACKSONVILLE.

This place is three to four miles south of Indian River Inlet, and is a resort for tourists and sportsmen who fish mostly at the inlet. Rowboats, sailboats and launches can be hired for fishing at the cuts and trolling outside. The details of the fishing from here are all given in the account of Indian River Inlet. It is quite a business point, and is the largest fish-shipping point on the East Coast of Florida.

$$
\text { ANKONA, EDEN, AND JENSEN. }
$$

RESPECTIVELY TWO HUNDRED AND FIFTY AND TWO IIUNDRED AND FIFTY-FIVE AND TWO HUNDRED AND FIFTY.

\section{SEVEN MILES FROM JACKSONVILLE.}

Stations on the railroad between Fort Pierce and Gilbert's Bar, and on the river.

Parties stopping at these points can get some fishing for Whiting, Channel Bass, Trout, etc., in the river; and can, with sailboats or launches, visit Indian River Inlet, or Gilbert's Bar; the latter only six or seven miles distant. 
Pompano are caught in nets and seines in the river all the way from Indian River Inlet to Gilbert's Bar; Fort Pierce being the largest shipping point for them on the East Coast.

\section{GILBERT'S BAR.}

\section{SEWELL'S POINT, POST-OFFICE.}

TWO HUNDRED AND SIXTY-TWO MILES FROM JACKSONVILLE.

Stuart nearest railroad station, six miles up St. Lucie River.

This place is twenty-five miles south of Indian River Inlet, Sewell's Point being on the west shore of the river and at the mouth of the St. Lucie River, where it empties into Indian River. Gilbert's Bar was an old inlet or pass from the ocean, but closed many years ago. About ten years ago the residents reopened it, since which time it has been one of the best sport and market-fishing places on the river. Season same as at Indian River Inlet. Fishes: Bluefish, Kingfish, Cavalle, Channel Bass, Groupers, Gulf-fish, Jewfish, Lady-fish, Mullet, Pigfish, Pilot-fish, Pompano, Sheepshead, Sailor's Choice, Sergeant-fish, Snappers (Gray, Mangrove, and Rabirubia), Spanish Mackerel, Sea Trout, Whiting and all the foul fishes.

Bluefish, still fishing in the main channel inside near the sand banks on either side of channel, from Sewell's Point down to the bar. Trolling with hand line, or rod and reel with Mackerel squid, red and white rag on No. 8 hook, or fish bait on same size hook, over the same water as above. Snappers and Groupers, still fishing close to the North Peninsula shore near the mangrove trees and the roots (in the water) of fallen trees. Spanish Mackerel, outside trolling with hand line or rod and reel, with Mackerel squid, red and white rag, or fish bait, the squid preferred.

Occasionally a few are caught inside in same way, and by still fishing. While trolling for Mackerel outside there are usually a few Groupers caught, some large ones. Kingfish are only caught outside trolling with Kingfish squids. There is a "patch" or "rock reef" about one-fourth mile off the inlet and extending south about two miles, and one-half to three-fourths mile north of the inlet, on which in quiet weather sailboats, launches, or rowboats can be anchored, and on which Snappers, Groupers, and the smaller fish above mentioned, are very plenty, and can be taken with rod and reel, still fish- 
ing. As the word "patch" will be often used, I will explain that it means places or spots outside, either where the bottom is usually rocky or sandy, or on the Great Florida Reef, where there is rock bottom more or less covered with loggerhead and other sponges, sea fans, loose or fast, coral, etc. The word is used by the "Conchs" of the Keys and has so come into general use. Cavalle, Bluefish, Channel Bass, and Trout are caught in the channels running to the inlet, still fishing and possibly a few trolling. Sheepshead along the north shore above mentioned, with rod and reel, Virginia hook, and Fiddlers, Crab, or sand flea bait.

Pompano are caught in the channels inside, light rod and reel, No. 3 or 4 hook, $2 \frac{1}{2}$-inch reel, No. 9 line, with steel violin string, piano wire, or gut leader, eighteen inches long; and sand fleas, Fiddlers, Sea Crab, or Hermit Crab bait. They will not take any fish bait nor any troll. Gilbert's Bar is one of the star fishing localities of the East Coast.

\section{SAINT LUCIE RIVER.}

\section{TWO HUNDRED AND SIXTY-TWO MILES FROM JACKSONVILLE.}

This is a large fresh-water river running into Indian River at Sewell's Point and opposite Gilbert's Bar. It has two branches, north and south, forking at the railroad bridge at Stuart Station. During the winter and spring there are many Tarpon in the north branch.

During the spring of 1899 there were many caught by Mr. Lorillard and guests. There are a few Snappers, Cavalle, Groupers, Jewfish, and small fish near the bridge.

Large-mouth Black Bass and Bream are plentiful up each of the branches, the distance depending each season upon the amount of rainfall, and the consequent supply of fresh water. The distance will vary from fifteen to twenty miles from Sewell's Point.

During the past few years very few sport fishermen have frequented the stream.

\section{JUPITER NARROWS AND HOBE SOUND.}

These waters extend from Gilbert's Bar to Jupiter Inlet, a distance of twenty-three miles. I have never done well in them. "There is some trolling done with spoon and other artificial baits, for Cavalle and Sea Trout, in Hobe Sound, which I have often tried; but of late 
years have not considered it sufficiently attractive to induce me to persevere in my trials.

\section{JUPITER INLET.}

TWO HUNDRED AND EIGHTY-THREE MILES FROM JACKSONVILLE.

This place, up to within a few years, was one of the best and most attractive fishing resorts on the coast, but as the inlet has closed two or three times within the past twenty-five years, its importance as a fishing resort has declined.

The inlet is now closed (May, 1901), which, of course, shuts the ocean fish out, and leaves the place an undesirable one for sport fishermen to visit at present.

As the inlet will probably be opened within this year, that is before the season of 1902 opens, I deem it proper to give the names of fish caught there in recent years by me, as well as the same information given about other places.

Season same as Gilbert's Bar. Fishes: Bluefish, Cavalle, Channel Bass, Drum, Flounders, Groupers, Gulf-fish, Jewfish, Kingfish (outside), Ladyfish, Margate Fish, Mullet, Pigfish, Pompano, Sheepshead, Sailor's Choice, Sergeant-fish, Snappers (Mangrove, Gray, and Rabirubia), Spanish Mackerel (outside), Sea Trout and all the foul fishes of Indian River. The Bluefish are caught in the main channel between the inlet and the railroad bridge, either trolling or still fishing, as at Gilbert's Bar; Channel Bass, Sea Trout and Cavalle along the channel near the Oyster bars, still fishing; Snappers, Groupers, Sergeant-fish, and Sheepshead along the deep places near the shores, near mangrove trees and roots.

Pompano may be caught in the channel, all the way between the inlet and the lighthouse, with tackle and bait heretofore mentioned. I have had good success at Jupiter with Pompano as late as spring of 1900. The other fishes mentioned are caught in the channel.

I have heretofore caught Bluefish, sometimes very many, right in the inlet, standing on the shore, casting a medium-size squid as far into the channel as possible, with a Tarpon rod, reel and line, and winding it in as rapidly as possible. This has been a very pleasant and successful method of taking Bluefish.

I have also taken them, with rod and reel, cut Mullet bait, casting into the surf outside, letting the bait sink, at both north and south beaches. 
In March, 1892, I caught a Bluefish weighing $12 \mathrm{I} / 2$ pounds near the inlet inside, with rod and reel, still fishing, cut Mullet bait. I was "high hook" just one day, as the next day a gentleman from Philadelphia caught three in the Bluefish hole just east of the present railroad bridge, which weighed, respectively, $13 \mathrm{I} / 2,14 \mathrm{I} / 2$, and $16 \mathrm{I} / 2$ pounds.

During the winter and spring there is fair trolling for Kingfish off Jupiter Inlet, about a mile from shore.

The Loxahatchie River comes in here from the northwest, and there is fair fishing in it two miles or more from the inlet, for Mangrove Snappers, Groupers, Sea Trout, Sheepshead, etc. Just above the railroad bridge there is a hole, or deep place, along under the mangrove on the north side, called "Snapper Hole" and "Jewfish Channel," where Snappers, Jewfish and Groupers have been plenty. There are creeks about two miles up, coming in from the south, where the Snapper fishing was good while inlet was open. In leaving Jupiter, we leave the Oyster, which is, or was, plenty, as also in Hobe Sound. There are none farther south.

On arrival at Ponce Park, October 10, 1901, I learn that Jupiter Inlet was opened on the 14 th of June last, by the residents there, with the assistance of the United States Government, and that the inlet and bay inside are in good condition, with three feet on the bar at low tide, and the usual good fishing inside and out.

Before taking leave of Indian River I wish to repeat, that from the Haulover Canal south to the northern end of Jupiter Narrows, faithful and industrious trolling with a rowboat, along the shores, and sometimes in the middle of the river, will result in reasonable catches of Sea Trout, with occasional Channel Bass, and when local guides are employed some of the smaller fish can be caught, but please remember that the "man with the net" has been industriously at work on the river for twelve years or more. He has during the past four or five years been forbidden by State law to fish within one mile of any inlet; so the angler still has a fair chance at the four inlets.

I do not like to leave Jupiter without indulging in a little reminiscence regarding the railway from there to Juno on Lake Worth. That railway has become historic, because it was the means of solving some of the astronomical, mythological, and meteorological problems of the times.

As it began at Jupiter on Indian River and ended in Juno on 
Lake Worth, a distance of seven miles, passing by Venus, Mars, and Saturn, as indicated by signboards on stakes driven into the ground, it afforded a fine opportunity to the patent medicine almanac scientific weather prophets, to study the transit of Venus, and their theories regarding the "juxtaposition" of some of the other planets, which it had been before difficult for them to prove. It finally settled the much-mooted question as to whether or not Mars is inhabited, and in the negative, as there were no people there, have never been since, and probably never will be.

The road could hardly be called a mythological one, at any rate not to its owners, as their revenue from the road must have settled that question. "If you don't believe that, ask Mr. Flagler."

Is it not strange that the people in charge of the weather burean, who have been thoroughly trained in colleges, technical schools, etc., and are placed in their positions by the Government because of their proved attainments in their profession, only pretend to forecast the weather from twelve to thirty-six hours ahead, while the almanac gentlemen can, and do, forecast it all the way from one day to a year?

The above weather business was written because I was once awfully disappointed by an almanac.

Just before Mr. Borden and I started on our cruise around the coast on the "Manatee," while buying some supplies at Jupiter, I picked up a patent medicine almanac, which I took aboard.

When I came to read it, I stood aghast, as it told me that on April 1st (I may be mistaken in the date, but April 1st will answer first rate) there would be a terrible storm all over the Gulf of Mexico and the south Atlantic Coast. I hid that almanac for fear the captain, Mr. Borden, or some of the crew would get hold of it, and want to give up the cruise, desert, or mutiny.

Well, we went along all $\mathrm{O} . \mathrm{K}$. and the fatal day finally approached. I trembled, but never said a word. The day finally came, and a finer one I never saw anywhere ; the night came, and that was perfect. I then brought out the almanac and read it to the captain, Mr. Borden, and the crew.

We were all very thankful, of course, for our narrow escape, and blessed the almanac man. 


\section{CHAPTER XII.}

\section{LAKE WORTH.}

Railroad Stations: Riviera, 296; West Palm Beach, 300 ; Hotel Royal Poinciana, 301 ; The Breakers, 301 1/2 ; Lantana, 309 ; Hypoluxo, 310 miles from Jacksonville.

This body of water, like Indian River and the other continuous inside waters north of it, is not a lake, but is a salt-water lagoon, bay or arm of the sea, with one inlet about three miles from its north end. It is connected with Indian River by the Jupiter and Lake Worth Canal, and to the south with Biscayne Bay by canal, thus having a free flow of salt water through its entire length of twentyfour miles.

The seasons here are somewhat different from that of Indian River, because the Gulf Stream, which increases the temperature of the water, is nearer the shore. The migratory fishes, therefore, come earlier and usually leave earlier.

For the above reasons no general statement as to the seasons will apply to all the fishes, and I will have to state seasons for the different varieties.

Fishes (season all the year round) are: Amber Jacks, Barracuda, Cavalle, Drum, Flounders, Groupers, Grunts, Gulf-fish, Bream, Jewfish, Ladyfish, Margate Fish, Mullet, Pigfish, Pompano, Runners, Sheepshead, Sailor's Choice, Snappers, Spadefish, Sea Trout and the foul fishes.

The above fishes are all caught in the inside, in the inlet and the channels leading to it, and also on the "patches" or reefs, about one-fourth to one mile from the shore. And the following kinds of the above can at times be caught standing dry-shod on the beach casting into the surf: Barracuda, Cavalle, Ladyfish, Pompano, Runners, Sea Trout. This, however, requires skill, patience, and a continuous spell of warm weather lasting several days, so parties wishing to try it will have to watch the shores and pick their time. It has been done by myself repeatedly. I have also known the Permit to be canght from the beach. 
The season for Bluefish, Kingfish, and Spanish Mackerel is from November 1 st to April 15th, varying with the different years. The Bluefish is caught inside, trolling with sailboat or launch, and with rod and reel, the best ground being within a mile north and south of the inlet, in the inlet, and trolling outside. Also from the beach, surf fishing, and from the pier at the Breakers Hotel. I have repeatedly caught them in all of these different ways. All these different methods will not be successful all through the season, but parties on the ground can watch the lake, the inlet, and the surf, and at times can be reasonably successful.

The Kingfish and Mackerel are caught outside trolling with hand line or rod and reel, from sailboat or launch.

From the pier, the following fishes have been caught with rod and reel, or hand line: Amber Jacks, Barracuda, Cavalle, Bonito, Groupers, Permits, Grunts, Gulf-fish, Jewfish, Kingfish, Ladyfish, Margate Fish, Bluefish, Pigfish, Spots, Runners, Sheepshead, Sailor's Choice, Snappers, Spade Fish, Sea Trout, Sharks and other foul fishes.

The larger kinds can be taken with a Tarpon rod, reel and line, with Mullet or other small fish, dead or alive, as bait. The Mangrove Snappers, Groupers, and other fish can be taken with Crab, Mullet, or sand flea bait, and usual size rod and reel. These fishes are all (except the small ones) exceptionally wary and shy, more so than at any other places I have fished for them.

Still, parties fond of fishing can while away many hours on the pier, and may at times do well. I have seen as many as twenty-five Kingfish caught there in a day, with six Amber Jack; this was in 1897. Parties fond of catching Sharks and Sawfish can use the clothes line and large Shark hook, and usually catch Sharks to their heart's content, and stand a chance of getting a Sawfish.

On 15th April, 1898, Capt. Gardner and myself caught fourteen Pompano with light rods, small reels, No. 6 Hall lines, No. $3 \%$ Harrison Sproat Hooks with double gut leaders, sand flea bait, casting from the beach into the surf about 500 feet south of the pier. Thirteen of the Pompano weighed about three pounds each, as they averaged large, and one weighed $22 \mathrm{I} / 2$ pounds. We were catching them lively when we quit, but stopped because we had no use for them. Mr. Allen, who had charge of the Poinciana and The Inn, weighed the large fish on the scales at The Inn.

IVe gave it to Mr. Cory, the taxidermist opposite The Inn, who 
mounted it, and sold it the next season. He also saw it weighed. We laid one of the smaller fish on the pavement beside the large one, and critically compared the shape, the head, the fins, and the coloring of the two, and could detect no difference. Mr. Allen and the taxidermist joined in the examination, and we all agreed, to the best of our judgment, the two fishes were identical in species, that the large one was a true Pompano or what is called the "Common" Pompano. The day before we made our catch the market fishers there had caught 500 Pompano at one haul, as we were informed by several parties. IVe saw hundreds of them in schools along the beach for half a mile or so south of the pier.

Mr. Edward P. Borden of Philadelphia has several times fished for Amber Jack with rod and reel, Tarpon rig, from rowboat, near the pier, and we here give his method of catching them, as follows, viz :

"For Amber Jack fishing off the 'Breakers' at Palm Beach, use the usual Tarpon rod, reel, and line, with a No. $10 \%$ hook with gimp or wire snood, and live bait. Go with your boat two or three hundred yards south of the pier, and anchor over the rocky bottom; you will catch Sheepshead and perhaps 'Spot'; the latter makes fine bait and is what you want for the Amber Jack. If you cannot get 'Spot,' small Mullet will answer, but will not attract like the 'Spot.' Then anchor about 100 yards off the pier. Let your bait run out with the current fifty feet, more or less, and when you get a strike let the fish run ten or fifteen feet before snubbing. You will probably hook him; play him as you would any large fish.'"

Barracuda and Kingfish are caught by same method, but a quiet day must be selected.

In former times Pompano were caught with rod and reel in the lake, some two miles or more south of the Royal Poinciana, at what is called Rock Island, but none have been caught there within the past few years. They are caught at night in gill nets in different parts of the lake, nearly all near the inlet. I assisted in one haul at night, catching fourteen, six years ago, near the Riviera Hotel.

Almost every season there is very fair trolling for Bluefish with launches or sailboats, the best ground being from one to two miles south of the inlet north, by the inlet, to Pitts Island, a distance of three miles or so. One season I saw as high as fifty to 100 caught per day, for market, by a party residing at Lake Worth P. O., who 
ran up and down the above track with a launch nearly every day for weeks. I have never trolled there all day, but have often caught ten to twenty, with sailboat, in half a day, counting time from Poinciana.

I have done well with rowboat, anchored on the edge of the steamboat channel, just opposite inlet; fishing only the incoming tide for an hour or two. Cut Mullet bait, 6\% wired hook, 21 line, rod, reel, and barrel float.

There is usually fair Mangrove Snapper, Grouper, Grunt, etc., fishing in the north and south channels, just inside the inlet. Anchor rowboat in the deep or deepest water, rod and reel, 6\% hook, 21 line, for the Snappers and Groupers, sinker, cut Mullet bait, bottom fishing, no float; best time "last of ebb and first of flow." I have done well there many times.

I have never but once tried the "patch" fishing and then did not do well, but I have seen some very large catches, consisting of three kinds of Snappers, Groupers, Sheepshead, Mutton-fish, Grunts, etc., etc. During three or four seasons the sloop "Robinson Crusoe" made a business of taking parties out, not over a mile, anchoring over the patches or reefs. In rough weather she could not go out, and finally had to give it up. Parties can go out on very quiet days, now, and do well.

The next largest, but one, catch of Kingfish ever made by sportsmen on the East Coast was made here, the one illustrated in the East Coast hotel literature. Modesty, and a little shame, forbids me to tell here who made the largest catch. Very little of that has been done lately, but the fish are there every year. They certainly run as far north as Indian River Inlet, probably some farther. 


\section{CHAPTER XIII.}

\section{THE CANAL BETWEEN LAKE WORTH AND BISCAYNE} BAY.

This canal is fifty-five miles long, commencing at the south end of Lake Worth and ending at the north end of Biscayne Bay. The waters and sounds of Hillsboro River and New River have been utilized as much as possible in constructing the canal.

\section{HILLSBORO INLET AND SOUND.}

There is no fishing in the canal until Hillsboro Inlet and Sound are reached, about thirty miles. At the inlet and in the canal, for a distance of half a mile to the south, there is fair fishing for the following fishes: Barracuda, Cavalle, Snappers (Mangrove and Rabirubia), Groupers, Grunts, Mullet, Runners, Sailor's Choice.

We have always done well here. The Mangrove Snappers should be fished for at night, and within 500 feet of the inlet, on the north side of the channel, about 100 feet from the north shore. 'The other fishes in the channel and the entrance to the canal on the south of the sound.

The largest Mangrove Snappers I ever caught were here, near the north shore, close to the inlet, just opposite a lone cocoanut tree which leans out over the channel.

B. J. Pacetti and myself caught eighteen one night after dark; one of his and one of mine each weighing $10 \mathrm{I} / 2$ pounds; rod and reel, 21 line, $6 \%$ hook, sinkers, cut Mullet bait. We could catch nothing there during the day, but did catch a few large ones in the forenoon in a small slough leading from the sound into the canal at south entrance, one weighing $10 \mathrm{I} / 2$ pounds. Groupers at that time (1897) were plentiful in the canal, and near the inlet, some of them running to twenty pounds. Barracuda are in the running water of the inlet, but I have caught none there. Reefs outside, where there are plenty of fish. Our fishes there are returned to the water, except a few for the table, there being no one around to give them to. 
NEW RIVER INLET AND SOUND.

RAILROAD STATION, FORT LAUDERDALE, THREE HUNDRED AND FORTY-ONE MILES FROM JACKSONVILLE.

When I first visited this sound I had good success, but during the past three years have not done well. This and Hillsboro Sound have been fished during the past few years for market with gill nets and seines, so the sport fishing has been very much lessened. This sound is hardly worth visiting at present time. The season same as Lake Worth, and the fishes same as Hillsboro Sound.

There are many patches and reefs from one-fourth to one mile off shore, all the way between Lake Worth and Biscayne Bay, where the usual variety of reef fishes are caught, and trolling for Kingfish, Spanish Mackerel, Bluefish and Groupers, in their season, is good. Barracuda, Cavalle, Runners, etc., are caught in the surf all the way.

\section{SNAKE CREEK, ARCH CREEK, LITTLE RIVER.}

Snake Creek is the lower, or southern, end of the canal. Arch Creek is a fresh-water stream emptying into Biscayne Bay, and Little River is two or three miles south of Arch Creek. There is said to be Snappers in all of these creeks, but, as we have never fished there, can give no opinion in the matter. 


\section{CHAPTER XIV.}

\section{BISCAYNE BAY AND MIAMI, INDIAN CREEK.}

This creek is on the eastern shore, opposite Lemon City, and about six miles north of Miami. It is an inside bayou, or slough, running parallel with the peninsula north and south. It is said to be a good water to troll for Sea Trout.

\section{MIAMI.}

\section{THREE HUNDRED AND SIXTY-SIX MILES SOUTH OF JACKSONVILLE.}

The City of Miami is on the west shore of Biscayne Bay, at the mouth of the Miami River, and ten miles south from the south end of the canal.

It is the southern terminus of the Florida East Coast Railway, and the port of departure for the Steamers of the Peninsular \& Occidental Steamship Co., for Key West, Havana, and Nassau. It is a point of call for many medium-size yachts, and the winter rendezvous of many of the smaller class which cruise in the Halifax, Hillsboro, and Indian rivers, Lake Worth, Biscayne Bay, among the Keys to Key West, and on the West Coast to the Tarpon grounds of Charlotte Harbor, and other points.

It is also the headquarters of many sailboats, launches, rowboats, etc., for charter from one day to a number of months, for cruising and sport fishing. Virginia Key, the most northerly of all the Keys reaching from Biscayne Bay to Key West, and beyond to the Dry Tortugas, lies opposite the city. From here, south, the inlets from the ocean are nearly all broader than those of Lake Worth, Indian River, etc., and are called "cuts," "creeks" "passes," and "channels," instead of "inlets."

The water is warmer, much more clear and transparent than those heretofore mentioned, and are more highly colored, blue and green. Biscayne Bay is thirty-six miles long, north and south, and varies in width from three to eight miles. The distance to Key West is 143 
nautical miles by the Hawkes Channel route on the "Great Florida Reefs," which extends to that city from Cape Florida, nine miles south of Miami. The width of this reef from the line of Keys to its eastern edge is from two to six miles, and its edge is nearly coincident with the inner line of the Gulf Stream. The proximity of the warmer water of the Gulf Stream has a decided effect upon the fish life, as the species are far greater in number than farther north, very many of which are of the highly-colored varieties.

As all the species of fishes whose habitat extends from Biscayne Bay to Key West are caught in the Bay, or the passes leading into it, I will have to, in many cases, group them together, to avoid repetition. I will say, however, that larger numbers of the highly-colored kinds are caught as we proceed south to Key West.

I consider the season from the Bay to Key West to be all the year round, except for the migratory species, such as Kingfish, Bluefish, Spanish Mackerel and some others, which I will treat separately.

I consider the Sailfish a migratory one, South America being his home, and the waters off Biscayne Bay being the northern limit of his migration, except in rare instances.

It is well to repeat here what I have said in my instructions, that the "Northers," especially when cold, and windy weather, sadly interfere with the angler's success, the same as'farther north. However, many more good days may be expected here, as the cold ones are not so frequent, nor of so long continuance. Even in the worst weather I have always been able to pick up enough to eat.

In the U. S. Fish Commission Report of 1899, B. W. Evermann and W. C. Kendall give a "Check List of the Fishes of Florida," which contains 576 species, a very large proportion of which they locate in the waters of Biscayne Bay, the Keys, and Key West. I will give a list of those I consider important to my subject, nearly all of which I have caught, observed, or know to have been caught by anglers or market fishermen, viz :

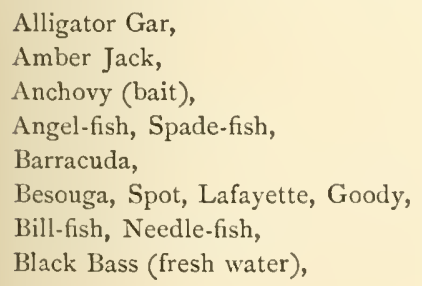

Black Drum, Gray Drum, Blow-fish, Puffer, Bluefish, Bone-fish, Big-eyed Herring, Bonito, Little Tunny, Bur-fish, Swellfish, Puffer, Blackfish, Sea Bass (one specimen), Bream (salt-water), 
Bream (fresh-water),

Bladder-fish, Puffer, Toad-fish,

Swell-fish, Blow-fish,

Catfish -

Common Sea Cat,

Gaff Topsail Cat,

Cavalle, Crevalle, Jack,

Channel Bass, Redfish, Red Drum,

Chub, Sea Chub, Bermuda Chub,

Cowfish, Trunk-fish, Shell-fish,

Croaker,

Cutlass-fish, Scabbard-fish,

Dogfish,

Flounders -

Summer,

Southern,

Flyingfish,

Gobies (bait),

Gulf-fish, Spot.

Grunts -

Margate-fish,

Gray Grunt,

Sailor's Choice, Ronco Blanco,

Yellow, Boar Grunt,

Common Grunt,

French Grunt,

Tom Tate, Red Mouth,

White Grunt,

Pork-fish,

Pig-fish, Hog-fish,

Groupers -

Yellow-finned, Dolly Varden,

Nassau, Cherna, Criolla,

Nigger-fish,

Rock Hind,

Red Hind, Cabrilla,

Speckled Hind, John Paw, Polka

Dot,

Red Grouper,

Black Grouper,

Gag, Ajuaji,

Scamp, Bacalao,

Hogfish (repetition of Grunt),

Jewfish, Black Grouper,

Kingfish, Cero,

Lady-fish, Bonefish, Skipjack,

Lizard-fish, Ground Spcaring,
Margate-fish, Market-fish (repetition of Grunt),

Morays, and Conger Eels,

Mudfish, Mud Sucker (Miami River),

Mullets -

White, Silver,

Common,

Fan-tail,

Whirligig,

Menhaden (bait),

Moon-fish, Look Down, Horse-fish,

Mutton-fish, Pargo (repetition of Snappers),

Needle-fish (repetition of Bill-fish),

Nigger-fish (repetition of Grouper),

Permit, Pampanito,

Permit (Key West),

Pig-fish (repetition of Grunt),

Pinfish (repetition of Porgy),

Pipe-fish,

Pilot-fish,

Pompanos -

Common Pompano,

Round Pompano,

Parrot-fishes -

Blue Parrot-fish,

Green Parrot-fish,

Red Parrot-fish,

Mud Parrot-fish,

Pork-fish (repetition of Grunts),

Pilchards (Key West bait),

Porgies -

Scup,

Saucer-eye,

Little-head,

Jolt-head,

Little-mouth,

Sheepshead,

Grass, Shad,

Red,

Pin-fish, Chopa Spina,

Salema,

Pudding-wife, Wrasse-fish,

Puffers (repetition of Bur-fish, etc.),

Razor-fisl, Wrasse-fish,

Rabirubia (repetition of Yellow-tail),

Rudder-fish, Chub, Chopa Bianca, 
Runners -

Yellow-tail Runner, Cojirera,

Goggle Eye, Goggler, Big-eyed Scad,

Goggle-eye Jack, Chicarro,

Horse-eye Jack,

Hard-tail Runner, Jurel,

Yellow Mackerel, Crevelle,

Running Jack, Dollar-fish,

Tide Runner, Blue Runner,

Sardines (Key West bait),

Sawfish,

Sail-fish, Banner-fish, Spear-fish,

Sailor's Choice, Ronco Blanco (repetition of Grunts),

Scamp (repetition of Grouper),

Squirrel-fish,

Sharks -

Shovel-head, Bonnet-head,

Hammer-head,

Mackerel,

Nurse, Gata,

Sand,

Sea Horse,

Sheepshead,

Sea Robbin,
Sea Trout, Weak-fish, Squeteague,

Sergeant-fish, Snook, Rovalia,

Schoolmaster (repetition of Snapper),

Snappers -

Mangrove or Gray, Cabalerote,

Dog Snapper, Jocu,

Schoolmaster,

Red,

Mutton-fish,

Lane,

Yellow Tail, Rabirubia,

Sand Perch, Goat-fish,

Spade-fish, Angel-fish,

Skate,

Shell-fish (repetition of Cowfish),

Spanish Mackerel, Carita,

Sole, American Sole,

Ray, Sting Ray, Stingaree, Whiptail Ray,

Trippletail, Flasher, Chopa,

Tarpon, Tarpum, Grand Ecalle,

Turbot, Trigger-fish, Leather Jacket,

Trunk-fish (repetition of Shell-fish),

Whiting, Kingfish (small),

Yellow Tail, Rabirubia,

Yellow Jack.

I have added to the list some local names, not in J. \& K., and have not given in every instance all of their common and Spanish names. Have endeavored to give all in general use where the fishes are caught.

These fishes are not equally plenty in all the waters from Biscayne Bay to Key West, but they are all caught in the waters. Some of them are more plentiful in the channels leading into the Bay, and some are more plentiful as you proceed south, the latter being the case especially with the highly-colored fishes.

I was one of a party on the schooner "Privateer," in winter of 1897, out for the day only, who brought into the Royal Palm Hotel thirteen species of choice fishes, which included Parrot-fish, Cowfish, Porkfish, Angel-fish, Porgies, Grunts, Groupers, Snappers, and Turbot. Our catch was a large one, as there had been a long warm spell. The thirteen varieties were placed on a tray on a counter of the hotel. All caught in Bears Cut.

Any one cruising below Miami will soon get on to the kinds of 
fishes to catch at each point, but I will try to indicate the most plentiful, as well as the choice ones, at each point.

Bluefish, Kingfish, and Spanish Mackerel, make their appearance about November 1st, although a few stragglers, especially the Mackerel, are caught all the year round. The Kingfish never come inside.

Trolling with squids for Spanish Mackerel inside the Bay is fair at times, but without any periodicity or regularity which can be reduced to any stated dates within the season.

The best catches are often opposite Cutler, about fifteen miles south of Miami, and about half way across the Bay; and between Cocoanut Grove and Soldier Key, the former six and the latter twelve miles distant from Miami, running to and fro over the ground following the fish.

A few stragglers are picked up all through the winter and spring by parties going for, and coming from, a day's fishing to Bears Cut, Cape Florida, or Soldier Key ; so it is well to always put out a squid going and coming. I have taken them in the channel (called the canal) all the way out, commencing within half a mile of the Royal Palm.

During March, 1901, a large school remained just inside the outer bar at Bears Cut for two weeks or more, and large catches were made from it ; on one day a catch of 360 , and another of 325 , with several smaller, the number brought to the Royal Palm that day being between 900 and 1,000, all caught by sport fishermen. Many were taken the same day by parties from the other hotels and boarding houses in Miami and Cocoanut Grove. 'That school afforded fine sport while it lasted.

Usually, while ontside after Kingfish, by putting on a Mackerel squid you can take them. Sometimes when you strike it right, it will pay to let the Kingfish go and catch Mackerel; but you are apt to lose a lot of squids, as they and the line being smaller will not hold the Kingfish, who will often go for it. I am inclined to think the season of 1901 was the best the East Coast has ever had for Spanish Mackerel.

Outside trolling for Kingfish, Amber Jacks, Barracuda, Scabbard or Cutlass-fish, Permit, Sail-fish, Groupers, and the above stated chance for Spanish Mackerel, and sometimes Bluefish, with squids, red and white cloth, live or cut fish, red cedar squid, for bait, according to the fish you desire to catch. Localities from Fowey Rock 
Lighthouse, north, to the House of Refuge, about fifteen miles, which with launch can be covered in one day, and by sailboat with good wind. Very few will care to make the whole distance unless they are after numbers of some one variety, usually Kingfish. I am almost ashamed to say I was one of three who caught 135 Kingfish one day in the winter of 1897 , on the "Ada B.," Capt. Charles Brickle, and we covered the distance from near Fowey Rock Light to the House of Refuge; it was a pretty rough day, too. Mr. Alfred Costello of New York and Mr. B. J. Pacetti of Ponce Park were my accomplices in the business.

As stated heretofore, you can on sufficiently quiet days leave the launch or sailboat in a rowboat, and with rod and reel, with the bait desired, take the above fishes. This is the most scientific method, and to those who have fished a great deal, one fish caught this way affords more pleasure than a hundred caught on a hand line. Still we will all take the hand line once in a while. A very good way is to troll from launch or sailboat, and when a fish takes your bait, luff up if a sailboat, or stop the launch, play your fish until he is exhausted. Or, when the fish strikes, get out into the rowboat and "follow the fish" until you "bring him to gaff."

The "patches" are very numerous off Biscayne Bay, and any of the experienced boatmen can take you to them, where all of the reef fishes can be caught, such as Snappers, Groupers, Mutton-fish, Jewfish, etc. The Groupers up to fifty or sixty pounds, Jewfish and Sharks up to almost any weight you can think of, certainly up to 400 to 500 pounds, if you can hold them. Mr. Costello and Mr. Miller of Buffalo took one such day's work last winter and got all they wanted of it. They brought a part of their catch up to the hotel, which consisted of Groupers and Jewfish, of thirty to sixty pounds, and several heads, and larger parts of the same kinds of fishes, the Sharks having relieved them of the other parts while they were hauling in. They had hold of many fish which they could not "stop" at all, and had to cut their lines.

Sharks will nearly always follow a boat trolling, and will usually take the whole or a part of some of the fishes you hook. Of the 135 mentioned above, I presume eight or ten had lost all but their heads, and probably as many lost one-fourth to half their length, this in addition to many where the Sharks had "gone the whole hog." 
Ball Brothers of the schooner "Privateer" have invented a method of not catching Kingfish, which affords the same sport as catching them, and gives the Kingfishes themselves opportunity of joining in the amusement. The device is simply the regular Kingfish squid with the hook entirely broken off.

Of course, the fishes will jump at this just the same as they will if the hook were on, knocking the squid sky high, and while Ball Brothers and their "parties" laugh, the Kingfishes can join in the hilarity of the occasion.

There is fair trolling with rowboat, hand line, or rod and reel, phantom, spoon, cut strip of fish or Minnow bait, along the west shore, any distance north and south of the Royal Palm. Fishes are Spotted Trout mostly, with occasional Groupers, Cavalle, and some of the smaller fishes.

Up the Miami River affords about the same sport, with an occasional small Channel Bass, and the Mudfish or Mud-sucker is caught, mostly, by the colored people.

Above the rapids a few small Black Bass (large mouth) and Bream (fresh water) can be caught, but the trip of five miles is not worth the candle, as far as the fishing is concerned. The water has been overfished.

Groupers, Grunts, Porgies, etc., can be caught, with rod and reel, $1 \%, 2 \%, 3 \%, 4 \%$ hooks, small line, cut Mullet, or Crab bait, opposite the Royal Palm, and just east of the main steamboat channel (or canal), at any place where there is rock bottom, or patches, the whole length of the canal. As the distance is less than a mile from the hotel to the first grounds, it is handy for a rowboat fish of half a day.

Quite small Mangrove Snappers are caught in the mouth of the river, and toward night, from the dock; but they are hardly worthy of attention.

About three miles south of Cocoanut Grove, in Snapper Creek, Mangrove Snappers up to two pounds, and plenty of Grunts, are caught.

Black Creek, about sixteen miles south of Miami, is a very fine stream (or everglade slough) for Large-mouth Black Bass and Bream (fresh water). The stream where it comes into a small bay is very narrow and sinuous for about four miles, when it opens into some comparatively broad water. There is barely enough width and water to push a skiff through the creek to reach the fishing ground, but it is 
worth the trouble if you are fond of Black Bass and Bream fishing. During my one visit to the creek I used a small phantom, a small spoon, very small Bream, which I caught with a worm taken out of the decayed tops of the flag stems, cut Mullet, fishing with an Oconomowoc Henshall rod, $6 \mathrm{r} / 2$ feet long, silk line, Nos. 2 and 3 Harrison Sproat gut snood hooks, and all casting, no room for trolling. I also did well with flies and fly rod, medium size Parmachene Belle, Brown Hackle, Montreal, Ibis, and Miller. They took any and everything I offered them, as the Black Bass of all these everglade streams will do until they have been fished for considerably. I had with me, as additional guide, Eddie Pent of Cocoanut Grove. I did the same as above in the Miami River, just above the rapids, nine years ago.

Some Tarpon have been taken in Biscayne Bay north of Miami, but I have never caught any there. I have tried them at Norris Cut, just inside the channel, where I saw many, in fact was right in a school of them there several times, but never could catch one, and I know of no one who has been able to take one. Have made diligent inquiry without success. Neither have I been able to get any detailed information as to anyone's success in the northern part of the bay. The Tarpon are there in plenty, and I have seen them.

There are Bonefish, Barracuda, Trout, and Cavalle all along the west shore of the bay south to Arsenecker Keys, which are on the west side, about twenty-six miles from Miami, and south of these seven miles to Card Point. And there are the same fishes, with the addition of Channel Bass and Mullet, in the small bays of the west side. I have caught all these fishes on the shores, and in some of the small bays, with the tackle and bait mentioned for each.

In my opinion, the greatest attraction for the angler in this region, and in fact from here to Key West, lies in the waters of the passes, cuts, creeks, and channels between the ocean and the inside bays. So I will now commence to give in detail the waters I have fished in among the Keys from Norris Cut to Key West.

My statements of distances are calculated in nautical miles from the charts of the United States Geodetic Survey, and are direct from point to point; making no allowance for the necessary deviations in navigation, and I ignore fractions of miles. 


\section{NORRIS CUT.}

THREE MILES SOUTHEAST OF MIAMI.

The fishes here are Bonefish, Bluefish (rare), Barracuda, Cavalle, Groupers, Grunts, Sand Perch (Goatfish), Pompano (rare), Porgies, Sailor's Choice, Snappers, Tarpon.

\section{BEARS CUT.}

\section{FOUR MILES SOUTHEAST OF MIAMI.}

The fishes are Angelfish, Spadefish, Blackfish (Sea Bass), one specimen, Bonefish, caught in the sand bars or "banks" inside, on each side of the channel, Bream (salt water), Barracuda, Cavalle, Sea Trout, Sea Chub, Cowfish, Groupers, Grunts of all varieties, Sand Perch, Lizard-fish, Margate-fish, Mutton-fish, Pigfish, Spots, Parrot-fish in three varieties, Pompano, Porkfish, Porgies of all varieties, Runners, Sailor's Choice, Snappers, Schoolmaster, Turbot, or Trigger-fish, Yellow Tail and all the foul fishes.

See method of catching these fishes under their description.

Here you will begin to need the Conch and Crawfish baits, as they are both good all the way to Key West.

The Conch shells are picked up in shallow water, say two or three feet deep, and can usually be found at all passes, cuts, etc., either outside or inside. And you will also now need "grains," which is a two-pronged fish spear, made of A No. 1 cast steel. The best are made by a blacksmith at Cocoanut Grove, whose name I do not know. Those bought at the dealers are usually " no good." Some dealers may have good ones, but I have never been fortunate enough to buy one worth one cent. When you need grains you need 'em bad, especially when you are "forty miles from nowhere," down among the Keys. You can buy grain handles in Miami or Cocoanut Grove.

You will also need a "water glass," which is simply a common wood bucket with a glass bottom. The dealers can usually have one marle if they have none in stock. Try to get one made of white cedar, unpainted, and with brass hoops, as it will last much longer. Get one or two extra glasses, as they are apt to get broken. The grains are to grain the Crawfish, which lie on the bottom all the way 
from two or three feet to ten, so the grain handles should be twelve to fourteen feet long. The boatmen go out with the rowboat, and lean over the stern looking through the water glass, and spear the Crawfish on the bottom and under the mangroves along the shores. Usually it takes two men, one to handle the boat, while the other hunts for and grains the Crawfish.

The grains are also used by the "Conchs" to spear fishes, such as Snappers, Groupers, and other larger kinds. They call it "striking" instead of graining or spearing. Some of the guides and boatmen indulge in the same "sport."

The water from here down is quite clear, so that in places on quiet days the bottom and fishes, sea fans, sponges, corals, etc., can be seen twenty feet or more down. I believe that the "spongers" get sponges with hooks over twenty feet down, and they all use the water glass. 


\title{
CHAPTER XV.
}

\author{
CAPE FLORIDA.
}

\section{ABOUT EIGHT MILES FROM MIAMI.}

Here there are ten channels marked on the chart, within a distance of about four miles from north to south, the most northern one running alongside Key Biscayne. The main channel has been dredged out, and beaconed (I presume) by Mr. Flagler at his own expense, for use of his vessels, as well as those of Uncle Sam, and all comers, foreign and home alike.

"Uncle Henry" has done as much (or more) for the East Coast, in fact for the whole State, as "Uncle Sam" has done during the whole time he has been in possession.

In the Steamboat Channel, as the main one is called, there is rather the best fishing on the north side near the present largest beacon, say 200 feet west of it. Here you will get Groupers of two to ten pounds, occasional good-sized Snappers, Porgies, Grunts, etc., etc. From Bears Cut all the way south, quite frequently, in warm weather, a Barracuda will follow up a small fish while you are reeling him in. When this occurs, take off your small hook, put on an $8 \%$ or $10 \%$ and wire snood, a small Grunt or Porgie for bait. You will be almost sure to get hold of the Barracuda.

The north channel is the best one for Snappers, along the shore and mangroves, and where the water is deepest. The fishing is good in all these channels, from their commencement in the Bay to where they terminate on the Great Florida Reef. On the sand "banks" between the channels, the "shallow-water Barracuda fishing," described in my description of that fish, is good, and there are many miles of these banks between Cape Florida and Soldier Key, the next Key south. Here it will be advisable to use Crawfish bait, if obtainable, for the smaller fishes. For Groupers and Snappers, I have found cut Mullet or other cut fish more taking than any other bait.

This is the most southern point where I have found Mullet at all plenty, in fact they are hard to get here and at Bears Cut, at times, 
and are very scarce in all the channels and passes below; but can be gotten in many of the creeks and bays on the west shore of Biscayne Bay, Card Sound, Little Card Sound, and Barnes Sound to the south.

When I am on good Grouper and Snapper ground and cannot get Mullet for bait, if I have no small fish, I troll with small phantom, and can usually catch a small Grouper and cut him up for bait. The Groupers and Snappers are "cannibals," so will take their own species readily when cut. If my phantom fails me I have recourse to my canned clams or shrimp, for a starter. Sometimes the grains come in handy.

From here south you will need to use a method of chumming in vogue with all the market fishers of Key West, which is as follows, viz :

Cut out the meat of your Crawfish, which is mostly in the tail and part of the body, leaving the shell and antennæ (they have no claws). Tie two or three of these together with a string, then put on a sinker, and fasten it over the side of the boat with a line, so it will go within a foot or two of the bottom. This is very attractive to the fish, as more or less of the meat left on, and the antennæ, disintegrate slowly, and float away. This is much better than throwing overboard any kind of chum, as it will float away with the tide and you lose the desired use of it.

From Cape Florida south to Key West there is a natural law for the protection of fishes which beats any law the State of Florida can pass. This law is the fact that the rock formation is coral and underlies all the passes, creeks, channels, and the whole country. That rock is jagged, crooked, lumpy, and irregular beyond description. In many of the passes the bottom varies in depth from four or five feet to twenty feet in a distance of thirty or forty feet. There are holes and caverns of which you cannot see the bottom, while you can see it around them where the water is twenty feet deep. The outside shores show the same condition, and it is very troublesome to land a boat and get out of it in many places, and of course walking on such shores is difficult. I cannot compare it with anything, unless it would be with a gigantic empty honey comb, with depressions and elevations on its surface. As a consequence, seine fishing is an impossibility. A few drift and gill nets are used for Spanish Mackerel, but I think without profit. I have seen none during the past two years.

All of the "Conchs" among the Keys use only hand lines and 
grains. The market fishers of Key West catch all their fishes with hand lines, from small sailboats, usually sixteen to twenty feet long, with wells in them, and thus bring the fish in and sell them alive. They put them in sunken boxes alongside the fish market dock, usually separating the fishes according to species.

Their customers come and select the variety and size wanted. There are no "middle men," each fisherman sells out his stock direct to the consumer, who goes on his way rejoicing, and the fisherman starts out after more fish. Now, there is an ideal anti-trust situation for you.

\section{SOLDIER KEY.}

\section{TWELVE MILES FROM MIAMI.}

This Key belongs to the United States Government and was used as a residence for the men who built Fowey Rock Lighthouse, four and a half miles east, very near the outer edge of the Great Reef. When this lighthouse was completed, the old Cape Florida Light, on the extreme lower end of Key Biscayne, was abandoned. Soldier Key is approached from the inside by two principal channels, in which there is fair fishing for all the fishes of the bay; but I have never done very well in them except for the smaller varieties, such as Grunts, Porgies, Small Groupers, and Snappers. I have seen many Barracuda near the Key, but never caught one there. At times there is fine Bonefishing around Little Soldier Key, a small "bump" or rock a short distance to the south, and some are taken all around the Key itself. In my general resume of Biscayne Bay I have described the fishing on the reef east of this Key, and around Fowey Rock Light.

I will here say that I have now reached the limit of one day's fishing which can usually be done from Miami, either with sailboat or launch.

Parties desiring to fish from here south to within a few miles of Key West will have to "cruise," that is, will have to use their own craft, or charter one large enough to live aboard. Such boats can be chartered in Miami, of all suitable sizes, from twenty-five feet to sixty-five feet, providing accommodations for from one person and the skipper up to a party of five or six, with a crew of three or four. One, two, or three small boats are necessary in all cases. The 
owners usually provide a cast net, grains, and water glasses, but no tackle. A bargain can be made by the day, including board; but the usual, and better, method is to pay for the boat and crew a price per day, and provide your own provisions, buying what you need or desire. There are no hotels or boarding houses on any of the Keys between Miami and Key West.

The reader may take it for granted that he may from here south catch one or more of all the fishes I have mentioned in my book so far, and possibly some that I have not mentioned, as there are probably 400 , or more, mentioned in these waters by Jordan \& Kendall. Their entire "Check List of Florida Fishes" includes 576 species, so I guess I am within bounds.

As I have mentioned all that I consider is of importance to the angler, have described them, and given their appropriate tackle and bait, I will at each point mention only those that I think are remarkable, especially plenty, or deserving of mention from some other standpoint.

\section{RAGGED KEYS.}

The most northern of these Keys is about fifteen miles from Miami.

They are five in number, and each one has a channel on each side of it. They are numbered 1 to 5 , commencing with the north one. I especially recommend the fishing in the channels between Nos. 2 and 3 , and 3 and 4 , for all sorts of fishes. The bay entrances to the channels are, in my opinion, the best, althongh just in line with the Key north of No. 3 is A No. 1 . Here I caught my first "Sea" or "Bermuda Chub," which is a very gamy fish. I have also caught a great variety of Groupers here, among them those that were named, by my crew and myself, "Polka Dot" and "Dolly Varden". Crawfish are readily obtainable here, more so than at any point to the north. No Mullet as far as I know. Conchs plenty. Small Barracuda, one to two feet long, are plenty around the shores inside, and large ones in the channels; and outside on the reef, in three to six feet of water, there are many large ones, but they have always been shy when I have been there. I saw plenty, but caught none. These Keys are the property of Ball Brothers of the schooner "Privateer." 


\section{SANDS CUT.}

\section{EIGHTEEN MILES FROM MIAMI.}

This cut is between Sands Key on the north and Elliots Key on the south. It is also called the "Aquarium," I presume because there are so many fishes in it, and especially so many handsome ones. In quiet weather the water is very clear and you can see the rock bottom down twenty feet in many places. I have seen here very many Angel-fish, Spadefish, Snappers, Groupers, Grunts, etc., etc. It is an especially good place for large Mangrove Snappers and Groupers.

The best spots for large Snappers are in the middle of the main channel about two-thirds through from the inside, and under some mangroves on the north side just at the entrance from the ocean. While fishing for the Snappers you will get large Groupers.

The Grunts, Porgies, etc., run all over the bottom of the cut, but rather the best place is nearly in line with the Keys on the inner side. The cut is a narrow and short one, and zery rocky and uneven, with deep wells, holes, or caverns in the bottom. You will lose lots of sinkers and hooks here, which is unavoidable, as you must fish on the bottom, and take the chance of your hook, sinker, or line catching. I presume I have left ten to fifteen pounds of lead in this cut.

On quiet, warm days you can get Angel-fish by fishing near the bottom, not on it, with No. 3 hook, No. 6 line, strong double gut (not twisted) snood, small long sinker, float, and Crawfish bait. They are wary and will not bite freely, but will come up out of the wells, or holes, sailing around your bait apparently undecided whether to take it or not. Once in a while you will get one, but not many. They are probably the most beautiful fish in the world, are very gamy, and a fine table fish. In my experience they are generally an accidental fish, that is, are caught while fishing for other small fish with rather small hook.

During the winter or spring of 1899, Mr. Edward P. Borden, who was with me on a cruise, while fishing for Snappers and Groupers, hooked a Porgy or Grunt. While reeling him in a Barracuda made for the Porgy or Grunt, but did not get him. Mr. Borden made a lightning change of tackle, baited with a Grunt, cast it out, and in a minute or two hooked the Barracuda, and in a short time landed him. He weighed twenty-five pounds.

I very seldom give the "go by" to Sands Cut, but on every cruise endeavor to take it in, going or coming. 


\section{CHAPTER XVI.}

\section{CASAR'S CREEK.}

\section{TIVENTY-FOUR MILES FROM MIAMI.}

This is the pass between Elliots Key, north, and old Rhodes Key, south, and is one of the most noted and important sport fishing places on the coast. All the fishes of the Keys are at times taken here. It is especially frequented by sportsmen after Tarpon, which are very often running in the outside channel.

Hogfish are more plentiful here than in any locality I have visited, and are caught in the outside channel just inside the line of the Keys, in about fifteen feet of water, $5 \%$ or $6 \%$ hook, 15,18 , or 21 line, rod and reel, still fishing on the bottom. A little farther out in the channel, in eight to twelve feet of water a great variety are caught. Sharks plentiful, Rays not bad. Mangrove Snappers and Groupers in the channel at each place designated, and along the shores where there is deep water under the mangroves; but the good fishing does not extend far into the cut to the west, and the western end and the approaches to it are not good.

The outer channel here is peculiar, in that it has the appearance of a canal for two miles out from the line of Keys, with shallow banks on each side, north and south. On the south side, near the shore, there is a cut or deeper place through the bank carrying two and a half feet of water. Boats drawing only that water can go over and save the long run out to the end of the channel or canal.

\section{BROAD CREEK.}

\section{TWENTY-SIX MILES FROM MIAMI.}

This creek is the pass between Old Rhodes Key, north, and Palo Alto Key, south. There is no channel through from the bay to outside. One starts from the bay and runs about half way between the Keys to half the distance through, when the water decreases to half a foot, then, in a short distance, it again deepens and runs out to the 
reef. In addition to this there is a slough, or old channel, commencing outside with two feet and running alongside Old Rhodes Key, carrying seven feet of water and then down to less than a foot. I have been in the channels and have done well for Snappers, Groupers, Grunts, Porgies, etc. At high tide there is a fair flow of water through and at all times enough to keep the fish there. There are thousands of Crawfish in the creek and along near the shores. The best way to approach this creek is to go by rowboat from anchorage at the outside of Angelfish Creek, the next pass below.

\section{ANGELFISH CREEK.}

\section{TIENTY-EIGHT MILES FROM MIAMI.}

This is the pass between Palo Alto Key, north, and Key Largo, south, the latter the largest of all the Keys, it being twenty-five miles long.

This is celebrated fishing ground, especially for Angelfish, after which it is named.

In addition to the main channel through from the west to the east, there are two smaller creeks to the south running west and coming out into the main channel, one of them is Little Angelfish Creek, which runs between Angelfish Key and an unnamed Key to the south of it, and the other is Pumpkin Creek, running between the unnamed Key and Key Largo. There are also two creeks to the north, which branch out from the main channel and run out into Card Sound, as the inside water, or bay, is here called. One of these two creeks has a branch which runs out north into Broad Creek. All these waters carry good depth, and there is good fishing in all of them.

The main channel has many holes, caverns and wells, like those at Sands Cut, and all sorts of fish are plenty. Anchor in five to ten feet water on the outside, a little beyond the line of Keys, in the channel, for Snappers, Groupers, Porgies, etc., etc. For large Mangrove Snappers follow the south shore close to the mangroves. One of the best spots is about half a mile inside the line of Keys, where you will see a ledge of coral some six or eight feet down, suddenly dropping to fifteen or twenty feet. Around the edges of that ledge there are Snappers up to ten pounds, certainly. The very largest do not seem inclined to bite, but you will get them up to seven and 
eight pounds. All through the channel nearly to the western end they are always in evidence.

Pumpkin Creek is deep, six to fifteen feet, and at times Snappers and Groupers are very plenty. The other creeks are all good for all the variety of Key fishes. The western approach is not good. The Mangrove Snapper is usually in clear water a very shy and wary fish, so sometimes when you can see literally hundreds of them you can catch but few. I think cut fish bait for them here is better than any other.

Angle for Angel-fish the same as at Sands Cut. There are more of them here, in my opinion, than anywhere on the coast. You are quite sure to catch some while fishing for other fish. There is little inducement to troll in these channels and passes among the Keys, as the tides are strong, making the rowing hard, and you can catch fish in more scientific ways. Of all the places on the entire East Coast, Capt. John and I are agreed that we like Angelfish Creek somewhat the best.

The usual route for sport fishing from here to Indian Key is through the inside waters, as they afford far better sport than the outside. This arises from the fact that outside we have for twenty-five miles the blank shores of Key Largo, with two or three inside sounds, which are supplied with salt water only from the outside, no connection through to Card Sound, etc.

I will now take you by the inside route to Indian Key.

\section{STEAMBOAT CREEKS.}

\section{SIX MILES FROM ANGELFISH CREEK, AND THIRTY-TWO MILES FROM MIAMI.}

There are three of these creeks less than a mile apart at their Bay entrances. They enter Key Largo from Card Sound, describe part of a circle within the Key, and come out into Little Card Sound to the south, varying in length from one to two miles.

The fishing in these creeks is not much affected by the tides, and only the most northerly one is navigable for sailboats, launches, etc. I have had very good success in them, especially for Mangrove Snappers and Groupers, the best ground for them being in the first, or north, creek, all the way through it - being somewhat the best commencing about half a mile from the entrance and continuing about a 
mile. The north, or left, side rather the best; but it is well to try both sides, which are alike in having a heavy growth of mangroves to the water's edge and into it.

The other fishes are Cavalle, Groupers, Grunts, Jewfish, large if you want them, Sailor's Choice, Rabirubia, Turbot, Sea Trout, Parrot-fish, Porgies, Spot, and, near the entrances on the "banks," Bonefish. Some Mullet on shallows around an island inside near the entrance. Fiddlers can be found around the larger mangroves, where there are little sandy places three or four feet from the shore.

At the entrance to the second, or middle, creek there is usually a large lot of Snappers in quite deep water, near the north shore. The water is more clear there than in any other place, so the Snappers take the alarm as soon as two or three are taken.

The third, or south, creek is about the same as the second. Two or three days can be spent here very pleasantly unless the mosquitoes appear, which is apt to be the case if the weather is warm.

\section{BONEFISH BANKS.}

\section{TIIRTY.TWO MILES FROM MIAMI.}

These "banks" extend from near the mouths of Steamboat Creeks across the southern end of Card Sound (the next body of water south of Biscayne Bay) to the west shore, about two and threequarter miles, and extend north and south about three-fourths of a mile.

They are the dividing line between Card Sound, north, and Little Card Sound, south, and during the last four years have acquired the name of "The Bonefish Banks," well known to the devotees of Bone fishing.

There is a cut, or channel, through the banks about half way between the shores, which carries three to six feet of water, through which all the craft traveling north or south are obliged to pass. The banks themselves carry from nothing to two or three feet, a considerable part of them being out of water at low tide.

I presume more Bonefish have been caught here than in any one place in Florida. In the cut there are Cavalle, Runners, Mangrove Snappers (small and medium size), Groupers, Grunts, Porgies, etc. I have seen Tarpon here, many of them, but never caught one.

Near the bank, on the west side of the sound, there are, north 
and south, several inside shallow bays, with everglade creeks running into them. I have had my boat held at the mouths of the creeks, north, while the tide was rumning in and have done very well with Bonefish ; and in the small bay, even with, and a little south of, the bank, I have caught, and seen caught, Bonefish, Channel Bass, and Spotted Trout. Mullet are quite plenty in the creeks coming into these bays, but it is a bad place to throw a cast net, because of deep mud. These bays extend on the north to Arsenecker Keys, and south quite a distance; I have not been far south in them. Between the first bay, south, and Little Card Sound there is a little pass, or hole, which is only ten feet or so deep, and about as wide, all covered over by the branches of the mangroves, in which I caught a dozen or so Snappers before they found me out. They soon quit and I could get no more bites. Fiddlers are tolerably plenty on the sandy shores of these bays and creeks, and a few on the main west shore. Bonefish take them tolerably well.

\section{JEIVFISH CREEK.}

\section{EIGHT MILES FRON BONEFISH BANKS AND THIRTY-EIGHT MILES FROM MIAMI.}

This creek is at the southeast corner of Barnes Sound (the next body of water south of Little Card Sound), and is the only channel between Barnes Sound and Black Water Bay (the next bay to the south). The creek is nearly one and a half miles long, with two branches leaving it part way through, all emptying near each other into Black Water Bay. Mangrove bushes and trees all the way through.

The fishing in this creek and branches is A No. 1, for large Snappers and Groupers. The water is not clear and so they are not very shy. Fish all the way through on both sides, up near the roots and branches of the mangroves. There are Sailor's Choice, small Groupers, and other small and medium fishes, just at the entrance of the deep water on the west side.

The tides do not affect the fishing here. Jewfish are here, if you desire them.

\section{BOGGY.}

Black Water Bay is nearly round and will average four and onefourth miles across. Boggy is nearly west from Jewfish Creek and 
about the same distance from the south end of the creek. It is a cut, or channel, from Black Water Bay into Florida Bay, sometimes called the Great Bay of Florida, which extends to Cape Sable on the west and to Key West on the southwest. It is a shallow bay, and the water is usually roily and whitish from the disintegration of the coral rock. More and more mangrove islands, or Keys, are constantly forming in it.

Boggy carries tolerably clear water from Black Water Bay, and the Snapper and Grouper fishing is usually very good.

The best places are on the south shore in the cut about half way through, and along the north shore all the way through, and for half a mile or more inside under the mangroves, out into Black Water Bay.

In December, 1900, I had very successful fishing there. Capt. Gardner caught an eight-pound Sheepshead while fishing for Snappers along the south side, which was a surprise to us.

Now we will have quite a sail through milky water, until we near

TAVENIER CREEK.

TWELVE MILES (DIRECT) FROM BOGGY AND FIFTY-THREE FROM MIAMI (DIRECT).

This creek is the pass from Great Florida Bay into the ocean, and runs between Key Largo, north, and Long Island, south. The entrance to it from the inside is shallow, and outside the same; only very small sailboats can pass through. But there is deep water in the creek, and very fair fishing for all the Key fishes. For Snappers and Groupers there is an especially good place about one-third through on the south side, where there is quite a bend to the south. Under the mangroves there I have caught, and seen caught, a great many three to eight-pound Snappers and Groupers.

About two-thirds through, in the middle of the channel, there is good Grunt, Porgie, etc., with occasional good Snappers. The approaches at each end are not good.

Before leaving Tavenier Creek I must tell what I will call my "Alibi Story."

On Christmas morning, 1890, I arrived on my boat in an inside bay, three miles or so north of Tavenier Creek, and about two and 
a half miles across the Key from Planter, which fronts on the ocean, and is the only post-office between Miami and Key West. I always have mail at Planter, so, whether going inside or outside, always call for it.

We anchored a few hundred feet from the shore, where there is a dwelling house, tomato patch, pineapple patch, etc. During our calls in previous years a Swede family were in charge of the place, which belonged to a gentleman residing in Miami; but this time we found two colored men in charge, who were working the place. We landed and asked the darkies if we could get a barrel or two of water, and were told we could.

In talking with them, we found they were from Daytona and had worked for people whom Capt. John knew. I told my crew we would all take a day off, so the "captain, and the cook, and the sailor, too," and myself, all walked across Key Largo to Planter, over the worst trail you ever saw, through tomato, pineapple, and cucumber patches, and through clumps of small timber, over coral rock, through swamp, etc.

In the brush and timber it was like "Nesmuck's" trail, which finally ran up a tree into a squirrel hole.

We reached Planter, however, about 10.30 or so, and found the place entirely deserted. Three or four families reside in the place, comprising probably twenty men, women and children.

We four lounged around, sitting on the wharf, the house porches, etc., an hour or so, and then walked back to the bay. When we arrived the darkies were at work, and I said to them that we would have to stay there until the next day, because all the people at Planter were off to a Christmas frolic, or to church, and we could not get our mail. I said, "There was not a living soul in the place."

The crew got a barrel of water and took it out to the boat, and, except the cook, remained on shore some time.

Finally, I had my dinner about half-past one, and the crew had their's about two o'clock, after which the captain went ashore, and with one of the darkies went hunting for squirrels.

The next morning the captain, the sailor, and myself walked over to Planter after our mail.

Mr. Johnson, the storekeeper and postmaster, was not there, the office being in charge of his son, or nephew, a boy of about eighteen. We had been there several times before and were well known. The 
young man asked me if we were there the day before, and being told we were, he said that a friend had gone by in a sailboat and had told him there were four men on the wharf about eleven o'clock. I asked him why he mentioned that fact, and he said the post-office had been robbed while they were all away Christmas morning to church, the loss being $\$ 107$. I turned to Capt. John and said, "John, we are in a scrape"; and he replied, "No, the amount is not large enough."

The boy at once said, "We don't think you did it, not for a moment; you don't think we would have the least idea you did it, do you?" I replied, "No, I don't think you would; but if we did not do it, who did?" I then questioned him as to all the people living within ten miles, and they were all accounted for, in fact, were all at the church, and no boats had passed, as they were only two miles to the south and could see boats if there had been any. He then said, "Nobody but those two niggers over on the bay front could have done it "; and we all replied that it was impossible, as we had seen them all day; and I said I would swear I had seen them all day, and that they could prove an alibi by all four on my boat.

I told the boy all about it, and when I spoke of having said to the darkies, "There was not a living soul on the place," he replied, "They did it, and that remark led them to do it." We all protested that it could not be, and said, "The darkies can prove an alibi, and we cannot." We felt a little cheap over the matter, and I thought of the elder Weller's advice to his son Sam, when he said, "I have got some friends as'll do either for him, but my advice 'ud be this here - never mind the character, and stick to the alleybi. Nothing like a alleybi, Sammy, nothing." But we had no "alleybi" to stick to. That burglary lay between those two darkies and ourselves, and the darkies could prove an "alleybi" by us.

Well, we were not arrested; in fact, there was no officer there to do that work, and we went on our way, rejoicing, down to Key West, where we remained a few days. From there we worked north outside, and about two weeks after the burglary landed at Planter for our mail.

We found the same young man in charge, and asked him if they had found out who committed that robbery. He said, "Yes, it was those two niggers."

We said at once, "Impossible, they could not have done it"; and 
he replied, "Not much impossible, as they have confessed, given up the money, and are in jail in Miami waiting their trial."

If I am ever called upon to prove an "alleybi" for a friend I shall be very careful what I swear to.

\section{WINDY ISLAND CHANNEL.}

ABOUT FIVE MILES SOUTH OF TAVENIER CREEK.

This channel is between Windy Island and Upper Mattacombe Key. In it are all of the Key fishes.

\section{UPPER MATTACOMBE CHANNEL.}

\section{ABOUT SEVEN MILES FROM TAVENIER.}

These channels are between Windy Key, north, and Upper Mattacombe Key, south. One channel runs clear through and carries good water, and against Windy Key there is an old channel closed in the middle, but having fair water at each end. All of the fishes of the Keys are caught here. Crawfish are plentiful all along here, but no Mullet, or only occasionally a small school. 


\section{CHAPTER XVII.}

\section{INDIAN KEY. \\ THIRTY-SIX NAUTICAL MILES FROM MIAMI BY THE USUAI OUTSIDE ROUTE.}

Upper Mattacombe Key is to the north of it and Lower Mattacombe to the south.

This is a small key of thirteen acres and stands out in the ocean about one and one-fourth miles from the line of the Keys. It is historic as the place where Doctor Perrine was killed by the Indians during the Seminole War. While Alligator Lighthouse was being built, about four miles out on the edge of the reef, it was used as a base of supplies, and as a residence for the workmen. As there has been a large cistern under the house, built by the Government, which usually had a supply of rainwater, it has been a place of call for most light-draft yachts and fishing boats traveling up and down the coast. It is quite an attractive stopping point. I have called there many times, remaining from one to four days each visit. It is uninhabited at present (May, 1901).

As a fishing resort it has no superior on the coast, especially as to a great variety of highly-colored species.

There are two channels between it and Upper Mattacombe, and two between it and Lower Mattacombe, all four leading up into Florida Bay, and there is good water south of it. Mangrove Snappers, Groupers, Runners of several varieties, Yellow Tails, Angel-fish, Spadefish, Porgies in variety, Porkfish, Hogfish, Parrot-fish of several varieties, Grunts, etc., etc., are all caught here, as well as Bonefish, Barracuda, Spanish Mackerel and Kingfish, the latter two outside. Yellow Tails here begin to be more plentiful.

There is very little choice in the channels, but possibly the first one to the north and the Lower Mattacombe may be the best two. During a cruise, in the winter of 1900 , Professor Walker and myself each caught thirteen varieties of fishes in a forenoon's fishing.

To the east and south of the Key, Mangrove Snappers, Groupers, as well as smaller fishes, are quite plentiful within a few hundred feet 
of the shore, in eight to ten feet of water. There is fine trolling around Alligator Lighthouse for Barracuda, with hand line or rod and reel, with a chance, also, of taking Amber Jacks, Kingfish and Groupers. Run around the lighthouse, from 100 to 500 feet distant from it, and to the east, to the edge of the reef.

Mangrove Snappers, of from three to ten pounds, are very plentiful immediately around the lighthouse, as they gather there to eat the refuse thrown down by the keepers. Anchor your rowboat within ten or fifteen feet of the iron columns, use only 18, 21 line, $6 \%$ hooks, with cut fish or Crawfish bait.

After you have fished awhile the Sharks will come in for their share, and will take your fish entirely or partly off. Professor Walker and myself were there in April, 1900, having fine success, until the Sharks one after another put in their appearance, increasing in number to fifteen or twenty, and in weight from 100 to 200 pounds. We kept at it until we concluded we were in danger, as some of the Sharks in following up our fish ran within an oar's length of our boats, and some ran under them. Discretion was the better part of valor, so we quit. Nearly all fish caught are returned to the water, as there is no use for them, except a few for the boat's table.

When I was there last the keeper in charge of the lighthouse invited me to fish from the lower platform, some ten or twelve feet above the water; but I politely declined, as I preferred the boat. I presume he will accord the privilege to any applicant.

During our cruise on the "Manatee," Mr. Borden and myself had good success around the lighthouse with Barracuda, trolling, block tin squid, from rowboat.

There are many Bonefish banks within two or three miles of the Key, up in the Bay of Florida, among them, on each side of the main channel to the north, between Upper Mattacombe Key and Shell Key, in two channels between Shell Key and Lignum Vitæ Key to the west, and in the channel between Lignum Vitæ and Lower Mattacombe. Sand Crabs or "Sprites" for bait can be found around the shores of the Keys.

In the above I tell of Professor Walker and myself each catching thirteen species of fishes, and in my account of Biscayne Bay tell of taking into the Royal Palm thirteen different species. The number thirteen seems to be an especial angling favorite of mine. I have had two other instances of its occurrence. 
While en route from St. Louis to Florida, during the winter of 1890, I met in the smoking room of the Pullman a gentleman from Chicago who had a bundle of fishing rods with him; I also had a bundle. We got to talking about fish, and as we each had rods along we each knew the other was all right, and were warm friends in fifteen minutes. I told him what my plans were and that I was alone, and the conversation ended in an agreement to make the cruise together, which I had intended to make alone. The cruise was on the "Lillie Shippy," Capt. Dick McCarty, with John Gardner, assistant. The gentleman was Mr. John B. Zimmerman.

I stated to him that I had seen somewhere, I believe in Henshall, that ten different fishes had been caught at one anchorage of a small boat in Indian River Inlet, all with cut Mullet bait. We resolved to test its truth, and caught thirteen species.

A year or two after the above occurrence an acquaintance of mine came to Indian River Inlet with only fly tackle, and caught thirteen Trout and Ladyfish with it; nearly all the former.

The Trout is almost the only salt-water fish in Florida which will take a fly; and he rarely does so.

Some are caught off the bridge at Daytona; usually only in the fall, when they are plenty and hungry. I have caught a few small Mangrove Snappers under the mangroves, one-fourth to one-half pound, never a large one, and I have faithfully tried.

When at Indian Key, three years ago, a family, consisting of a man and wife, two or three half-grown boys and some younger children, occupied the house, and had charge of the Key for the owner, who resided in Key West. The old gentleman was originally from the "Bamas," as the "Chonchs" all pronounce Bahamas. He had resided on several Keys, lived in Key West, "sponged," fished, and last, but not least, had "wracked" (as they call wrecking) a great deal. He had a great fund of wrecking stories to tell, and would say that such and such a ship made a "fine wrack," paid $\$ 25,000$, $\$ 40,000$, etc., etc., to the wreckers.

He had two or three claims in the United States Court at Key West, as I think is constantly the case with about half the "Chonchs," and many of the residents of Key West.

Wrecking is one of the important, and lucrative, industries of the Key people.

One morning after breakfast, in looking toward the house from 
the boat, I saw something projecting from the sea gable window which I could not quite understand, so asked Capt. John to get the glasses and let me know what it was. He looked a moment or so, and said, "That is a two-foot boy looking for "wracks" with a three-foot telescope." And so it was, as we afterwards found. Some one of the family was always at that window with the telescope. Some of those unsophisticated "Chonchs" actually think that once in a while a vessel gets onto the reef "on purpose," for the sake of the insurance, but we business men know that cannot be the case. I heard the next year that our friend of Indian Key had gotten into a share in a "good wrack," and had retired from business temporarily. I hope the story is true, as he entertained us nicely, giving us much information, and was very kind in every way.

\section{LOWER MATTACOMBE CHANNELS.}

The southwest end of Lower Mattacombe Key is five miles southwest of Indian Key. There are four channels between it and the northern end of Long Key, four miles distant.

These channels leading into the Bay of Florida, as all south of Tavenier Creek to Key West do, carry from four to fifteen feet of water, and all the fishes of the Keys are caught in them.

\section{LONG KEY.}

This Key is four miles long, and is well known, as the southern end is the usual starting point for small and medium-size craft bound for Cape Sable across the Bay of Florida, on the West Coast.

All of the fishes of the Keys are caught in the six channels between it and Duck Key, the next one south on the Key line, and five miles distant.

Spanish Mackerel are frequently very plenty here during the season, outside, and well to the inside at times. The two small Conch Keys lie about one mile inside the Key line, between channels, about two-thirds distance between Long and Duck Keys.

Between Duck Keys and Bahia Honda Key harbor and channels there are on the outside Key line sixteen Keys, not counting some very small unnamed ones (on the charts). They are Harbor, Toms, 
Grassy, Crawl (3), Vaca (3), Boot, Knight, Pigeon, Molasses, Duck, Bahia Honda.

As all of the fishes of the Keys are caught in the channels between these Keys, and as the story of one is the story of all, I will have to group them together, and turn the twenty channels within the distance over to the reader to make his own choice.

\section{BAHIA HONDA HARBOR.}

THIRTY-TWO MILES NORTHEAST OF KEI WEST.

This is one of the most important fishing points on the East Coast. The Harbor, so-called, is about four miles long east and west, and about a mile wide north and sonth. I mean by this the part carrying good depth of water. From this Harbor three principal channels lead into the Bay of Florida to the west; the largest and deepest one being Big Spanish Key Channel, between Little Pine, Grassy, and Little Spanish Keys on the north and No Name, Porpoise, Mayos and Annette Keys on the south.

The northern channel is between Little Pine on the south and Johnson and Shellfish Keys on the north.

The southern channel is between No Name, Porpoise, and Mayo Keys on the north and Big Pine Key on the south.

There are lesser channels and banks to the north of the above mentioned northern one. All of the last mentioned Keys are inside of the outer line of Keys and lie at nearly right angle with the outer line.

About one and one-quarter miles to the southwest of, and in line with, Bahia Honda Key lie the two West Summerland Keys, with a channel to the west between Big Pine and Torch Keys.

In all of these channels there are all sorts of Key fishes. Tarpon are especially abundant here at times, and Barracuda, Permits, Groupers, Snappers of all varieties, Mutton-fish, Pork-fish, Yellow Tail, Grunts, Porgies, Angel-fish of four varieties, Spanish Mackerel and Kingfish in their season; Shell-fish, Jewfish, Hog-fish, Mullet, Jack, Crevalle, and Rumners. I have seen many Spanish Mackerel running half a mile inside, and the school extending out onto the reef. On the sides of the deepest water in the channel, on hard bottom and 
five to eight feet of water, Yellow Tails, Porgies, and Grunts, in all their varieties, are plenty.

One drawback here is the large number of small Sharks, from three to four feet long, who will take your fishes off while you are reeling them in.

\section{FROM BAHIA HONDA TO KEY WEST (OUTSIDE).}

As all of these channels are similar in their variety of fishes, to save repetition I will have to group them, mentioning especially only Boca Chica channels.

The outside line of Keys, with their channels of same names, are as follows, viz: New Found Harbor Keys (4), with a good channel to the west between Ramrod, north, and Summerland and Knock Down Keys, south; then Pyes Harbor Key, with a first-class channel west between Summerland and Knock Down, north, and Cudjoes Key, south. Then, in regular line, Sugar Loaf Key, with two channels, Deer Island, Saddle Bunch Keys Harbor and channels, which last afford especial fine sport; Saddle Hill Island, Bird Key, Pelican Key and channels, Geigers Key, with Big Coppit, Rockland and East Rockland Keys west of it.

The next is Boca Chica Key, with three channels. This is quite a noted fishing ground. Here there is almost every fish of the Keys. Mango Snappers along all the mangroves where there is deep water. There was formerly a rock quarry here, to supply rock in the northwest channel and for use in Key West. Near the old dock, and in a slough coming in near it, there are fine Snappers. I have caught some off the little bridge over the slough, long casting. A very pleasant place to spend a few days.

Next comes Cow Key Channel, and then Key West Channel to Key West. 


\title{
CHAPTER XVIII.
}

\author{
KEY WEST.
}

ABOUT ONE HUNDRED AND FORTY-THREE NAUTICAL MILES FROM MIAMI, USUAL STEAMBOAT COURSE.

This is a very interesting old city, but I have very little to add, from the angler's standpoint, to what I have already written. Here during a short stay you can usually see every one of the Key fishes brought in alive to the fishermen's wharf, and it is of course quite a rendezvous for yachtsmen and sport fishermen. All sorts of boats can be chartered for long or short cruises, on about the same terms as at Miami. As is well known, it is the market for the spongers of the East Coast, of whom there are hundreds; and it is the market and supply point for the residents of the near-by Keys.

The range of the market fishers to the north is, as a general statement, to Bahia Honda. Their cruises are from twelve to forty-eight hours, as they cannot keep their fish longer, and their boats are open and small, with little, or no, cabins.

I made a trip to within a short distance of East Crawfish Key northwest of Key West, where I caught a great variety of fishes, including Snappers (Lane and Mangrove), Groupers, Porgies, Grunts, and the salt-water Bream I have heretofore mentioned, and which I have not been able to identify with anything in Bulletin 47 or anything I had caught before. He is a fine game and edible fish. I would rank him A. Weight averages about three-fourths pound.

Mr. Henry J. Pierce, a veteran pilot, guide, and boatman of Key West, piloted me to the above grounds, and I am indebted to him for the description of the following inside route from Key West to Bahia Honda, which I have never taken; as also for other information given me regarding fishes, baits, etc., in the Key West waters.

He recommends as bait for Tarpon: Mullets, Finny Crabs, Pilchards alive, and Bollioes. For Bluefish, Snappers, Mutton-fish, and Groupers: Mullet and Crawfish. Crabs for Permits ; and Crawfish and Conchs for all the other fishes; and told me Mullet could be 
had all around Key West. I have never used them there. Narrow Shad (I presume Menhaden) are good bait for most any kind of fishes. His opinions are the same as my own.

Yellow Jacks, Bluefish, Pompano, and Amber Jacks are caught on all the outside reefs, same as farther north. 


\section{CHAPTER XIX.}

INSIDE ROUTE FROM KEY IVEST TO BAHIA HONDA.

N. W. in Calda Channel to Flemmings Key ; then N. E. between Channel and Desolation Keys, sailing nearest the former; then between Dog and Hawk, nearest the latter; then midway between Snake and Eagle Nest; then between Crane and Wall, nearest the latter; then west of Whiting; then midway between Saddle Bunch and Snipe; then on N. E. to the west of Sugar Loaf and Cudjoes ; then between Michaels and Budd ; then south of Raccoon; then between Water and Torch; then N. W. of Howes; then S. E. into the channels between Annette and Howes, and Big Pine, south, and Mayos and Porpoise, north; then down on the north side of No Name Key into Bahia Honda Harbor.

No boat drawing over two to two and a half feet of water should attempt the above route. Fishes on the route: Tarpon, Gray Snapper, Lane Snapper, Groupers, Pompano, Bluefish, Lady-fish, Grunts, Porgies, etc., of course in the channels and rock bottoms. 


\section{CHAPTER XX.}

\section{EAST COAST HOTEL AND BOARDING HOUSE LIST.}

\begin{tabular}{|c|c|c|c|}
\hline $\begin{array}{l}\text { LOCATION AND NAME } \\
\text { OF HOTEL. }\end{array}$ & $\begin{array}{c}\text { NAME OF PROPRIETOR } \\
\text { OR MANAGER. }\end{array}$ & $\begin{array}{c}\text { RATE } \\
\text { PER DAY. }\end{array}$ & $\begin{array}{c}\text { RATE } \\
\text { PER WEEK. }\end{array}$ \\
\hline $\begin{array}{l}\text { ATLANTIC BEACH. } \\
\text { Continental Hotel...... }\end{array}$ & Florida East Coast Hotel Co. & & \\
\hline $\begin{array}{l}\text { BOYNTON, FLA. } \\
\text { Hotel Boynton.... }\end{array}$ & N. S. Boynton...... & $\$ 2.00$ & $\$ 12.00$ \\
\hline $\begin{array}{l}\text { City Point, Fla. } \\
\text { Hatter House...... }\end{array}$ & Mrs. J. D. Hatter.... & 1.50 & 8.00 \\
\hline COCOA, FLA. & & & \\
\hline $\begin{array}{l}\text { Jarvis House............ } \\
\text { Thomas House......... }\end{array}$ & Mrs. Jarvi & 2.00 & 10.00 \\
\hline $\begin{array}{l}\text { Thomas House........... } \\
\text { Indianola (Cocoa Sta'u) }\end{array}$ & Mrs. Thon & 1.00 & 6.00 \\
\hline Indianola House......... & G. W. Schuyler. & & 8.00 \\
\hline DAYTONA, FLA. & & & \\
\hline The Colonnades.. & C. C. Post.... & 3.50 & 17.50 \\
\hline The Ridgewood.... & Rose \& Langworthy.. & 3.00 & 20.00 \\
\hline Schmidt's Villa...... & Henry Schmidt.......... & 2.00 & Special. \\
\hline Holly Inn............ & $\ldots \ldots \ldots \ldots \ldots \ldots \ldots \ldots \ldots \ldots$ & 2.50 & Special. \\
\hline Palmett & $\cdots$ & 2.00 & Special. \\
\hline Voluntet & $\cdots$ & 1.50 & 10.00 \\
\hline Halifax House & T. L. Roge & 1.00 & Special. \\
\hline Daytona House....... & $\begin{array}{l}\text { T. L. Rogers................. } \\
\text { Mrs. IV. Van Dorn..... }\end{array}$ & 2.00 & 10.00 \\
\hline Van Dorn Cottage... & 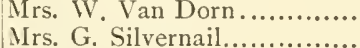 & 1.50 & 10.00 \\
\hline The Oa & Mrs. G. Silvernail......... & 1.50 & 8.00 \\
\hline Troy $\mathrm{Ho}$ & 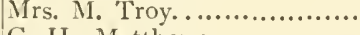 & 1.50 & Special. \\
\hline City Hotel... & G. H. Matthews ................ & 1.50 & Special. \\
\hline Clarendon Inn & Leonard Gill..... & 2.50 and up & \\
\hline $\begin{array}{l}\text { Restaurant and Rooms } \\
\text { Fountain City Hotel... }\end{array}$ & $\begin{array}{l}\text { Miss Parkins............... } \\
\text { Leon Despland.......... }\end{array}$ & 1.50 & $\begin{array}{l}\text { Special. } \\
\text { Special. }\end{array}$ \\
\hline EAU GALLIE, F LA. & & & \\
\hline $\begin{array}{l}\text { Grenada. ................ } \\
\text { Boarding House........ }\end{array}$ & 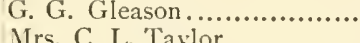 & 2.50 & Special. \\
\hline EDEN, FLA. & Mrs. & & \\
\hline Netherly Hous & M. A. Curtis. & 2.50 & 15.00 \\
\hline $\begin{array}{l}\text { Fort LaUderdale, Fla. } \\
\text { IVallace House............. }\end{array}$ & A. J. & e. & 9 \\
\hline FORT PIERCE, Fla, & & & \\
\hline JENSEN, FLA. & J. L. Jensen... & 2.00 & 8.00 to 12.00 \\
\hline $\begin{array}{l}\text { KEY WEST, FLA. } \\
\text { Hotel Key West.. }\end{array}$ & & & \\
\hline Duval House..... & ....... & 2.00 & Special. \\
\hline Edgar Hous & ..... & 2.00 & Special. \\
\hline Private Board.... & Mrs. O'Bryan... & 1.50 & Special. \\
\hline $\begin{array}{l}\text { LANTANA, FLA. } \\
\text { Lantana House.. }\end{array}$ & M. B. Lyman. . & 2.00 & 12.00 \\
\hline $\begin{array}{l}\text { LEMON CiTY, Fi. } \\
\text { Carey House...... }\end{array}$ & J. T. Carey... & 2.00 & 8.00 to 10.00 \\
\hline
\end{tabular}


EAST COAST HOTEL AND BOARDING HOUSE LIST. - (CONTINUED.)

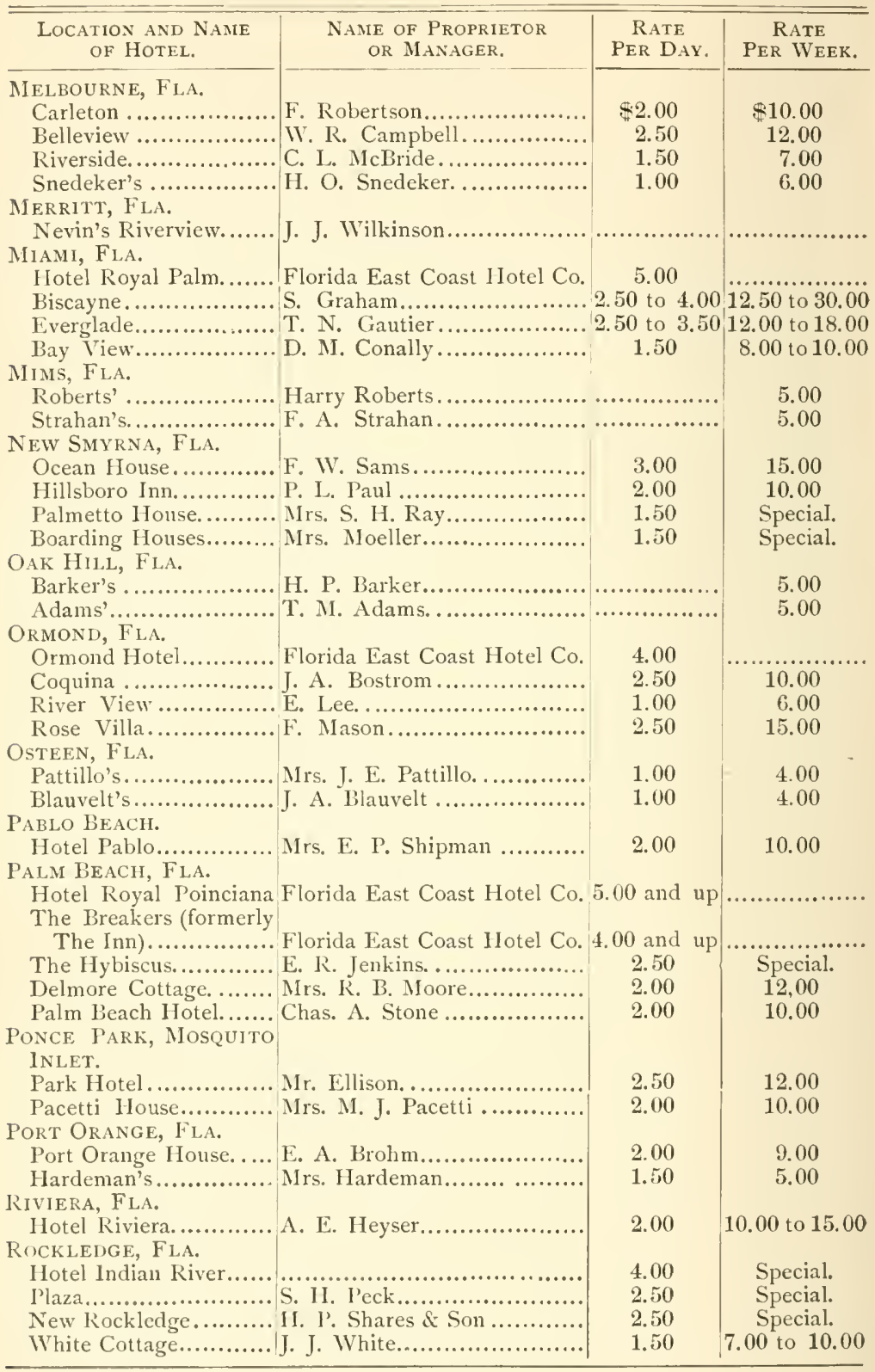


EAST COAST HOTEL AND BOARDING HOUSE LIST. - (CONTINUED.)

\begin{tabular}{|c|c|c|c|}
\hline $\begin{array}{l}\text { LOCATION AND NAME } \\
\text { OF HOTEL. }\end{array}$ & $\begin{array}{c}\text { NaMe of Proprietor } \\
\text { OR MANAGER. }\end{array}$ & $\begin{array}{c}\text { RATE } \\
\text { PER DAY. }\end{array}$ & $\begin{array}{c}\text { RATE } \\
\text { PER WEeK. }\end{array}$ \\
\hline $\begin{array}{l}\text { Roseland, FLA. } \\
\text { Ercildoune Inn. . }\end{array}$ & . Lawrence C. Moore ..... & $\$ 3.00$ & $\$ 20.00$ \\
\hline St. Augustine, Fla. & & & \\
\hline $\begin{array}{l}\text { Ponce de Leon.......... } \\
\text { Alcazar .................... }\end{array}$ & $\begin{array}{l}\text { Florida East Coast Hotel Co. } \\
\text { Florida East Coast Hotel Co. }\end{array}$ & $\begin{array}{l}5.00 \text { and up } \\
400 \text { and up }\end{array}$ & \\
\hline Cordova ................ & Florida East Coast Hotel Co. & Rooms & only. \\
\hline Magnolia. & . Palmer \& McDowell.. & 3.00 & Special. \\
\hline St. George.... & . Mrs. Tyler .... & 2.50 & Special. \\
\hline Florida ............. & . F. C. Hayden ........ & 2.00 to 300 & Special. \\
\hline Buckingham.............. & Geo. C. Howe................... & 2.50 & Special. \\
\hline Granada & . H. Wauchenheusen.............. & 2.50 & Special. \\
\hline Bar & Miss Hasseltine........ & 2.00 & 10.00 \\
\hline (............... & . Mrs. Mary Frazier. .............. & 2.50 & Special. \\
\hline Algonquin. ................ & . $\cdots \ldots . .$. & 2.00 & Special. \\
\hline Ocean View..... & W.......... & 2.50 & Special, \\
\hline $\begin{array}{l}\text { Craddock House..... } \\
\text { Argyle................. }\end{array}$ & $\begin{array}{l}\text { Mrs. J. E. Craddock. } \\
\text { Mrs. Atwood............ }\end{array}$ & $\begin{array}{c}2.00 \\
1.50 \text { and up }\end{array}$ & Special. \\
\hline La Posada. ............ & Mrs. Rumley .. & 1.50 & Special. \\
\hline $\begin{array}{l}\text { The Neligan............... } \\
\text { La Borde.................. }\end{array}$ & 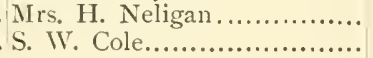 & 1.50 & 7.00 \\
\hline 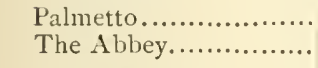 & $\begin{array}{l}\text { J. S. Bentley } \ldots \ldots \ldots \ldots \ldots \ldots \\
\ldots \ldots \ldots \ldots \ldots \ldots \ldots \ldots \ldots \ldots \ldots \ldots \ldots\end{array}$ & 1.50 & 7.00 \\
\hline Spear Mansion. & Mrs. A. R. Spencer............... & 2.00 & $\left\{\begin{array}{r}\text { Special } \\
\text { by week. }\end{array}\right.$ \\
\hline Teahan House... & IV. M. Teahan... & 2.00 & $\begin{array}{l}\text { Special } \\
\text { by week. }\end{array}$ \\
\hline Plaza Hotel... & B. D. Sanchez...... & .50 & $\{$ Rooms \\
\hline Lynn's Arcade & J. H. Lynn & 2.00 & Special. \\
\hline $\begin{array}{l}\text { Allen House...... } \\
\text { Munson House.. }\end{array}$ & - Mrs. D & 1.50 & Special. \\
\hline $\begin{array}{l}\text { Munson House.......... } \\
\text { SEABREEZE (see Daytona). }\end{array}$ & 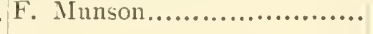 & 1.50 & Special. \\
\hline $\begin{array}{l}\text { SEABREEZE (see Daytona). } \\
\text { SEBASTIAN, FLA. }\end{array}$ & & & \\
\hline House...... & S. Ketchir & 2.00 & 10.00 \\
\hline Morrow House. . & Mrs. J. Morrow............ & 2.00 & 8.00 \\
\hline STUART, FLA. & & & \\
\hline $\begin{array}{l}\text { Ketching's, ........... } \\
\text { Boarding House.... }\end{array}$ & B. Ketching ........................... & 1.50 & 7.00 \\
\hline E, FLA. & & & \\
\hline River Hotel...... & I. T. Bast. & 2.50 & 10.00 \\
\hline Cottace. & Mis. G & 1.50 & 7.00 \\
\hline & Mrs. G & 1.00 & 5.00 \\
\hline Bauknight's ....... & C. Bauknight.......... & 1.00 & 5.00 \\
\hline $\begin{array}{l}\text { WEET JUPITER. } \\
\text { Carlin House........ }\end{array}$ & & & \\
\hline $\begin{array}{l}\text { Carlin House........... } \\
\text { VEST PALM BEACH. }\end{array}$ & Mrs. M. M. Carlin. & 2.00 & 10.00 \\
\hline The & J. C & 2.00 & 10.00 to 18.00 \\
\hline The Seminole.... & Geo. Zapf. & 2.00 & 12.00 to 15.00 \\
\hline Earman House........... & . Mrs. S. F. Earman.... & 2.00 & 10.00 to 12.00 \\
\hline The Leamington....... & Mrs. Madison. & 2.00 to 2.50 & Special. \\
\hline & L. D. Lc & 2.50 & Special. \\
\hline Boarding House........... & 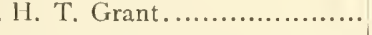 & 2.00 & 8.00 and up. \\
\hline
\end{tabular}

Handsome Souvenir Pamphlet will be mailed upon application. 


\section{CHAPTER XXI.}

As I have heretofore said, the market fishing at Key West is with hand lines and wire fish traps. The latter appliance is made of $1 / 8$-inch iron wire and usually is about three feet long, one and onehalf broad, and one and one-half high. The fisherman takes it out in his boat and puts into it the shells, antennæ and some of the meat of crawfishes, sinking it alongside his boat. The fish enter it by a circuitous route, nearly all not being able to find their way out; the catch with it will average about the same as with the hand line, possibly somewhat more, so the fisherman has two strings to his bow. My especial wary friends of the Snapper and Pompano families are not often inveigled into the contrivance, one or two to the "drop" being a fair average. The "drop" is a term by which the fishermen here designate each anchorage.

Messrs. Walter and Jefferson Griffin make a specialty of Pompano fishing. During my visit of sixteen days, in December, 1901, they brought in eighty-five one day and seventy-five the next day; as that fish sells at a higher price than any other, they are not much called for and, consequently, not many are caught; none are shipped. On December 26th I went out with Walter after Pompano, a party of four catching forty in about three hours - twenty with rod and reel and twenty with hand line.

The Griffins are also very expert in catching all the bottom and other fishes, having caught on several separate occasions thirty-one different varieties during a morning's fishing of two to four hours, and three or four "drops." Several times I knew of Jefferson catching 250 fishes, leaving home about $5 \mathrm{~A}$. M. and returning about $12 \mathrm{M}$. He often stopped at my boat to show me his rare specimens. They do not bring in the foul fishes, such as Sharks, Rays, Sawfish, Catfish, Toadfish, etc., etc. These are much less troublesome here, and among the near-by Keys, than at any other place I have visited in the State of Florida. Nearly all the highly colored species are quite plenty, such as Angel-fish, Parrot-fish, Groupers, Mangroves, Schoolmasters, Lane and Yellowtail Snappers, Porkfish, Hogfish, Spanish Mackerel, etc. 
I have visited the Naples (Italy), Brighton (England), and New York aquariums, and the U. S. Fish Commission's aquarium exhibits at the National Expositions at Philadelphia, New Orleans, Chicago, Atlanta, and Buffalo; and have looked through the fish markets of London (Billingsgate), New York (Fulton), Boston, Philadelphia, New Orleans, Mobile, Pensacola, San Francisco, Portland, Ore., Victoria,Columbia, Quebec, Havana, Cuba, Nassau, Bahamas, Amsterdam, Vienna, Venice, Catania, Genoa, Palermo, Naples, Messina, Nice, Marseilles, Malta, Algiers, Tunis, and those of many smaller places, and must say I think that during any one week of good weather several of the most expert fishermen of Key West each catch a greater number of species than were in any one of the abovementioned collections.

Nearly all the fish are sold by the fishermen direct to the consumer, there being no so-called "Fish House," or "Factor," in the city. Many Kingfish are, however, sold, or shipped for sale, to Cuba, the fishermen receiving written tenders or bids for them, selling to the highest bidder.

Localities for bottom fishing: About one-fourth mile northwest of the "Small Fleet Harbor" and continue about six miles in same direction on the edge of, in, and near the northwest channel: for Grunt, Porgies, Sailor's Choice, Snappers of all kinds, Cavalles, Runners, etc., and occasional Pompanos, Bluefish, and Spanish Mackerel. Also for same fishes, Pearl Channel, American Banks, Target Bank, about northwest of city; Crawfish Channel, and Head and Pebble Channel, about west; and Bluefish Channel, three miles due north.

Trolling, called in Key West " towing," for Kingfish, Barracuda, Amber Jacks, Large Permits, etc., in the channel leading out to the sea, and in front of the city, south and southeast.

For Yellow Tails, especially: At the red buoy off Fort Taylor; on the edge of Crawford Bar ; and in the ship channel to the western dry rocks, on the patches. All sorts of fish are caught on the various reefs.

Owing to the coral formation, which precludes the use of seines, and the peculiar methods of fishing and sale of the fish, it would seem they cannot be so easily partially exhausted as they have been in some localities on both the western and eastern coasts.

In view of all of the above, I wonder why Key West has not 
heretofore attracted more attention from the salt-water angling fraternity. Parties stopping at the Royal Palm, Miami, and at the Royal Poinciana and The Breakers, Palm Beach, can take the steamer at Miami, arriving at Key West within sixteen hours, spend some days fishing, if they have favorable weather, and return same route in same time.

The Griffin Brothers and Merritt Brothers, although market fishers, and Henry J. Pierce, will at all times be glad to take parties out and will usually give them good sport.

On leaving Key West, December 27, 1901, I took what the fishermen and sailors call the "bay way" north, running out through Calda Channel into the Bay of Florida, and then northeast, leaving the inside line of Keys on the right to the east, running into Big Spanish Key Channel to Bahia Honda. A very pleasant and comparatively easy course during southerly and easterly winds. This course can be continued on to Knight's Channel leading east to Knight's Key, on the coast, thus passing by, to the west, all the inner Keys between Key West and Sombrero Lighthouse.

I arrived at Ponce Park October 10, 1901, and found heavy rains had prevailed for several weeks, which had made the water in Halifax River so fresh that the fishing, usually very good at that time, was very poor. There were no Bluefish, or but occasionally one, and very few Trout, or others of the great variety caught there in other seasons. Channel Bass were in moderate supply in the surf, and near the inlet on the banks inside. I left there on the 30th for a cruise to Key West, remained three days at New Smyrna on Hillsboro River, five miles south of Ponce Park, where I found very good fishing for all the fishes of the locality, the water there being almost as sait as usual, because there are no fresh-water streams emptying into the Hillsboro.

My next stop was at Indian River Inlet, where I found all the conditions favorable; plenty of Snappers, Groupers, Channel Bass, Cavalle, etc., etc.

During the year 1891 a law has been passed forbidding seine fishing entirely in Indian River, but allowing gill nets and, of course, cast nets. This law, and the one regarding the one-mile limit, are well observed at the inlet, so it will soon be known what the result of the new law will be. In addition to the above stops, I made one, each, at Jupiter, Lake Worth Inlet, Miami, Bears Cut, Cæsar's 
Creek, Angelfish Creek, Jewfish Creek, Boggy, Tavernier Creek, Cow Pen, Indian Key, and Bahia Honda, at all of which places I had very poor success, except at Indian Key, Boggy and Cow Pen, owing to prevailing "Northers." At Indian Key I had fine Barracuda fishing, trolling with rod and reel, $10 \%$ hook, cut fish bait, around Alligator Lighthouse, and inside in the channels for the assortment of bottom fishes and Pompano. At Boggy and Cow Pen, Snappers, Groupers, Grunts, etc.

The above cruise shows plainly the effect cold weather will have on the fishing. I had warm days at the points named, where I did well, and cold at all the others. This season, so far, has been an unusually cold, wet, and windy one, the worst I have ever seen in Florida.

I ascertained that a new inlet had been cut at New River, which carries six to seven feet of water, and that the fishing there had inproved. I came through the canal to the inlet going through it, and outside to Bears Cut on Biscayne Bay.

Before taking leave of my readers I will say that during an angling experience of sixty-four years 1 have never had as much pleasure in any other locality as I have on the East Coast of Florida.

Not many years ago it was the fashion among the Brook Trout, Black Bass, Salmon, Onananiche, and other fresh water anglers of the North to look down upon their salt water brothers; but that feeling does not now prevail to any great extent, because more and more of the fraternity have taken to the ocean fishes, and especially so since the Tarpon has become known as a game fish, and since the Flagler System of Hotels on the East Coast and the Plant System on the West Coast have been inaugurated.

The Tarpon, Barracuda, Amber Jack, Kingfish, and Bonefish, when caught with rod and reel, certainly deserve to rank with the Salmon and Mascalonge in game qualities; the Lady-fish and Pompano are the equals of the Onananiche; and the Mangrove Snapper, Spanish Mackerel, and Bluefish far excel the Black Bass, Wall-eyed Pike and Pickerel in game and edible qualities.

I have fished in nearly all of the States and Territories of the Union, including the Pacific Coast, and in British America, in many places, from Victoria on the West to Lake St. John and the Saguenay River on the east, including the north and south and east and west shores of the Great Lakes, Georgian Bay, and the St. Lawrence 
River; in the Adirondacks, Rangely Lakes, as well as in very many lakes and rivers in the States of New York, Michigan, Wisconsin, and Minnesota, catching all the game fishes in those localities.

I have also fished in salt water along the Atlantic Coast from Atlantic City to Old Orchard, Maine, trolling for Bluefish at all of the most important places north to Nantucket, and still fishing all along the route; and still I say, give me the East Coast of Florida from Ormond to Key West.

I will add, too, that I have fished a little in Scotland, France, Germany, Austria, and Italy, but none of their waters even deserve mention as compared to the American and Canadian, salt or fresh.

During the past few years, while on cruises down Indian River from the Haulover to Jupiter, I have wondered why the residents along the river have not availed themselves of the State laws to stop the indiscriminate fishing done there.

I am not writing this from a visiting angler's standpoint, but, I believe, in the interest of all concerned - the angler, the resident, the market fisher, and the railroad and express companies who carry the fish to market.

If the quantities of fish caught can be even temporarily curtailed by the adoption of the laws in force on the Halifax and Hillsboro rivers, the fish will, the first season, become more plentiful, and will last as long as the laws are enforced.

It might be a good plan to adopt the laws for a period of two or three years, then open season for the same length of time, and again a close season, and so on indefinitely. This plan of open and close seasons was several years ago tried in the State of Maine, where they have the best system of game laws, and the most rigidly enforced, of any State in the Union, with the sure and natural result, that there is plenty of game and fish for everybody, and the hunting and fishing resorts, clubs, and hotels are full of people during the proper seasons. The law should not apply to Spanish Mackerel and Bluefish, as they are migratory fishes and are caught mostly outside.

As it is now, on Indian River, Lake Worth, and the canal between Lake Worth and Biscayne Bay, "the goose that lays the golden egg" is certainly being killed. I venture to quote here the saying attributed to a northwestern Indian, which reads: "White man, heap dam fool, he kill all the deer and catch all the fish, bime by he got none ; heal dam fool." 
Now, a few words about yachts. If you buy, build, or charter a boat, desiring to cruise and fish in the inside waters of the East Coast, anywhere between Ormond and Key West, select the sailboat, launch, or auxiliary, of the kind, size, or rig you wish, but don't have it drawe more than two feet. More draught will surely bring you to grief, and will prevent you from visiting many very desirable places.

In closing, I desire to acknowledge my obligations to Capt. John Gardner for his invaluable assistance and information in the preparation of this book; to Messrs. Julius vom Hofe, Edward vom Hofe, B. C. Milam \& Sons, and the H. H. Kiffe Co., for the loan of their electrotypes for the illustrations of fishing tackle; to the Florida East Coast R'y Co. for the loan of their map of the East Coast, and hotel and boarding house list; and to the officials of the United States Fish Commission, and the United States National Museum, for their many courtesies, in promptly and kindly sending me books and information asked for.

It has been intimated to me that because I have used the map of the East Coast of Florida, and the list of hotels and boarding houses of the coast issued by the East Coast Railway Company, and because the Matthews-Northrup Works, who do much work for that Company, are my printers, that my book may be considered by some people an advertising medium for the East Coast Railway and East Coast hotel companies.

I deem the subject of enough importance to explain the situation.

When I first concluded to write and publish my book I called on the proper official of the Railway Company and requested the privilege of using the map and hotel list, explaining that I was not soliciting an advertisement, directly nor indirectly; that my book would be my own individual venture, and that I neither needed nor wanted any advertising matter in the work.

On the above basis the official kindly allowed me the use of whatever literature of the Company I might want, and I have acknowledged the favor and repeat the acknowledgment here. The net result of the interview was, that the railway and hotel companies were not to stand sponsors for my book, and that I was not to stand sponsor for the conduct of their business, so the reader may not fear he is being trapped into reading an advertisement after the fashion of some of the modern newspapers. If the book should, incidentally, be of any benefit to the companies by leading few, or many, sportsmen to 
come to Florida who would not otherwise come, I shall certainly feel gratified, but do not.want, nor expect, any recompense, directly, indirectly, nor remotely.

All I desire is the same kind, considerate, and very liberal and lavish entertainment and treatment which has always been accorded to the patrons of the companies, including myself.

When Charles Hallock wrote his "Fishing Tourist," in 1873, he mentioned the routes of travel to reach the localities he described; and Doctor Henshall, in his "Camping and Cruising in Florida," 1884, did the same, mentioning hotels, boarding houses, routes of travel, boatmen, guides, other individuals, etc., and nearly all angling writers have done the same, as all should have done, as the information is, or may be, very valuable to their readers.

I read the two above mentioned books soon after their publication. The first one took me to the Adirondacks, Maine, and Canada; and the later one, I am very glad to say, brought me to Florida for the first time. The railways and hotels got some of my money, but I don't think either Mr. Hallock or the Doctor got any of it, except what I paid for their books. In fact, I consider myself in debt to both those gentlemen, as they have given me much pleasure, and also improvement in health.

At the risk of being charged with repetition after repetition, I will again say: Do not try to catch fish on the East Coast of Florida, except the migratory ones - the Bluefish, Kingfish, and Spanish Nackerel - during the prevalence of a "Norther," or during unusual cold weather. If you do not heed this admonition, going contrary to it, and catch no fish, please do not blame me, nor accuse me of telling big fish stories.

While examining the Ladyfish and the Bonefish among the illustrations in Bulletin 47 I became fully satisfied that the illustrations of the two fishes were transposed, either by typographical error or otherwise, so have placed the engraving of "Albula Vulpes" over the Ladyfish, and the "Elops Saurus" over the Bonefish.

In making this change for insertion in my book I inadvertently omitted to also change the descriptions in the text, of which fact the reader will please take notice, and read accordingly.

My angling experience told me at a glance that the illustrations were misplaced, as I had caught many of each species; but the ques- 
tion arose as to which was entitled to the scientific name of "Albula Vulpes," and which to that of "Elops Saurus."

To satisfy my doubts on that subject I have examined the U.S. Fish Commission reports, and other works, and am satisfied the "Albula Vulpes" is the well-known Ladyfish, and the "Elops Saurus " is the less-known "Bonefish" of Biscayne Bay and the Keys, brought into prominence among the anglers of the East Coast within the last ten years by Mr. J. B. McFerran of Louisville, Ky., of which more anon.

My authorities for making the change are as follows :

Jordan \& Gilbert, Bulletin 16, 1883, page 258, who classify "Albula Vulpes" with common name of "Ladyfishes," and, page 261, "Elops Saurus" with common name "Big-eyed Herring." The former in family "Albulidæ," the latter in family "Elopidæ."

Bulletin 47, 1896, Jordan \& Evermann, pages 409, 410, 411, "Albula Vulpes," common names, "Lady-fish," " Bone-fish," "Macabi," "Sanducha," "Banana-fish." Family "Albulidæ." This is the only Lady-fish described in the Bulletin 47.

Albula or albus, Latin for white, and Vulpes is fox, so the Latin name of the fish is "White Fox."

Same work, pages 408, 409, 410, has "Elops Saurus," common names, "Ten-pounder," “John Mariggle," " Boney-fish," “ Bigeyed Herring," “Matajuela Real," "Chiro," "Lisa Francesca." The fish is classified as of the family "Elopidæ," "The Tarpons," species "Elops." The common name of Lady-fish is not applied to this fish in the work.

G. Brown Goode, "American Fishes, 1887," page 410, "Albula Vulpes." Common names, "Lady-fish," "Bonefish."

U. S. Commission, 189.5, Jordan \& Evermann. In check list, page 280, "Albula Vulpes." Common name, "Lady-fish," etc.

Same work, "Elops Saurus." Common name, "Ten-pounder,' etc.

U. S. Commission, 1896, "Fishes of Indian River," page 240, "Elops Saurus." Common names, "Big-Eyed Herring," "Tenpounder," “Boney-fish." Page 285, “Elops Saurus.' Common name, "Ten-pounder."

U. S. Commission, 1897, page 91, Hugh M. Smith, "Albula Vulpes." Common name, "Lady-fish." 
Same work, "Elops Saurus." Common names, "Ten-pounder," "Big-Eyed Herring.",

U. S. Commission, 1899, Evermann \& Kendall, page 55, "Albula Vulpes." Common names, "Ladyfish," "Bonefish." Page 54, "Elops Saurus." Only common name, "Ten-pounder." Classed in the "Elopidæ," "The Tarpons."

My excuse for inflicting upon my readers the above long explanation, or discussion, is that the Bonefish of Biscayne Bay and the Keys has become very prominent as a sportsman's fish, and there has been, and is now, considerable dispute as to his proper name. The scientific works are not accessible to all anglers and fishermen, so I have undertaken to clear up the difficulties as far as possible. There is no doubt whatever that the fish has borne the name of Bonefish where he is mostly caught, on the East Coast, for fifteen years or more.

Mir. J. B. McFerran of Louisville, Ky., who has fished for sport on the East Coast during the winter seasons for twenty-six years, was the first sportsman to catch the fish with rod and reel, and is entitled to all the credit for the discovery, and inauguration of the Bonefish "industry" among his brother anglers.

I call it an "industry" partly because a man most assuredly has to be very industrious if he catches the fish.

I requested Mr. McFerran to write out for publication in my book an account of his early experiences with the fish and he kindly consented to do so, and his letter will close my last chapter. He kindly refers to my, possilbly, knowing nearly as much about the fish as he does, in which he gives me too much credit, as he has probably caught many hundreds, while I have caught a total of only about forty-five during the past five years. I, however, was fortunate to have as guide during one week William Brickle, who has been his guide for many years, and I at once was taught just "where, when, and how" to hook, handle, and land Mr. Bonefish.

Mr. W. H. GREGG.

MiAмı, Fi.1., January 11, 1902.

Dear Sir:

In response to your request regarding the Bonefish of the Florida East Coast, 1 beg to say that, possibly, I have had as much practical experience with him as any amateur angler that I know of, saving, possibly, yourself. I had been coming to Florida ten years at least before I knew there was such a fish in existence. 
While cruising up the coast from Key West to Miami, about ten years since, and calling at Cocoanut Grove to replenish supplies, in casual conversation with Mr. Peacock, the proprietor of the store, about fishes in the contiguous waters, he mentioned many with which I was familiar, and asked me if I had caught the Bonefish. I answered, "O, yes, plenty of them." His manner implied a doubt, and he then said, "I don't mean the Ladyfish, which is often called the Bonefish." "O, well," I said, "that is what I mean. I never heard of any other." I then became much interested; he stepped to the door and pointed to Cocoa Plum Point, about two miles away, and said, "There at the flooding of the tide, close up to the shore where the water will oftentimes scarcely cover their backs, you will find them." So, as it was on our return route, I told my skipper we would take the rowboat and call at the Point, and he could pick us up as he came down. IVe rowed to the Point, a long sand shoal, with the water from six to ten inches deep and everything on the bottom for an acre around as open to view as the bare ground ashore was. I began to think he had put up a joke on us, deeming it the most unlikely place to catch a fish of any I had almost ever seen; however, I thought that being there it would be best to try, and so I fished around for a couple of hours with never a sign of fish, much less of a strike; but just as I was reeling home my line to leave there came along about a half dozen of what I thought at first glance to be shadows in the water, the movements of which, I quickly detected as fish, were so rapid and entirely unlike anything I had ever seen in the way of fish before, that I immediately realized that I was in front of a distinctly new proposition in the piscatorial line. But the skipper and friends were hailing me to the ship and I reluctantly left the ground, with, however, the mental resolve that, living until another season, I would interview that distinguished individual at closer quarters.

So the following February found me at Cocoanut Grove, prepared with such weapons as I supposed would suit the case. I could hear of no one who had ever caught a Bonefish with rod and line, and the natives said it could not be done, and that the only way they could be taken was occasionally with the grains, and sometimes by seeking a school on the banks and wading stooping down, throwing a hand line some distance in advance of the school, the hook baited with chonch, and if they weranot alarmed they would come along and take it; but to go in a boat and cast with a rod, never, it could not be done.

IVell, I set to work under these discouraging prognostications. I removed my station from Plum Point to Bears Cut, and for three solid weeks I worked and worried over those fishes. The bottom of the flats was covered with grass and the feeding ground was very extensive; I could see them by hundreds almost in every direction, but no sooner would I get within casting distance and the lead would strike the water near them, then away they would go like a badly scared flock of quail ; and not only the small bunch being angled for, but every "mother's son" would be off like the wind. At last, about wearied out, I had determined to give it up as a bad job, when I discovered a space of about an acre of bare sand bottom adjoining a small channel which connected with the main inlet, and beyond that bare spot, extending a long distance, was a shallow bay, the bottom of which was covered with a heavy growth of grass. I said to my boatman, "Put me on the far side of that bare spot, and if we cannot catch one coming up out of that channel we will give it up and put out for Key West." Well, we laid there very quiet for 
about ten minutes with the line out towards the edge of the little channel, when I saw eight or ten of the hopefuls poke their noses over the edge of the channel, and within five minutes I had my fish hooked. Well, I had been angling in many waters, far and near, salt and fresh, and caught, as I thought, about all the fishes known in this country, but here was a sensation indeed, a new edition of chain lightning, and that greased. I caught during the remainder of that day nine fish, and an old hunter who has trailed his old buck through the forest until foot-sore and heart-sick, finally bringing him down with a well-directed shot, can alone fully: appreciate my feelings.

Afterwards, studying the fishes and their habits closely, I was able to take them with little difficulty. Four of us caught in one day sixty-four (of course turning loose all but the few we could eat). That constitutes the Bonefish record with rod and reel, and I doubt not will stand as such for many a long year.

The fish is known to comparatively few anglers and the books do not allude to him at all, or have him confused with the Ladyfish. His habitat is very circumscribed in this country, being confined mainly within the waters of the East Coast of Florida from Biscayne Bay to Mattecombe Keys, occasionally a few as far north as Lake Worth, and as far south as Key West.

We usually, in fact almost invariably, fish for them on extended areas of banks, where at flood tide the water is from six to fifteen inches deep. Their habit is to feed up on the top of the banks with the flood, falling back with it into the deep water. They live solely upon the most delicate of Crustacea, Perriwinkles, Crabs, Shrimp, etc., and they will not take a stale bait; I have tried them repeatedly. I have had a seven-pound fish run 500 feet straight away without a pause, carrying in addition to the weight of the line an ounce of lead, and they will make repeated runs, usually never making a flutter after being laid in the boat; they take all the chances and fight to a finish everytime; they are a very stoutly-built fish and every line is for speed; their only protection is their watchful timidity and speed. I am sure that, unhampered, nothing with fins, or scales, can catch them, unless it be a Porpoise. The genuine angier who has not caught the Bonefish has a sure enough sensation in prospect, which I envy. If the Bonefish were as large as the Tarpon, with speed increased with the size, no rod and reel that could be used by hand could be manufactured that could make him captive. I verily believe that, pound for pound, the Bonefish is, far and away, the king of all swimmers; and the only objection I can urge against him is that an experience with him forever disqualifies one for all other fishing. 


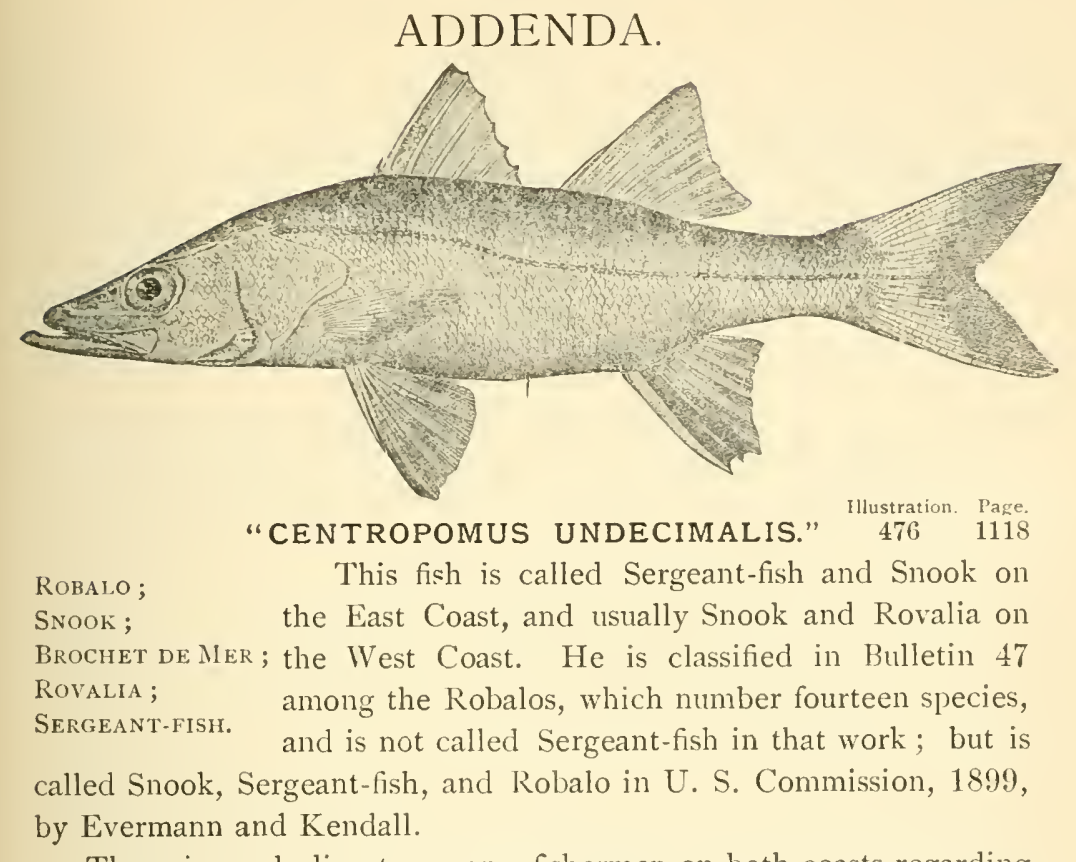

There is much dispute among fishermen on both coasts regarding his correct name. Weight to 15 pounds or more.

$\mathrm{He}$ is a very game fish. Caught: Trolling, casting, with or without sinker, and still fishing. Will take any bait, spoon, or phantom. Not considered a first-class game fish. Edible, C.

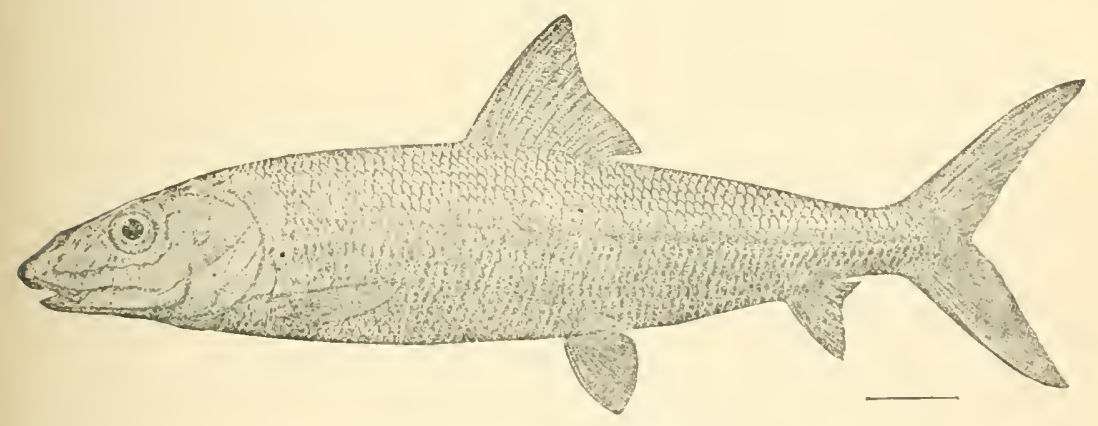

"ALBULA VULPES."

Bulletin 47, illustration 179, page 411 .

Common Names: Lady-fish ; Bonefish ; MaCabi; Sanducha ; Banana-fish. 


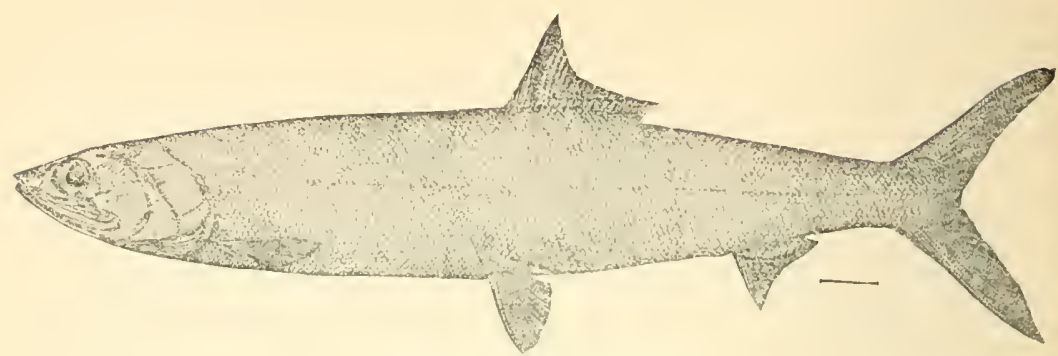

"ELOPS SAURUS."

Bulletin 47, illustration 178 , page 410 .

Common Names: Ten-pounder; John-Mariggle; Bony-fisil ; Big-eyed Herring; Matajuelo Real; Chiro; Lisa Francesa.

OCtOBER 1, 1902.

MORE ABOU'T THE BONEFISH, LADY-FISH, ALBULA VULPES, AND ELOPS SAURUS SUBJECT.

After an extended examination of the works of the United States Fish Commission, and other books written from an angling standpoint, I have come to the conclusion that I was mistaken in thinking, and saying on pages 248 and 249 , that the engraving of the Lady-fish and the Bonefish of Biscayne Bay and the Keys had been transposed in printing Bulletin 47; and in saying, "I am satisfied the Albula Vulpes is the well-known Lady-fish, and the Elops Saurus is the lessknown Bonefish of Biscayne Bay and the Keys," etc.

When I first visited the East Coast of Florida in 1885, and the West Coast a few years later, I saw and caught a fish at many points which was called by the market fishermen, the residents, and the home and visiting anglers, the Lady-fish, Bonefish, and Skipjack.

How or why the fish was called by the names I do not know, but the two latter can hardly be called misnomers, because they are very appropriate and characteristic names for the fish, as he certainly does skip and jump more than any fish I know except the Ouananische, and is not excelled by him in game qualities, and is certainly very bony.

Jordan \& Gilbert of the U. S. Fish Commission, in 1883, produced Bulletin 16 of the U.S. National Museum, in which they classify the above fish in "Family Elopidre (the Big-eyed Herrings)," under 
species, "Elops Saurus." Common name: "Big-eyed Herring," and not calling it the Lady-fish.

Jordan \& Evermann of the same commission, in 1896, produced Bulletin 47 of the U. S. National Museum, in which they classify the fish in "Family Elopidæ (the Tarpons)," under species, "Elops Saurus." Common names: Ten-pounder, John-Mariggle, Bony-fish, Big-eyed Herring, Matajuelo Real, Chiro, Lisa Francesa. The illustration is of the Lady-fish as known in Florida, but it is not called the Lady-fish anywhere in the book.

Jordan \& Gilbert, in Bulletin 16, have "Family Albulidæ (the Lady-fish)," Species: "Albula Vulpes; common name, Lady fish, Bonefish."

Jordan \& Evermann, in Bulletin 47, have "Family Albulidie (the Lady-fishes)," the illustration being the Bonefish of Biscayne Bay and the Keys. Common names: Lady-fish, Bonefish, Macabi, Sanducha, Banana-fish.

These citations show plainly the source of the confusion which has existed regarding the correct scientific and common names of these two fishes. The people of Florida and the sportsmen, who have paid any attention to the subject, thought their Lady-fish was the true Lady-fish, so when the scientific men mentioned a fish of that name they took it to be the one they had known by the same name. I naturally fell into the same error, taking, so to speak, the Lady-fish I had seen and caught as my basis or "premise" in the discussion. The scientific people have been right all the time, and others differing with them, myself included, have been in error all the time.

As I desire to exhaust the subject as well as I possibly can, and in the interest of my readers who desire to read the authorities I have consulted, I give below quotations in full of such authorities, and place above my caption to this article the illustration (reproduced from Bulletin 47) of the "Albula Vulpes," the Lady-fish and Bonefish of the text books, and the Bonefish of Biscayne Bay and the Keys; as also of the "Elops Saurus," 'Ten-pounder, Big-eyed Herring, Bony-fish, etc., of the text books; and the Lady-fish, Bonefish, and Skipjack of the sportsmen and market fishermen of Florida. 


\section{GUNTHER'S STUDY OF FISHES, 1880.}

Classified in the Herring Family. Page 660. No Illustration. No Common Name.

“AlbulA. - Body oblong, moderately compressed; abdomen flat. Scales of moderate size, adherent; lateral line distinct. Eyes covered with a broad annular adipose membrane. Snout pointed, the upper jaw projecting beyond the lower. Mouth inferior, of moderate width, with villiform teeth; intermaxillary juxtaposed to the upper anterior edge of the maxillary. Dorsal fin opposite to the ventrals; and fin shorter than dorsal. Gill membranes entirely separate, with numerous branchiostegals.

"One species only, $A$. conorhynchus, ranging over all tropical and subtropical seas, and very common in many localities near the coasts. It grows to a length of from two to three feet, and is not valued as food."

Classified in the Herring Family.

Same work, page 661. No Common Name. Illustration of the Lady-fish of Florida.

"ELops. - Body rather elongate, moderately compressed; abdomen flat. Scales small, adherant; lateral line distinct. A narrow osseous lamella, attached to the mandibulary symphysis, covers the part between the mandibles. Snout pointed; mouth wide, anterior; intermaxillary short, maxillary forming the lateral part of the mouth. Bands of villiform teeth in the jaws, on the vomer, palatine and pterygoid bones, on the tongue, and on the base of the skull. Dorsal fin opposite to ventrals; anal rather shorter than dorsal. Gill membranes entirely separate, with very numerous branchiostegals.

"Two species, of which one, $E$. saurus, is like the preceding fish, spread over all tropical and subtropical seas; it exceeds a length of three feet, and is not estecmed as food."

Jordan \& Gilbert's Bulletin 16. United States National Museum, 1883. 


\section{"Family XXXIV-ALBULID王."}

"(The LADy-Fishes.)"

Page 258.

No Illustrations.

"Body rather elongate, little compressed, covered with rather small, brilliantly silvery scales. Head naked. Snout conic, subquadrangular, shaped like the snout of a pig, and overlapping the small, inferior, horizontal mouth. Maxillary rather strong, short, with a distinct supplemental bone, slipping under the membranous edge of the very broad preorbital. Premaxillaries short, not protractile. Lateral margin of upper jaw formed by the maxillaries. Eye large, medium in head, with a bony ridge above it, and almost covered by an annular adipose eyelid. Opercle moderate, firm. Preopercle with a broad, flat membranaceous edge, which extends backward over the base of the opercle. Pseudobranchiæ present. Gill rakers short, tubercle-like. Gill membranes entirely separate, free from isthmus. Branchiostegals about 14. A fold of skin across gill membranes anteriorly, its posterior free edge crenate. No gular plate. Both jaws, vomer and palatines with bands of villiform teeth. Broad patches of coarse, blunt, paved teeth on the tongue behind and on the sphenoid and pterygoid bones. Lateral line present. Belly not carinate, flattish, covered with ordinary scales. Dorsal fin moderate, in front of ventrals, its membranes scaly. No adipose fin. Anal very small. Caudal widely forked. Pyloric coeca numerous. A single species known, found in all warm seas."

(Clupeida group, Albulina. Gunther, VII, 468, 469.)

\section{"II6-ALBULA Gronovius."}

Same work, page 258 .

("Gronovius; Bloch \& Schneider, Syst. Ichth., 1801, 432 : type, Albula conorhynchas. Bloch \& Schneider-Esox vulpes, L." ) "Characters of the genus included above. (Latin albus, white.) “431. A. vulpes (L.). Goode._Lady-fish; Bonefish.

"Brilliantly silvery; olivaceous above; back and sides with faint streaks along the rows of scales; fins plain; axiles dusky. Upper lobe of caudal the longer. A band of peculiar, elongate, membranaceous scales along middle line of back; accessory ventral scale large. Head, $33 / 4$; depth, 4. D. 15 ; A. 8 ; scales, $9-71-7$; I. 18 inches. Cape Cod to Southern California and East Indies; 
abundant in tropical seas. Not much valued as food, but beautiful and gamy.

"(Esox zulpes, L. Syst. Nat.: Albuli conorhynchus. Gunther, VII, 468. )"

\section{"Family XXXVI, - ELOPID Æ." \\ "(The Big-eyed Herrings.)"}

Same work, page 260 .

No Illustration.

"Body elongate, not much compressed, covered with cycloid scales. Head naked. Mouth broad, terminal, the lower jaw prominent. Premaxillaries not protactile, short, the maxillaries forming the lateral margins of the upper jaw. Maxillary composed of about three pieces, extending backward beyond the eye. An elongate bony plate between the branches of the lower jaw (like the gula plate in Amia). Bands of villiform teeth in both jaws and on vomer, palatines, pterygoids, tongue, and base of skull. No large teeth. Eye large, with an adipose eyelid. Gill membranes entirely separate, free from the isthmus. Branchiostegals numerous (20-35). Gill rakers long and slender. Pseudobranchix present or absent. Belly not keeled nor serrated, covered with ordinary scales. Lateral line present. Dorsal fin over or rather behind ventrals. Caudal fin forked. No adipose fin. Pyloric coeca numerous. Two genera, not much alike, with 4 or 5 species, widely distributed, sometimes entering fresh waters.

“(Clupeida group, Elopina. Gunther, VII, 469-472.)

"Body elongate, covered with small scales; anal fin smaller than dorsal. (Elopince.)

" $a$. Pseudobranchiæ present, . . . . . Elops, 118.

"Body oblong, covered with long scales; anal fin larger than dorsal. (Megalopince.)

“b. Pseudobranchiæ obsolete, . . . Megalops, 119."

Same work, page 261.

\section{"Ir8. ELOPS, Linnæus."}

"(BIG-EYED HERrings.)"

"(Linnæus, Syst. Nat.: type, Elops saurus, L.)"

"Body elongate, covered with thin, small, silvery scales. Dorsal fin slightly behind ventrals, its last rays short, the fin depressible into 
a sheath of scales; anal fin smaller, similarly depressible. Pectorals and ventrals moderate, each with a long accessory scale. Opercular bones thin, with expanded, membranaceous borders ; a scaly occipital sheath or collar. Lateral line straight, its tubes simple. Pseudobranchiæ present, large. Species 2 or more, widely distributed, remarkable for the development of scaly sheaths. ( $\boldsymbol{\epsilon}^{\prime} \lambda \psi^{\prime}$, name of some sea fish - a sword-fish or sturgeon; from $\epsilon^{\prime} \lambda \alpha^{\alpha} \omega$, to drive or move. )"

\section{"435. E. saurus L." \\ "(Big-eyed HeRrings. )"}

Same work, page 261 .

"Uniform silvery, darker above. Gular plate $3-4$ times as broad as long. Head, 41/4; depth, 5-6. Eye large, 4-5 in head. D. 20 ; A. 13 ; V. 15 ; B. 30 ; scales, 12-120-13. L. 24 inches. Cape Cod to Cape of Good Hope and China. A handsome fish, not rare on our Atlantic coast.

"(Linn. Syst.; Gunther, VII, 470.) "

\section{JORDAN \& EVERMANN BULLETIN 47. U. S. NATIONAL} MUSEUM, 1896.

\section{"Family LVI. Elopidæ."}

"(THE TARPONS.)"

Page 409.

\section{"I98. ELOPS, Linnæus."}

"Elops, Linnæus, Syst. Nat., Ed. XII, 518, 1766, (Saurus). Magilomorus, Lacepede, Hist. Nat. Poiss., V, 398, 1803, (annacarolina).

"Trichonotus, Rafinesque, Analyse de la Nature, 1815, 88, (annacarolina) ; substitute for Mugilomorus, considered objectionable."

"Body elongate, covered with thin, small, silvery scales. Dorsal fin slightly behind ventrals, its last rays short, the fin depressible into a sheath of scales; anal fin smaller, similarly depressible; pectorals and ventrals moderate, each with a long accessory scale. Opercular bones thin, with expanded, membranaceous borders; a scaly occipital collar. Lateral line straight, its tubes simple. Pseudobranchice 
present, large. Vertebræ $43+29-72$. Large fishes of the open seas, remarkable for the development of scaly sheaths. The young are ribbon-shaped and elongate, passing through a series of changes like those seen in Albula. ( $\varkappa^{\prime} \lambda o \psi$, name of some sea fish - a swordfish or sturgeon; from $\epsilon^{\prime} \lambda \alpha \omega$, to drive or move. )"

\section{"67r. ELOPS SAURUS. Linnæus."}

Same work, page 410 .

(Ten-Pounder ; John-Mariggle; Bony-fish ; Big-eyed Herring ; Matajuelo Real; Chiro; Lisa Francesa.)

The illustration is of the Lady-fish of Florida.

" Head, 41/4; depth, 5 to 6 ; eye large, 4 to $5 . \quad$ D. 20 ; A. 13 ; V. 15 ; B. 30 ; scales, $12-120-13$. Gular plate 3 to 4 times as long as broad. Length, 3 feet. Tropical seas; abundant and very widely distributed. Common in America, north to Carolina and the Gulf of California; straying on the Atlantic coast to Long Island. (Suurus, бaîpos, lizard.)

Elops saurus. Linnæus, Syst. Nat., Ed. XII, 518, 1766, Carolina. Gunther, Cat. VII, 470, 1868; Jordan \& Gilbert, Synopsis 261, 1883 , and of most authors.

"Argentina carolina. Linneus, Syst. Nat., Ed. XII, 519, 1766, Carolina.

"Argentina machnata. Forskal, Descr. Anim., 68, 1775, Djidda, Arabia.

"Mtugilomorus anna-carolina. Lacepede, Hist. Nat. Poiss., V, 398, 1803, South Carolina.

"Elops inermis. Mitchill, Trans. Lit. and Phil. Soc. N. Y., I, 1815, 445, New York.

"Elops capensis. Smith, Zool. S. Africa, 1845, pl. 7, Cape of Good Hope.

"Elops purpurascens. Richardson, Ichth. China, 311, 1846, China."

Same work, page 410.

\section{"Family LVII. Albulidæ."}

"Body rather elongate, little compressed, covered with rather small brilliantly silvery scales; head naked. Snout conic, subquadrangular, shaped like the snout of a pig, and overlapping the small, inferior, horizontal mouth. Maxillary rather strong, short, with a distinct supplemental bone, slipping under the membranous edge of 
the very broad preorbital; premaxillaries short, not protractile, Lateral margin of upper jaw formed by the maxillaries; both jaws, vomer, and palatines with bands of villiform teeth; broad patches of coarse, blunt, paved teeth on the tongue behind and on the sphenoid and pterygoid bones. Eye large, median in head, with a bony ridge above it, and almost covered with an annular adipose eyelid. Opercle moderate, firm; preopercle with a broad, flat, membranaceous edge, which extends backward over the base of the opercle. Pseudobranchiæe present. Gill rakers short, tubercle-like. Gill membranes entirely separate, free from the isthmus, branchiostegals about 14 ; a fold of skin across gill membranes anteriorly, its posterior free edge crenate; no gular plate. Lateral line present. Belly not carinate, flattish, covered with ordinary scales. Dorsal fin moderate, in front of ventrals, its membrane scaly; no adipose fin; anal very small; caudal widely forked. Pyloric coeca numerous. Parietal bones meeting along top of head. Vertebræ numerous, 42-28-70. A single species known, found in all warm seas. In this, and probably in related families, the young pass through a metamorphosis analogous to that seen in the Conger Eels. They are for a time elongate, band-shaped, with very small head and loose transparent tissues. From this condition they become gradually shorter and more compact, shrinking from 3 to $3 \mathrm{r} / 2$ inches in length to 2 inches. According to Dr. Gilbert, this process, like that seen in various eels, is a normal one, through which all individuals pass. In the Gulf of California, where these fishes abound, these band-shaped young are often thrown by the waves on the beach in great masses. 1868.)",

" (Culpeida, group Albulina. Gunther, Cat. VII, 468, 469,

\section{"I99. ALBULA (Gronow). Bloch \& Schneider."}

Same work, page 411.

$$
\text { "(LADY-FISHES.)" }
$$

"Conorhyncus. Nozeman, Act. Select., III, 382, 1757 (nonbinomial).

"Albula. Gronow, Zoophyl., 102, 763 (nonbinomial).

"Albula. Bloch \& Schneider, Syst. Icth., 432, 1801 (conorhyncus-vulpes).

"Butyrinus. Lacepede, Hist. Nat. Poiss., V, 45, 1803 (bananavulpes). 
"Glossodus. Cuvier, in Agassiz, Spix, Pisc. Bras., 48, 1829 (forskali-rulpes).

"Characters of the genus included above. (Latin albus, white.)"

\section{"672. ALBULA VULPES. (Linnæus.)"}

"(Lady-fish ; Bone-fish ; Macari ; Sanducila ; Banana-Fish.)"

The illustration is of the Bone-fish of Biscayne Bay and the Keys. Same work, pages $411,412$.

" Head, $33 / 4$; depth, 4. D. 15 ; A. 8 ; scales, 9-71-7. Upper lobe of caudal the longer. A broad band of peculiar, elongate, membranaceous scales along middle line of back; accessory ventral scale large. Brilliantly silvery; olivaceous above ; back and sides with faint streaks along the rows of scales; fins plain; axils dusky. Length, 18 inches to 3 feet. Tropical seas, on sandy coasts, almost universally distributed and generally abundant, ranging northward on our coasts to San Diego and Long Island. A beautiful and active fish, in most places little valued as food ; but in some regions, as Key West, highly appreciated." (Vulpes, fox.)

"Unbarana. Marograve, Hist. Bras, 1648, Brazil.

"Vulpes bahamensis (the Bone-fish). Catesby, Nat. Hist.

"Carolinas, etc., pl. 11, fig. I, 1737, Bahamas.

"Esox vulpes. Linnæus, Syst. Nat., Ed. X, 1758, 313, Bahamas; based on the Bone-fish, Vulpes bahamensis, of Catesby.

"Argentina glossodonta. Forskal, Descr. Anim., 68, 1775, Djidda, Arabia.

“Macabi. Parra, Dif. Piezas Cuba, 88, pl. 35, fig. I, 1787, Cuba ; based on Unbarana of Marcgrave.

"Synodus argenteus. Bloch \& Schneider, Syst. Icth., 398, 1801, Asia.

"Clupea brasiliensis. Bloch \& Schneider, Syst. Icth, 427, 1801, Brazil.

"Albula conorynchus. Bloch \& Schneider, Syst. Icth., 432, 1801, Antilles; after Gronow and Plumier; called Albula phumieri on plate 86 .

"Amia immaculatt. Bloch \& Schncider, Syst. Icth., 451, 1801, Central America; after Macabi of Parra.

Butyrimus banana. Lacepede, Hist. Nat. Poiss., V, 46, 1803, Isle de France. 
"Clupea macrocephala. Lacepede, Hist. Nat. Poiss., V. 426 , 1803, Martinique ; on a drawing by Plumier.

"Glossodus forskali. Agassiz, Spix. Pisc. Bras. 49, 1829, Bahia; called Engraulis sericus and Engraulis bahiensis on the plates 22 and 24 .

"Albula parra. Cuvier \& Valenciennes, Hist. Nat. Poiss., XIX, 339, 1846, Martinique; Bahia; Rio de Janeiro.

"Albula goreensis. Cuvier \& Valenciennes, Hist. Nat. Poiss., XIX, 342, 1846, Gorea.

"Albula neoguinaica. Cuvier \& Valenciennes, 1. c., XIX, 350, 1846, New Guinea.

"Albula seminuda. Cuvier \& Valenciennes, 1. c., XIX, 351, 1846, New Guinea.

"Albula erythrocheilos. Cuvier \& Valenciennes, 1. c., XIX, 352, pl. 540, 1846, Friendly Islands.

"Albula forsteri. Cuvier \& Valenciennes, l. c., XIX, 35t, 1846, Tahiti.

"Albula rostrata. Gronow, Cat. Fishes, 189, 1854, American Ocean, etc.

"Albula conorhynchus. Gunther, Cat. VII, 468, 1868.

"Albula vulpes. Jordan \& Gilbert, Synopsis 258, 1883.

\section{G. BROWN GOODE; AMERICAN FISHES. 1887.} Page 410.

No Illustrations.

Under heading of the Herring and its allies, Mr. Goode says :

"The Lady-fish, Albula zulpes, occurs in the West Indies, in the Gulf of Mexico, on the Atlantic and Pacific coasts of North and South America, and sparingly along our Atlantic shores as far north as Cape Cod. It is also found about the Bermudas and Cape Verde Islands, in the Indian Ocean, the Red Sea, and on the coast of Japan. With us it is usually called the 'Lady-fish'; in the Bermudas the 'Bonefish,' or 'Grubber.'

"At the Bermudas large schools are taken, and it is there considered a most excellent food fish. From personal observation I can testify that its reputation is by no means a false one.

"Henshall found it in the Indian River inlet, and gives it a fine character as a game-fish. Describing winter angling experiences, he writes: "In the course of an hour, and in quick succession, I took 
several more salt-water trout, a few red fishes or channel bass, some ravallia or snooks of from three to ten pounds, some crevalle of three or four, and, finally, a Bone-fish of about three pounds, which gave more real sport than any of the others. The Bone-fish or Lady-fish, as it is sometimes called, is a slender, silvery fish, and fights in the water and in the air like the black bass, but mostly in the air - Silver Shuttle.'

"The species is found in some numbers in San Diego Bay, on the coast of California, where it is taken with the mullet. On account of its beautiful color, it sells readily, but is not especially esteemed as a table-fish."

\section{NOTE BY GREGG.}

Goode and Henshall here must refer to the Lady-fish of the Florida fishermen. Henshall says it is a "slender fish," which the Bone-fish of Biscayne Bay is not. Only one or two "stragglers" of the latter have been taken at Indian River Inlet, and they do not " fight in the air," but keep under water. They had not been taken with rod and reel when Hensall wrote above, and they do not range to Cape Cod, except as occasional stragglers.

\section{U. S. FISH COMMISSION REPORT OF 1895.}

Jordan \& Evermann's Check List of Fishes of North and Middle America.

\section{“Genus 199. Elops Linnæus."}

Page 279. No illustration.

“Elops. Linnæus, Syst. Nat., ed. XII, 518, 1766 (samms).

“687. Elops saurus, Linnæus. Ten-pounder; John-Mariggle; Bony-fish; Bone-fish; Big-eyed Herring; Matajuelo Real; Lina Francesa. Tropical seas; common north to the Gulf of California and to Long Island on the Atlantic Coast.

“Elops saurus. Linnæus, Syst. Nat., ed. XII, 518, 1766, Carolina."

\section{"Family LVII. Albulidæ."}

"(TIIE LAIN-Fisiles.)"

Same work, page 280. No illustration.

"Genus 200. Albula (Gronow). Bloch \& Schneider. Albula Gronow, Zoophyl., 162, 1763 (nonbinomial).'”

"688. Albula vulpes (Linneus). Iady-fish; Bone-fish ; Macalbi ; Banana-fish. 
"Tropical seas, ranging northward to San Diego and Long Island. Esox vulpes. Linnæus, Syst. Nat., ed. X, 313, 1758, Bahamas, etc.; based on the bone-fish, Vulpes bahamensis, of Catesby."

W. F. McCormick's List of fishes in Biscayne Bay. Same work, page 175. No illustration.

\section{"Bone-fish (Albula vulpes)."}

\section{U. S. FISH COMMISSION REPORT OF 1896.}

"Annotated List of the Fishes known from Indian River." Page 240. No illustration.

"Elops saumus, Linneus. Big-eyed Herring, Ten-pounder, 'Bony-fish.' Observed at Fort Pierce and at mouth of St. Lucie River. Known to some of the fishermen as 'Lady-fish.' Frequently taken in the seines. Examples from Fort Pierce preserved." Allula vulpes not in the list.

"Fisheries of the Coastal Waters of Florida, by John J. Brice." Same work, page 285. No illustration.

"There are many other species of fishes found at Key West which are used to a greater or less extent as food. Among them are the bonefish (Albula vulpes), ten-pounder (Elops saurus)."

\section{U. S. FISH COMMISSION BULLETIN, 1897.}

Page 90.

No Illustration.

Annotated List of Fishes known to inhabit the Woods Hole Region, by Hugh M. Snith.

"32. Elops Saurus, Linnæus."

"(Ten-pounder; Big-eyed Herking. )"

"Common in fall, none appearing before October. Taken in traps in Vineyard Sound and in Herring gill nets at Vineyard Haven. Nany have been sent to the Fish Commission by fishermen for identification. Average length 18 to 20 inches. No young fish observed." 
Same work, page 91 .

No Illustration.

\section{SAME LIST BY HUGH M. SMITH.}

\section{"Albula vulpes (Linnæus)." "(L,ADY-FISH ; BONEFISH.)"}

"Very rare. Reported by Professor Baird in 1871, and since observed only once or twice. None seen for many years."

\section{U. S. FISH COMMISSION REPORT, 1899.}

Page 54.

No Illustration.

"Check List of the Fishes of Florida, Evermann \& Kendall."

\section{"84. Elops Saurus (Linnæus)." \\ "(TEN-POUNDER.)"}

Cape Cod to Florida (Holbrook, 1860); St. Johns River (Bean, 1880); Pensacola (Jordan \& Gilbert, 1882; and Bean, 1883); Key West (Jordan, 1884a); Florida Keys (Jordan, 1884d); Tampa Bay to Punta Rassa, and Little Sarasota Bay (IVilcox, 1886); Marco (Henshall, 1889), Key West and Tampa (Henshall, 1894); and St. Johns River at Welaka (Kendall Coll., 1897).'"

\section{"85. Albula Vulpes (Linnæus)." \\ "(LADY-FISH ; BONE-FISH.)"}

Same work, page 55.

No Illustration.

" Pensacola (Stearns Coll., Bean, 1883); Key West (Jordan, 1884a; and Jordan \& Evermann, 1896); Florida Keys (Jordan, 1884d); Garden Key (Grampus Coll., Kendall, 1889); Key West, Pavilion Key, and San Carlos Pass (Henshall, 1889); New Smyrna (Lonnberg, 1894); Key IWest and Tampa (Henshall, 1894); and Biscayne Bay (McCormick Coll., Smith, 1895.)'"

FISHERIES OF PORTO RICO. U. S. FISH COMMISSION, 1900. Page 81. B. W. EVERMANN.

The illustration is of the Lady-fish or Bone-fish of the Florida fisherman and sportsman.

\section{"GENUS 20. Elops, Linnæus."}

"Body elongate, covered with thin, small, silvery scales. Dorsal fin slightly behind ventrals, its last rays short, the fin depressible; 
into a sheath of scales; anal fin smaller, similarly depressible; pectorals and ventrals moderate, each with a long accessory scale. Opercular bones thin, with expanded membranaceous borders; scaly occipital collar. Lateral line straight, its tubes simple. Pseudobranchiæ present, large. Vertebræ, 43-29-72.

"Large fishes of the open seas, remarkable for the development of scaly sheaths. The young are ribbon-shaped and elongate, passing through a series of changes like those seen in Albula."

\section{"25. Elops saurus, Linnæus."}

“Piojo'; Matajuelo Real; Chiro; Lisa Francesa; Ten-pounder; John-MARIGgle ; Bony-fish ; Big-eyed Herring."

"Head, 4.3 ; depth, 5 to 6 ; eye, 5 ; snout, 4.3 ; maxillary, 1.6 ; mandible, 1.5 ; interorbital, 5.6 ; D. 20 ; A. 13 ; pectoral, 1.8 ; ventral, 2 ; caudal, 0.8 ; scales, $13-110-12$. Body very elongate, moderately ccmpressed, scales small and thin, none on head; head small, pointed; mouth very large, the extremely long maxillary reaching far beyond eye, which has a well-developed adipose eyelid, sheathing the eye anteriorly and posteriorly; rather blunt, villiform teeth on jaws, vomer, and palatines and along lower edge of maxillary; jaws subequal; a pointed gular plate; dorsal and anal fins with well-developed basal sheaths of scales, that of dorsal large; ventral with a very large and pointed scale; caudal lobes long and slender. Blue above, the sides silvery.

"This species is abundant and widely distributed in the tropical seas. It is common in America north to the Carolinas and the Gulf of California. Probably not uncommon about Porto Rico, though seen by us only at Arecibo, where a species 15 inches long was obtained."

"Elops saurus. Linnæus, Syst. Nat. ed. XII, 518, 1766, Carolina ; Jordan \& Evermann, I. C., 410, 1896.

"Argentina carolina. Linnæus, Syst. Gat. ed. XII, 519, 1766, Carolina.

"Argentina machnata. Forskal, Deser. Anim., 68, 1775, Djidda, Arabia.

"Anugilomonus anna-carolina. Lacepede, Hist. Nat. Poiss., V, 398, 1803, South Carolina.

"Elops incermis. Mitchill, Trans. Lit. and Phil. Soc. N. Y., I, 1815, 445, New York. 
“Elops capensis. Smith, Zoöl. South Africa, 1845, pl. 7, Cape of Good Hope. China."

"Elops perpurascens. Richardson, Icth., China, 311, 1846,

Pages 81-83.

"Family XVI. ALBULIDE."

"(The Lady-Fishes.)"

The illustration is of Bone-fish of Biscayne Bay and the Keys.

"Body rather elongate, little compressed, covered with rather small, brilliantly silvery scales; head naked. Snout conic, subquadrangular, shaped like the snout of a pig, and overlapping the small, inferior, horizontal mouth. Maxillary rather strong, short, with a distinct supplemental bone, slipping under the membranaceous edge of the very broad preorbital; premaxillaries short, not protractile. Lateral margin of upper jaw formed by maxillaries ; both jaws, vomer, and palatines with bands of villiform teeth; broad patches of coarse, blunt, paved teeth on the tongue behind and on the sphenoid and pterygoid bones. Eye large, medium in head, with a bony ridge over it, and almost covered with an annular adipose eyelid. Opercle moderate, firm; preopercle with a broad, flat, membranaceous edge, which extends backward over the base of opercle. Pseudobranchir present. Gill rakers short, tubercle-like. Gill membranes entirely separate, free from isthmus; branchiostegals about 14; a fold of skin across gill membranes anteriorly, its posterior free edge crenate; no gular plate. Lateral line present. Belly not carinate, flattish, covered with ordinary scales. Dorsal fin moderate, in front of ventrals, its membranes scaly; no adipose fin; and very small caudal widely forked. Pyloric coeca numerous. Parietal bones meeting along top of head. Vertebræ numerous, 42-28-70.

"A single species known, found in all warm seas. In this, and probably in related families, the young pass through a metamorphosis analogous to that seen in the Conger Eels. They are for a time elongate, band-shaped, with very small head and loose, transparent tissues. From this condition they become gradually shorter, shrinking from 3 to $3 \frac{1}{2}$ inches in length to 2 inches. According to Dr. Gilbert, this process, like that seen in various eels, is a normal one, through which all individuals pass. In the Gulf of California, where these fishes abound, these band-shaped young are often thrown by the waves on the beach in great masses." 


\section{"Genus 21. ALBULA (Gronow). Bloch \& Schneider."}

"The characters of this genus are included above with those of the family."

\section{"26. Albula vulpes (Linnæus)."}

"MACABI"; "PIOJO"; LADY-FISH ; BONE-FISH ; BANANA-FiSH.

"Head, 3.4; depth, 4.5; eye, 7; snout, 2.2; maxillary, 3; interorbital, 3.8 ; preorbital, 5.6 ; D. 15 ; A. 8 ; pectoral, 1.9; ventral, 2.4 ; caudal, 1.1 ; scales, 9-70-6. Body elongate, robust ; the trunk covered with long shining scales with membranous edges; head large, naked, subconic; the snout pig-like, overhanging the inferior mouth, which is armed with villiform teeth; eye high in position, midway between tip of snout and edge of opercle, entirely covered, save for a circular central opening smaller than pupil, with an adipose eyelid; vertical fins scaled, the dorsal and anal very densely; caudal widely forked, upper lobe the longer; median line of back with one series of modified scales, which are smaller and narrower than those of body and have a long membranous appendage much narrower than the scale, this appendage alone exposed. Color bright-silvery, darker above ; faint longitudinal dark or bluish streaks. A metamorphosis (as in Elops) takes place in the young, previous to which they do not resemble the adult.

"Tropical seas, on sandy coasts, almost universally distributed and generally abundant, ranging northward on our coasts to San Diego and Massachusetts. Three examples in the collection, one 19 inches long, the others about 12 inches, from San Juan market and Culebra Island. Used as food to some extent, but not highly esteemed."

"Uinbarana. Maregrave, Hist. Bras., 1648, Brazil.

"Vulpes bahamanesis (the bone-fish). Catesby, Nat. Hist. Carolinas, pl. 11, fig. 1, 1737, Bahamas.

"Esox vulpes. Linnæus, Syst. Nat., ed. X, 1758, 313, Bahamas; after Catesby.

"Argentina glossodonta. Forskal, Descr. Anim., 68, 1775, Djidda, Arabia.

"Macabi. Parra, Dif. Piezas, Cuba, 88, pl. 35, fig. 1, 1787, Cuba ; on Umbarana of Maregrave.

"Synodus argenteus. Bloch \& Schneider, Syst. Icth., 398, 1801, Asia. 
"Clupca brasiliensis. Block \& Schneider, Syst. Icth., 427, 1801. Brazil.

"Albula conorhynchus. Bloch \& Schneider, Syst. Icth., 432, 1801, Antilles; after Gronow and Plmier, Poey, Fauna Puerto Riquena, .342, 1881 ; Stahl, I, c., 80 and 165, 1883.

"Amia immaculata. Bloch \& Schneider, Syst. Icth., 451, 1801, Central America; after Parra.

"Butyrimus hanana. Lacepede, Hist. Nat. Poiss., V, 46, 1803, Isle de France.

"Clupea macrocephala. Lacepede, Hist. Nat. Poiss., V, 426, 1803, Martinique; on a drawing by Plumier.

"Glossoulus forskali. Agassiz, Spix. Pisc. Bras., 49, 1829, Bahia ; called Engraulis sericus and Engraulis bahiensis on the plates 22 and 24 .

"Allula parre. Cuvier \& Valencienness, Hist. Nat. Poiss., XIX, 339, 1846, Martinique, Bahia, Rio de Janeiro.

"Albula goreensis. Cuvier \& V'alenciennes, Hist. Nat. Poiss., XIX, 342, 1846, Gorea.

"Albula ncoguinaica. Cuvier \& Valenciennes, l. c., XIX, 350, 1846, New Guinea.

“Albula seminuda. Cuvier \& Valenciennes, 1. c., XIX, 351, 1846, New Guinea.

“Albula erythrocheilos. Cuvier \& Valenciennes, 1. c., XIX, 352, pl. 540, 1846, Friendly Islands.

"Albula forsteri. Cuvier \& Valenciennes, 1. c., XIX, 354, 1846, Tahiti.

"Albula rostrata. Gronow, Cat. Fishes, 189, 1854, American Ocean, etc.

"Albula vulpes. Jordan \& Evermann, 1. c., 411, 1896."

\section{THE FISHES OF NORTH AMIERICA. WILLIAM \\ C. HARRIS, 1898.}

Volume 1. Pages 91, 92, 93.

\section{"THE BONEFISH OR LADYFISH."}

"An earnest discussion has recently taken place among anglers as to the proper classification of the so-called bonefish or ladyfish, particularly the one taken, most frequently, in Biscayne Bay, Florida. 
This perplexity is caused, in part, by the existence and general use of the same common or popular name for two widely differentiated fish. I have passed many winters in Florida, and have, doubtless, caught more than a thousand of the so-called 'ladyfish or bonefish,' and in 1895 , my companion, Mr. J. L. Petrie, the artist, painted a portrait of one, in oils, before its life colors had faded, on examination of which it was plain to see that it was not the true bonefish, Albula vulpes, although so called on both coasts of Florida. It was a full brother of the tarpon - a big-eyed herring, Elops saurus, a fish that has many of the physical markings of the silver king, and some of its game qualities when restrained by the rod. That the angler may, on sight, distingush one from the other, illustrations of both are given. Upon examination of a captured fish, it will be seen that the true bonefish, $A$. zulpes, has fifteen rays in the dorsal fin and eight in the anal, and the ladyfish, or more properly the bigeyed herring, E. saurus, has twenty rays in the dorsal and thirteen in the anal fin. The first-named fish is much stouter in build, has large scales and is brilliantly silvery in color, shading into olive on the back, with faint streaks along the rows of scales. The big-eyed herring has much smaller scales, is also of a bright silvery coloration, but in lieu of the olivaceous shading above the lateral line and on the back, which occurs in the true bonefish, there is a distinct, but soft, bluish coloration extending from the shoulder to the fleshy part of the tail.

"It is difficult to ascertain from the articles appearing from time time in the sportsman's journals, on the capture of the ladyfish or bonefish, which of these two fishes the writers are describing, but in most instances they doubtless refer to the big-eyed herring, as the frantic leaps of the fish are described in glowing terms. The Hon. Matthew S. Quay wrote me in 1882: 'The bonyfish - I took two of them, two feet in length, each, on a spinner at Jupiter and one at Punta Rassa. They resemble the herring, except they are narrower in proportion to their length. When hooked, they are as frantic in their leaps as the tarpon.'

"These fish were certainly the big-eyed herring, E. saurus. The true bonefish does not leap from the water when under the restraint of the line.

"The bonefish or ladyfish, Albula zulpes - generic name from the Latin, 'white'; the specific, also Latin, meaning 'fox' - is 
classed in the order Isospondyli-from two Greek words signifying 'equal,' 'vertebra.' In this order we find many other fishes that are taken on hook and line - the salmons, trouts, graylings, mooneyes, tarpons, herrings, shad, smelt, whitefishes (cisco), pike, pickerel and mascalonge. The fishes of this order are characterized by the soft rays in their fins; presence of a flat bone on the upper side of the head; an arch of bone in front of the shoulder; absence of bones in the ear formation, and the bones in the mouth and in front of the resophagus are not shaped like a scythe, as in the fishes previously described.

"The true bonefish (Albula vulpes) is the only representative of the family Albulida. Its range is stated in the text-books to be from Cape Cod southward to the warm seas, but it has occurred to me that the confusion arising from a similarity of popular names, alluded to above, might possibly have led to error as to range of habitat of this fish. I have examined a specimen of the big-eyed herring, wrongly called ladyfish, that was caught on a hook in the waters of Princes Bay, Staten Island, but in my familiar personal and editorial intercourse, extending over a quarter of a century, with the salt-water fishermen of New York City, ten thousand of whom go a-fishing every week of the season, I have never heard of $A$. vulpes being taken by any of these rodsters. But negative proof is no proof at all, even when reinforced by the fact that no angling record exists of the true bonefish being caught on the hook in any waters north of Biscayne Bay, Florida, a circumstance which is unusual when we consider that the east and west coasts of that State are annually visited by thousands of eager, intelligent and observant anglers, a few only of whom have caught this fish, and only in Biscayne Bay. They at once classed it as the fiercest fighter for its size in southern seas, and in this connection it must be noticed that the presence of game qualities in a fish is an assurance that its habits, habitat and physical markings will be studied by the angler who catches it, particularly when the fish is the first of its species that has fallen to his rod. With this fact before me, I am impelled to question the accuracy of the recorded northern range of the bonefish.

"But little is known of the angling traits of $A$. vulpes, although for several years past there has been great interest shown by anglers, in Florida, as to its fighting qualities and habitat. In the winter of '94-'95, a large number of enthusiastic anglers gathered at Naples on 
the Gulf of Mexico, and none of them had any personal knowledge of this much-talked-about fish. It seems to have fallen to the good fortune of an intelligent and olservant, but anonymous, writer to herald its superiority as a game fish. He wrote:

" For the past two winters, skillful fishermen among the Northern tourists, whom I knew personally or by reputation among mutual acquaintances, have been reporting with enthusiasm the discovery in Biscayne Bay of a new game-fish which is to surpass all the other ministers to piscatorial amusements. Some went so far as to say that the Tarpon is superseded as the king of fish; as expressed by one of them, who kills annually more than fifty tarpon, 'the tarpon is not in it.'

"Being inflamed by this story of the "new planet which swims within our ken,' I took a day at Biscayne Bay, returning to-night with three of the fish.

"The Bone-fish is new to me, and, so far as I can ascertain, is taken only in Florida, at Biscayne Bay and probably southward, though as to this I have no information. A guide did tell me that it is abundant in Cuba, where it is called what he pronounced leetha, or 'the swift.'

"The three specimens taken by my friend and myself, weighed (by estimations) six, five, and four pounds respectively. The bait is surf-bugs or sand-fleas, such as are used occasionally on the Jersey coast for sheepshead when that capricious fish declines his ordinary diet. They are taken in the same manner as there, by a scoop or net, or digging with the fingers, when the breaker recedes.

"The cast - two hooks, No. 7 O'Shaughnessy, above a small sinker and one foot apart - is made seventy feet or more from the boat, along a sandbar, on the rising tide. Three inches of water on the top of the bar are preferable, but the day I was fishing was at the tail end of a 'norther,' and I had to fish the shallow channels next the bar in three or four feet of water. The strike is a slow nibble or mumble, and it requires quickness and discretion to hook the fish. But when he is hooked, which is by a sudden slight motion of the wrist, the aspect of the contest changes from apathy to fierce activity. There is a lightning-like run of perhaps one hundred yards, then a return nearly to the boat, then an equally extensive run which cannot be checked, and then zigzag rushes and flourishes here, there, and everywhere until the fish is exhausted, and finally lifted into the boat 
by the line - no gaffing or other ceremonial; there is no leaping or jumping - all honest fishwork, below the surface and in his own element. I have taken small-mouth bass of similar weight and length, and brook trout not so large, and they simply do not compare with this fighter. There is no fish (of his class) which can be named with him. They are not in the same category unless it be in beauty. It would be like comparing snipe shooting with hunting deer.

"This fish is round-barrelled and heavy for its size. It has a pointed snout, with mouth under its nose like the hake, which is most erroneously called by New York fishermen kingfish. Its head has no scales, but is covered by a shining silver epidermis. The eye is black and quite large. The scales are large and are closely set on the body, and look like a network of closely compacted silver rings. A most gleaming fish.

"The first question asked as to a fish is: 'Is it good to eat?' This one is very good to eat. It has the disadvantage of all the fish for the table - the shad - of being full of bones, but the flesh in the intervals is delicious. I like it better than the pompano, and next after the shad."

\section{NOTE BY GREGG.}

Mr. Harris agrees with the scientific men in his classification, and has illustration of the "Albula vulpes" as the Bonefish of Biscayne Bay, and of the "Elops saurus" as the Lady-fish Bonefish of the fishermen and sportsmen of Florida. His article on the subject, is, in my opinion, the best one ever written, and is here copied with his kind permission. His work, Vol. I, is a large folio, containing, in addition to the text, forty colored illustrations, and ninety-three engravings of fishes.

He was my guest during all of April, and part of May last, on a cruise from Miami to Key West, which he continued from Key West north to Ponce Park (Mosquito Inlet), thus visiting nearly all the best fishing grounds of the East Coast, a distance of 422 statute miles. While at Key West I happened to catch, within a few minutes, one each of the two fishes in question, both of which we took aboard and carefully examined and compared with Bulletin 47, the result confirming all that he had said on the subject in his "Fishes of North America."

He has kindly written the following affirmation of his previous statements and conclusion, for insertion herein, viz :

"August 20, 1902. Since writing the above (in 'Fishes of North America') I have encountered the bone-fish (Albula z'ulpes) in the waters of the Florida Keys, and accord them all the game qualities allotted by angling writers and rod users; certainly, for size, they are the ablest fighters of the seas. I had heard of them, years ago, from hundreds of frshing tourists on the UVestern Coast of Florida, where they were not found, and where they were known as the bone-fish of Biscayne Bay.

" $\Lambda$ fish (Elops saurus), of another family, was called on the West Coast the 
'lady' or bony-fish, it being almost ubiquitous on both the East and West coasts; the name 'bone-fish' was never applied by anglers to any fish other than that of Biscayne Bay, Fla. All of these three names were assigned respectively to both of the above-named species in the official publications of the United States Fish Commission.

"This confusing popular nomenclature, authoritatively endorsed by scientists, led me temporarily last spring to confuse the two fishes when first taken on my rod, and I am glad to see that Jordan \& Evermann in their latest publication, 'American Food and Game Fishes,' have dropped the perplexing name of 'lady fish' which they formerly applied to Elops saurus, the fighting brother of the tarpon, leaping into the air, 'dancing on its tail,' with snout and greater portion of its body in full view, every action showing it to be of the same noble stock as the 'Silver King.'

"Per contra, Albula r'ulpes, the true bone-fish of Biscayne Bay, never leaps, fights straight away in long desperate surges, being apparently ignorant of other devices of escape, and is seldom caught in deep water, in which the 'lady-fish' habitually feeds. The different actions of these two fishes, when on a restraining line, indicate, from an angling standpoint, no kindred of species; in fact, the leaper is close kin to the tarpon, and the surger belongs to a different family (Albulidi) the lady-fishes, of which but one species is known, the one here considered.

"Again, the question of range of these two fishes, as stated by Jordan \& Ever. mann, still continues to confuse the angler. The bone-fish of Biscayne Bay, according to the consensus of opinion and experience among rod fishermen, has never been seen, or caught, north of Indian River, Florida, albeit the ichthyologists state that they range as far north as Long Island. The migrations of the "lady-fish" (Elops), so called by anglers, are confined by the same authorities to the seas south of the Carolinas and the Gulf of Carolina, while one straggler, at least, roamed north to the south side of Staten Island, N. Y. 


\section{RES U M E.}

In conclusion, I will say that inasmuch as there has certainly been two different fishes in Florida called Bonefish, and two different ones called Ladyfish, two so called by the residents and sportsmen, and the other two so called by the scientific men, it was natural that the confusion of names should arise. Although the scientific men have been technically right all the time, some of them have, in my opinion, added to the confusion in some of the ranges of habitat and edible qualities. For instance, Gunther says of "Albula" (the Bonefish of Biscayne Bay and the Keys): "It grows to a length of two to three feet, and not valued as food." Now, no bonefish has been caught in Biscayne Bay and among the Keys which has weighed over $10 \mathrm{I} / 2$ pounds, or measured over two feet long, but he may reach a length of three feet in the West Indian, or other tropical seas; and the fish is in Florida, Cuba, and Nassau considered a fairly edible one. I class him B, but "tastes differ," and many people consider him A No. 1, and A. He says of the "Elops saurus," "It exceeds a length of three feet and is not esteemed as food," which is, I think, correct.

Jordan \& Gilbert, page 258, say of the Albula aulpes: "Cape Cod to Southern California and East Indies, abundant in tropical seas." Only an occasional straggler has been found north of Biscayne Bay, a few in Lake Worth, and occasionally one caught in net by market fishermen near Indian River Inlet.

H. M. Smith, in "Annotated List of Fishes known to inhabit the Woods Hole Region," says, under heading "Albula zulpes": "Very rare, reported by Prof. Baird in 1871, and since observed only once or twice. None seen for many years.",

They say, "Not much valued as food, but beautiful and gamy," which, in my opinion, is incorrect as to edible qualities. They say of Elops saurus, "A handsome fish, not rare on our Atlantic coast." Which I think correct, if confined to southern part of the coast, say from Virginia south.

Jordan \& Evermann say of Albula vulpes: "Length 18 inches to 3 feet, and a beautiful and active fish, in most places little valued as food, but in some regions, as Key West, highly appreciated." 
An error as to edible qualities. They cite two authorities, who call the fish "Banana Fish," and they put it in as one of their common names.

Now, the Bone-fish of Biscayne Bay and the Keys does not in the least resemble a banana in shape, but the Lady-fish Bone-fish of Florida does decidedly resemble a banana. Where, or how, did the Albula vulpes of the books get the name of Banana Fish? They say, "Ranging northward on our coasts to San Diego and Long Island." See H. M. Smith, as quoted, as to latter point.

They say of Elups saurus: "Tropical seas, abundant and very widely distributed, common in America, north to Carolina and the Gulf of California, straying on the Atlantic coast to Long Island." Which I believe to be correct. They say nothing of its edible qualities.

G. Brown Cioode, page 410 , as quoted. He very evidently classed the Iady-fish of Florida in the Albula family. He says Henshall found it in the Indian River Inlet, etc.

I am inclined to think Doctor Henshall simply wrote of the "Lady-fish" of Florida, and had nothing to do with Goode's description. He speaks of the fish he caught as a "slender fish," so surely" was writing of the so-called Lady-fish of Florida.

Goode says : "At the Bermudas, large schools are taken, and it is there considered a most excellent food fish. From personal observation I can testify that its reputation is by no means a false one." After quoting from Henshall, he says: "On account of its beautiful color it sells readily, but is not esteemed as a table fish."

U. S. Fish Commission Report of 1895 , in Check List by J. \& E. Elopdx: "Common north to the Gulf of California and to the Long Island Sound on the Atlantic coast." See H. M. Smith as to this statement.

Of Albula t'ulpes, they say: "Tropical seas, varying northward to San Diego and Long Island."

In same work is quotation from list of J. F. McCormick, "Bonefish. Albula z'ulpes." Nothing to indicate which Bonefish he meant. I presume, the one of Biscayne Bay and the Keys.

U. S. Fish Commission Report, 1896, page 240. Evermann \& Kendall say, under heading Flops saumus: "Observed at Fort 
Pierce, and at mouth of St. Lucie River. Known to some fishermen as Ladyfish. Frequently taken in seines. Examples from Fort Pierce preserved." The above is, of course, the Ladyfish Bonefish of Florida.

The Albula aulpes is not reported in the list of Indian River Fishes, showing plainly that Mr. Goode was mistaken in saying that Doctor Henshall caught them there.

Same work, "The Fish and Fisheries of the Coastal Waters of Florida," John J. Brice, reference at foot page 285: "There are many other species of fishes found at Key West which are used to a greater or less extent as food. Among them are the Bonefish (Albula vulpes), Ten-pounder (Elops sulurus), Barracuda, etc." All consistent with other scientists.

U. S. Fish Commission Bulletin, 1897: "Annotated List of Fishes known to inhabit the Woods Hole Region, by Hugh M. Smith." Pages 90, 91: "Elops saurus, Ten Pounder ; Big-eyed Herring. Common in fall, none appearing before October, etc., " $\mathrm{Al}$ bula aulpes" (Linnæus), "Ladyfish ; Bonefish." "Very rare. Reported by Prof. Baird in 1871, and since observed only once or twice. None seen for many years." All consistent with other scientists.

U. S. Fish Commission Report, 1899. "Check List of the Fishes of Florida, Evermann \& Kendall." "Albulu r'ulpes and Elops saurus." All consistent.

Mr. Wm. C. Harris. "The Fishes of North America." "Albulu zulpes and Elops saurus," is consistent with the scientists.

Fishes of Porto Rico. U. S. Fish Commission, 1900, B. W. Evermann, has "Elops saurus" (the Florida Ladyfish Bonefish); all consistent in every way. "Albula zulpes" (the Bonefish of Biscayne Bay and the Keys); all consistent except the range to Massachusetts. See H. M. Smith, quoted above.

I trust the alove quotations may fully establish the fact that the "Albula rulpes" of the text books is the "Bonefish of Biscayne Bay and the Keys," and that the "Elops saurus" of the text books is the "Iadyfish Bonefish" of both coasts of Florida, so called by the sportsmen and market fishermen of the State. 


\section{N D E X.}

Atlantic Beach, . . . . 179

Ada B., Sloop, . . . . . . 211

Arch Creek, . . . . . . . 205

Artificial Flies, . . . . . . 213

Aquarium, . . . . . . 220

American Anglers' Book, . . . 3,4

Al Fresco, . . . . . . . . 3

American Game Fishes, . . 4

Asten, Commodore, . . . . . 5

America, . . . . 9

American Fishes (Goode), 13, 14, 44

American Angler, . . . . . 4

Alewife, . . . . . . 34, 158

American Shad, . . . . . 35

Armes, Mr., . $\quad$. . . . . 53

Allen, Mr., . . . . . . . 55

Amber Jack, . 60, 61, 62, 158, 160

Angel-fish, 130, 131, 132, 132 $\frac{1}{2}, 133,222$

Angel-fish, Black, . . . . . 131

Angelichthys Ciliaris, . . . . 132

Angelichthys Isabelita, . . . . 133

American Sole, . . . . 148, 149

Angel Fish Creek, . . . 177, 222

Arch Creek, . . . . . . . 205

Arsenecker Keys, . . 213, 225

Angelfish Creek, Little, . . . 222

Angelfish Key, . . . . . . 222

Annette Key, . . . . . . . 238

Aetobatus Narinari, . . . . . 26

Alligator Lighthouse, $8,87,230,231$

Alligator Gar, . . . . . . . 27

Ahlia Egmontis, . . . . . . 30

Anisotremus Virginicus, . . . 106

Achirus Lineatus, . . . . . 148

Achirus Inscriptus, . . . . . 148

Achirus Fasciatus . . . . . 149

Artificial Baits, . . . . 158, 159

Alligator Story, . . . . . . 191

Alibi Story, . . . . . . . 226

Anclote River, . . . . . 8, 84

Alosa Sapidissima, . . . . . 35

Anchovy, . . . . . 38, 158

Archosargus Unimaculatis, . . 114

Archosargus Probatocephalus, . 115

Ankona, . . . . . . . . 194

Aquarium, . . . . . . 8

Audubon, . . . . . . . . 15

Albula Vulpes, . . . . . . 34
PAGE.

39

39

52

79

52

146

Barracuda, . . . $8,45,158,160$

Bay of Florida, . . . . . 8

Bay St. Louis, . . . . 8

Baits, . . . . 32, 157, 158

Banana-fish, . . . . . . 34

Branch Herring, . . . . . . 34

Barracuda, Great, . . . . . 45

Bars, . . . . . . . 177

Bannerfish, . . . . . 52

Black Bass, Large-mouth, . . 72, 74

Bayou Bass, . . . . . . . 72

Black Grouper, . . . . 78,79

Bacalao, . . . . . . . . 79

Black Jewfish . . . . . . 79

Bairdiella Chrysura, . . . . 97

Black Grunt, . . . . . . 99

Bastard Margaret, . . . 99, 152

Bathystoma Rimator, . . . 103

Bathystoma Striatum, . . . 105

Bathystoma Aurolineatum, . . 105

Bajonado, . . . . . . . 110

Bass, . . . . . . . . 118

Black Drum, . . . . . . . 123

Black Angel-fish, . . . . . 131

Balistes Carolinensis, . . . . 133

Balistes Vetula, . . . . . . 134

Bladder-fish, . . . . . . 141

Black Creek, . . . . . . . 212

Bat-fish, . . . . . . 141, 150

Barnes Sound, . . . . 217,225

Black Sea Bass, . . . . . . 150

Black Water Bay, . . . . . 225

Black-fish, . . . . . . 150, 156

Black Will, . . . . . . 150

Black Harry, . . . . . . 150

Bravo, Capt., . . . . . 56-59

Black Bass, . . $72,73,74,75$

Ball Brothers, Brainerd and Charles, . . . 2 212, 219

Bass line, . . . . . . . 161

"Bay Way," from Key West to 
Brass Box Swivels, 161

Bahia Honda Key, . . . 233, 234

Banana River, . . . . . . 191

Bahia Honda Harbor and Channels, . . . . . 234, 238

Banana Creek, . . . . . . 191

Beverly, Fred, . . . . . . 3

Benson, Mr., . . . . . . . 5

Bears Cut, . 7, 34, 177, 209, 214, 216

Behring Sea, . . . . . . . 10

Brevoortia Tyrannus, . . . . 37

Brevoortia Tyrannus Patronus, . 37

Becuna,

45

Breakers, The, . . . 55, 200, 201

Bream, . . . . . 72, 113, 152

Bream (salt water), $113,114,121,152$

Bermuda Chub, . . . . 117, 219

Besougas, . . . . 112, 120, 151

Biscayne Bay, $6,7,10,39,46,50,61$, $82,93,177,205,221$

Biloxi,

Birds of America,

15

Billfish,

27,39

Big-eyed Herring, . . . . 33, 34

Big-eyed Scad, . . . . . . 62

Biajaiba, . . . . . . . . 94

Brickle, Capt. Charles, . . . 211

Biscayne, Key, . . . . . . 216

Big Spanish Key and Channel, . 234

Bird Key and Channel, . . . 235

Big Coppit Key and Channel, . 235

Big Pine Key and Channel, 234, 238

British Museum,

14,65

Birch Lake, Minn.

74

Borden, Edward P.,

$5,7,8,199,202,220,231$

Brookings, H. G.,

Bonnet-head Shark, .

Bonedog,

Boca Grand Pass, .

Bonefish,

Bond Iron Boat,

Bony-fish,

Bonito,

Boohoo,

Brochet de Mer, . . . . . 69, 253

Brown Hackle Fly, . . . . . 73

Bonaci de Piedra,. . . . . . 78

Bonaci Arara, . . . . . . . 78

Boar Grunt, . . . . . . . 100

Blower, . . . . . . . 138

Blow-fish, . . . . . . . 139

Brook Trout, . . . . . . . 74

Block-tin Squids, . . . . . 158

Broad Creek, . . . . 177, 221, 222

Boca Chica,

$177,221,222$

Bonefish Banks, The, . . . . 224

Baggy,
Boot Key and Channel PAGE.

Boca Chica Key and Channel, 235

Bollioes (see Balaos).

Bluefish, 4, 7, 10, 64, 68, 68 $\frac{1}{2}, 158,159$

Bulletin 47, . . . 11, 64

Bulletins and Reports of United States Fish Commission, .9, 11, $12,13,14,59,60,86,116,121$, $140,152,154$

Bulletin No. 16, . . . . . . 11

Bugfish, . . . . . . . 37

Blue-back Mullet, . . . . . 43

Blue Runner, . . . . . . . 63

Blunt-nosed Shiner, . . . . . 67

Blue Bream, . . . . . . . 71

Blue Sunfish, . . . . . . . 71

Blue-gill, . . . . . . . . 71

Blue Bonito, . . . . . . . 49

Bull Red-fish, . . . . . . . 118

Bullon, . . . . . . . . . 129

Blue Parrot-fish, . . . 127,129

Burr-fish, . . . . . . . 140

Blue Hole Cut, . . . . 177, 193

Budd Key, . . . . . . . . 238

Buel Spoon, . . . . . . . 31

Clarke, S. C., . . • . 3, 4, 5, 186

Camp Life in Florida, . . . . 3

Camping and Cruising in Florida, 3

Cape Florida, . . . 8, 210, 216, 217

Cape Florida Light, . . . . . 218

Cape Florida Pass, . . . . . 177

Cresar's Creek, . . . . 8, 177, 221

Charlotte Harbor, . . 8, 81, 32, 44

Cape Sable, . . . . . . 8, 233

Caloosa River, . . . . . . 8, 32

California, Gulf of, . . . . 10

Cavalles, $\quad 10,12,44,50,63,64,66$

Canal, Lake Worth to Biscayne Bay, 204

Catfishes, . . . . . . 12,64

Carps, . . . . . . . 12,64

Cannibals, . . . . . . 217

Catalogue of the New York Aquarium, The, . . . . . 13

Carcharias Littoralis, . . . . 17

Card Sound, . . . . 217, 222

Clam Cracker, . . . . . . 26

Captiva Pass, . . . . . . . 32

Crawfish, . 19, 66, 156, 157, 158, 217

Cameron, Mr., . . . . . . 53

Carolina coast, . . . . . 55

Caranx Crysos, . . . . . . 63

Caranx Llippos, . . . . . . 66

Crab, . . . . 66, 156

Caranx Bartholomai, . . . . 68

Crab Eater, . . . . . . . 69

Card Point, . . . . . . . 213

225, 226 Chænobryttus Gulosus, . . . 70 
PAGE.

Calico Phantom Minnows, . . . 158

Cabra Mora, . . . . . . . 75

Cabrilla,

Channel Key, . . . . . . 238

Cabrilla de Raizero, . . . . 78

Cabellerote, . . . . . . . 85

Crane Key, . . . . . . . . 238

Caji, . . . . . . . 88

Cæsar, . . . . . . . . 103

Catalineta, . . . . . . . 106

Calamus Calamus, . . . . . 110

Charts U. S. Geodetic Survey, . 213

Calamus Proridens, . . . . . 110

Calamus Bajonado, . . . . . 110

Calamus Penna, . . . . . . 111

Calamus Arctifrons, . . . . . 111

Channel Bass, . . . . . . . 118

Carolina Whiting, . . . . . 122

Capitaine, . . . . . . . 126

Clamagore, . . . . . . . . 129

Chretodipterus Faber, . . . . 130

Chapin,

136,136

Crayfish, $156,157,214$

Crappies, . . . . . . . 73

Calda Channel, . . . . . . 244

Clams for Bait, . . . . 158, 158

Crawl Key and Channel, . . . 234

Charleston News and Courier Shark Stories, . . . . 20, 21, 22

Cedar Keys, : . : . . 3, 10

Clear Water, . . . . . . . 8

Clear Water Harbor, . . . . 8, 18

Crevalle (see Cavalle).

Check List of Fishes of Florida, 11, 219

Check List of Bulletin 47, . . 11, 12

Cefalo, . . . . . . . . 42

Cero, . . . . . . . 50

Cherna Americana, . . . . . 76

Cherna de Vivero, . . . . . 76

Cherna Criolla, . . . . . . 77

Creole Fish, . . . . . . . 83

Cephalacanthus Volitans, . . 141

Centropomus Undecimalis, . . 253

Centropristes Striatus, . . . 150

Chicarro, . . . . . . . 62

Cibi Amarillo,. . . . . . . 68

Chirivita, . . . . . . . . 131

City Point, . . . . . . . . 190

City of Key West, Steamer, . . 57

Connor, W. E., ' · 5

Cocoanut Grove, $8,210,212,213,214$

Common Skate, . . . . . . 24

Common Sea Cat, . . . . 28

Conger Eel, . . . . . . . 29

Common Shad, . . . . . . 35

Common American Sea-horse, 41

Common Mullet, . . . . . . 42

Conchs, . . $61,66,105,215,217$
Conch Shells,

PAGE.

Cobbler,

Common Pompano, . . . 54, 55

Cory, Mr., . . . . . . . . 55

Cobb, John N., . . . . . 59

Coronado, . . . . . . 60, 187

Coginera, . . . . . . . . 62

Cobia, . . . . . . . . . 69

Copper-nosed Bream, . . . . 71

Common Sunfish, . . . . . 72

Chopa, . . . . . . . 84

Chofa, . . . . . . . . . 81

Common Grunt, . . . . . . 101

Common Scup, . . . . . 108

Chopa Spina, . . . . . 113, 152

Chopa Blanca, . . . . . . 117

Common Weakfish, . . . . . 117

Croaker, . . . . . . 120,121

Chonch Keys, . . . . . . . 233

Corvina, . . . . . . . 121

Common Drum, . . . . . . 124

Common Angel-fish, . . . . 133

Cochino, . . . . . . . 134

Cow-fish, . . . . . . . 137

Coldweather, effect of, . . . 245

Common Burr-fish, . . . . . 140

Common Flatfish, . . . . : 147

Common Sea Crab, . . . . 156

Corbett's Docks, . . . . . 44, 180

Costello, Alfred, . . . . . . 211

Cod Line, . . . . . . . . 161

Cork Floats, . . . . 162, 172

Courtney, . . . . . . . 190

Continental Hotel, . . . . . 239

Coon Oysters, . . . . . . . 180

Coronado Beach, . . . . . . 187

Cocoa, . . . . . . . 190

Cow Key and Channel, . . . 235

Chuckaluska, . . . . . . 8

Chubs, . . . . . . . 10,117

Crustace, . . . . . . . 33, 40

Cutlass Fish, . . . . . . . 51

Chub (salt water), . . . . 117

Cuban Fish, . . . . . . . 121

Cucuyo, . . . . . . . 133

Cuckold, . . . . . . . 137

Cuttle Fish, . . . . . . . 156

Cut Mullets, . . . . . . 158

Cut Sailor's Choice, . . . . . 158

Cudjoes Key and Channel, . 235, 238

Cut Kingfish， . . . . . . . 158

Cutler, . . . . . . . . 210

Cynoscion Regalis, . . . . . 117

Cynoscion Nebulosus, . . . . 118

Chylomycterus Schæepfi, . . . 140

Cyprinodon, . . . . . . . 142

Cryptotomus Beryllinus, . . . 127 
PAGE.

$5,6,182$

Daytona,

Dasyatis Say,

Darwinian Theory,

Dark Green Parrot Fish,

Deer Island and Chamnel,

Desolation Key,

Diehl, Dr.

Dimmick's Hotel,

Disston City,

Diplectrum Formosum,

Diplodus Holbrookii

Diodon Hystrix

Diablo,

Dogfish,

Dogfish, Picked,

Dollar-fish,

Dollardee,

Dolly Varden Grouper,

Dormeur,

Dog Key,

Doctor Perrine,

Duneden,

Drum,

Drumfish,

Drunken-fish,

Duck Lake, Mich.

Ducks

Duck Key,

Elagatis Bipinnulatus,

East Coast Railway Steamer "Santa Lucia,"

Egg-shaped Sinkers, .

Eau Galle,

East Rockland Key.

East Crawfish Key, • • • • • 236

Eagle Nest Key, . . . . . . 238

East Coast, . $3,4,5,6,7,10,11,91$

East Coast Hotel List, . . . . 177

El Capitaine, . . . . . . . 126

East Coast Railway, . . . . . 177

Eddie Pent, . . . . . . 213

Enterprise, . . . . . . . 3, 5

Evermann, Barton Warren, 9, 11, 13

Echeneis Naucrates, . . . . 143

Eden, . . . . . . . 59, 194

Everglades,

English Lookout, . . . . . 8

Ellwife, . . . . . . . . 34

Epinephelus Adscensionis, . . . 75

Epinephelus Drummond-Hayi, . 75

Epinephelus Maculosus, . . . 75

Epinephelıs Morio, . . . . 76

Epinephelus Striatus, . . . . 77

Erizo, . . . . . . 139

English Pilchard, * : • • 155

Elliots Key, . . . . . 220, 221
PAGE.

Elops Saurus, . . . . . . 33

Exoccetus Volitans, . . . . 40

Eupomotis Gibbosus, . . . 72

Eques Lanceolatus, . . . . . 125

European Languages, . . . . 65

Encyclopredia Britannica, . . . 65

Fatback, . . . . . . 37, 68

Flasher, . . . . . . . 84

Flagler, Mr. H. M., . . 57, 58, 216

Frankfort Reel, B.C. Milam \& Son, Frankfort, Ky., . . . . 161

Faustina, . . . . . . . 190

Flatfish, Common, . . . . 147

Fairy Land, . . . . . . 190

Fernandina, . . . . . . 3, 6

Felichthys Marinus, . . . . 29

French Grunt, • . . . . . 102

Flemmings Key, . . . . . . 238

French Names of Fishes, . . . 13

Fish and Fishing, . . . . . 3

Finny Crabs, . . . . . . 236

Fishing in American Waters, . 3

Fishes of North and Middle A merica, a Descriptive Catalogue of the Species of Fish-like Vertebrates found in the waters of North America, North of the Isthmus of Panama, The . 11

Fishes of Porto Rico, . . . . 12

File Fish, . . . . . . . . 135

Fishes of North America (Harris), 65

Fishery Congress, . . . . . 9

Fishing Localities, . . . . . 177

Fiddler Crabs, . . . . . 33, 158

Frigate Mackerel, . . . . . 49

Fishing Tackle, . . . . 160-175

Forester, Frank, . . . . . . 3, 13

Florida, . . . . . 3, 6, 9, 10,31

Forest and Stream, . . . . . 3,4

Fort Meyers, . . . . . . . 8, 31

Florida, Bay of (Great Florida Bay), . . . . . . 231

Fort Pierce Cut, . . . . 177,193

Floats, Cork, . . . . . 162, 172

Florida Cat, . . . . . . 28

Fort Capron, . . . . . . . 193

Fodiator Acutus, . . . . . . 41

Fowey Rock Light, 51, 52, 60, 61, 68, 218

Fool Fish, . . . . . . 135

Fort Lauderdale, . . . . . . 205

Flounders, . . . 145, 146, 147, 149

Florida Food, . . . . . . 44

Fort Pierce, . . . . . . . 194

Flounder, Spotted, . . . . 147

Formula of Jordan \& Evermann, 14, 15

Fundulus Heteroclitus, . . . . 154

Flying-fish, . . . . . 4 40,41 
PAGE.

Flying-fish, Sharp-nosed,

Flying Robin,

41

Gardner, Capt. John, 4, 5, 7, 8, 31, $44,45,55,61,62,87,105,116$

Gata (Shark), 17

Gar (fresh water), . . . . . 27

Gar, Short-nosed, . . . . . 27

Gaff, Topsail Cat, . . . . . 29

Grande Ecaille, . . . . . . 31

Gaspereau, . . . . . . . 34

Galliwasp, . . . . . . 38

Gag, . . . . . . . . 79

Garrupa Nigrita, . . . . . 79

Gray Snapper, . . . . . 85, 87

Gray Grunt, . . . . . . . 98

Grass Porgy, . . . . . . . 111

Garfield Cut, . . . . . 177, 193

Galeichthys or Hexanematichthys

Felis, ·
Grains, ·

Grain Handles, . . . . . 214

Grasshoppers (bait), . . . . 72

Grassy Key and Channel, . . . 234

Gregg, W. H., 5

Gregg, WV. H., Jr., . . . . . 5

Great Gar, . . . . . 27

George, Mr., . . . . . . 31,32

Great Barracuda, . . . . . 45

Great Pompano, . . . . . . 59

Great Amber-fish, . . . . . 60

Green Bass, . . . . . . . 72

Greek Language, . . . . . 65

Gerres Olisthostomus, . . . 116

Green Parrot-fish, . . . 127, 129

Green Lake, Wis., . . . . . 74

Georgiana, . . . . . . 190

Great Florida Reefs, 207, 216, 218

Great Bay of Florida, 226, 231, 233, 244

Geodetic Survey, U. S., . . . 213

Geigers Key and Channel, . . . 235

Gilbert's Bar, 7, 50, 55, 177, 194, 195

Ginglymostoma Cirratum, . . . 17

Gill Nets, . . . . . 202, 205

Grits, . . . . . . . . 43

Grits and Grunts, . . 104, 105

GriffinBrothers, IValter and Jefferson, 242

Goode, G. Browne, . . 4, 13, 14, 44

Groupers, $12,64,74 \frac{1}{2}, 75,76,77$,

$78,79,158,159$

Ground Spearing,

38

Goat Fish, . . . . . . 39, 82, 129

Goat-fish, Yellow, . . . . 129

Goggle-eye Runner, . . . . . 62

Goggler, . . . . . . . . 62

Goggle-eye Jack, . . . . . . 62

Gogrle-eye, . . . . . 70

Goode \& Beane, . . . . . 116
PAGE.

Gogebig, Lake, Wis., . . . . 74

Goody, . . . . . 120, 151

Globe Fish, . . . . . 139,141

Gobies, . . . . . . 142, 158

Gobius Stigmaticus, . . . . . 142

Gobius encœeomus, . . . . . 142

G. boleosoma, . . . . . . 148

Gulf of Mexico, . . . . $8,10,35$

Grunts, 10, 12, 98, 99, 100, 101,

$102,103,105,158$

Grunt Story, . . . . . 104, 105

Gulf of California, . . . . . 10

Gulf Menhaden, . . . . . 37

Guardfish, . . . . . . . 39

Guebucu, . . . . . . . 52

Guasa, . . . . . . . . 80

Grunters, . . . . . . 98-105

Guapena, . . . . . . 125

Guacamaia, . . . . . . 129

Günther, Albert C. L. G., . 14, 65

Gulf Flounder, . 146

Guides for Rods, . . . . 161, 174

Gulf-fish, . . . . . . . 121

Gulf Coast, . . . . . . 10

Gut Snood, . . . . . . 33, 55

Gymnosarda Alleterata, . . . 49

Hallock, Charles, . . . . . 3, 14

Haldeman, IV. N., . . . . . 4

Halifax River, . . . . 4, 149, 182

Hawley, Frederick, . . . . . 5

Hays, Charles M., . . . . . 5

Haulovers, The, . . . . 6, 7, 189

Hammer-headed Shark, . . . 16

Hard Tail Runner, . . . . . 63

Hamlet, . . . 30, 77

Hremulon Album, . . . . 98, 155

Hæmulon Macrostomum, . . 98

Hæmulon, . . . . . 98-102, 153

Hæmulon Bonariense, . . . . 99

Hæmulon Parra, . . . . . 99, 153

Hæmulon Sciurus, . . . . . 100

Hæmulon Plumieri, . . . . . 101

Hremulon Flavolineatum, . . 102

Harpe Rufa, . . . . . . . 126

Hakes, . . . . . . . , 144

Hake, Silver, . . . . . . . 144

Haunabill, . . . . . . . . 150

H. acutum, . . . . . . 153

H. serratum, . . . . . . . 153

H. macrostomum, . . . . 154

H. rimator, . . . . . . . 154

Harris, W. C., . . . . . . 65

Hall's Lines, . . . . . . . 32, 161

Harrison's blued ringed Sproat Hooks, . . . . . 161, 173

Haulover Canal (see Haulover).

Hawkes Channel,. . . . . 207 


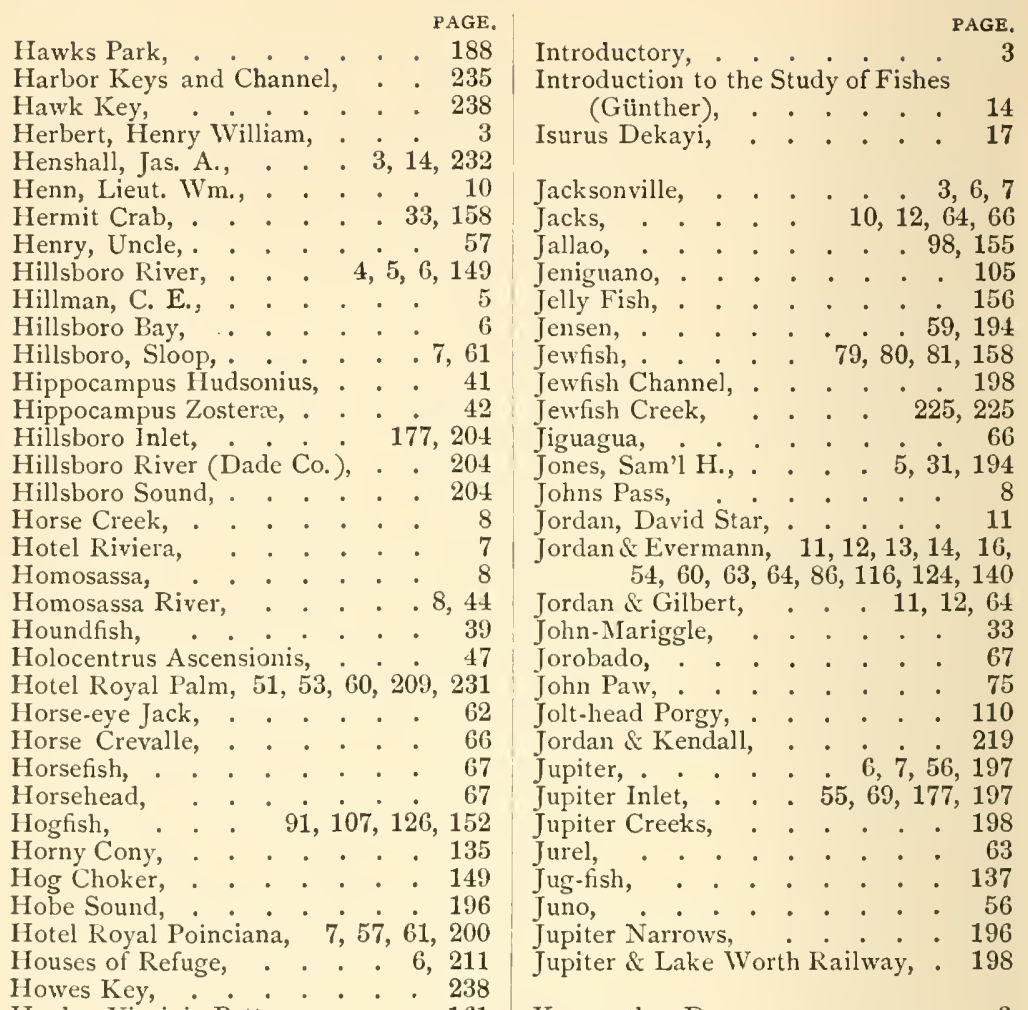

Hooks, Virginia Pattern, . . . 161

Hooks, . . . . . . . . 161

Huling, Mr. Geo. D., . . . 52,53

Huxley, Thos. H., . . . . . 157

Hypoluxo, . . . . . . . . 200

Hybridism, . . . . . . . 65

Isabelita, . . . . . . . 132

Indian River, 4, 6, 7, 10, 35, 44, $45,54,55,116,190,193,244,246$

Indian River Inlet, $7,10,31,50$,

$55,177,194$

Indian Key, . . 8, 19, 87, 230, 245

Istiophorus Nigricans, . . . . 52

Indian River Permit, . 55, 59

Irish Pompano, . . . . 116, 116

Ink Fish, . . . . . . . . 156

Indianola, . . . . . . . . 190

Indian River Narrows, . . . . 192

Indian Creek, . . . . 206

Inn, The (Lake Worth), . . 55, 201

Inside Route from Key West to Bahia Ionde,
Kenworthy, Dr., · $\dot{0}$ Key $\dot{18}$, 19, 50 , $54,93,104,105,213,217$, $236,237,242,244$

Key West Channel, . . . . . 235 Kendall, W. C., . . . . . . 59 Key West Permit, . . . . 54,60

Key West Sailor's Choice, . • . 153

Key Largo, · . 177, 222, 222, 226

Key Biscayne, . . . . . 216

Keys, The, 6, 9, 13, 34, 64, 116,

213,217

Kingfish, . . . 7, 10, 50, 158, 159

Kingfish (small), . . . . . 122

Knight Key and Channel, . 234, 244

Knock Down Key and Channel, . 235

Kyphosus Sectatrix, . . . . . 117

Lake Worth Inlet, • . . . 201

Lake Worth, . 6, 7, 10, 50, 55, 56, 87

Lake Worth Creek, . . . . 6

Lake Worth Pier, . . . . 87, 201

Lake Poinset, . . . . . . 7 
P.AGE.

Large-Mouth Bass,

Lancelets, . . . . . . . 13

Lake Gogebig, Mich., . . . . 74

Lake Superior, . . . . . . 75

Lampreys, . . . . 13

Lake Gogebig, Mich., . . . . 74

Lady-fish, . . . . . . 34, 126

Latin Language, . . . . . 65

Lagarto, . . . . . . . 38

Lake Worth Inlet, . . . . 55, 177

Large Permit, . . . . . . . 60

Lawyer, . . . . . . . . 85

Lane Snapper, . . . . . . 91

Lagodon Rhomboides, . . 113, 152

Lafayette, . . . . . 120,151

Lachnolaimus Maximus, . . 126

Lactophrys Tricornis, . . . . 137

La Forge, Miss, . . . . . . 53

Lactophrys Trigonus, . . . . 136

Lactophrys Triqueter, . . . . 136

Lagocephalus Lrevigatus, . . . 137

Lagocephalus Pachycephalus, . 137

Lantana, . . . . . 57, 200

Lake Minnetonka, Minn., . . 73, 74

Lemon City, . . . . . . 206

Lepisosteus Tristcechus, . . . 27

Lepisosteus Platostomus, . . . 27

Leptocephalus Conger, . . . . 29

Lepomis, . . . . . . . 71

Lepomis Pallidus, . . . . . 71

Leiostomus Xanthurus, . . 120, 151

Leather Jacket, . . . . . . 133

Leather Fish, . . . . . 131, 135

Leaders, . . . . . . 33, 55

List of Fishes, . . . 207, 208, 209

List of Fishing Tackle, . 160, 161, 162

List of Baits, . . . . . . 33, 158

List of Artificial Baits, . . 158, 159

Lillie Shippey, Sloop, . . . . 7

Little Skate, . . . . . . 24

Lisa Francesa, . . . . . . 33

Lizard Fish, . . . . . . . 38

Lisa Cabezuda, . . . . . . 42

Liza, . . . . . . . . . 43

Lisa Blanca, . . . . . . . 43

Little Tunny, . . . . . . . 49

Little-head Porgy, . . . . . 110

Little-mouth Porgy, . . . . . 111

Lija, . • . . . . . 134, 135

Ligget, John, . . . . . . 45

Linen Tarpon Line, . $. . \quad \cdot \quad . \quad . \quad 161$

Little Pine Key and Channel, . 234

Little River, . . . . . . . 205

Little Spanish Key and Channel, . 234

Little Card Sound, . . . 217, 225

Little Soldier Key, . . . . . 218

Lignum Vitæ Key, . . . . . 231

Lorillard, Jacob,
Long Key, . . . . . 8, 833

Look-Downs, . . . . . . 12,67

Lorillard, Pierre, . . . . . . 196

Long-jaws, . . . . . . 39

Lobotes Surinamensis, . . . . 84

Loro, . . . . . . . . 129

Lophogobius Cyprinoides, . . . 142

Lophopsetta Maculata, . . . . 147

Lobster, . . . . . . . 157

Lower Minnetonka Lake, . . . 73

Loxahatchie River, . . . . . 198

Long Island, . . . . . . . . 226

Lower Mattacombe Key, . . . 230

Lower Mattacombe Channels, . . 233

Lupe, James, . . . . . . . 5

Lutken, Dr., . . . . . . . 68

Lycodontis Moringa, . . . . 30

Lycodontis Funebris, . . . . 30

McFarren, Mr., . . . . . . 5

McCarty, Dick, . . . . . . 7

McCarthy, Eugene, . . . . . 14

Mandeville Bros.,. . . . . . 5

Matanzas River, . . . . . . 6

Matanzas Bridge, . . . . . . 180

Mascalonge, . . . . . . . 74

Matanzas Inlet, . . . . . 6, 6,180

Mademoiselle, . . . . . . 97

Mayport, - . . . . 7, 18, 178

Manatee, Schooner, . . . 7, 199, 231

Mammoth Spring Hotel, . . . 59

Marco, . . . . . . . 8

Mangrove Snappers, . $\quad 85,86,86 \frac{1}{2}, 87$

Mackerel Shark, . . . . . . 17

Mackerel Squid, . . . . . . 63

Manjuari, . . . . . . . . 27

Matejuelo, . . . . . . . . 47

Matajuelo Real, . . . . . 33

Macabi, . . . . . . . . 34

Malabar, . . . . . . . . 190

Manjua, . . . . . . . . 38

Macho, . . . . . . . . 42

Machuto, . . . . . . . 42

Matejuelo, . . . . . . . . . 47

Mangrove Grouper, . . . . . 78

Mackerel Phantom Minnow, . . 119

Mademoiselle, . . . . . . . 97

Margate-fish, . . . . . . 98, 155

Margaret Grunt, . . . . . 98, 155

Market Fish, . . . . . . . 155

Mayos Key and Channel, . 234, 238

Mexico, Gulf of, - . . . 8, 10, 35

Merrit, . . . . . . . . 190

Merrits Island, . . . . . . 190

Menhaden, . . . . . . 37, 158

Menhaden, Gulf, . . . . . . 37

Mero de lo Alto, . . . . . . . . . 79

Mero, . . . . . . 80 


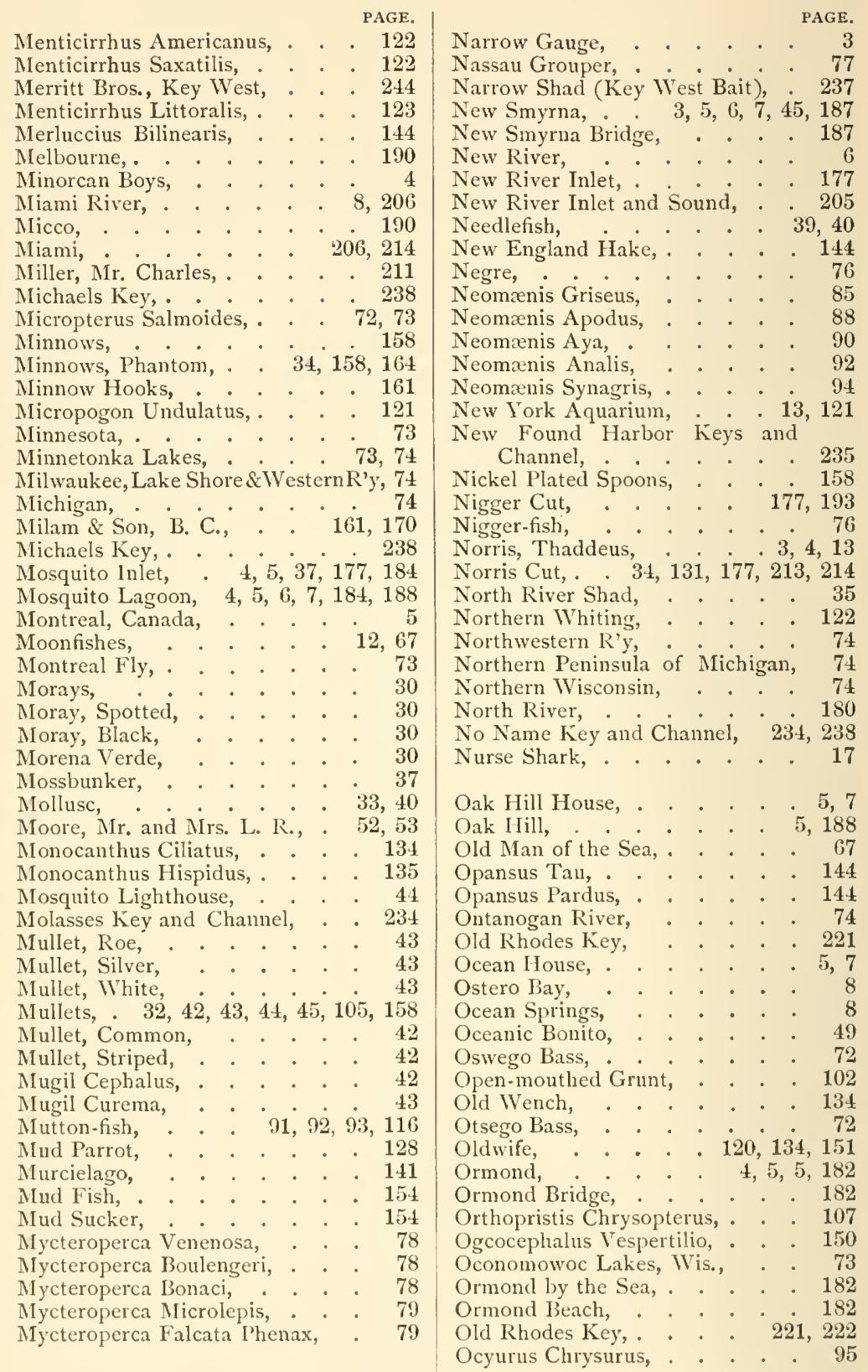


PAGE.

Oyster Crabs, . . . . . . 158

Oyster-fish,

Oysters for Bait

144,156

158

Palatka,

Prather, John G.,

Paine's Boarding House,

Pacetti, B. J.,

Pass a Grille,

Pass Christian,

Pablo Beach,

Panama,

Paines, James and Thos.,

Pampanos (see Pompano).

Palmasola Bay,

Palm Beach,

Palometa,

Parmachene Belle Fly,

Paranthias Furcifer,

Prawns,

Pargo Colorado,

Pargo Guachinango,

Pargo,

Pargo Criollo,

Pagrus Pagrus,

Parrot Fish,

Parrot Fish, Green . $04,127,128,129$

Parrot Fish, Blue,

Plate-fish,

127, 129

Paralichthys Dentatus, • • • 130

Paralichthys Lethostigmus, . . 145

Paralichthys Squamilentus, . . 146

Paralichthys Albiguttus, . . 146

Palo Alto Key, . . . . 221, 222

Phantom Ninnow, . . 34, 158, 164

Planter, . . . . . . . 227

Peninsular R. R., 3

Peabody, Geo. F., . . . . . 5

Pease "Creek, . . . . . . . 8

Pearl River, 8

Pensacola, . . . . . . . 8

Permits, . . . 12, 54, 55, 59, 60

Permit, Small, . . . . . 59

Pez Sierra, . . . . . . . 23

Pez de Espada, . . . . . . 23

Permit of Indian River, . . $\quad 55,59$

Permit of Key West, . . . . 54

Pez de Pluma, . . . . . 110, 110

Pescado Colorado, . . . . . 118

Perro Perro, . . . . . . . 126

Perro Colorado, . . . . . . 126

Pseudoscarus Guacamaia, . . . 129

Pega, . . . . . . . . 143

Pseudopleuronectes Americanus, . 147

Perch, . . . . . . . . 73

Peninsular \& Occidental Steamship Co., . . . . 206

Pent, Eddie, . . . . . . . 213
Perrine, Doctor PAGE.

Pelican Key and Channel, . . . 235

Pine Island, . . . . . . . 8

Picked Dogfish, . . . . . . 23

Pristis Pectinatus, . . . . . 23

Picuda, . . . . . . . . 45

Prieto, . . . . . . . . . 99

Pilchard, . . . . . . 155, 158

Pigfish, . . . . . . 107, 152

Pinfish, . . . . . 113, 121, 152

Prinotus Scitulus, . . . . . 141

Pilot Fish, . . . . . . . . 144

Pitts Island, . . . . . . . 202

Pickerel, . . . . . . 73, 74

Piano Wire, Steel, . . . . 50, 161

Privateer, Schooner, . . 209, 212, 219

Pigeon Key and Channel, . . . 234

Pierce, Henry J., . . . 236, 244

Pintado, . . . . . . 50

Pier, The (Lake Worth), . . 87, 201

Ponce Park, . . . 4, 5, 6, 84, 184

Port Tampa, . . . . . . 8

Poinset, Lake, . . . . . 7

Porgies, 10, 12, 108, 109, 110,

$111,112,151,158$

Porkfish, . . . . 10, 106, 106.

Pomolobus Pseudoharengus, . . 34

Potomac Shad, . . . . . . 35

Pogy, . . . . . . . . 37

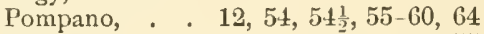

Pompano, Round, . . . . . 55

Pompano, Irish, . . . . . . 116

Pomatomus Saltatrix, . . . . 68

Polka Dot Grouper, . . . . 75, 219

Promicrops Guttatus, . . . 80

Post-croaker, . . . . . 120, 151

Pogonias Cromis, . . . . . 124

Portugais, . . . . . . . 131

Pomacanthus Arcuatus, . . . 131

Porcupine-fish, . . . . . . 139

Porpoise, . . . . . . . . 44

Port Orange, . . . . . . . 183

Porpoise Key and Channel, . 234, 238

Punta Rassa, . . . . . . . 8

Punta Gorda, . . . . . . . 8

Pumpkin Seed, . . . . . . 72

Pudiano, . . . . . . . 126

Puffers, . . . . . 137, 138, 140

Puerco Espino, . . . . . . 139

Pumpkin Creek, . . . . 222, 223

Pyes Harbor Key and Channel, . 235

Quay, Senator,

Quays Canal, .

193

Rand, McNally \& Co., . . . . 4, 13

Ragged Keys, . . . . . . 8, 219

Rays, . . . . 12, 13, 25, 160 
PAGE.

Raja Erinacea, . . . . . . 24

Rachycentron Canadus, $\quad$. $\quad 69$

Rabirubia, . . . . 83, 84, 95, 96

Rabirubia de lo Alto, . . . 83

Rabbit.fish, . . . . . . 140

Ragged Keys Passes, . . . . 177

Ram Rod Key and Channel, . . 235

Raccoon Key, . . . . . . . 238

Red Snappers, . . . 10,90, $90 \frac{1}{2}, 91$

Red Groupers, . . . . . 10,76, $76 \frac{1}{3}$

Red Ibis Fly, . . . . . . . 73

Red Hind, . . . . . . . . 75

Red-tail Snapper, . . . . . . 94

Red-mouth Grunt, . . . . . 103

Red Porgy, . . . . . 112, 151

Red Drum, . . . . . . . . 118

Red-fish, . . . . . . . 118

Regador, . . . . . . . . 143

Remora, . . . . . . . 144

Remora Brachyptera, . . . . 144

Red Cloth as Bait, . . . . . 159

Red Cedar as Bait, . . . . . 159

Reid, Mr. and Mrs. W. M., . . 53

Reid, Miss,. . . . . . . . 53

Ribbon Fish, . . . . . . . 125

Riviera, . . . . . . . 200

Riviera, Hotel, . . . . 7

Rock Ledge, . . . . 7, 45, 190

Royal Poinciana, . . . 7, 57, 61, 200

Roe Mullet, . . . . . . . 43

Royal Paim Hotel, 51, 53, 60, 209, 231

Round Pampano, . . . . . 55, 59

Rovalia, . . . . . 69, 253

Roach Bream, . . . . . . 71

Rock Hind, . . . . . . 75

Rockfish, . . . . . . 77,78

Robalo, . . . . . . . 69, 253

Ronco Prieto, . . . . . . 99, 152

Ronco Blanco, . . . . 99, 152

Ronco Amarillo, . . . . . . 100

Ronco Ronco, . . . . . . 101

Ronco Arara, . . . . . . . 101

Ronco Condenado, . . . . . 102

Roncadina, . . . . . . . . 121

Rock Shellfish, . . . . . 136

Rock Bass, . . . . . . . . 73

Roseland, . . . . . . 190

Rockland and East Rockland Keys and Channels,

Robinson Crusoe, Sloop, : : 203

Rosenhof, Rosel von, . . . . 157

Rhodes Key, Old, . . . . . 221

Rods, . . . . . . . 160

Rod Tips, . . . . . . . . 161

Rod Guides, . . . . . . . 161

Runners, . . . . . 62, 63, 64

Running Jack, . . . . . . 63

Rudder-fish, . . . . . 117
Rushton Cedar Boat,

PAGE.

St. Augustine, . . 3, 4, 6, 124, 180

St. Augustine Inlet, . . . 177

St. Johns River, . . . . 3, 5, 6, 7

St. Johns Bar, . . . . . . . 177

Sanford, . . . . . . 3,7

Sands Key, . . . . . . . 220

Saury, Mr., . . . . . . 5, 18

Sams, Frank W., . . . . . 5, 6

St. Sebastian River, . . . . . 6

St. Lucie River, . . . 195, 196

Spanish Mackerel, 7, 10, 18 $\frac{1}{2}, 49,158,159$

Sands Cut, . . . 8, 177, 220, 222

Shark Creek, . . . . . . . 8

San Carlos Pass, . . . . . 8

St. Petersburgh, . . . . 8, 18

Sarasota, . . . . . . . 8

Sarasota Bay, . . . . . 8, 44

St. James City, - . . . . . 8

St. Louis, Bay, . . . . . . 8

Snappers, - $10,12,85,88,90,92,94$

Small.Mouth Bass, . . . . 74

San Pablo, . . . . . . . . 179

Snapper Banks, . . . . . . 10

State of Florida, . . . . . . 217

Sharks, 12, 13, 16, 18-22, 44, 64, 158, 160

Shark Hooks, . . . . . . . 161

Shark Stories, . . . . . 18-22

Skates, . . . . . . . 13, 24

Skate, Common, . . . . . . 24

Sand Shark, . . . . . . . 17

Spanish Names of Fishes, . . . 13

Swamp Bass, . . . . . . . 72

Sawfish, Common, . . . . . 23

Saw-fish, . . . . . . 158

Savanilla, . . . . . . 31

Snake Eel, . . . . . . . . 30

Sabalo, . . . . . . 531

Sand Fleas, . . . . . . 33

Savalle, . . . . . . . . 31

Sand Crab, . . . . $33,158,231$

Sarno, . . . . . . . 190

Shad, . . . . . . . . 35

Small Permit, . . . . . . . $\quad 59$

Sardinella Sardina, . . . . . 36

Sardines, . . . . . . . 158

Sardina De Ley, . . . . . 36

Sand Perch, . . . . . . 39, 82

Sand-fish, . . . . 48,82

Scabbard Fish, . . . . . . 51

Sable, . . . . . 51

Savola, . . . . . . 51

Sailfish, . . . . . . 52, 158

Small Permit, : : : . 59

Snap Nackerel, . . . . . . 68

Scamp, . . . . . . . . 79

Stake-fish, . . . . . . 84 
Sailor's Choice, 99, 107, 113, 121,

$152,153,158$

Saw Grass,

Saucer-eye Porgy,

Shad Porgy, . . . . . 111

Salt-water Bream, . 113, 114, 121

Salema,

114

Sargo Raiado, . . . . . . 115

Sclænops Ocellatus, . . . . . 118

Sand Whiting, . . . . . . 122

Spanish Lady-fish, : : : 126

Spanish Hogfish, . . . . . . 126

Sparisima Chrysopterum, . . . 127

Sparisima Viride, . . . . . 127

Sparisima Flavescens, . . . . 128

Scarus Croicensis, . . . . . 129

Scarus Cæruleus, . . . . . . 129

Snake Key, . . . . . . . 238

Salmonete, . . . . . . . 129

Saddle Hill Island and Channel, . 235

Spade-fish,. . . . . . . 130

Saddle Bunch Keys and Channels, . . . . . 235, 238

Shark-sucker, . . . . . . 143

Snake Creek, . . . . . .

Sapo, . . . . . . 144

Salt Water Chub, : $: 0^{\circ} \quad 117$

Santa Lucia, East Coast Railway Steamer,

57,58

Salt Water Pike, . . . . . . . 45

Salt Water Mascalonge, . . . 45

Sea Bass, . . . . . . . 4, 150

Sea Trout, Spotted, . . . . 118

Sheepshead, . . 114, 114 $\frac{1}{2}, 115$

Sheepshead, Holbrook, . . . 116

Sea Catfish, . . . . . . 28

Stearns, . . . . . . . 31

Sea-horse, . . . . . 41, 42

Serrano, . . . . . . 48, 82

Spearfish, . . . . . . . . 52

Seriola Lalandi, . . . . . . 60

Seriola dumerili, . . . . $. \quad . \quad 61$

Selene Vomer, . . . . . . 67

Sergeant Fish, . . . . 69, 253

Seth Green Fly, : . . $\quad . \quad \cdot 73$

Speckled Hind, . . . . . . . . 75

Sebastian River, . . . . . . 6

Sebastian Bridge, . . . . . 180

Stenotomus Chrysops, . . . . 108

Stenotomus Aculeatus, . . . . 109

Sheepshead Porgy, . . . . . . 111

Sea Crabs, . . . . . . 158

Sea Trout, . . . . . 117, 118

Sea Mink, . . . . . . . . 122

Serrana, . . . . . . 125

Shelifish, . . . . . . 136

Swell-fishes, . . . 137, 139, 140

Spheroides Spengleri, . . . . 137
Swell Toad,

Swerl Toad, * • . 137, 138, 140

Spheroides Marmoratus, · · 138

Spheroides Testudineus, . . . 139

Sea Robin, . . . . . . . 141

Steamer City of Key West, : . 57

Sebastian River Bridge, . . . 180

Sea Breeze, . . . . . . . 183

Sea Breeze Pier, . . . . . . 183

Sebastian, . . . . . . . 190

Sebastian River, . . . . . . 191

Sebastian Bay, . . . . . . 191

Sewell's Point, P. O., . . . . 195

Sea Chub, . . . . . . 117, 219

Steamboat Creeks, . . . . 223

Shell Key, . . . . . . . . 231

Sea Fisherman (Wilcocks), . . 13

Seminole War, . . . . . . 230

Siberia, . . . . . . . . 10

Smithsonian Institution, . . . 11

Skittle-dog, . . . . . . . 23

Stingray, . . . . . . . 25

Stingaree, . . . . . . . . 25

Smiths Creek, . . . . . . 182

Silver King, . . . . . . 31

Sprite, . . . . . 33, 158, 231

Skip Jack, . . . . . . . 34,68

Striped Anchovy, . . . . . . 38

Striped Mullet, . . . . . . 42

Silver Mullet, . . . . . . . 43

Sierra, . . . . . . 49, 40

Silverfish, . . . . . . . 31, 51

Spikefish, . . . . . . . . 52

Silver Moonfish, . . . . . . 67

Shrimp, . . . . . 156, 158

Striped Grunt, . . . . . . 98

Silver Whiting, . . . . . . 123

Shippy, Lillie, Sloop, . . . . 232

Spiny-back, . . . . . . . 139

Slimer, . . . . . . . . 144

Silver Hake, . . . . . . . 144

Shiny Scup, . . . . . . 152

Skinner's Fluted Spoons, 119, 158

Silver Plated Spoons, . . . . 163

Squids, . . . . . . . . 165

Silvered Minnows, . . . . . 158

Snipe Key, . . . . . . . 238

Swivels, . . . . . . . 166

Sinkers, Eggshaped, and others,

$161,167,175$

Simmons Hardware Co., . . . 175

Scott, Genio C., . . . . . . 3, 14

Sportsmen's Gazetteer, . . . . 3

Spongers, . . . . . . 215

Soldier Key, 8, 34, 51, 52, 68, 177 ,

$210,216,218$

Spotted Sea Trout, . . 10,118, $118 \frac{1}{2}$

Spotted Sting Ray, . . . . . 26 
Shovel-head Shark,

Southern Sting Ray,

Soldier Crabs,

Spoons,

Stolephorus Perthecatus,

Stolephorus Brownii,

Soapfish,

Spot, .

Soldado,

Scomberomorus Cavalla, . . 50

Spolia Atlantica,

Snook,

Spotted Jewfish

Schoolmaster,

Southern Porgy,

Spotted Weakfish,

Smooth Puffer,

Southern Puffer

Southern Flounder,

Spotted Flounder,

Sole, American,

Soles,

Stone Crab,

"Sproat, Mr.,"

Sombrero Lighthouse,

Schooner Tarpon,

Scudder, Jno. A.,

Suckers,

Squirrel Fish, . . . . 39, 47, 48, 82

Squalus Acanthias,

Sunfish,

Sunny,

Scuppaug,

Squeteague,

Surf Whiting,

Stuffonier

Sucking-fish,

Summer Flounder,

Sunfish, Blue Gill,

Superior, Lake,

Squids, .

Spruce Creek, . . . . . . . 181

Stuart,

Scup, Common,

Key and Channel, 235, 238

Summerland Keys and Channels, 235

Synopsis of the Fishes of North America,

Sphyma Tiburo, . . . . .

Sphyrna Zygæna,

Synodus Foetens, .

Synodus lucioceps,

Sphyraneana Barracuda,

Tarpon,

Table of Contents,

$4,5,8,31,45,160$

Tampa,
16

88

38

38

38

158

9

68

253

80

88

109

118

137

145

147

148

158

162

244

45

82
23

73

72

108

117

123

158

145

74

75

158
184

195

108

11

16

Tarpon Springs,

PAGE.

Tampa Bay, . 8, 10,44

Tarpon Atlanticus, . . . . . 31

Tarpum, . . . . . . . . 31

Trachinotus Carolinus, . . . . 54

Trachinotus, . . . . . 54-60

Trachinotus Falcatus, . . 55, 59, 60

Trachinotus Goodei,. . . . 54, 59

Trachurops Crumenophthalmus, . 62

Tambor, . . . . . 137, 139

Tally-IVag, . . . . . . . . 150

Tautoga Onitis, . . . . . 156

Tautog, . . . . . . 156

Tarpon Rod, . . . . . . . 161

Tarpon Gaff, . . . . . . . 161

Tarpon Reel, . . . . . . . 161

Tarpon Hooks and Snoods, . 32, 161

Tackle Box, . . . . 162

Tavernier Creek, . . . 177, 226

Ten Pounder, . . . . . . . 33

Titusville, . . . . . . $3,7,190$

Thirteen Yarn, . . . . 231, 232

Trichiurus Lepturus, . . . . 51

Tide Runner, . . . . . . . 63

Tripple-tail, . . . . . . 84

Trigger-fish, . . . . 133, 134, 135

Tips for Rods, . . . 161, 168, 169

Tides, The, . . . . . 177

Tomoka River, . . . . . 4, 182

Tobacco Box, . . . . . . . 24

Thompson, Charles, . . . 52,53

Toro, . . . . . . 66, 137

Trout, . . . . . . . . 73

Tom Tate, . . . . . . 103

Toad-fish, . . . . . 140, 144

Toms Key and Channel, . . . 233

Torch Key and Cliannel, . . . 234

Trolling, . . . . . . 34

Trollinglines, . . . . . . . 161

Turbot, . . . . . . 133, 135

Trunkfish, . . . . . . 136

Thumb Stalls, . . . . . . 161

Turkey Creek, . . . . . . 191

Tylosurus Acus, . . . . . . 39

Tylosurus Raphidoma, . . . . 39

Upeneus Martinicus, . . . . 129

Uncle Henry, . . . . . . . 57

Upper Minnetonka, . . . . . 73

Upper Matacumbe Channel, 177, 229

Upper Matacombe Key, . $\quad 229,230$

Uncle Henry, . . . . . 57,58

U. S. Com. Bulletin, 1897, . 121, 152

U. S. Com. Bulletin, 1898, • . 121

United States National Museum,

$11,13,15$

United States Geodetic Survey, . 213

United States Fish Commission, 9, 11, 12 
PAGE.

United States Fish Commission, 1899, 12

U. S. Com., 1895, . 59, 60, 116, 140

U. S. Com. Report, 1896, 54, 59,

$60,86,116,121,133,152,154$

Uncle Sam, . . . . . . 216

Uncle Henry, , . . . . . . 216

United States Government, . . 218

Vaca Keys and Chamnels, . . . 234

Verma Kendalli, . . . . . . 30

Venus, . . . . . . . . . 199

Vieja, . . . . . . . . 127

Vieja Colorado, . . . . . . 128

Vieja Muger, . . . . . . . 128

Virginia Hooks, . . . . . . 161

Virginia Key, . . . . . . . 206

Voilier, . . . . . . . . 52

Volador, . . . . . . . 141

Vom Hofe Reel, Edward, 161,

Volusia Co., . . . . . 186

Vom Hofe Reel, Julius, . . . 161

Walker, Prof. WV. A., 5, 87, 230, 231

Ward, Capt., . . . . . 6, 56

Vall-eyed Herring, . . . . . 34

Warmouth, . . . . . . 70

War Eagle Lake, Minn., . . . 74

Watersmeet, Mich., . . . 74, 75

Water Glass, . . . . . . . 214

Wall Key, . . . . . . . 238

Water Key, . • . . . . . 238

"Wrack"Yarn, . . . . . . 232

Welshman, . . . . . . 47

West Palm Beach, . . . . 57, 200

Weakfish, . . . . . . . 117

West Summerland Keys and Channel,

West Coast, $3,6,7,8,10,31,32,82,233$

Webster's Dictionary,

Whitewater Bay, .

13

Whip Tailed Ray,

8

White Mullet, $\cdot{ }^{*} \cdot 37$

White Perch, . . . . . . . . 97

White Grunt, . . . . . . . 105

Windy Key, . . . . . . . 229

Whiting, . . . . 122, 123, 144

Whiting, Surf, . . . . . . 123

Windy Island Channel, . . . 229

Whiting, Northern, . . . . . 122

Whiting, Carolina, . . . . . 122

Whiting, Silver, . . . . . . 123

Whiting, Sand, : . . . . . . 122

Winter Flounder, . . . . . 147

Whiting, Key, . . . . . . 238

Window Pane, . . . . . . 147

White Cloth as Bait, . . . . 159

White Cotton Line, . . . . . 162

White Bear Lake, Minn., . . 73, 74

White Phantom Minnows, . . . 158

Wilcocks, J. C., . . . . . . 13

Wolf River, . . . . . . 8

Worm Eel, . . . . . . . 30

Wood, W. H., . . . . . . 32

Worth Inlet, Lake, - . . 201, 203

Worth Canal, Lake, . . . . 200

Worth P. O., Lake, . . . . . 202

Worms (bait), . . . . . . 72

Yachts, . . . . . . 247

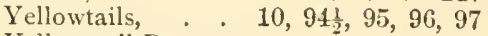

Yellow-tail Runner, . . . . . 62

Yellow Mackerel, . . . . . . . $\quad .63$

Yellow Jack, . . . . . 68, 158

Yellow-finned Grouper, . . . . 78

Yellow Grunt, . . . . . . 100

Yellow Goatfish, . . . . . . 129

Yellowstone Lake, . . . . . 59

Yellowstone Park, . . . . 59

Zellers, Capt. John, . . . . . 7,8

Zimmerman, John B., • . . . 232

\section{ADDITIONAL INDEX.}

Atlantic City. .

Addenda,

American Banks, Key Vest, . 243

Adirondacks, . . . . . . . 246

Albula Vulpes, Discussion, 249, 250 ,

Aquariums, Various,

$253-278$

Bears Cut, Biscayne Bay,

251
Biscayne Bay, 249, 252, 255, 255, $270,273,274,275,277,277,278$

Big-eyed Herring, . . . 249, 250

Brice, Jolın J., . . . . . . 278

Brighton England, Aquarium, . 243

Billingsgate Fish Market, . . . 243

British America, . . . . . . 245

Brickle, Wm., Niami, Fla., . . 250

Bonefish, . . . . . 248-252 
PAGE.

Bonefish Discussion, 248-252, 253-278

Brochet de Mer, . . . . . . 253

Bluefish Channel, Key Wrest, . . 243

Bulletin 47, U. S. Nat. Museum, 249

Bulletin 16, U. S. Nat. Museum, 249

Crawfish Channel, Key West, . 243

Crawford Bar, Key West, . . . 243

Centropomus Undecimalis, . . 253

Cocoa Plum Point, Biscayne Bay, 251

Cocoanut Grove, Biscayne Bay, . 251

Cow Pen Bay of Florida, . . . 245

Cuba, . . . . . . . . 243

Evermann, Barton, Warren, 266, 278

Evermann \& Kendall, 250, 266, 277, 277,278

Elops Saurus Discussion, 248 252,

$253-278$

Fish Markets, Various,

243

Florida Fish Laws, . . 186, 190, 246

Fishes of North America, W. C.

Harris, . . . . . 270-274

Florida East Coast Railway Co., 247

Florida East Coast Hotel Co., . 247

Fort Taylor, Key West, . . . 243

Georgian Bay, Ontario, Canada, . 245

Grood, G. Browne, . . 249, 263, 277

Giinther, A. C. L., . . . 256, 276

Harris, WVm. C., . 270-275, 278

Hallock, Charles, . . . . . 248

Herring Family, . . . . . 256

Head Channel, Key West, . . 243

Henshall, J. A., . . . 248, 263

Hotel and Boarding House List, . . . . 2 239-241

Jordan \& Evermann, 250, 255, 259,

264,276
Jordan \& Gilbert, 249, 254, 255,
256,276

Key West, Florida, . . . . . 251

Kiffe \& Co., H. H., . . 168, 169, 247

Ladyfish Discussion, 248-252, 253-278

Lake Saint John, Quebec, . . 245

PAGE.

Maine Fish Laws, . . . . 246

McFerran, J. B., . . . . 249-252

McCormick, W. F., Collection, . 265

Matthews-Northrup Works, . . 247

Mattacombe Keys, . . 229, 230, 251

Milam \& Son, B. C., . . 170,247

Map of Florida, . . . . . 271

Naples Aquarium, . . . . . 243

Nantucket, . . . . . . . 246

New River, . . . . . . . 245

New York Aquarium, . . . . 243

Old Orchard, Maine, . . . . 246

Ouananische, . . . . 245, 245

Pacific Coast, . . . . . . 245

Pebble Channel, Key TVest, . . 243

Peacock, Mr., Cocoanut Grove, . 251

Pearl Channel, Key WVest, . . . 243

Porto Rico, Fish and Fisheries, 266, 278

Plum Point, Biscayne Bay, . . 251

Rangely Lakes, Maine, . . . . 246

Resume of Bonefish, etc., Discus-

sion, . . . . 276278

Robalo, . . . . . . . 253

Rovalia, . . . . . . 253

St. Lawrence River, . . . . . 245

Saguenay River, . . . . . 245

Small Fleet Harbor, Key West, . 243

Sergeant-fish, . . . . . . . 253

Smith, Hugh M., 249, 265, 266, 276,277

Target Banks, Key West, . . . 243

United States Fish Commission, 243,

United States Fish Commission 249,250

Exhibits, Various, . . . 243

Victoria, British Columbia, . . 245 Vom Hofe, Edward, 163-167, 171, 172,

$174,175,2.7$

Vom Hofe, Julius, . . . 170, 247 




\section{UNIVERSITY OF CALIFORNIA}

Santa Barbara College Library

Goleta, California

Return to desk from which borrowed.

book is DUE on the last date stamped below.
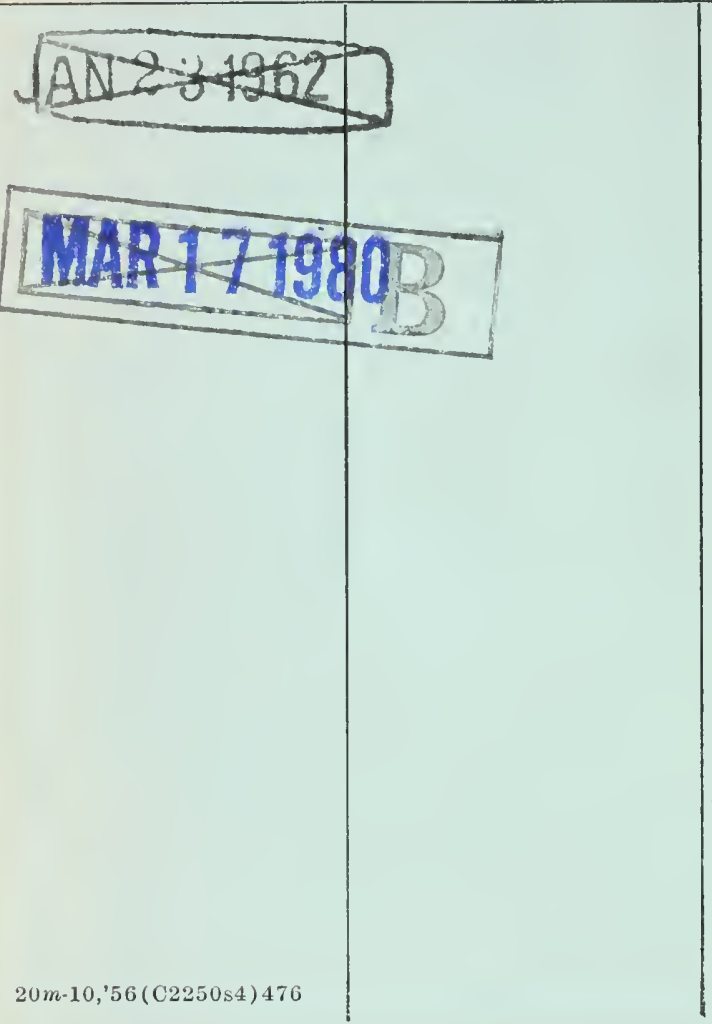
UC SOUTHERN REGIONAL LIBRARY FACILITY

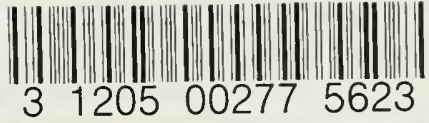

3 
